\title{
Pharmacological modulation of vascular abnormalities in experimental diabetes
}

Citation for published version (APA):

Heesen, B-J. (1996). Pharmacological modulation of vascular abnormalities in experimental diabetes. [Doctoral Thesis, Maastricht University]. Maastricht University. https://doi.org/10.26481/dis.19960515bh

Document status and date:

Published: 01/01/1996

DOI:

10.26481/dis.19960515bh

Document Version:

Publisher's PDF, also known as Version of record

\section{Please check the document version of this publication:}

- A submitted manuscript is the version of the article upon submission and before peer-review. There can be important differences between the submitted version and the official published version of record.

People interested in the research are advised to contact the author for the final version of the publication, or visit the DOI to the publisher's website.

- The final author version and the galley proof are versions of the publication after peer review.

- The final published version features the final layout of the paper including the volume, issue and page numbers.

Link to publication

\footnotetext{
General rights rights.

- You may freely distribute the URL identifying the publication in the public portal. please follow below link for the End User Agreement:

www.umlib.nl/taverne-license

Take down policy

If you believe that this document breaches copyright please contact us at:

repository@maastrichtuniversity.nl

providing details and we will investigate your claim.
}

Copyright and moral rights for the publications made accessible in the public portal are retained by the authors and/or other copyright owners and it is a condition of accessing publications that users recognise and abide by the legal requirements associated with these

- Users may download and print one copy of any publication from the public portal for the purpose of private study or research.

- You may not further distribute the material or use it for any profit-making activity or commercial gain

If the publication is distributed under the terms of Article $25 \mathrm{fa}$ of the Dutch Copyright Act, indicated by the "Taverne" license above, 


\title{
Pharmacological Modulation of Vascular Abnormalities in Experimental Diabetes
}

\author{
PROEFSCHRIFT \\ Ter verkrijging van de graad van doctor \\ aan de Rijksuniversiteit Limburg te Maastricht, \\ op gezag van de Rector Magnificus, Prof. Mr. M.J. Cohen, \\ volgens het besluit van het College van Dekanen, \\ in het openbaar te verdedigen \\ op woensdag 15 mei 1996 om 14.00 uur \\ door

\section{Bart-Jeroen Heesen}

geboren op 1 oktober 1966 te Schiedam 
Promotores

Prof. dr. A.C. Nieuwenhuijzen Kruseman

Prof. dr. H.A.J. Struijker Boudier

\section{Co-promotores}

Dr. B.H.R. Wolffenbuttel

Dr. J.G.R. De Mey

Beoordelingscommissie

Prof. dr. P.W. De Leeuw (voorzitter)

Dr. M. Daemen

Prof. dr. ir. A.P.G. Hoeks

Prof. dr. P.A.B.M. Smits (Katholieke Universiteit Nijmegen)

Prof. J.R. Williamson (Washington University, St. Louis, USA)

$P P N=146087948$

Universiteitsbibliothoek

Aijksunivarsitett Limburg 


\section{Contents}

1. Introduction 9

2. Material and Methods 29

3. Effects of glucose and diabetes duration on responses to 41 phenylephrine, acetylcholine, and sodium nitroprusside in aortic rings from streptozotocin-induced diabetic rats

4. Contractile and relaxing responses in mesenteric and renal 53 resistance arteries

5. Inhibition of nitric oxide formation by guanidines 63

6. Effects of guanidine compounds or insulin treatment on responses 75 to vasoactive agents in aortic rings of streptozotocin-induced diabetic rats

7. Effects of perindoprilat treatment on vascular responses of aorta 85 and resistance arteries of diabetic and non-diabetic rats

8. Aldose reductase inhibitors have little effect on altered reactivity in 95 aortic rings of diabetic rats

9. Aorta compliance in intact diabetic rats 105

10. General discussion 121

Summary 131

Samenvatting 135

$\begin{array}{ll}\text { Curriculum vitae } & 139\end{array}$

$\begin{array}{ll}\text { Publications } & 140\end{array}$

$\begin{array}{ll}\text { Nawoord } & 142\end{array}$ 


$\begin{array}{ll}\text { Abbreviations } \\ \text { ACE } & \text { angiotensin converting enzyme } \\ \text { ACH } & \text { acetylcholine } \\ \text { AGE's } & \text { advanced glycation endproducts } \\ \text { ALX } & \text { alloxan } \\ \text { AR } & \text { aldose reductase } \\ \text { ARI } & \text { aldose reductase inhibitor } \\ \text { B-mode } & \text { brightness mode } \\ \text { BB } & \text { bio-breeding } \\ \text { BG } & \text { blood glucose } \\ \text { BW } & \text { body weight } \\ \text { CC } & \text { compliance coefficient } \\ \text { CSA } & \text { cross sectional area } \\ \text { DC } & \text { distensibility coefficient } \\ \text { DCCT } & \text { diabetes control and complications trial } \\ \text { EC-50 } & \text { concentration needed to reach } 50 \% \text { of pharmacological effect } \\ \text { EDRF } & \text { endothelium-derived-relaxation factor (see also NO) } \\ \text { FBG } & \text { fasting blood glucose } \\ \text { HbA }{ }_{1 c} & \text { glycated haemoglobin } \\ \text { ID } & \text { internal diameter } \\ \text { IDDM } & \text { insulin-dependent-diabetes-mellitus } \\ \text { M-mode } & \text { motion mode } \\ \text { Mt } & \text { media thickness } \\ \text { NE } & \text { norephinephrine } \\ \text { NIDDM } & \text { non-insulin-diabetes-mellitus } \\ \text { NO } & \text { nitric oxide (see also EDRF) } \\ \text { PHE } & \text { phenylephrine } \\ \text { RAS } & \text { renin-angiotensin system } \\ \text { RF } & \text { radio frequency } \\ \text { SD } & \text { sorbitol dehydrogenase } \\ \text { SDI } & \text { sorbitol dehydrogenase inhibitor } \\ \text { SEM } & \text { standerd error of the mean } \\ \text { SNP } & \text { sodium nitroprusside } \\ \text { STZ } & \text { streptozotocin } \\ \text { r } & \text { radius } \\ \text { WTS } & \text { vessel wall tracking system } \\ & \end{array}$




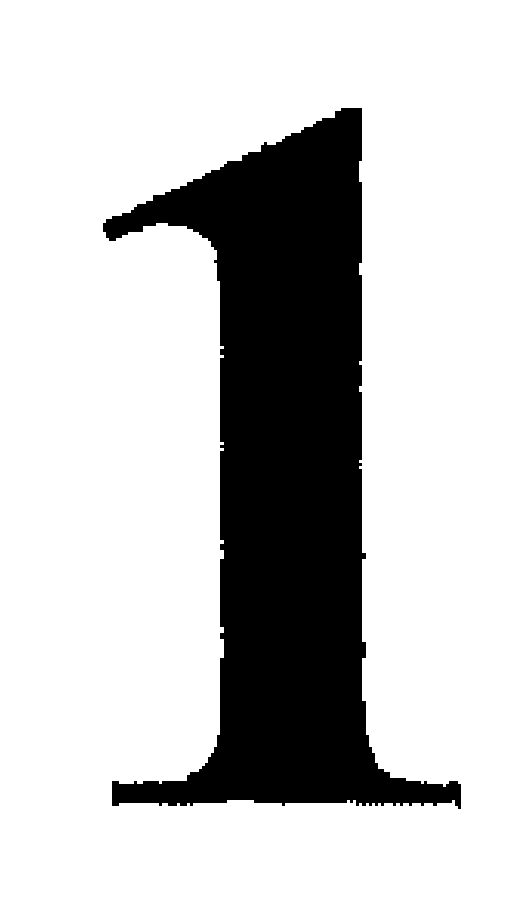

Introduction 


\section{VASCULAR DYSFUNCTION IN DIABETES MELLITUS}

\section{INTRODUCTION}

Diabetes mellitus is a disorder which is characterized by a chronic elevation of the blood glucose concentration and a disturbance of carbohydrate, fat, and protein metabolism. It is caused by either absolute or relative deficiency of insulin ${ }^{[1]}$. Diabetes affects more than 300 thousand people in the Netherlands and about 200 million worldwide. Its prevalence increases with age, from about 0.2 percent in persons younger than 17 years of age to about 10 percent in persons aged 65 years and above, and is more frequent in females. In the United States the prevalence of diabetes varies markedly among ethnic groups, with an occurrence about 20 percent higher in non-Caucasians than in Caucasians.

\section{Types of Diabetes Mellitus}

Diabetes occurs when the pancreas is unable to secrete enough insulin to maintain a normal concentration of blood glucose. When the blood glucose level exceeds $8-10$ $\mathrm{mmol} / \mathrm{l}$, glucose is excreted in the urine and more urine is passed " $"$. Chronic hyperglycemia can be caused by a decreased production and/or by an impaired action of insulin ${ }^{[2,3]}$. The two main forms of diabetes are the insulin-dependent (type I) and the non-insulin-dependent (type II) type.

Insulin-dependent diabetes generally starts in childhood and is characterized by severe insulin deficiency, due to the destruction of the insulin secreting $\beta$-cells of the pancreas. Without insulin the person develops severe hyperglycemia, leading to dehydration due to glucosuria and to ketoacidosis (high levels of ketone bodies in the blood, causing acidosis) eventually developing into cerebral disturbances and coma.

The non-insulin-dependent form usually presents in people over the age of 40 years. These people have higher-than-normal levels of insulin but are resistant to its action; ketoacidosis is rare. More than $60 \%$ of subjects are obese at the time of diagnosis. This type of diabetes is also seen in populations that have recently adopted Western lifestyle and diets. Some women may develop diabetes during pregnancy (gestational diabetes). Glucose levels usually return to normal after delivery, but these women have an increased risk to develop non-insulin-dependent diabetes later during life.

\section{Treatment}

After the isolation of insulin by Banting and Best in 1921, and its subsequent use in the treatment of diabetes, death from ketoacidosis and diabetic coma decreased dramatically. As people with diabetes live longer, long-term complications related to the disease begin to develop, including kidney failure, heart disease, blindness, and nervous system disorders. These complications are believed to be related to elevated blood-glucose levels and its biochemical sequelae. The objective of diabetes treatment is to restore blood glucose levels to normal. For obese people with noninsulin-dependent diabetes diet is the cornerstone of treatment aiming to loose weight. If this method does not suffice, oral hypoglycemic agents, which act by stimulating the pancreas to secrete additional insulin or improving insulin action, or insulin injections are required. People with type I diabetes are treated with insulin promptly from the time of diagnosis: modern treatment comprises multiple daily insulin injections, in 


\section{CHAPTER 1}

which fast-acting insulin is injected before each meal, and intermediate-acting insulin is injected at bedtime. The amounts required are determined by frequent measurements of blood glucose.

It has long been thought that maintaining normoglycemia would prevent the development of diabetic complications. Final proof was given by the 'Diabetes Control and Complications Trial' (DCCT), which showed that maintaining the blood glucose concentration as normal as possible prevented the development or delayed the progression of complications ${ }^{[4]}$. However, even when tight control has been attained long-term complications still develop. In addition, intensive insulin treatment poses a significant threat for the occurrence of severe hypoglycemia.

In this chapter a summary will be given of the different forms of diabetic complications, with special attention to features as vascular reactivity and arterial compliance. We will briefly discuss pathogenesis of vascular complications, and possible pharmacological interventions.

\section{CLINICAL FEATURES OF CHRONIC COMPLICATIONS}

\section{Macrovascular disease}

The role of diabetes as a risk factor for cardiovascular disease is well established. The annual incidence of cardiovascular disease among diabetic patients is increased almost 3 -fold compared with non-diabetic persons. Atherosclerosis in diabetic patients shows identical development compared with non-diabetic persons, but occurs 10-20 years earlier ${ }^{[5]}$. The risk ratios appear to decrease slightly with advancing age. This may be caused by an increased mortality of diabetic patients due to cardiovascular disease at a younger age. Several factors are involved in the pathogenesis of macrovascular abnormalities in diabetic patients. These are, amongst others, direct toxicity of glucose per se, abnormal lipoprotein metabolism, non-enzymatic glycation of proteins, hyperinsulinaemia, and genetic factors. It seems that the development and extend of macro-angiopathy are not related to the severity of diabetes ${ }^{[5,6]}$, nor to the form of therapy. Both treatment with oral agents and with insulin have failed to lower cardiovascular mortality compared to diet alone ${ }^{[5]}$, although the degree of glycemic control reached might have been insufficient to obtain results with a similar impact as in the DCCT ${ }^{[4]}$.

\section{Diabetic retinopathy}

Diabetic retinopathy can be divided into two types: the non-proliferative and the proliferative form. The first may develop early in the course of diabetes, and the second mainly develops in a subset of people with a longer duration of insulindependent-diabetes ${ }^{[7]}$. Oedema of the macula due to increased vascular permeability is the most common cause for visual loss in diabetes. Progression into proliferative retinopathy takes place when new vessel formation (neovascularization) occurs. Ingrowth of vessels into the vitreous body leads to an increased risk for hemorrhage and scar formation ${ }^{[8,9]}$. 


\section{VASCULAR DYSFUNCTION IN DIABETES MELLITUS}

\section{Diabetic nephropathy}

In a substantial percentage of the diabetic population diabetic nephropathy develops. This condition often leads to end-stage renal failure, which in turn will require intensive therapy such as hemodialysis or even kidney transplantation. Early in the disease an increase in the size of the kidney can be observed ${ }^{[10,11]}$, which is due to hyperperfusion and only temporal. Microalbuminuria is an important feature of 'incipient nephropathy'. After this early stage the kidney becomes smaller and scar tissue is formed in the intima and media of its larger vessels ${ }^{[12]}$. Microscopic lesions that can be found include increased glomerular size and filtration surface [13,14], mesangial expansion ${ }^{[15]}$, and glomerular basement membrane thickening ${ }^{[16,17]}$. These changes may progress into diffuse glomerulosclerosis and loss of glomerular filtration surfaces. With these changes the normal renal function cannot be preserved.

\section{Diabetic neuropathy}

Peripheral neuropathy is one of most common complications in diabetes mellitus ${ }^{[18,19]}$. It is rarely found in subjects with a diabetes duration of less than five years, except in NIDDM where asymptomatic hyperglycemia may be present several years before the diagnosis of diabetes is made. Neuropathy ultimately affects up to $50 \%$ of patients with long-duration of diabetes ${ }^{[20]}$. The pathogenesis is poorly understood, but there are indications that vascular dysfunction plays a role in its etiology ${ }^{[21]}$. Endoneural vascular abnormalities such as basement membrane thickening, endothelial cell swelling and proliferation, and platelet aggregation resulting in vessel occlusion have been noted in nerve biopsies ${ }^{[22]}$. These changes are thought to play a role in the development of diabetic neuropathy.

\section{ETIOLOGIC MECHANISMS IN THE DEVELOPMENT OF DIABETIC ANGIOPATHY}

Advanced glycation endproduct formation

Advanced glycation describes the chemical pathway that leads from the interaction of simple sugars to the formation of complex heterocyclic structures with varied spectral and cross-linking properties. Much of the basis of advanced glycation chemistry has originated from studies of the Maillard reaction, named after the French chemist who described the effect produced by heating sugars ${ }^{[23]}$. The term advanced glycation, however, has come to encompass those aspects of Maillard chemistry that involves macromolecules and that occur under physiological conditions ${ }^{[24]}$. Over the last several years, it has become clear that advanced glycation occurs in vivo and plays an important role in protein turnover, tissue remodeling, diabetes, and aging.

Advanced products of nonenzymatic glycation are thought to play a critical role in the evolution of diabetic complications because of their characteristic chemical properties. These slowly-formed glucose-derived compounds are chemically irreversible, and thus accumulate over time. The degree of this accumulation in patients' dermal collagen has been shown to correlate with the severity of diabetic retinopathy ${ }^{[25]}$. These products participate in glucose-derived crosslink formation ${ }^{[26]}$, 


\section{CHAPTER 1}

and may thereby alter the structure and function of the vascular wall. Nonenzymatic glycation begins with glucose attachment to amino groups via nucleophilic addition [25]. This reaction of glucose with epsilon-amino groups of lysine residues results in the formation of unstable Schiff base adducts. Levels of the labile Schiff base increase rapidly and equilibrium is reached in a matter of hours [27]. Ambient glucose concentration during that brief period determines the steady-state level of Schiff base adducts. Once formed, Schiff base adducts of glucose and protein amino groups undergo a slow chemical rearrangement over a period of weeks to form a more stable, but still chemically reversible sugar-protein adduct, the Amadori product. Equilibrium of Amadori glycation products is reached over a period of approximately 28 days. Thus, even on very long-lived proteins, the total amount of Amadori product is proportional only to the glucose concentration during the preceding four weeks. After the relatively brief period of time necessary to attain equilibrium, measured levels of Amadori products reach a constant steady-state value which does not increase as a function of time beyond that point (see figure 1). This has been experimentally confirmed by measuring Amadori products on diabetic tissue proteins exposed to similar levels of hyperglycemia for widely differing periods of time. A twofold to threefold increase in the level of Amadori product is consistently observed, whether diabetic samples are compared to normals after 18 weeks ${ }^{[28]}$ or after many years ${ }^{[2 \%]}$.

$$
\begin{gathered}
\text { hours } \rightarrow \quad \text { days } \rightarrow \text { weeks, months } \rightarrow \\
\text { Glucose }+\mathrm{NH}_{2}-\mathrm{R} \leftrightarrow \text { Schiff base } \rightarrow \text { Amadori product } \rightarrow \rightarrow \text { AGE's }
\end{gathered}
$$

Figure 1. The formation of advanced glycation endproducts, AGEs (adapled from Bucala, 199.4)

Advanced glycation endproducts (AGEs) have been implicated in many of the complications of diabetes. These products accumulate on vascular wall collagen and basement membrane proteins as a function of age and glycemia ${ }^{|30|}$. Many studies have suggested a causal relationship between AGE accumulation and the development of diabetic complications; in this regard, protein crosslinking and trapping reactions as well as AGE ligand receptor interactions may play a role ${ }^{[31]}$. Even if good glycemic control is obtained in a diabetic subject, the formation of AGEs continues, although probably at a slower rate.

Thus, additional pharmacological intervention may be necessary to prevent AGErelated tissue damage. Aminoguanidine is a drug that prevents the formation of advanced glycation endproducts. Aminoguanidine prevented the development of several diabetes-associated abnormalities in diabetic animals, such as retinal changes, advanced glycation endproducts accumulation in the glomerulus, glomerular basement membrane thickening, microalbuminuria, and structural and functional nerve abnormalities. Our group has demonstrated that long term aminoguanidine treatment prevented the increase of general vascular albumin leakage, and the decrease of arterial elasticity that developed as a consequence of the diabetic state ${ }^{[32,33]}$. 


\section{VASCULAR DYSFUNCTION IN DIABETES MELLITUS}

The polyol pathway

For the last ten years, attention has been payed to an alternative route for glucose metabolism, the polyol pathway. In this pathway glucose is first reduced to sorbitol by the action of aldose reductase. Then it is oxidized to fructose by the enzyme sorbitoldehydrogenase. Metabolism through this pathway becomes important when elevated tissue blood glucose are attained.

Aldose reductase has been found in many tissues including nerves ${ }^{[34]}$, retina and retinal micro vessels, glomeruli, smooth muscle, and aortic endothelium ${ }^{[35-36]}$. When hyperglycemia is present the polyol pathway can account for as much as 30 percent of the glucose metabolism ${ }^{[37]}$. Activation of this pathway leads to sorbitol accumulation, since these sugar alcohols can not easily pass cell membranes. Associated with sorbitol accumulation is the depletion of myo-inositol ${ }^{[38-40]}$. These phospholipids are thought to play a major role in cell signaling by activating protein kinase $\mathrm{C}$, which has an important effect on cellular function by influencing contraction and cell growth ${ }^{[41-43]}$.

In some animal studies the prevention of polyol accumulation by aldose reductase inhibition seemed a way to prevent late complications. Aldose reductase inhibition has been shown to prevent diabetes-induced increases in vascular permeability and enhanced regional blood flow in granulation chamber tissue and other tissues from streptozotocin-induced diabetic and spontaneously diabetic $B B / W$ rats [44-47]. Williamson and his group postulated that aldose reductase inhibitors have advantageous effects in experimental diabetes by normalizing the increased $\mathrm{NADH} / \mathrm{NAD}^{+}$ratio resulting from an increased sorbitol pathway metabolism ${ }^{[48]}$. Cohen et al. showed that the aldose reductase inhibitor sorbinil normalized the decreased glomerular $\mathrm{Na}^{+} / \mathrm{K}^{+}$-ATPase activity in experimental diabetic nephropathy ${ }^{[49]}$. Aldose reductase inhibitors also had positive effects on nerve $\mathrm{Na}^{+} / \mathrm{K}^{+}$-ATPase activity and neurophysiologic parameters ${ }^{[50,5]]}$.

There are also reports of studies that did not reveal any beneficial effects of aldose reductase inhibitors ${ }^{[52]}$. The disappointing effects of these compounds on complications in diabetic humans and chronic studies in animals may be explained by the fact that the studies in human subjects have all been intervention trials: treatment is

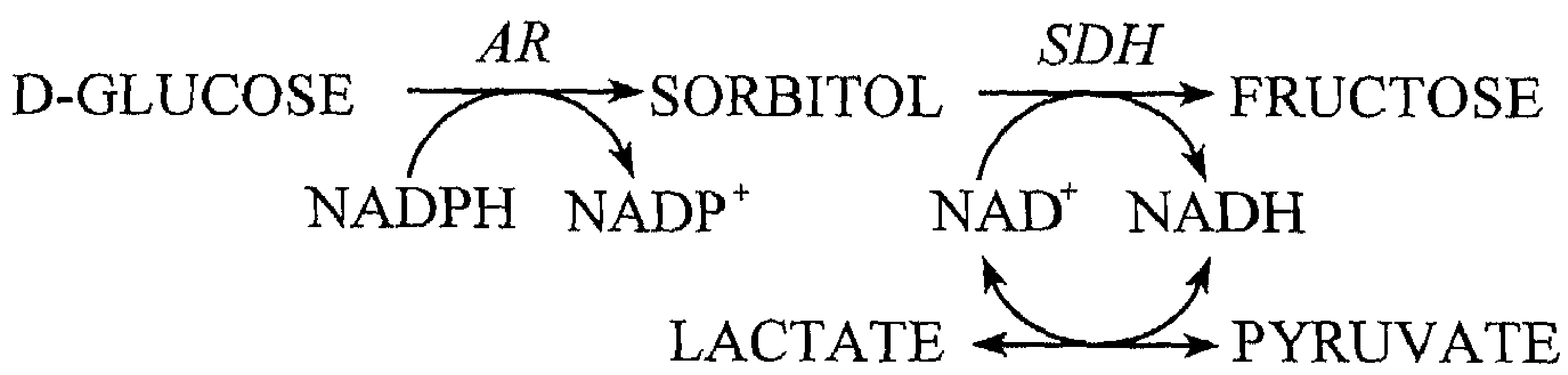

Figure 2. Reduction of glucose to sorbitol and oxidation of sorbitol to fructose. Reduction of glucose to sorbitol by aldose reductase $(A R)$ is coupled to oxidation of NADPH to NADP ${ }^{+}$. $N A D P^{+}$is reduced to NADPH by the hexose monophosphate pathway. Oxidation of sorbitol to fructose by sorbitol dehydrogenase (SDH) is coupled to reduction of $N A D^{+}$to $N A D H$. The cytosolic ratio of free $\mathrm{NADH} / \mathrm{NAD}^{+}$is equilibrium with lactate and pyruvate. (adapted from Williamson et al, 1993) 


\section{CHAPTER 1}

initiated after years of tissue damage due to the hyperglycemia ${ }^{[53]}$. In addition, the doses of aldose reductase inhibitors used in diabetic humans and animals may not have completely inhibited metabolism of glucose via the sorbitol pathway. Furthermore, aldose reductase activity is much higher in rodents compared to humans, and the relevance of this mechanism for the development of diabetic complications in patients is still under debate.

Hyperglycemic pseudohypoxia

Another mechanism by which an increased flux through the polyol pathway might affect vascular function in diabetes is the subsequent generation of an increased $\mathrm{NADH} / \mathrm{NAD}^{+}$ratio. One attractive feature of this hypothesis is that it allows for polyol pathway flux to be linked to diabetes-induced vascular dysfunction without necessarily invoking a critical role for the concentration of tissue sorbitol.

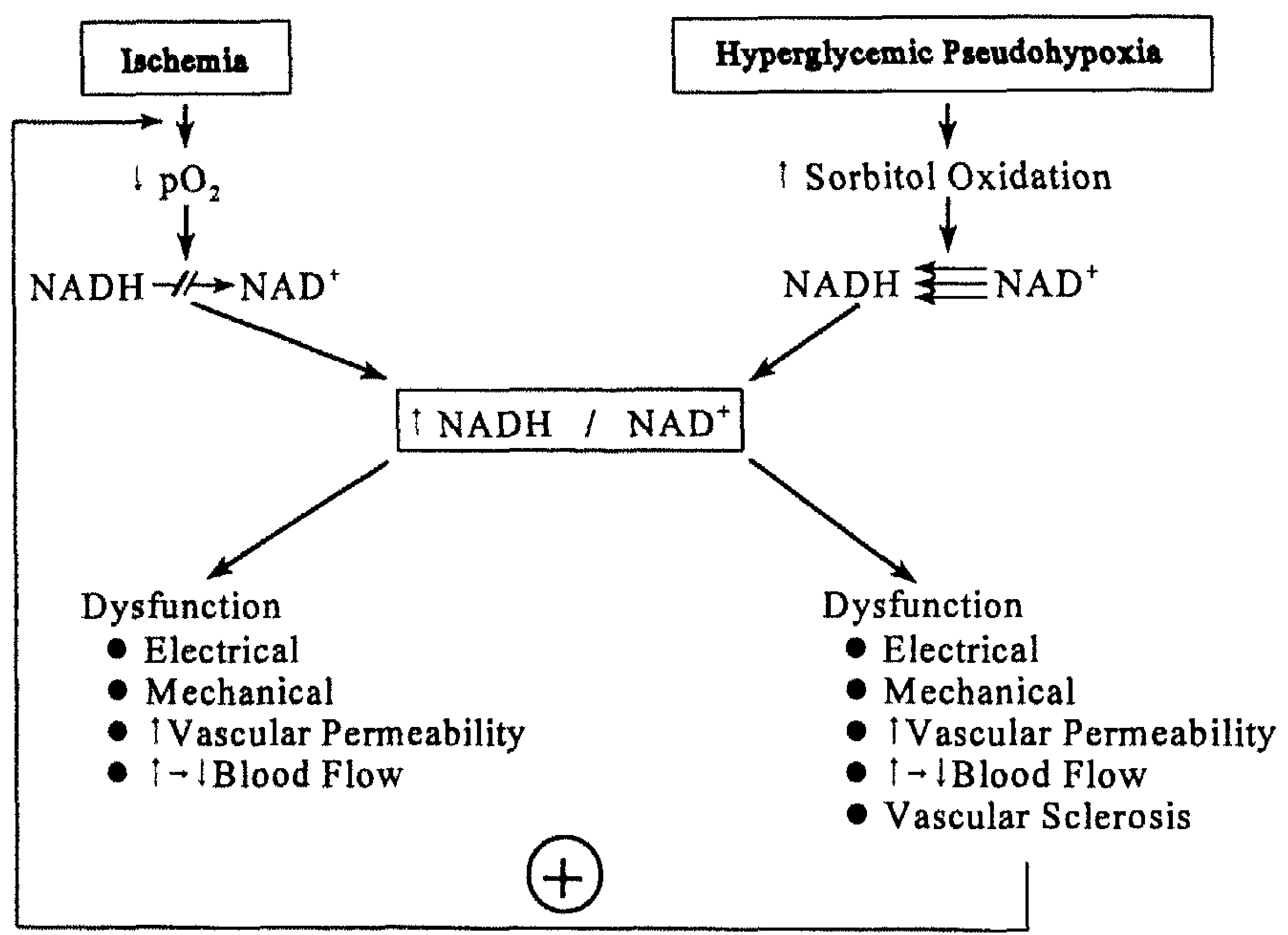

Figure 3. Parallels between functional consequences of an increased cytosolic NADH/NAD linked to hyperglycemic pseudohypoxia in diabetic tissues and hypoxia or ischemia in myocardial tissue. (adapted from Williamson 1993)

In early diabetes, vasodilation and increased blood flow are characteristics of the initial vascular response to acute hyperglycemia and tissue hypoxia. In hypoxic tissues these vascular changes are linked to metabolic imbalances associated with impaired oxidation of $\mathrm{NADH}$ to $\mathrm{NAD}^{+}$and the resulting increased ratio of $\mathrm{NADH} / \mathrm{NAD}^{+}$. In hyperglycemic tissues these vascular changes are also linked to an increased ratio of $\mathrm{NADH} / \mathrm{NAD}^{+}$, in this case because of an increased rate of reduction of $\mathrm{NAD}^{+}$to $\mathrm{NADH}$. The glucose flux through the sorbitol pathway is probably the most important 


\section{VASCULAR DYSFUNCTION IN DIABETES MELLITUS}

rate of conversion of glucose to sorbitol increases with increasing glucose levels in tissues that do not require insulin for glucose uptake (most mammalian tissues, except muscle and adipose tissue). Increased sorbitol levels will increase the rate of oxidation of sorbitol to fructose coupled to a reduction of $\mathrm{NAD}^{+}$to $\mathrm{NADH}$. At elevated glucose levels, glucose metabolism via the sorbitol pathway accounts for $33 \%$ of glucose consumption by the lens and $10 \%$ by human erythrocytes ${ }^{[37,54]}$.

The ratio of free $\mathrm{NADH}$ to $\mathrm{NAD}^{+}$modulates the activity of many metabolic pathways ${ }^{[55]}$. Because the cytosolic pool of free $\mathrm{NADH}$ and $\mathrm{NAD}^{+}$is in equilibrium with cytosolic lactate and pyruvate, and because oxidation of $\mathrm{NADH}$ to $\mathrm{NAD}^{+}$by $\mathrm{LDH}$ is coupled to reduction of pyruvate to lactate (Figure 2), an increased ratio of free $\mathrm{NADH} / \mathrm{NAD}^{+}$will be reflected by an increased lactate/pyruvate ratio. The tissue lactate/pyruvate ratio is a more reliable parameter of the cytosolic ratio of free $\mathrm{NADH} / \mathrm{NAD}^{+}$than measurements of $\mathrm{NADH}$ and $\mathrm{NAD}^{+}$in tissue extracts because it is not possible to distinguish between mitochondrial and cytosolic pools and between free and bound nucleotides in tissue extracts ${ }^{[56]}$. Thus, for simplicity, changes in tissue lactate/pyruvate ratios are referred to as changes in cytosolic NADH/NAD .

Several lines of evidence support the existence of an increased cytosolic ratio of free $\mathrm{NADH} / \mathrm{NAD}^{+}$. This is referred to as pseudohypoxia because tissue partial pressure oxygen is normal, and can be considered as a characteristic feature of poorly controlled diabetes that mimics the effects of true hypoxia on vascular and neural oxide formation. Several parallels between functional abnormalities associated with an increased NADH/NAD in diabetic tissues and in hypoxic or ischemic myocardium are depicted in figure 3. Although the metabolic imbalances that mediate these abnormalities may differ in hypoxic and hyperglycemic tissues the redox imbalance in tissues of diabetic animals appears to result largely from an increased rate of oxidation of sorbitol to fructose by sorbitol dehydrogenase. In hypoxic and ischemic myocardium, the same redox imbalance results from impaired mitochondrial oxidation of NADH to $\mathrm{NAD}^{+}$because of decreased $\mathrm{pO}_{2}{ }^{[57]}$. Functional consequences associated with this redox imbalance in isolated perfused hearts include; 1) electrophysiological dysfunction (arrhythmias), 2) impaired myocyte contractile function, 3) increased vascular permeability, and 4) increased blood flow during reflow after mild hypoxia or brief ischemia but decreased blood flow after prolonged hypoxia/ischemia. Corresponding functional changes in diabetic tissues include; 1) electrophysiological dysfunction in many tissues, best characterized in peripheral nerve and retina; 2) impaired contractile function of heart, skeletal muscle, and vascular smooth muscle; 3 ) increased vascular permeability; and 4) increased blood flow early after the onset of diabetes but decreased blood flow later in the course of diabetes. Most of these early changes in tissues of diabetic animals are prevented by inhibitors of aldose reductase [48,58,59]. An important feature of this glucose-induced redox imbalance is that it provides an explanation for the increased susceptibility of diabetic subjects to hypoxic and ischemic injury.

\section{The renin-angiotensin system}

For a long time the renin-angiotensin system (RAS) has been regarded primarily as an endocrine system. Renin, which is secreted by the kidney, stimulates the conversion of 


\section{CHAPTER 1}

angiotensinogen to angiotensin $\mathrm{I}$. This is then cleaved by the angiotensin converting enzyme (ACE is present in endothelial cells and the blood) to the vasoactive peptide angiotensin II |stibil!. Angiotensin II has many different effects including vasoconstriction, aldosterone production, and release of catecholamines. This makes the RAS an important factor in maintaining the cardiovascular homeostasis. However, more and more evidence suggests that in parallel with the circulating RAS several organs show RAS activity, which may serve a paracrine or autocrine regulatory effect. Components of this renin-angiotensin system have been found in several organs like the heart, kidney, brain, adrenal and vascular tissue ${ }^{[62-64]}$. This local renin-angiotensin system is thought to be important in several physiologic and pathophysiologic conditions.

Angiotensin II has been shown to have effects on the vascular extra-cellular matrix, as well as mitogenic and hypertrophic effects on smooth muscle cells in vivo and in vitro ${ }^{16 \%}$ ! and to produce vascular proliferation. The RAS probably mediates vascular responses to inflammation and injury. In diabetes mellitus, serum levels of components of the RAS may be altered, although some controversies exist about this subject. Authors report low ${ }^{[66]}$, normal ${ }^{[67]}$ or even elevated plasma renin activity ${ }^{[68]}$ in diabetic patients. Explanations for the contradictory observations include variations in metabolic control and the presence or absence of neuropathy. It is generally believed that diabetic patients without signs of microangiopathy have a normal functioning renin-angiotensin system, although the renin-angiotensin system in patients with angiopathy is suppressed. This has also been observed in experimental models of diabetes ${ }^{[69.70]}$.

Inhibitors of the angiotensin converting enzyme are considered effective drugs for the prevention or delay of diabetic nephropathy. Besides decreasing blood pressure ${ }^{[7]}$, they seem to have a beneficial effect on renal hemodynamics, which in patients leads to slowing of the rate of decline of kidney function, and reduces urinary albumin excretion [72]. There is evidence that by treating IDDM patients who are still normotensive with angiotensin converting enzyme inhibitors the development of nephropathy may be retarded ${ }^{[73,74]}$.

\section{The streptozotocin-induced diabetic rat model}

Several experimental animal models of diabetes mellitus exist. Classically, experimental diabetes has been induced in laboratory animals by either alloxan or streptozotocin ${ }^{[99]}$. Streptozotocin is generally preferred as a diabetogenic agent in rodents. Unfortunately, streptozotocin induced diabetes is difficult to produce in certain species such as the rabbit or guinea pig ${ }^{[100]}$, therefor alloxan is usually chosen for these species. Studies on dysfunction of the cardiovascular system have been limited primarily to the rat, rabbit and dog models. More recently the genetic models like the $\mathrm{BB}$ rat have been developed ${ }^{[101]}$. One of the disadvantages of this model that the rats are difficult to care for as they can not survive without the administration of insulin. We chose the streptozotocin-induced diabetic rat since this is the most commonly used model. Therefor, comparisons can be made with numerous reports on different aspects of diabetes and diabetic angiopathy. In addition, not only cardiovascular alterations but also the characteristics of the endocrine system, and 


\section{VASCULAR DYSFUNCTION IN DIABETES MELLITUS}

different organs such as the liver, kidney and central nervous system have been extensively studied. Streptozotocin is a metabolite of Streptomyces Achromogenus that has antibiotic, antitumor and carcinogenic properties. The first report regarding its diabetogenic characteristics date from 1963. Streptozotocin is directly toxic for pancreatic $\beta$-cells through damage to the plasma membrane, a decrease in NAD levels and possibly free radical production. It induces a form of diabetes that resembles insulin-dependent diabetes in humans. Streptozotocin diabetic rats are hyperglycemic, lean, hypo-insulinemic and do not need insulin for their survival.

No single animal model mimics all of the clinical manifestations of diabetes mellitus, however the "standard model" to study cardiovascular changes is the rat model. For this reason we choose the streptozotocin-induced diabetic rat model as the model for our investigations. It has the advantage of delineating the effects of hyperglycemia per se without the complications of atherosclerosis and hypertension.

\section{ABNORMAL ENDOTHELIAL CONTROL OF VASCULAR REACTIVITY}

Impairment of endothelium-dependent-relaxation has been hypothesized as a mechanism to explain the pathophysiology of certain vascular diseases. For example, there are many studies that suggest that endothelium-dependent relaxation is impaired in atherosclerotic vessels derived from human and experimental animals ${ }^{[75,76]}$ and vessels obtained from the genetically hypertensive rat model ${ }^{[77,78]}$.

\section{Contractile properties}

So far most studies using diabetic blood vessels have focussed primarily on vasoconstrictor responses to $\alpha$-adrenoceptor agonists. For a review see the summary in table 1. Regarding $\alpha$-adrenoceptor agonists, most studies show that the $\mathrm{EC}_{50}$ values of individual agonists are not altered by diabetes whatever the species or model (i.e., chemical versus genetic models). However, several authors have shown increased maximum contractile tension to norepinephrine or selective $\alpha_{1}$-adrenoceptors agonists in the aorta from diabetic animals. Others showed a decreased contractile response. It has been argued that such discrepancies may be related to the method of calculating tension and the use of helical strips versus vessel ring preparations. However, the difference found could not be explained by this or by the rat model or technique used. One possibility could be the glucose concentration. In all studies tissue bath medium with 5 or $11 \mathrm{mM}$ glucose was used. This glucose concentration is too low for the vessels isolated from diabetic animals as the average blood glucose is $20 \sim 35 \mathrm{mM}$ in the various studies. So real differences existing in vivo may be masked when identical glucose concentration in the medium are used for vessels obtained from control and diabetic animals. 


\section{CHAPTER 1}

\begin{tabular}{|c|c|c|c|c|}
\hline Investigator & $\begin{array}{l}\text { Type of diabetes } \\
\text { Rat strain }\end{array}$ & Value & $\mathrm{NE}$ & PHE \\
\hline Head et al. ${ }^{[79]}$ & $\begin{array}{l}\text { STZ } \\
\text { Sprague-Dawley }\end{array}$ & $\begin{array}{l}\mathrm{EC}_{50} \\
\mathrm{Max} \text { tension }\end{array}$ & $\sim$ & $\begin{array}{l}\text { n.a. } \\
\text { n.a. }\end{array}$ \\
\hline Wakabayashi et al. ${ }^{[80]}$ & $\begin{array}{l}\text { STZ } \\
\text { Wistar }\end{array}$ & $\begin{array}{l}\mathrm{EC}_{50} \\
\mathrm{Max} \text { tension }\end{array}$ & $\tilde{\downarrow}$ & $\begin{array}{l}\text { n.a. } \\
\text { n.a. }\end{array}$ \\
\hline Pfaffman et al. ${ }^{[81]}$ & $\begin{array}{l}\text { STZ } \\
\text { Wistar }\end{array}$ & $\begin{array}{l}\mathrm{EC}_{50} \\
\text { Max tension }\end{array}$ & $\begin{array}{l}\text { n.a. } \\
\text { n.a. }\end{array}$ & 1 \\
\hline Scarbourgh \& Carrier ${ }^{[82]}$ & $\begin{array}{l}\text { STZ } \\
\text { Wistar }\end{array}$ & $\begin{array}{l}\mathrm{EC}_{50} \\
\text { Max tension }\end{array}$ & $\sim$ & $\sim$ \\
\hline Cameron \& Cotter ${ }^{[83]}$ & $\begin{array}{l}\text { STZ } \\
\text { Sprague-Dawley }\end{array}$ & $\begin{array}{l}\mathrm{EC}_{50} \\
\text { Max tension }\end{array}$ & $\sim$ & $\tilde{1}$ \\
\hline Owen \& Carrier ${ }^{[84]}$ & $\begin{array}{l}\text { STZ } \\
\text { Wistar }\end{array}$ & $\begin{array}{l}\mathrm{EC}_{50} \\
\text { Max tension }\end{array}$ & $\sim$ & $\begin{array}{l}\text { n.a. } \\
\text { n.a. }\end{array}$ \\
\hline MacLeod et al. ${ }^{[85]}$ & $\begin{array}{l}\text { STZ } \\
\text { Wistar }\end{array}$ & $\begin{array}{l}\mathrm{EC}_{50} \\
\text { Max tension }\end{array}$ & $\tilde{1}$ & $\begin{array}{l}\text { n.a. } \\
\text { n.a. }\end{array}$ \\
\hline Ramanadham et al. ${ }^{[86]}$ & $\begin{array}{l}\text { STZ } \\
\text { Sprague-Dawley }\end{array}$ & $\begin{array}{l}\mathrm{EC}_{50} \\
\text { Max tension }\end{array}$ & $\tilde{\tau}$ & $\begin{array}{l}\text { n.a. } \\
\text { n.a. }\end{array}$ \\
\hline Turlapathy et al. ${ }^{[87]}$ & $\begin{array}{l}\text { ALX } \\
\text { Sprague-Dawley }\end{array}$ & $\begin{array}{l}\mathrm{EC}_{50} \\
\text { Max tension }\end{array}$ & $\begin{array}{l}\uparrow \\
\downarrow\end{array}$ & $\begin{array}{l}\text { n.a. } \\
\text { n.a. }\end{array}$ \\
\hline
\end{tabular}

Table 1. NE = norepinephrine, $P H E=$ phenylephrine, $S T Z=$ streptozotocin-induced dialetes, n.a. $=$ not assessed, $t=$ increase in $E C_{S 0}$ or maximum tension, $\downarrow=$ decrease in $E C_{S 0}$ or maximum tonsion. and $\sim=$ unchanged $E C_{50}$ or maximum tension. All observations were made in aorta.

\section{Endothelium-dependent relaxation}

Nitric oxide (NO) is released from the endothelium at a basal level or after stimulation with acetylcholine. The nitric oxide activates the soluble guanylate cyclase in the smooth muscle cell, which then in turn releases the second messenger cyclic GMP. One of the first studies concerning endothelium-dependent relaxation in diabetic blood vessels appeared in the literature in a paper by Fortes ${ }^{[88]}$ using the alloxan diabetic Wistar rat. The authors showed that relaxation to histamine and bradykinin but not to acetylcholine were impaired in diabetic mesenteric arteries in situ. During the last decade several reports have been published either confirming or rejecting the notion of impaired endothelium-dependent relaxation.

Most investigations on endothelium-dependent relaxation have been performed using the diabetic aorta, but also mesenteric and renal arteries were used. A summary of these observations is provided in table 2. Nine different groups have shown impaired relaxation to acetylcholine in arteries of diabetic rats, whereas five publications reported no change. Bhardwaj and Moore ${ }^{[89]}$ reported an increase in sensitivity to acetylcholine in perfused kidney. The reports in which endotheliumdependent relaxation to acetylcholine were shown to be impaired also presented evidence that relaxation to other endothelium-dependent vasodilatators such as 


\section{VASCULAR DYSFUNCTION IN DIABETES MELLITUS}

histamine were impaired. From these results one can conclude that there is a broad variance in the response to acetylcholine in different diabetic models.

\begin{tabular}{l|l|l|l} 
Investigator & Rat strain & $\begin{array}{l}\text { Type of } \\
\text { diabetes }\end{array}$ & Acetylcholine \\
\hline \hline Orie et al. ${ }^{[90]}$ & Wistar & STZ & impaired \\
\hline${\text { Cameron \& Cotter }{ }^{[83]}}$ & Sprague-Dawley & STZ & impaired \\
\hline Pieper \& Gross ${ }^{[1]]}$ & Sprague-Dawley & STZ & impaired \\
\hline Kamata et al. ${ }^{92]}$ & Wistar & STZ & impaired \\
\hline Oyama et al. ${ }^{[93]}$ & Wistar & STZ & impaired \\
\hline Kam et al. ${ }^{[7]]}$ & Wistar & STZ & impaired \\
\hline Durante et al. ${ }^{[94]}$ & BB & Spontaneous & impaired \\
\hline Kappagoda et al. ${ }^{[95]}$ & BB & Spontaneous & impaired \\
\hline Meraji et al. ${ }^{[96]}$ & BB & Spontaneous & impaired \\
\hline Fortes et al. ${ }^{[97]}$ & Wistar & ALX & unchanged \\
\hline Fortes et al. ${ }^{[88]}$ & Wistar & ALX & unchanged \\
\hline Head et al. ${ }^{[9]}$ & Sprague-Dawley & STZ & unchanged \\
\hline Harris \& MacLeod ${ }^{[98]}$ & Wistar & STZ & unchanged \\
\hline Wakabayashi et al. ${ }^{[80]}$ & Wistar & STZ & unchanged \\
\hline
\end{tabular}

Table 2. Effects of diabetes on acetylcholine, an endothelium-dependent vasodilator. $(S T Z=$ streptozotocin induced diabetes, $A L X=$ alloxan induced diabetes, $B B=B$ Bio-Breeding rats) $A l l$ observations were made in aorta.

\section{THE PRESENT THESIS}

The investigations described in this thesis were performed to gain more insights into the pharmacology of the vascular system in the streptozotocin-diabetic rat model. To study the vascular reactivity in arteries we choose to use an in vitro method. One of the advantages of using isolated vessels in an organbath, in our case the myograph, is that this setup allows one to standardize all experimental conditions. In this thesis we standardized all experimental conditions except for the glucose concentration present in the modified Krebs bicarbonate solution.

We tested the following hypotheses. Firstly, we conceived that wide variation of observations regarding vascular reactivity in diabetes can be attributed to differences in experimental setup. Specific factors involved in the discrepancies may be: 1 . the glucose concentration of the medium; 2 . the duration of hyperglycemia/diabetes in the experimental animals; 3 . the specific vascular segment studied. Vascular reactivity to 


\section{CHAPTER 1}

vasoactive agents was therefore assessed under standardized experimental conditions, with studies performed in normal and high-glucose concentrations, in vessels obtained from animals with short-term (9-days), intermediate (6 weeks) and long-term duration of diabetes (3 months). We postulated that acute elevation of the glucose concentration, by increasing the amount of glucose in the tissue bath medium, or by acutely inducing hyperglycemia, could severely depress normal vasoreactivity. In addition, we postulated that with longer duration of diabetes the impairment vasoreactivity of diabetic animals restores towards normal. To assess the third factor, studies were carried out in the aorta, and in mesenteric and renal resistance arteries.

Our second hypothesis was that alterations in vascular reactivity due to the diabetic state could be influenced by pharmacologic interventions. We postulated that pharmacological agents specifically influencing pathways critical for the development of diabetic complications would prove beneficial. These pathways, as discussed earlier, are the formation of advanced glycation endproducts and the increased activity of the polyol pathway. To test this hypothesis, the effects of chronic treatment with aminoguanidine, an inhibitor of the formation of advanced glycation endproducts, and of treatment with inhibitors of the enzyme aldose reductase, on vascular reactivity of vessels from diabetic animals were assessed.

Our third hypothesis regarded the effects of the widely-used inhibitors of the angiotensin converting enzyme. These compounds have been shown to reduce increased arteriolar vasoreactivity in diabetic animals in vivo, and also beneficially influence the development of diabetic nephropathy ${ }^{[72-74]}$. We postulated that chronic treatment with an ACE-inhibitor would beneficially influence disturbed vascular reactivity.

Finally, we tested the hypothesis that the changes in vascular reactivity, as can be found in the aorta in vitro, are paralleled by similar changes and behavior of this vessel in intact animals. For this purpose, a new technique has been employed. Compliance and distensibility of the aorta were measured by ultrasound arteriography, to study the behavior of the aorta in vivo.

\section{Outline of this thesis}

The objective of the present thesis was to investigate the effects of experimental diabetes on the vascular reactivity and to evaluate whether changes in vascular reactivity can be prevented by different pharmacologic approaches. This thesis can be divided into three parts.

- In the first part (chapter 3 and 4), diabetes-induced alterations in vascular reactivity in different vessels under different circumstances are described.

- In the second part (chapter 5, 6, 7 and 8), the influence of in vivo treatment with different drugs is described.

- In the third part (chapter 9), compliance and distensibility of the aorta in vivo are measured using ultrasound arteriography. 


\section{VASCULAR DYSFUNCTION IN DIABETES MELLITUS}

\section{REFERENCES}

1. WHO Expert Committee on Diabetes Mellitus. Technical report series 646. Geneva: World Health Organisation, 1985.

2. DeFronzo R. The triumvirate: beta-cell, muscle, liver: a collusion responsible for NIDDM. Diabetes 1988;37:667-687.

3. Efendic S, Luft R, Wajngot A. Aspects of the pathogenesis of type 2 diabetes. Endocrine Rev 1984;5:395-410.

4. Wolffenbuttel BHR, Huijberts MSP, Heesen BJ, Leurs PB, Nieuwenhuijzen Kruseman AC. Goede instelling van diabetes verkleint de kans op diabetische complicaties. Ned Tijdschr Geneeskd 1993;137:2179-2183.

5. Fein FS, Scheuer J. Diabetes Mellitus, theory and practice. 4th ed. New York: Elsevier Science Publishing, 1990.

6. Keen H, Jarrett RJ, Fuller JH, McCartney P. Hyperglycaemia and arterial disease. Diabetes 1981;30(Suppl. 1):49-53.

7. Klein R, Davis MD, Mosse SE, Klein BEK, Demets DL. The Wisconsin epidemiologic study of diabetic retinopathy: a comparison of retinopathy in younger and older onset diabetic persons. In: Vranic M, Hollenberg C, Steiner G, Eds G, eds. Comparisons of type I and type II diabetes. New York: Plenum, 1985:321-325. (N)

8. Merimee TJ. Diabetic retinopathy, a synthesis of perspectives. N Engl J Med 1990;322:978983.

9. Dornan TL, Ting A, McPerson CK. Genetic susceptibility to the development of retinopathy in insulin-dependent diabetes. Diabetes 1982;31:226-231.

10. Mogensen CE, Gammelgaard J, Frandsen M, Parving HH. Increased kidney size, glomerular filtration rate and renal plasma flow in short-term insulin-dependent diabetes. Diabetologia $1981 ; 20: 451-456$.

11. Mogensen CE, Andersen MJF. Increased kidney size and glomerular filtration rate in early juvenile diabetes. Diabetes 1973;22:706-712.

12. Morley AR. Renal vascular disease in diabetes mellitus. Histopathology 1988;12:343-358.

13. Hirose K, Tsuchida H, Osterby R, Gundersen HJG. A strong correlation between glomerular filtration rate and filtration surface in diabetic kidney hyperfunction. Lab Invest 1980;43:434 437.

14. Ellis EN, Steffes MW, Goetz FC, Sutherland DER, Mauer SM. Glomerular filtration surface in type I diabetes mellitus. Kidney Int 1986;29:889-894.

15. Steffes MW, Osterby R, Chavers B, Mauer MS. Mesangial expansion as a central mechanism for loss of kidney function in diabetic patients. Diabetes 1989;38:1077-1081.

16. Williamson JR, Tilton RG, Chang K, Kilo C. Basement membrane abnormalities in diabetes mellitus: relationship to clinical microangiopathy. Diabetes/Metab Rev 1988;4:339-370.

17. Lash JM, Sherman WM, Hamlin RL. Capillary basement membrane thickness and capillary density in sedentary and trained obese Zucker rats. Diabetes 1989;38:854-860.

18. Pirart J. Diabetes mellitus and its degrenative complications: a prospective study of 4400 patients observed between 1947 and 1973. Diabetes Metab 1977;3:173-182. 


\section{CHAPTER 1}

19. Pirart J. Diabetes mellitus and its degenerative complications: a prospective study of 4400 puttents observed between 1947 and 1973. Diabetes Metab 1977;3:245-256.

20. Pirart I. Why don't we teach and treat diabetic patients better? Diab Care 1978;1:139-140.

31. Low PA, Tuck RR, Takenchi M. Diabetic neuropathy. In: Duyck PJ, Thomas PK, Abury AK, eds. Philadelphia: WB Saunders, 1987:266-278.

22. (ireene DA, Sima AAF, Albers JW, Pfeifer MA. Diabetic neuropathy. In: Rifkin H, Porte DJ, eds. Diabetes Mellitus, theory and practice. 4th ed. New York: Elsevier Science Publishing, 1990:710-755.

23. Maillard LC. Action des acides amines sur les sucres; formation des melanoidines par voie methodique. C R Hebd Seances Acad Sci 1912;154:66-68.

24. Bucala R. Cerami A. Advanced glycoylation: chemistry, biology, and implications for diabetes and aging. Adv Pharmacol 1992:23:1-34.

25. Monnier VM, Vishwanath V, Frank KE, Elmets GA, Dauchot P, Kohn RR. Relation between complications of type 1 diabetes mellitus and collagen-linked fluorescence. $\mathrm{N}$ Engl J Med $1986: 314: 403-408$.

26. Monnier VM, Kohn RR, Cerami A. Accelerated age-related browning of human collagen in diabetes mellitus. Medical Sciences 1984;81:583-587.

27. Kennedy L. Baynes JW. Non-enzymatic glycosylation and the chronic complications of diabetes: an overview. Diabetologia 1984;26:93-98.

28. Yue DK, McLennan S, Delbridge L, Handelsman DJ, Reeve T, Turtle JR. The thermal stability of collagen in diabetic rats: correlation with severity of diabetes and non-enzymatic glycosylation. Diabetologia 1983;24:282-285.

29. Vogt BW, Schleider ED, Wieland OH. epsilon-Amino-lysine-bound glucose in human tissues obtained at autopsy. Increase in diabetes mellitus. Diabetes 1982;31:1123-1127.

30. Brownlee M, Cerami A, Vlassara H. Advanced glycosylation end products in tissue and the biochemical basis of diabetic complications. N Engl J Med 1988;318:1315-1321.

31. Esposito C, Gerlach H, Brett J, Stern D, Vlassara H. Endothelial receptor-mediated binding of glucose-modified albumin is associated with increased monolayer permeability and modulation of cell surface coagulant properties. J Exp Med 1989;170:1387-1407.

32. Huijberts MSP, Wolffenbuttel BHR, Struyker Boudier HAJ, Crijns FRL, Nieuwenhuijzen Kruseman AC, Poitevin P, Levy BI. Aminoguanidine treatment increases elasticity and decreases fluid filtration of large arteries from diabetic rats. J Clin Invest 1993;92:1407-1411.

33. Huijberts MSP, Wolffenbuttel BHR, Crijns FRL, Nieuwenhuijzen Kruseman AC, Bemelmans $\mathrm{MH}$, Struyker Boudier HAJ. Aminoguanidine reduces regional albumin clearance but not urinary albumin excretion in streptozotocin-diabetic rats. Diabetologia 1994;37:10-14.

34. Orosz SE, Townsend SF, Tornheim PA, Brownscheidle CM. Localization of aldose reductase and sorbitol dehydrgenase in the nervous system of normal and diabetic rats. Acta Diabetol Lat $1981 ; 18: 373-381$

35. Kennedy A, Frank RN, Varma SD. Aldose reductase in retinal and cerebral microvessels and cultured vascular cells. Invest Ophthalmol Vis Sci 1983;24:1250 1254. 


\section{VASCULAR DYSFUNCTION IN DIABETES MELLITUS}

36. Brolin SE, Naeser P. Sorbitol in aortic endothelium of diabetic rats. Diabetes Res 1988;8:5961.

37. Cheng HM, Gonzalez RG. The effect of high glucose and oxidative stress on lens metabolism, aldose reductase, and senile cataractogenesis. Metabolism 1986;35(Suppl. 1):10-14.

38. Tesfamariam B, Palacino JJ, Weisbrod RM, Cohen RA. Aldose reductase inhibition restores endothelial cell function in diabetic rabbit aorta. J Cardiovasc Pharmacol 1993;21:205-211.

39. Schmidt RE, Plurad SB, Coleman BD, Williamson JR, Tilton RG. Effects of sorbinil, dietary myo-inositol supplementation, and insulin on resolution of neuroaxonal dystrophy in mesenteric nerves of streptozocin-induced diabetic rats. Diabetes 1991;40:574-582.

40. Schmidt RE, Plurad SB, Sherman WR, Williamson JR, Tilton RG. Effects of aldose reductase inhibitor sorbinil on neuroaxonal dystrophy and levels of myo-inositol and sorbitol in sympathetic autonomic ganglia of streptozocin-induced diabetic rats. Diabetes 1989;38:569579.

41. Tesfamariam B, Brown ML, Cohen RA. Elevated glucose impairs endothelium-dependent relaxation by activating protein kinase C. J Clin Invest 1991;87:1643-1648.

42. Inoguchi T, Battan R, Handler E, Sportsman JR, Heath W, King GL. Preferential elevation of protein kinase $\mathrm{C}$ isoform beta II and diacylglycerol levels in the aorta and heart of diabetic rats: differential reversibility to glycemic control by islet cell transplantation. Proc Natl Acad Sci U S A 1992;89:11059-11063.

43. Berridge MJ. Intracellular signaling through inositol trisphosphate and diacylglycerol. Biol Chem Hoppe Seyler 1986;367:447-456.

44. Williamson JR, Chang K, Tilton RG, Prater C, Jeffrey JR, Weigel C, Sherman WR, Eades DM, Kilo $C$. Increased vascular permeability in spontaneously diabetic BB/W rats and in rats with mild versus severe streptozocin- induced diabetes. Prevention by aldose reductase inhibitors and castration. Diabetes 1987;36:813-821.

45. Tilton GR, Chang K, Pugliese G, Eades DM, Province MA, Sherman WR, Kilo C, Williamson JR. Prevention of hemodynamic and vascular albumin filtration changes in diabetic rats by aldose reductase inhibitors. Diabetes 1989;38:1258-1270.

46. Pugliese G, Tilton RG, Speedy A, Santarelli E, Eades D, Province MA, Kilo K, Sherman WR, Williamson JR. Modulation of hemodynamic and vascular filtration changes in diabetic rats by dietary myo-inositol. Diabetes 1990;39:312-322.

47. Williamson JR, Chang K, Rowold E, Kilo C, Lacy PE. Islet transplants in diabetic Lewis rats prevent and reverse diabetes-induced increases in vascular permeability and prevent but do not reverse collagen solubility changes. Diabetologia 1986;29:392-396.

48. Williamson JR, Chang K, Frangos M, Hasan KS, Ido Y, Kawamura T, Nyengard JR, Van Den Enden M, Kilo C, Tilton RG. Hyperglycemic pseudohypoxia and diabetic complications. Diabetes 1993;42:801-813.

49. Cohen MP, Dasmahapatra A, Shapiro E. Reduced glomerular sodium/potassium adenosine triphosphatase activity in acute streptozotocin diabetes and its prevention by sorbinil. Diabetes 1985;35:1071-1074.

50. Griffin BW, McNatt LG, Chandler ML, York BM. Effects of two new aldose reductase inhibitors, AL-1567 and AL-1576, in diabetic rats. Metabolism 1987;36:486-490. 


\section{CHAPTER 1}

51. Greene DA, Lattimer S. Action of sorbinilin diabetic peripheral nerve. Relationship of polyol (sorbitol) pathway inhibition to a myo-inositol mediated effect in sodium-potassium ATP-ase activity. Diabetes 1984;33:712-716.

52. Engerman RL, Kern TS. Aldose reductase fails to prevent retinopathy in diabetic and galactosemic dogs. Diabetes 1993;42:820-825.

53. Pedersen MM, Christiansen JS, Mogensen CE. Reduction of glomerular hyperfiltration in normoalbuminiric IDDM pathients by 6 months of aldose reductase inhibition. Diabetes $1991 ; 40: 527-531$.

54. Travis SF, Morrison AD, Clements RS, Winegrad AL, Oski FA. Metabolic alterations in the human erythrocyte produced by increases in glucose concentration: the role of the polyol pathway. J Clin Invest 1971;50:2104-2112.

55. Langunas $R$, McLean $P$, Greenbaum AL. The effect of raising the NAD+ content on the pathways of carbohydrate metabolism and lipogenesis in rat liver. Eur J Biochem 1970;15:179190.

56. Williamson $\mathrm{DH}$, Lund $\mathrm{P}, \mathrm{Krebs} \mathrm{HA}$. The redox state of free nicotinamide-adenine dinucleotide in the cytoplasm and mitochondria of rat liver. Biochem J 1967;103:514-527.

57. Tilton RG, Baier LD, Harlow JE, Smith SR, Ostrow E, Williamson JR. Diabetes-induced glomerular dysfunction: links to a more reduced cytosolic ratio of NADH/NAD'. Kidney Int 1992;41:778-788.

58. Tilton RG, Chang K, Pugliese G, Eades DM, Province MA, Sheman WR, Kilo C, Williamson JR. Prevention of hemodynamic and vascular albumin filtration changes in diabetic rats by aldose reductase inhibitors. Diabetes 1989;38:1258-1270.

59. Pugliese G, Tilton RG, Williamson JR. Glucose-induced metabolic imbalances in the pathogenesis of diabetic vascular disease. Diabetes/Metab Rev 1991:7:35 59.

60. Dzau VJ. Circulating versus local renin-angiotensin system in cardiovascular homeostasis. Circulation 1988;77(Suppl. 1):14-13.

61. Campbell DJ. Circulating and tissue angiotensin systems. J Clin Invest 1987;79:1-6.

62. Ganten D, Hermann K, Bayer C, Unger T, Lang RE. Angiotensin synthesis in the brain and increased turnover in hypertensive rats. Science 1983;221:869-871.

63. Lindpaintner K, Ganten D. The cardiac renin-angiotensin system. An appraisal of present experimental and clinical evidence. Circ Res 1991;68:905-921.

64. Aguilera G, Schrirar A, Baukal A, Catt KJ. Circulating angiotensin II and adrenal receptors after nephrectomy. Nature 1981;289:505-509.

65. Schelling P, Fischer H, Ganten D. Angiotensin and cell growth: a link to cardiovascular hypertrophy. J Hypertension 1991;9:3-15.

66. Fernandez-Cruz A, Noth RH, Lassman MN, Hollis JB, Mulrow PJ. Low plasma renin activity in normotensive patients with diabetes mellitus: relationship to neuropathy. Hypertension $1981 ; 3: 87-92$

67. O'Hare JA, Ferris JB, Brady D, Twomey B, O'Sullivan DJ. Exchangeable sodium and renin in hypertensive diabetic patients with and without nephropathy. Hypertension 1985;7(Suppl.
2):43-48. 


\section{VASCULAR DYSFUNCTION IN DIABETES MELLITUS}

68. Drury $\mathrm{PL}$, Bodansky HJ. The relationship of the renin-angiotensin system in type I diabetes t microvascular disease. Hypertension 1985;7(Suppl. 2):84-89.

69. Cassis L. Downregulation of the renin-angiotensin system in streptozotocin diabetic rats. Am d Physiol 1992;262:E105-E109.

70. Everett AD, Scott J, Wilfong N. Renin and angiotensin expression during the evolution of diabetes. Hypertension 1992;19:70-78.

71. Passa P, Leblanc H, Marre M. Effects of enalapril in insulin-dependent diabetic subjects with mild to moderate hypertension. Diab Care 1987;10:200-204.

72. Taguma Y, Kilamot I, Futaki G. Effects of captopril on heavy proteinuria in azotemic diabetics N Engl J Med 1985;313:1617-1620.

73. Mathiesen E, Hommel E, Giese J, Parving H. Efficacy of captopril in postponing nephropathy in normotensive insulin dependent diabetic patients with microalbuminuria. BMJ 1991;303:81. 87.

74. Marre $M$, Chatellier G, Leblanc $H$. Prevention of diabetic nephropathy with enalapril in normotensive diabetics with microalbuminuria. BMJ 1988;297:1092-1095.

75. Bossaller C, Habib GB, Yamamoto H, Williams C, Wells S, Henry PD. Impaired muscarinic endothelium-dependent relaxation and cyclic guanosine $5^{\prime}$-monophosphate formation in atherosclerotic human coronary artery and rabbit aorta. J Clin Invest 1987;79:170-174.

76. Harrison DG, Freiman PC, Amstrong ML, Marcus ML, Heistad DD. Alterations of vascular reactivity in atherosclerosis. Circ Res 1987;61(Suppl. II):74-80.

77. Kam KL, Hendriks MGC, Pij1 AJ, Pfaffendorf M, Van Zwieten PA. Spontaneously hypertensive rats with diabetes: effects of some vasoconstrictors on isolated small arteries. $J$ Hypertension 1993;11(Suppl. 5):S268-269.

78. Lüscher TF, Vanhoutte PM. Endothelium-dependent contractions to acetylcholine in the aorte of the spontaneously hypertensive rat. Hypertension 1986;8:344-348.

79. Head RJ, Longhurst PA, Panek R, Stitzel RE. A contrasting effect of the diabetic state upon the contractile responses of aortic preparations from the rat and rabbit. $\mathrm{Br} J$ Pharmacol $1987 ; 91: 275-286$

80. Wakabayashi I, Hatake K, Kimura N, Kakishita E, Nagai K. Modulation of vascular tonus by the endothelium in experimental diabetes. Life Sci 1987;40:643-648.

81. Pfaffman MA, Ball CR, Darby A, Hilman R. Insulin reversal of diabetes-induced inhibition of vascular contractility in the rat. Am J Physiol 1982;242:H490-H495.

82. Scarbourgh NL, Carrier GO. Nifedine and alpha adrenoreceptors in rat aorta. II. Role of extracellular calcium in enhanced alpha-2 adrenoceptor-mediated contraction in diabetes. $J$ Pharmacol Exp Ther 1984;231:603-609.

83. Cameron NE, Cotter MA. Impaired contraction and relaxation in aorta from streptozotocindiabetic rats: role of polyol pathway. Diabetologia 1992;35:1011-1019.

84. Owen MP, Carrier GO. Calcium dependence of norepinephrine-induced vascular contraction in experimental diabetes. J Pharmacol Exp Ther 1980;212:253-258.

85. MacLeod KM. The effect of insulin treatment on changes in vascular reactivity in chronic, experimental diabetes. Diabetes 1985;34:1160-1167. 


\section{CHAPTER 1}

86. Ramanadham S, Lyness WH, Tenner TEJ. Alterations in aortic and tail artery reactivity to agonists after streptozotocin treatment. Can J Physiol Pharmacol 1984;62:41 8-423.

87. Turlapathy PDMV, Lum G, Altura BM. Vascular responsiveness and serum biochemical parameters in alloxan diabetic mellitus. Am J Physiol 1980;239:E412-421.

88. Fortes ZB, Leme JG, Scivoletto R. Vascular reactivity in diabetes mellitus: role of the endothelial cell. Br J Pharmacol 1983;79:771-781.

89. Bhardwaj R, Moore PK. Increased vasodilator response to acetylcholine of renal blood vessels from diabetic rats. J Pharm Pharmacol 1988;40:739-742.

90. Orie NN, Aloamaka CP, Iyawe VI. Duration-dependent attenuation of acetylcholine - but not histamine induced relaxation of the aorta in diabetes-mellitus. General Pharmacology $1993 ; 24: 329-332$.

91. Pieper GM, Gross GJ. Oxygen free radicals abolish endothelium-dependent relaxation in diabetic rat aorta. Am J Physiol 1988;255:H825-H833.

92. Kamata K, Miyata N, Kasuya Y. Impairment of endothelium-dependent relaxation and changes in levels of cyclic GMP in aorta from streptozotocin- induced diabetic rats. $\mathrm{Br} J \mathrm{Pharmac}$ 1989;97:614-618.

93. Oyama Y, Kawasaki H, Hattori Y, Kanno M. Attenuation of endothelium-dependent relaxation in aorta from diabetic rats. Eur $\mathrm{J}$ Pharmacol 1986;132:75-78.

94. Durante W, Sen AK, Sunahara FA. Impairment of endothelium-dependent relaxation in aortae from spontaneously diabetic rats. Br J Pharmacol 1988;94:463-468.

95. Kappagoda T, Jayakody L, Rajotte R, Thomson AB, Senaratne MP. Endothelium-dependent relaxation to acetylcholine in the aorta of streptozotocin induced diabetic-rat and the $B B$ diabetic rat. Clin Invest Med 1989;12(3):187-193.

96. Meraji S, Jayakody L, Senaratne MP, Thomson AB, Kappagoda T. Endothelium-dependent relaxation in aorta of $B B$ rat. Diabetes 1987;36:978-981.

97. Fortes ZB, Garcia Leme J, Scivoletto R. Vascular reactivity in diabetes mellitus: role of the endothelial cell. Br J Pharmac 1983;79:771-781.

98. Harris $\mathrm{KH}$, MacLeod KM. Influence of the endothelium on contractile responses of arteries from diabetic rats. Eur J Pharmacol 1988;153:55-64.

99. Rerup CC. Drugs producing diabetes through damage of the insulin secreting cells. Pharm Rev $1970 ; 22: 485-518$.

100. Kusher B, Lazar M, Fuman M, Lieberman TW, Leopold IH. Resistance of rabbits and quinea pigs to the diabetogenic effect of streptozotocin. Diabetes $1969 ; 18: 542-544$.

101. Tomlinson KC, Gardiner SM, Hebden A, Bennett T, Functional consequences of streptozotocin-induced diabetes mellitus, with particular reference to the cardiovascular system. Pharm Rev 1992;44:103-150. 


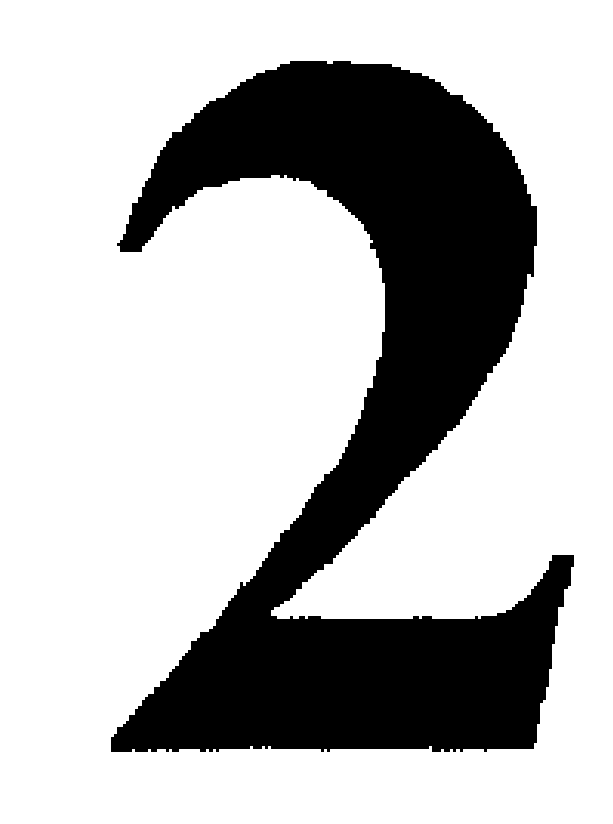

Material and methods 
MATERIAL AND METHODS

\section{MATERIALS AND METHODS}

\section{Experimental animals}

We used male Wistar RP (TNO-REPGO, Rijswijk, The Netherlands) or Sprague Dawley rats (Sasco, O' Fallon, MO, USA). In part of the rats diabetes was induced with streptozotocin. This is the most commonly used model for type I diabetes (insulin dependent) and therefore comparisons can be made with other reports on the different aspects of diabetes ${ }^{[1]}$. We injected streptozotocin $(65-70 \mathrm{mg} / \mathrm{kg}$ bw) intraperitoneal in rats at the age of 6-8 weeks. When rats were older (12-20 weeks), a lower dose of streptozotocin was used $(45 \mathrm{mg} / \mathrm{kg}$ bw). This was done because older rats are more sensitive to streptozotocin. Streptozotocin was obtained from Upjohn Co. (Kalamazoo, MI, USA) or SIGMA (St. Louis, MO, USA). The age of the rats ranged from 12 to 20 weeks and the diabetes duration from nine days to three months. In the Netherlands we used Wistar RP rats which were housed individually in standard laboratory cages. They received food (type RMM-TM, Hope Farms, Woerden, the Netherlands) and water ad libitum. In the United States we used Sprague Dawley rats which were housed and cared for according to the guidelines of the University Committee for the Human Care of Laboratory Animals, and NIH-guidelines on laboratory animal welfare. These rats were housed in separate cages, fed standard rat chow (Ralston Purina, Richmond, In, USA), and water ad libitum. Prior to the isolation of the arteries (aorta, mesenteric resistance artery or renal interlobar artery), the rats were anesthetized with pentobarbital or ether and a 5-10 $\mathrm{ml}$ blood sample was drawn.
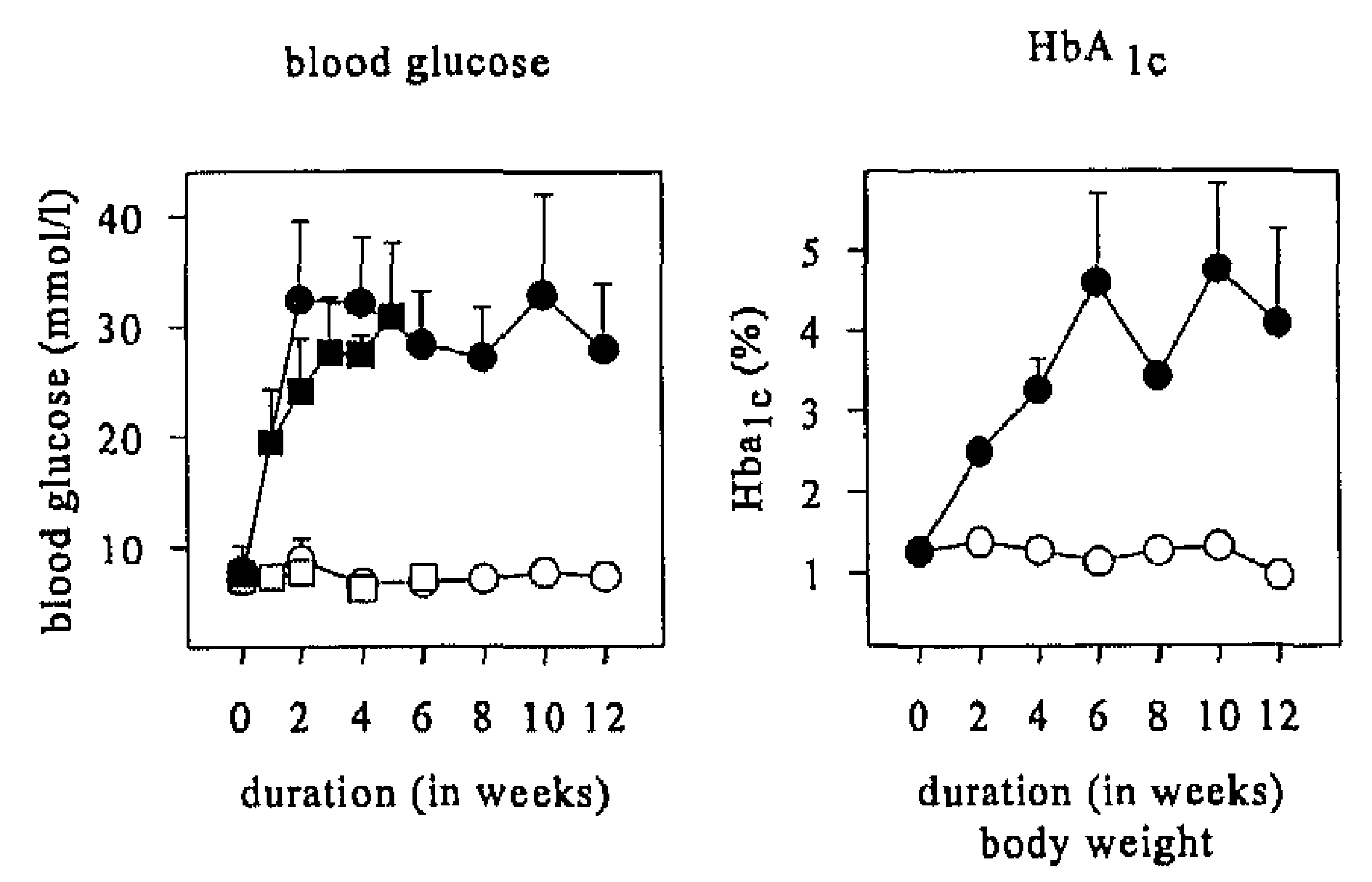

Figure 1. General characteristics of the animals used in this thesis; blood glucose (BG), glycated hemoglobin $\left(H b A_{l}\right)$, and body weight (BW). Data are shown as mean \pm standard deviation

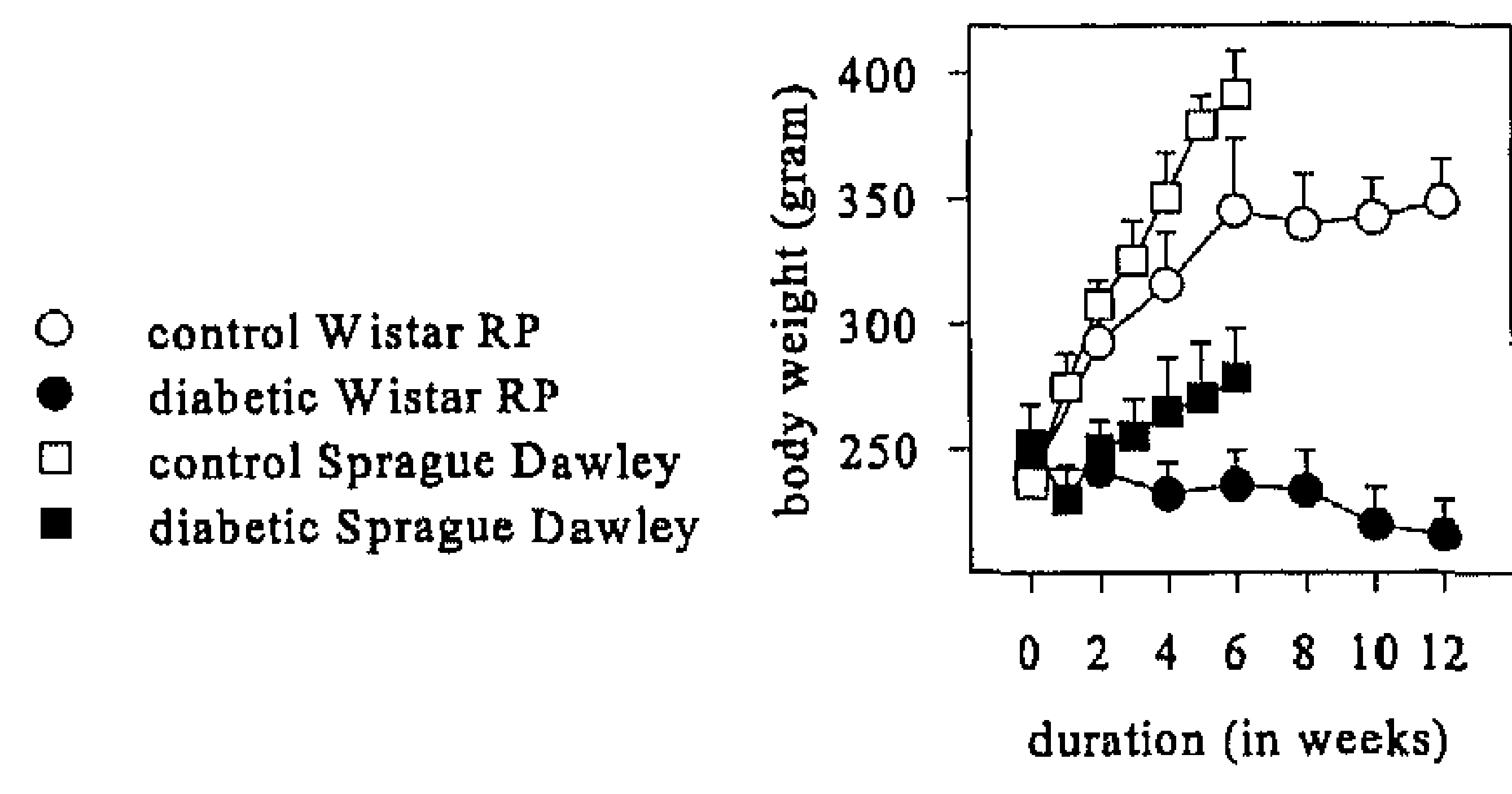




\section{CHAPTER 2}

General characteristics of the Wistar RP rats, which were used in the experiments performed in The Netherlands, and Sprague Dawley rats which were used in the United States, are depicted in figure 1 as mean \pm SD. Baseline body weights were comparable in both groups ( $238 \pm 14 \mathrm{~g}$ in control rats and $243 \pm 8$ in diabetic rats). Following induction of diabetes, body weight in these animals decreased slightly. After 6 weeks, body weights were markedly lower in the diabetic group compared to the control group ( $348 \pm 17$ vs. $216 \pm 14, \mathrm{p}<0.05$ ). Blood glucose was measured in whole blood with an automated hexokinase method. Glucose levels were in the $6-8 \mathrm{mmol} / \mathrm{l}$ range before induction of diabetes. After streptozotocin-administration, blood glucose levels in the diabetic group rose to $32 \pm 7 \mathrm{mmol} / \mathrm{l}$. Blood glucose levels in the diabetic group remained in the range of $27-32 \mathrm{mmol} / \mathrm{l}$, while the control group kept levels of 6$8 \mathrm{mmol} / 1$. Glycated hemoglobin $\left(\mathrm{HbA}_{\mathrm{Ic}}\right.$ ) was determined with HPLC (DIAMAT, BioRad Laboratories, Richmond, Ca., USA). $\mathrm{HbA}_{\mathrm{tc}}$ did not differ before induction of diabetes $(1.2 \pm 0.1 \%)$, but increased as a result of the elevated glucose to a maximal level of $4.7 \pm 1.0 \%$ after 12 weeks of diabetes $(p<0.05)$.

The Sprague Dawley rats used in the USA showed a more pronounced growth than the Wistar RP rats. However, blood glucose levels for control and diabetic rats were comparable with those found in the Wistar RP rat (Figure 1).

\section{MEASUREMENT OF THE REACTIVITY OF ISOLATED AORTA AND SMALL ARTERIES}

Isolation and mounting of the arteries

The thoracic aorta was isolated from the rat, trimmed free of adventitial connective tissue and rinsed with a buffered physiological salt solution ( $\mathrm{pH} \mathrm{7.4)} \mathrm{and} \mathrm{cut} \mathrm{into} \mathrm{small}$ rings ( $1.6 \mathrm{~mm}$ in length). The mesentery was isolated from the rats, rinsed with a buffered physiological salt solution and pinned out on a petri dish coated with Silgard (Dow Corning Corp.) filled with a buffered physiological salt solution. Third to fourth order branches of the superior mesenteric artery were dissected from the mesentery. The same procedure was followed when isolating renal intralobar arteries. Only the kidney was sliced into two pieces before being pinned out on a petri dish.

\section{The myograph}

For our experiments we used a myograph (Figure 2). This instrument makes it possible to study the isometric force development in vessels. The technique was developed by Bevan and Osher ${ }^{[2]}$ and by Mulvany and Halpern ${ }^{[3]}$ in the mid seventies to study small vessels (internal diameter 100-400 $\mu \mathrm{m}$ ). We used a similar setup (JP Trading Corp., Risskov, Denmark) to study small and large vessels from diabetic and non-diabetic rats. Segments of small or large vessels were cut into small rings (1.6 $\mathrm{mm}$ in length). Special care was taken to avoid damaging the endothelial layer. Two stainless-steel wires (diameter $40 \mu \mathrm{m}$ ) were inserted into the lumen of the vessel, which was then mounted horizontally in the myograph, between an isometric force transducer (Kistler Morse DSC6, Seattle WA, USA) and a displacement device (Mitatoyo, Tokyo, Japan) ${ }^{[4 !}$ (Figure 3). 


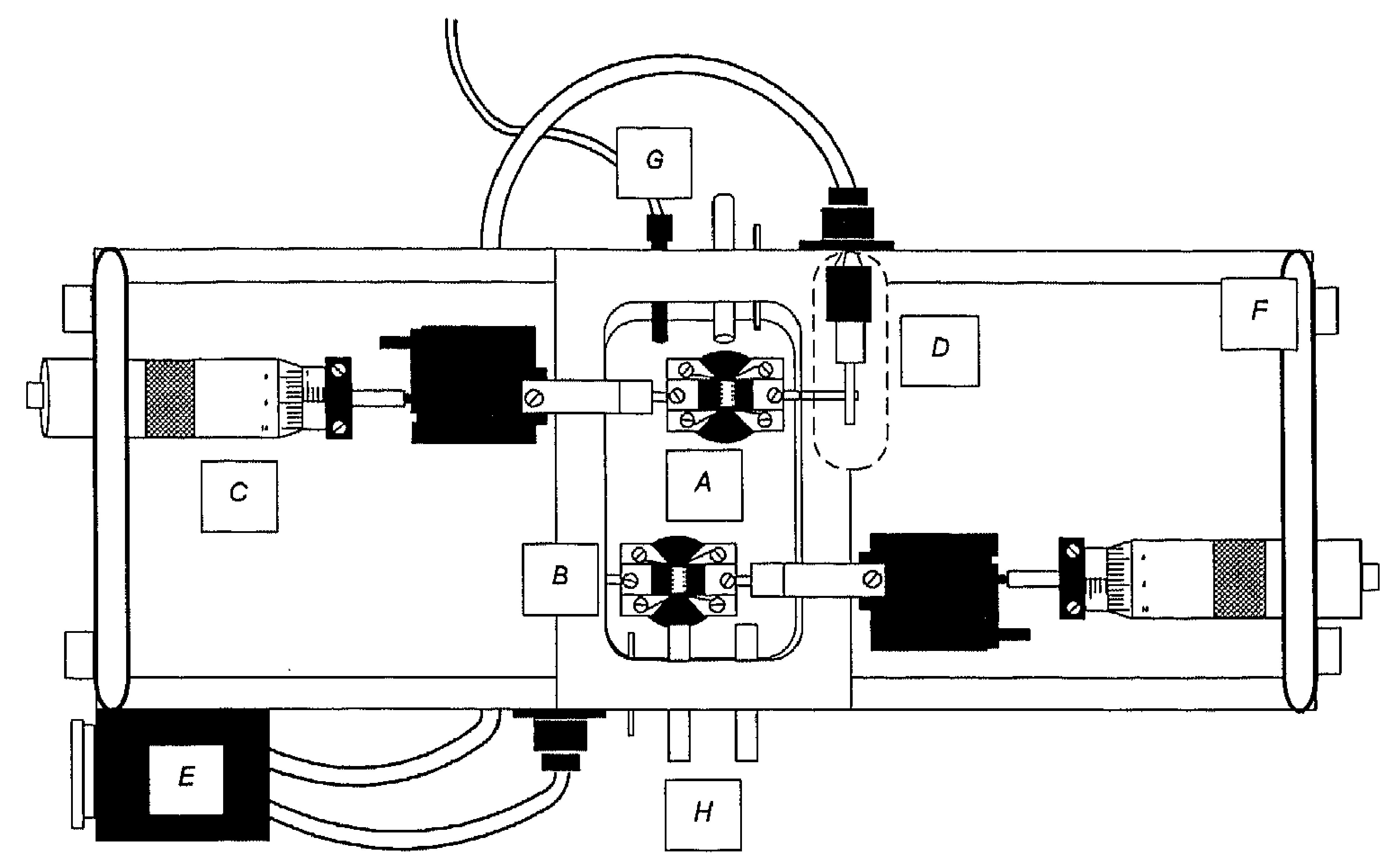

Figure 2. Drawing of the myograph used to record the reactivity of isolated blood vessels. The following essential parts can be distinguished: A stainless steel organ bath with a volume of $10 \mathrm{ml}(A)$ in which in parallel two preparations can be studied. Two pair of stainless steel supports (B) of which one is connected to a displacement device (C) and the other to a force transducer (D) that is embedded in the wall of the organ bath. The transducers are connected (E) to an amplifier and chart recorder. The myograph is water or electrically heated through an internal circuit. The actual temperature of the solution in the bath is registered through a temperature probe (G). Solutions in the bath can be aerated, removed or added through various small tubes (H) that enter the bath from both sides. Adapted with the kind permission from Boonen ${ }^{[8]}$.

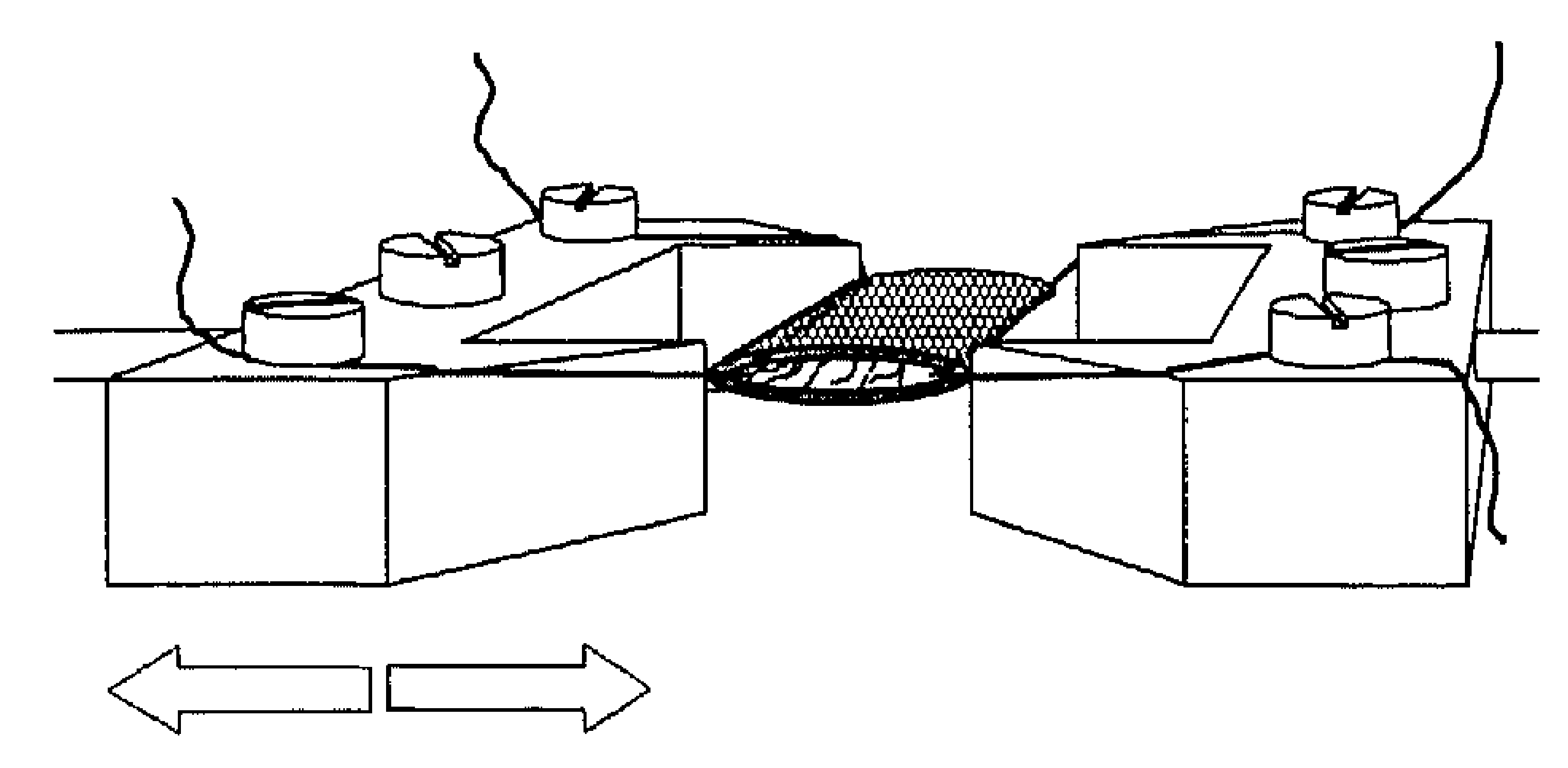

Figure 3. Illustration of a small artery segment mounted on two wires between two stainless steel supports that are either connected to a force transducer or a displacement device with which one is able to distend the segment in the indicated directions (arrows). Adapted with the kind permission from Boonen ${ }^{[8]}$. 


\section{CHAPTER 2}

\section{Physiological salt solutions}

During dissection, mounting and experimentation the preparations were immersed in a Krebs bicarbonate buffered physiological salt solution (KRB). This solution had the following composition in $\mathrm{mM}: \mathrm{NaCl} 118.3, \mathrm{KCl} 4.7, \mathrm{MgSO}_{4} 1.2, \mathrm{CaCl}_{2} 2.5, \mathrm{KH} \mathrm{PO}_{4}$ $1.2, \mathrm{NaHCO}_{3} 25.0$, Ca-EDTA 0.026 and glucose 5.0 or 30.0 . High potassium solution $(\mathrm{K}-\mathrm{KRB})$ was prepared by replacing all $\mathrm{NaCl}$ in normal $\mathrm{KRB}$ with an equimolar amount of $\mathrm{KCl}$.

\section{Mechanical parameters}

The mechanical properties of small and large arteries can be described by a model which consists of contractile, viscous, and elastic elements. These are coupled in parallel and in series as was previously described by Boonen ${ }^{|s|}$. The force transducer in the myograph can record the passive and active isometric forces. From these some of the mechanical properties of the vessel can be calculated.

In the myograph the vessel is distended to an ellipsoid conformation (Figure 3). An internal lumen diameter $(D,(\mu \mathrm{m}))$ can be calculated which the vessel would have when its lumen cross section would be a perfect circle. The diameter is calculated from the thickness of the wires $\left(\mathrm{d}_{\mathrm{w}}\right)$ and the imposed displacement of the micrometer $\left(\mathrm{X}_{\mathrm{m}}\right)$.

$$
D=\frac{2 \cdot X_{m}+\left(2 \cdot d_{w}+\pi \cdot d_{w}\right)}{\pi}
$$

Wall tension (WT, $(\mathrm{mN} / \mathrm{mm}))$ is calculated as:

$$
W T=\frac{F}{2 l}
$$

in which $F$ stands for the force $(\mathrm{mN})$ measured by the transdueer and / for the longitudinal length of the vascular preparation which is measured with the use of a microscope equipped with a scaled eye piece. The measured force can be divided into resting wall tension (RWT), which is the force developed in a resting distended vessel, total wall tension (TWT), representing the force developed upon stimulation of the vessel with a vasoactive substance, and active wall tension (AWT $=$ TWT-RWT).

\section{The transformation of tracings to graphs}

In figure 4, a typical tracing of an aorta developing contractile force is shown. After the aorta is brought to the optimal diameter, phenylephrine is injected into the bath. Starting with the smallest dose (Phe $8=10^{-8} \mathrm{M}=0.01 \mu \mathrm{M}$ ). The next dose is added when a plateau phase for the previous dose is reached. For contraction we used the absolute contractile tension (in $\mathrm{mN} / \mathrm{mm}$ ) or we plotted the basal reading as $0 \%$ and the maximal reading as $100 \%$. 


\section{MATERIAL AND METHODS}

Figure $5 \mathrm{~A}$ and $5 \mathrm{~B}$ are typical tracings for acetylcholine induced relaxation curves in aorta isolated from control $(5 \mathrm{~A})$ or diabetic $(5 \mathrm{~B})$ rats. These readings were plotted by setting the maximal reading, induced by phenylephrine to $100 \%$ and the basal line before adding phenylephrine to $0 \%$. For this reason relaxation in the graphs is shown as percentage starting at $100 \%$.

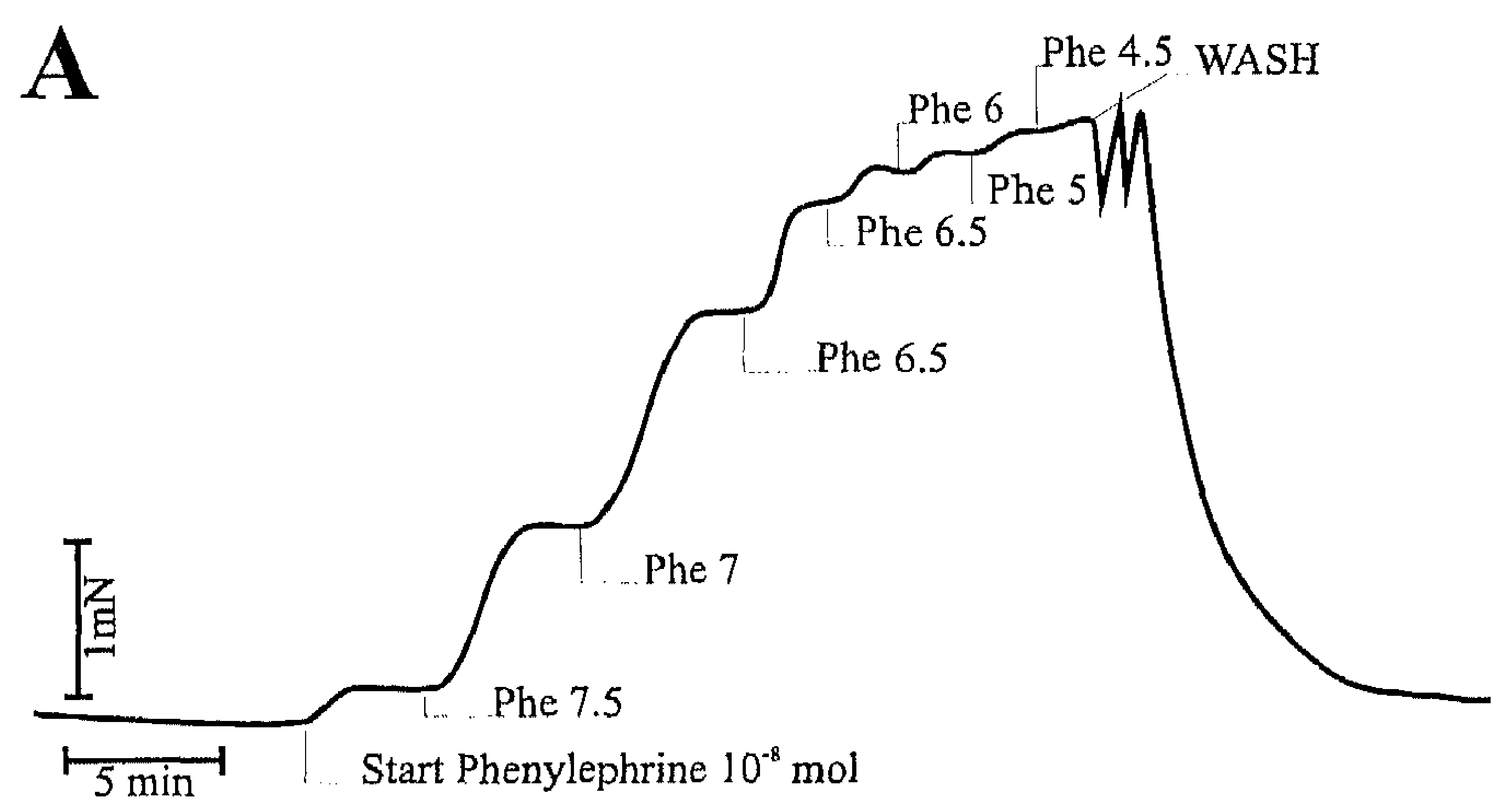

B

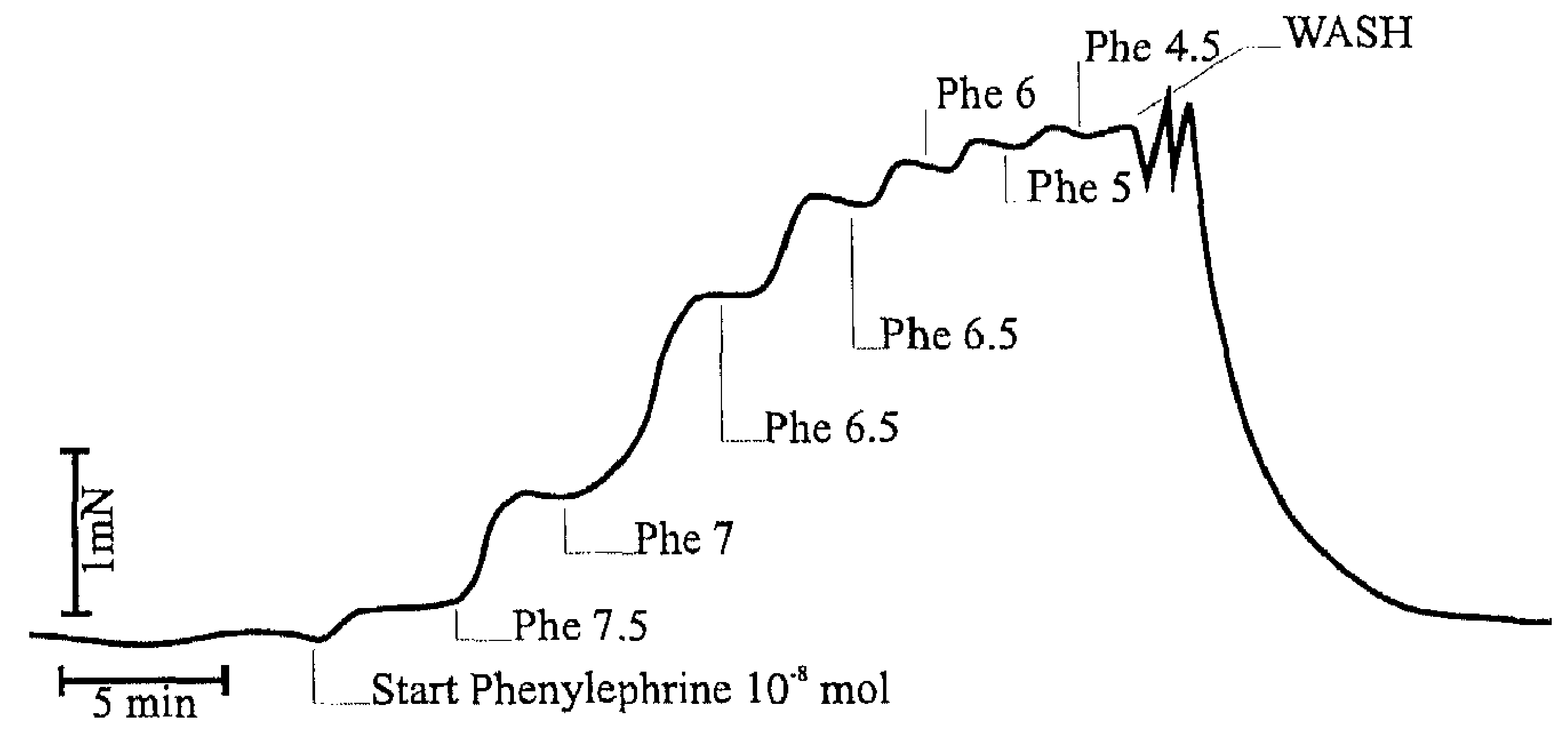

Figure 4. Tracings of isometric wall force versus time obtained in an isolated aorta of control $(A)$ and diabetic $(B)$ rat The tracings illustrate the effect of increasing concentrations of phenylephrine. $W A S H=$ changing the solution in the bath with a fresh Krebs buffer, not containing any pharmacological agents. The figures are representative of observations in 12 control rats. 


\section{CHAPTER 2}

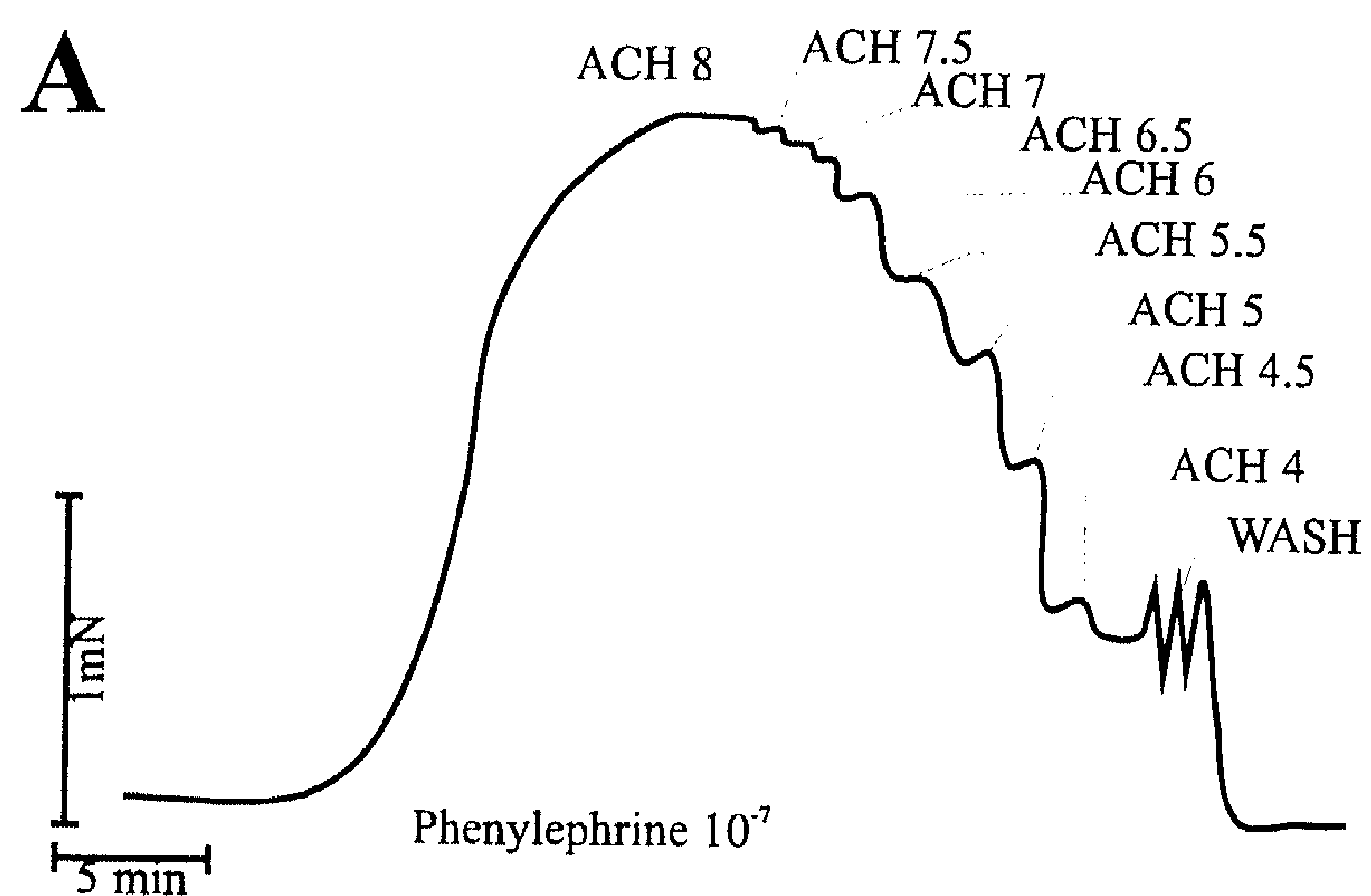

\section{B}

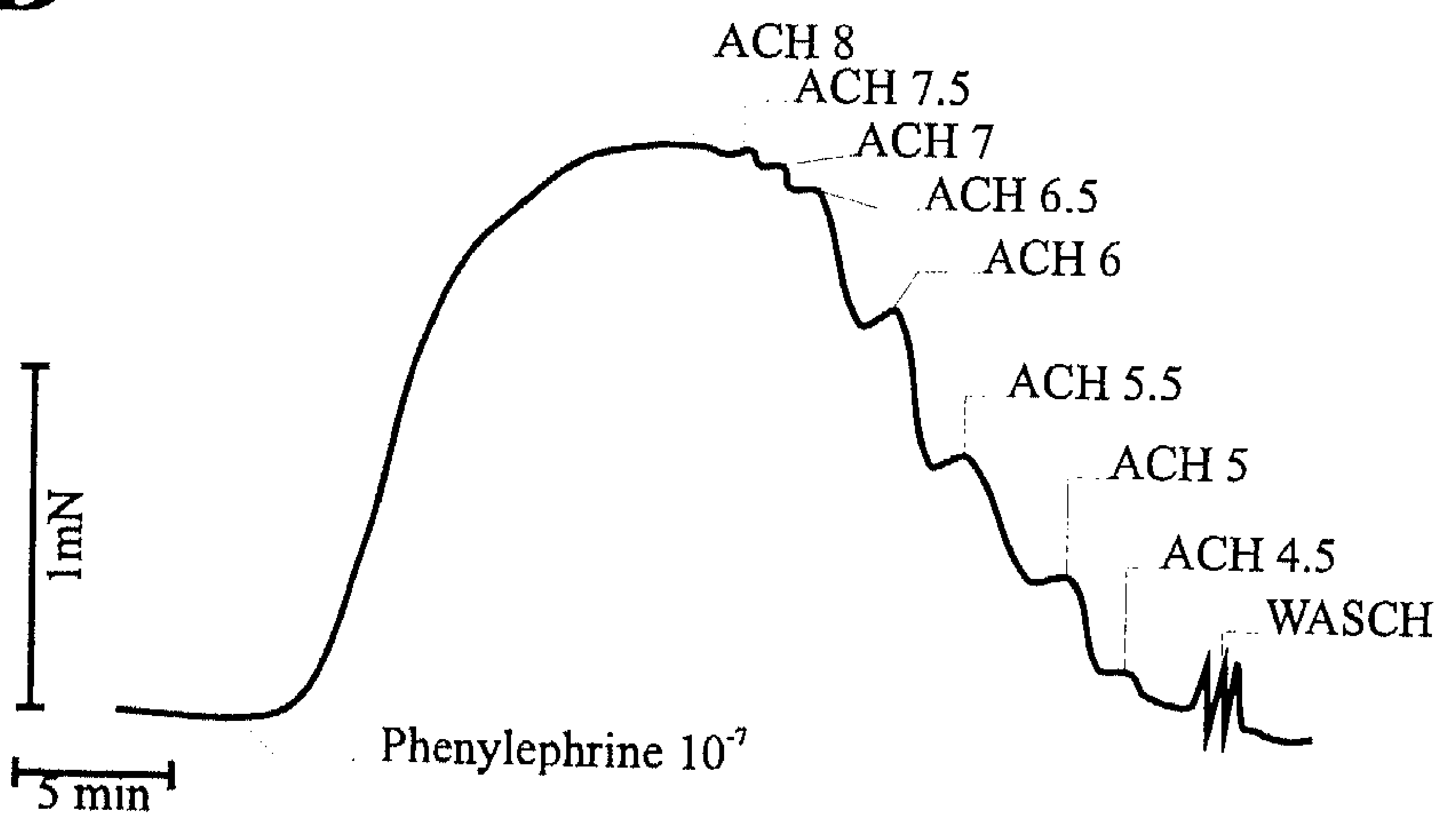

Figure 5. Tracings of isometric wall force versus time obtained in an isolated aorta of a control $(A)$ and diabetic ( $B$ ) rat. The tracings illustrate the effect of increasing concentrations of acetylcholine on the contractile response to $0.1 \mu \mathrm{M}$ phenylephrine. The figures are representative of observations in 


\section{MEASUREMENT OF DIAMETER, COMPLIANCE AND DISTENSIBILITY OF THE THORACIC AORTA IN INTACT ANESTHETIZED RATS.}

Besides the in vitro studies we also used a vessel wall tracking system to study the aorta in vivo. At the age of 18-20 weeks rats were anaesthetized using pentobarbital and received an intra-aortic and intravenous catheter for blood pressure measurement and iv drug infusion respectively. Two days later the animals were anaesthetized using Urethane $(800 \mathrm{mg} / \mathrm{kg}$ iv).

At the level of the thoracic aorta the diastolic diameter and distension during the cardiac cycle were assessed as a continuous function of time with a vessel wall tracking system (WTS, see below) attached to a conventional B-mode ultrasound system (Pie480, 7.5 MHz linear array, Pie Medical, Maastricht, the Netherlands). To investigate the arterial dynamics the thoracic aorta was localized in B-mode (B: brightness). Subsequently an $\mathrm{M}$-line was positioned perpendicular to the aorta walls at $1 \mathrm{~cm}$ proximal of the diaphragm, whereafter the ultrasound system was switched to M-mode (M: motion), where ultrasound was emitted and received along the selected line of sight at a programmable emission trigger frequency (Figure 6). The concept of the WTS has been described in detail before ${ }^{[6]}$. It is based on a data acquisition system, capable of capturing the received and amplified radio frequency (rf) signals synchronously with the emission trigger at a programmable sample frequency of up to

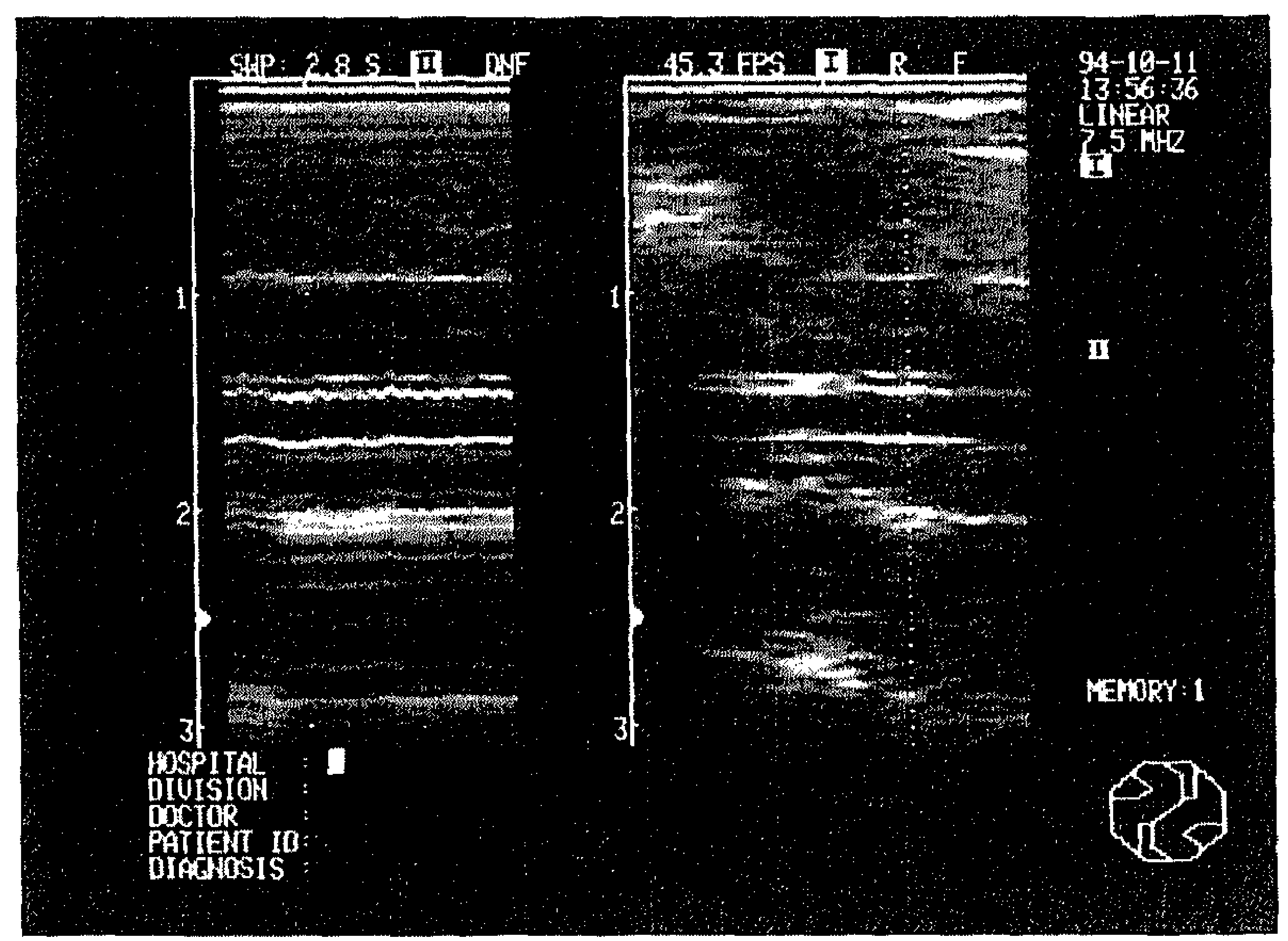

Figure 6. B-mode images of the thoracic aorta in an anesthetized rat. The dotted line perpendicular to the vessel represents the direction of the M-line. 


\section{CHAPTER 2}

$30 \mathrm{MHz}$ and with a dynamic range of $48 \mathrm{~dB}(8 \mathrm{bits})$. The position and width of the range of interest in depth is programmable. The WTS is also equipped with an acquisition system for reference signals, e.g., blood pressure, which are sampled synchronously with the emission trigger, activating the capture of an rf line (Figure 7). The first line acquired is graphically presented on a display, allowing for manual identification of the anterior and posterior wall lumen boundaries by placing two markers, representing the sample windows for data processing (Figure 6) ${ }^{[7]}$. The difference between the displacement signal of the posterior and anterior walls yields the change in diameter as a function of time. From the observed distention wave form, in combination with the initial distance between the sample windows, the end-diastolic diameter, the peak-to-peak change in diameter $(\Delta d)$, and the length of the cardiac cycle can be extracted for each cardiac cycle.

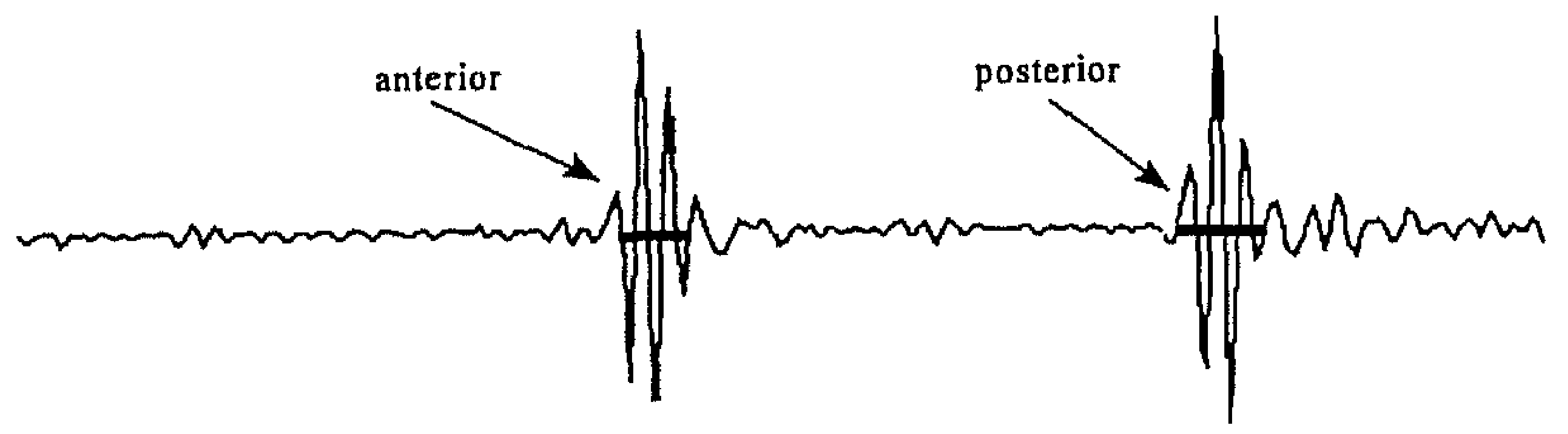

Figure 7. The RF signal of the first acquired M-line as displayed on the PC monitor. The markers representing the position of the sample windows, are positioned at the $R F$ signals from the anterior and posterior wall.

The WTS provides the distention wave form at a specific site of the arterial tree in combination with the local blood pressure as a continuous function of time (Figure 6). Since both are sampled synchronously any relative phase differences can be attributed to: (1) the response time of the WTS, (2) the response time of the blood pressure measurement system, (3) a discrepancy between the sites of distention and pressure measurement, and (4) the relationship between the pressure and distention. The response time of the WTS is fully specified by the emission trigger rate in combination with the length of the data window in time. The (invasive) blood pressure measurement system will introduce a time delay according to its frequency response which can be verified by an in vitro test set-up. The time shift due to the distance between the sites of distention and pressure assessment, visible in B-mode of the ultrasound system can be corrected for if the local pulse wave velocity is known.

\section{STRUCTURAL PARAMETERS OF ARTERIES}

Structural dimensions of arteries were evaluated using a software package for the personal computer, (JAVA V 1.21, Jandel Scientific, CA, USA). Arteries were isolated from diabetic or non-diabetic rats for evaluation of pharmacological characteristics, or for immediate fixation. The fixative used was phosphate buffered ( $\mathrm{pH}$ 7.4) formaldehyde (4\%). Preparations were paraffin embedded and cross sectioned using Lawson's solution (Boom B.V., Meppel, The Netherlands) 


\section{MATERIAL AND METHODS}

Video images were generated from the cross sections using a Zeiss Axioscope (Zeiss, Germany) and a standard CCD camera (Stemmer, Germany) ${ }^{[8]}$. The following structural parameters were measured; internal and external medial circumference, which were respectively demarcated by the internal and external elastic lamina. From these, assuming circular vessel conformation, the lumen area and the total area could be derived. Media cross sectional area (CSA) was obtained by subtracting lumen area from the total area. Internal lumen radius ( $r$ ) was calculated from the internal circumference assuming a circular conformation of the vessel. From these parameters average media thickness $\left(\mathrm{M}_{\mathfrak{t}}\right)$ was calculated using the following relation;

$$
M_{t}=-r+\sqrt{r^{2}+\frac{C S A}{\pi}}
$$

\section{STATISTICAL ANALYSIS}

Statistical analysis of the results were performed using SPSS for Windows (version 5.01 or 6.0, SPSS Inc, Chicago, Il, USA), a statistical software package for personal computers. Depending on the experimental design, the data were analyzed using ANOVA with Student-Newman-Keuls correction for multiple comparisons or a paired or unpaired student $t$-test ${ }^{[9]}$. A p-value smaller than 0.05 was considered to indicate statistical significance of differences.

\section{REFERENCES}

1. Rakieten N, Rakieten ML, Nadkarni MV. Studies on the diabetogenic action of streptozotocin. Cancer Chemother Rep 1963;29:91-94.

2. Bevan JA, Osher JV. A direct method for recording tension changes in the wall of small blood vessels in vitro. Agents Actions 1972;2(Suppl. 5):257-260.

3. Mulvany MJ, Halper W. Contractile properties of small arterial resistance vessels in spontaneously hypertensive and normotensive rats. Circ Res 1977;41:19-26.

4. Heesen BJ, De Mey JG. Effects of cyclic AMP-affecting agents on contractile reactivity of isolated mesenteric and renal resistance arteries of the rat. Br J Pharmacol 1990;101:859-864.

5. Boonen HCM. Excitation-contraction coupling in small arteries [Dissertation]. University of Limburg, Maastricht, The Netherlands, 1992.

6. Hoeks APG, Brands PJ, Smeets FAM, Reneman RS. Assessment of the distensibility of superficial arteries. Ultrasound in Med \& Biol 1990;16:121-128.

7. Hoeks APG. Non-invasive study of the local mechanical arterial characteristics in humans. In: Safar ME, O'Rourke MF, eds. The arterial system in hypertension. Amsterdam: Kluwer Academic Publishers, 1993:1 19-134. 


\section{CHAPTER 2}

8. Boonen HCM, Daemen MJAP, Eerdmans PE, Fazzi GE, Van Klecf E, Schiffers PMH, De Mey JGR. Mesenteric small artery changes following vasoconstrictor infusion in young rats. $J$ Cardiovasc Pharmacol 1993;22:388-395.

9. Wallenstein S, Zucker CL, Fleiss JL. Some statistical methods useful in circulation research. Circ Res 1980;47:1-9. 


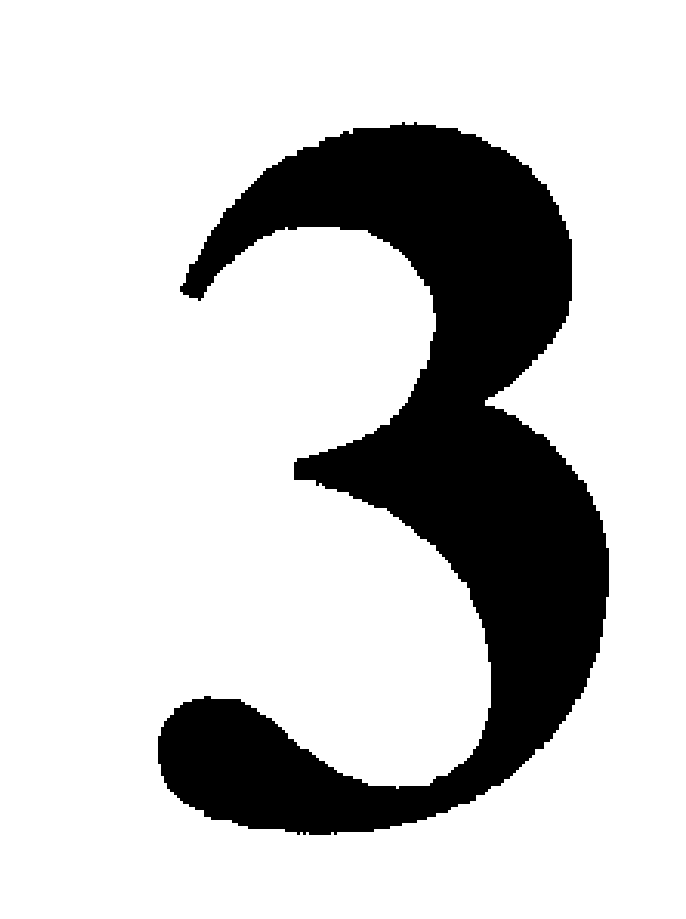

Effects of glucose and diabetes duration on responses to phenylephrine, acetylcholine and sodium nitroprusside in aortic rings from streptozotocin-induced diabetic rats

B.J. Heesen, J.G.R. De Mey, J.R. Williamson and B.H.R. Wolffenbuttel Cardiovascular Research Institute Maastricht (CARIM), Depts. of Internal Medicine and Pharmacology, University of Limburg, Maastricht (NL), and Dept. Of Pathology, Washington University, St. Louis (USA) 


\section{SUMMARY}

Although diabetes-associated impairments in autoregulation of vascular reactivity are well known, the nature of the metabolic imbalances that mediate these changes is unclear. We compared in vitro contractile responses to phenylephrine (PHE) and relaxing responses to acetylcholine $(A C H)$ and sodium nitroprusside $(S N P)$ in isolated aortic rings from diabetic and control rats in normal $(5 \mathrm{mM})$ and high $(30 \mathrm{mM})$ glucose. Aortic rings from male Sprague Dawley rats with 9-day, 6-week and 3-month duration of streptozotocin-induced diabetes and from age-matched control rats were mounted between an isometric force transducer and a displacement device in a $10 \mathrm{ml}$

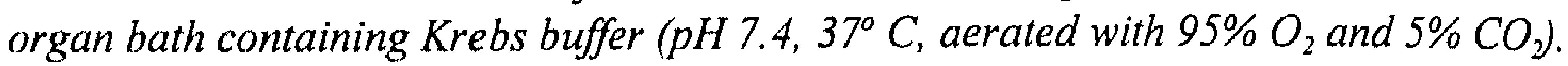
With increasing duration of diabetes, maximal contractile responses to PHE decreased, from $8.8 \pm 2.2 \mathrm{mN} / \mathrm{mm}$ in control aortas, to $5.1 \pm 0.9 \mathrm{mN} / \mathrm{mm}$ in 3-month diabetic aortas $(p<0.05)$. Aortic contractile force was also reduced by $26 \%$ in control aortas exposed to $30 \mathrm{mM}$ glucose for only 2 hours. ACH-induced relaxation was decreased in 9-day diabetic aortas compared to control aortas in $5 \mathrm{mM}$ glucose. This decrease in relaxation was also observed in control aortas exposed in vitro to $30 \mathrm{mM}$ glucose for only $45 \mathrm{~min}$. In contrast, $\mathrm{ACH}$-induced relaxation of 6-week and 3-month diabetic aortas in $30 \mathrm{mM}$ glucose was increased by $50 \%$ compared to control aortas in $5 \mathrm{mM}$ glucose. Relaxation to SNP was reduced in 9-day diabetic aortas compared to control aorta, but enhanced with longer duration of diabetes. These observations indicate that: 1) relaxing responses of the aorta is impaired by acutely elevated glucose levels after 9 days of diabetes or in vitro in control aorta exposed to hyperglycemia. 2) in $30 \mathrm{mM}$ glucose the six week and three month diabetic aortas show a better relaxation in vitro than control in $5 \mathrm{mM}$ glucose. 


\section{DIABETES DURATION AND GLUCOSE CONCENTRATION}

\section{INTRODUCTION}

Abnormalities in vascular response to vasoactive agents, such as phenylephrine (PHE) and acetylcholine $(\mathrm{ACH})$ have been described in experimental diabetes. Altered vascular response to vasoactive agents have been linked to disturbed endothelial function, altered prostaglandin production ${ }^{[1]}$, increased endogenous production of free radicals ${ }^{[2]}$, and increased formation of advanced glycosylation end products (AGE) ${ }^{[3]}$ The last two are both believed to quench the endothelium derived relaxing factor, nitric oxide ${ }^{[4-6]}$. Nitric oxide (NO) is released at a basal level or after stimulation with acetylcholine. Nitric oxide activates the soluble guanylate cyclase in the vascular smooth muscle, which then in turn provokes the second messenger cyclic GMP. Nitric oxide may be quenched by free radicals ${ }^{[7]}$ or increased AGE-formation in rats with experimental diabetes ${ }^{[3]}$. The in vivo system will then compensate by; increasing the basal production of NO, or by increasing the sensitivity of the second messenger cyclic GMP for NO. So far most studies show an impaired or an unchanged relaxation to acetylcholine. However, all these studies have been carried out in media containing 10 - $11 \mathrm{mM}$ glucose, which is hyperglycemic for control rats and hypoglycemic for diabetic rats. This may have an impact on the vasoreactivity of these aortic rings, as it is known from several studies that incubation for a few hours in elevated glucose can have a dramatic effect on metabolic parameters as $\mathrm{Na}^{+}-\mathrm{K}^{+}$-ATPase ${ }^{[8]}$. Our main objective was to assess the effects of ambient glucose levels, and the duration of experimental diabetes ( 9 days, 6 weeks, and 3 months) on the response of isolated aortic rings to phenylephrine, acetylcholine and sodium nitroprusside.

\section{RESEARCH DESIGN AND METHODS}

Diabetes was induced in six week old male Sprague-Dawley rats (Sasco, $\mathrm{O}^{\prime}$ Fallon, MO, USA) for a diabetes duration of 6 weeks or three months by intravenous injection of $65 \mathrm{mg} / \mathrm{kg}$ streptozotocin. To obtain animals with similar age and body weight at the day of the experiments, but with only 9 days duration of diabetes, $45 \mathrm{mg} / \mathrm{kg} \mathrm{STZ} \mathrm{was}$ injected in 6 animals at the age of 11 weeks. All diabetic and non-diabetic animals were housed and cared for in accordance with the guidelines of the University Committee for the Human Care of Laboratory Animals, and NIH-guidelines on laboratory animal welfare. Rats were housed individually, fed standard rat chow (Ralston Purina, Richmond, In, USA), and water ad libitum, and were on a 12 hour light/dark cycle. On the day of the experiments, performed at the age of 12 weeks (diabetes duration 6 weeks or 9 days) or at the age of 18 weeks (diabetes duration 12 weeks and age-matched non-diabetic controls), the animals were anaesthetized by intra peritoneal injection of pentobarbital $(45 \mathrm{mg} / \mathrm{kg})$, and a blood sample of $5 \mathrm{ml}$ was drawn by puncture of the abdominal aorta. The thoracic aorta was removed, trimmed free of adventitial connective tissue and cut into small rings (1.6 $\mathrm{mm}$ in length). Special care was taken to avoid damage to the endothelial layer. Two stainless-steel wires (diameter $40 \mu \mathrm{m}$ ) were inserted into the lumen of the aorta, which was then mounted horizontally in an organ chamber (JP Trading, Aarhus, Denmark, volume 10 


\section{CHAPTER 3}

$\mathrm{ml}$ ) between an isometric force transducer (Kistler Morse DSC6, Seattle WA, USA) and a displacement device ${ }^{[9]}$. The organ chamber was filled with a modified KrebsRinger bicarbonate solution (KRB, composition in $\mathrm{mM}: \mathrm{NaCl} 118.3, \mathrm{KCl} 4.7, \mathrm{MgSO}_{4}$ $1.2, \mathrm{CaCl}_{2} 2.5, \mathrm{KH}_{2} \mathrm{PO}_{4} 1.2, \mathrm{NaHCO}_{3} 25.0$, Ca-EDTA 0.026 and glucose 5.0 or 30.0) maintained at $37^{\circ} \mathrm{C}$ and $\mathrm{pH} 7.4$ and continuously aerated with $95 \% \mathrm{O}_{2}$ and $5 \% \mathrm{CO}_{2}$.

Before assessment of reactivity, the aorta was stretched to determine the optimal lumen diameter for mechanical performance ${ }^{[9,10]}$; the internal diameter was therefore initially set at $1.34 \mathrm{~mm}$ and increased by $0.22 \mathrm{~mm}$ increments. The preparations were exposed intermittently to Krebs-Ringer buffer in which all $\mathrm{NaCl}$ was replaced by an equimolar amount of $\mathrm{KCl}$. This procedure (which required 1.5 hours) was continued until a maximal contractile response to potassium was obtained. Subsequent experiments were performed at this optimal diameter. During this stretching procedure, control aortas were kept in a buffer containing $5 \mathrm{mM}$ glucose; while aortas from diabetic rats were kept in a buffer containing $30 \mathrm{mM}$ glucose. ACH- and sodium nitroprusside (SNP)-induced relaxation were assessed in arteries pre-contracted by 0.1 $\mu \mathrm{M}$ PHE to $55 \%$ of maximal contractile tension. Before assessing $\mathrm{ACH}$-induced relaxation 15 minutes were allowed for stabilization of the contractile tension. During pre-contraction, the aorta was exposed to the same buffer utilized for subsequent assessments of ACH- and SNP-induced relaxation and PHE-induced contraction. ACH dose response curves were obtained by addition of $\mathrm{ACH}$ at \pm 2 min intervals; thus, the duration of exposure of control aortas to $30 \mathrm{mM}$ glucose was $40 \mathrm{~min}$ by the time the dose response curve was completed. The bath was then rinsed at $10 \mathrm{~min}$ intervals during a 30 min rest before initiating the SNP- or PHE dose response curve. PHE was added at 5 minutes intervals; thus, by the time the dose response curve was completed the duration of exposure of control aortas to $30 \mathrm{mM}$ glucose was approximately 2 hours.

\section{Drugs}

Streptozotocin was purchased from Upjohn Co. (Kalamazoo, MI, USA), pentobarbital from Fort Dodge Laboratories (Iowa, USA), and phenylephrine hydrochloride, sodium nitroprusside and acetylcholine from Sigma Chemicals Co. (St. Louis, MO, USA). Stock concentrations of all drugs were prepared daily in distilled deionized water and $10 \mu \mathrm{l}$ aliquots were added to the organ bath to generate the dose-response curves. All drug concentrations are expressed as the negative log of the final molar concentration in the organ bath. Blood glucose in the animals was measured with a hexokinase method (Sigma Chemicals, St. Louis, MO, USA).

\section{Calculations and statistics}

Contractile responses are expressed as increases in wall tension (increase in force $/ 2 \mathrm{x}$ length of arterial segment). Effects of pharmacological agents are expressed as \% remaining tension versus initial (55\% of maximum) contractile tension. EC-50 values were calculated using GraphPad Inplot (GraphPad Software Inc., San Diego, Ca, USA). Differences between groups were tested by ANOVA with Student-NewmanKeuls correction for multiple comparisons, using the SPSS-PC ${ }^{+}$version 4.0 software (SPSS Inc, Chicago, Il, USA). The number of animals was 6 in all experiments except 


\section{DIABETES DURATION AND GLUCOSE CONCENTRATION}

for the control group $(n=10)$. Data in tables, figures and text are shown as means \pm SEM, unless stated otherwise. $\mathrm{P}$ values $<0.05$ were considered statistically significant.

\section{RESULTS}

Table 1 summarizes the data of internal diameter of the aorta, blood glucose levels and body weight in the different groups of animals. None of the diabetic animals was treated with insulin. The mean optimal internal diameter did not differ significantly between the groups $(2.59 \pm 0.14 \mathrm{~mm})$.

Table 1 Internal diameter of the aorta, body weight $(B W)$ and blood glucose level (BG) in control and diabetic animals

\begin{tabular}{l|c|c|c} 
& $\begin{array}{c}\mathrm{ID} \\
(\mathrm{mm})\end{array}$ & $\begin{array}{c}\mathrm{BG} \\
(\mathrm{mM})\end{array}$ & $\begin{array}{c}\mathrm{BW} \\
(\mathrm{gram})\end{array}$ \\
\hline non-diabetic & $2.6 \pm 0.04$ & $6.8 \pm 0.6$ & $365 \pm 18$ \\
\hline 9 days diabetic & $2.6 \pm 0.08$ & $27.0 \pm 2.0^{\mathrm{a}}$ & $330 \pm 22$ \\
\hline 6 weeks diabetic & $2.5 \pm 0.12$ & $26.0 \pm 2.7^{\mathrm{a}}$ & $230 \pm 14^{\mathrm{a}}$ \\
\hline 3 months diabetic & $2.5 \pm 0.08$ & $28.4 \pm 2.4^{\mathrm{a}}$ & $280 \pm 25^{\mathrm{a}}$ \\
" $\mathrm{p}<0.05$ vs. control & & &
\end{tabular}

Phenylephrine-induced contraction

The maximal PHE-induced contractile force in 6 week and 3 month diabetic aortas was decreased by $45 \%$ (figure 1) versus control aortas in $5 \mathrm{mM}$ glucose $(4.9$ $\pm 1.2,5.1 \pm 0.9$ and $8.8 \pm 2.2 \mathrm{mN} / \mathrm{mm}$ respectively, $\quad \mathrm{p}<0.05)$. $\quad$ PHE-induced contractile force in 9-day diabetic aortas was slightly, but not statistically significant $(\mathrm{p}=0.08)$ different from control aortas (figure 1). PHE-induced contractile force in control aortas exposed to $30 \mathrm{mM}$ glucose for only 2 hours was decreased by $26 \% \quad 6.5 \pm 2.5 \mathrm{mN} / \mathrm{mm}, \quad \mathrm{p}<0.05)$. Maximal PHE-induced contractile force in diabetic aortas did not differ significantly when studied in 5 or $30 \mathrm{mM}$ ambient glucose concentration. Sensitivity to PHE did not differ between the different groups, the EC-50 concentration expressed as the negative $\log$ was $7.1 \pm$ 0.3 .

\section{PHENYLEPHRINE}

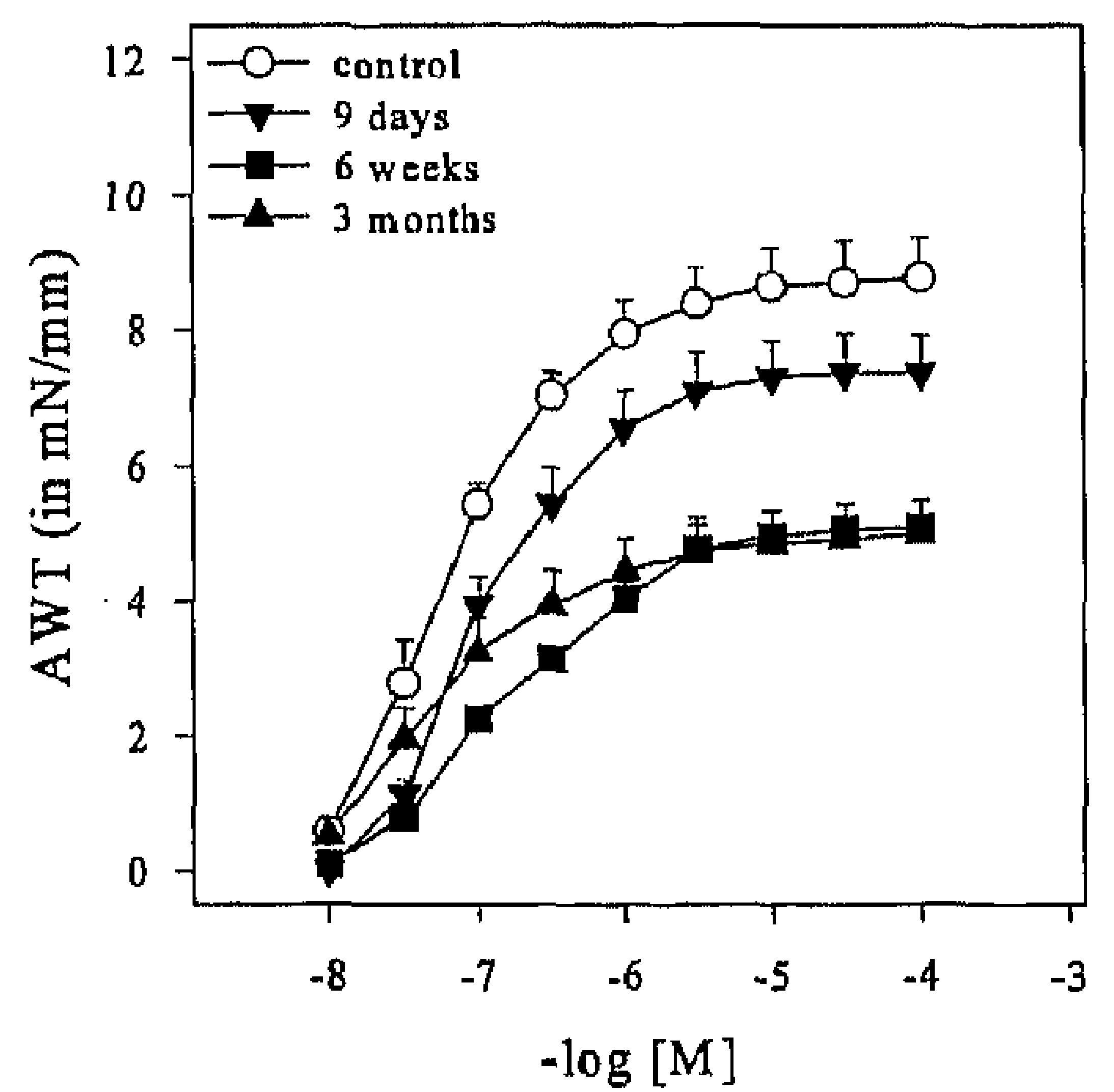

Figure 1. Phenylephrine induced contraction in aorta from diabetic and non-diabetic animals. $A W T=$ active wall tension 


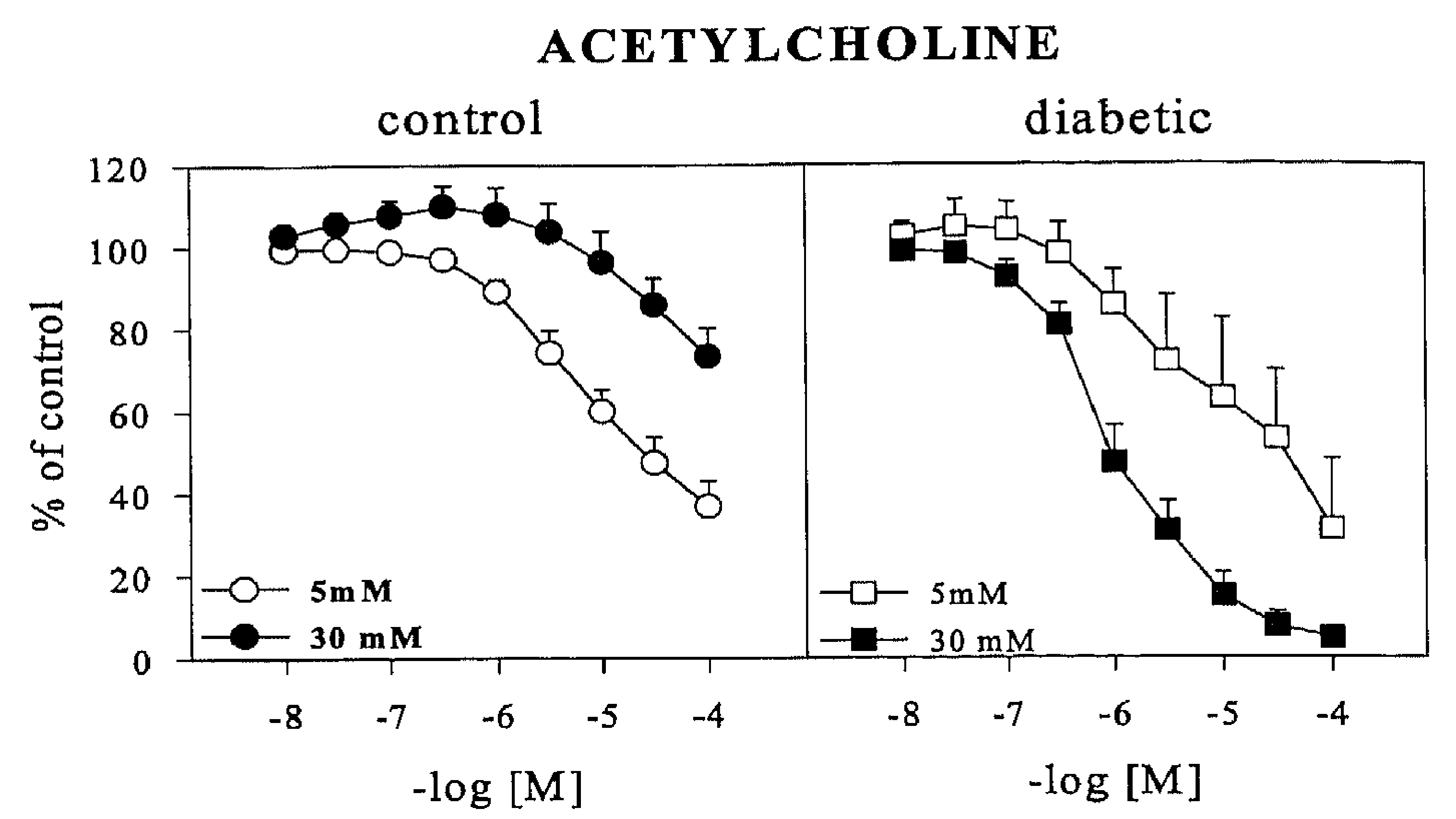

7igure 2. Acetylcholine induced relaxation in aorta from 6 week diabetic and non-diabetic animals in and $30 \mathrm{mM}$ glucose.

1cetylcholine-induced relaxation

$\mathrm{n}$ aortas precontracted with $0.1 \mu \mathrm{M}$ ' $\mathrm{HE}$, a concentration-dependent relaxation by $\mathrm{ACH}$ was observed. There was no i gnificant difference in $\mathrm{ACH}$-induced elaxation between control and 6-week liabetic aortas in $5 \mathrm{mM}$ glucose (figures :A and $2 \mathrm{~B}$ ); residual contractile tension n $100 \mu \mathrm{M} \mathrm{ACH}$ was $37 \pm 15 \%$ and $31 \pm$ $17 \%$, respectively. Relaxation of control tortas was impaired after exposure to 30 $\mathrm{nM}$ glucose for only 45 min (remaining ension was $73 \pm 18 \%$, figure $2 \mathrm{~A}$, Table 2), whereas relaxation of 6-week diabetic 1ortas in $30 \mathrm{mM}$ glucose (figure $2 \mathrm{~B}$ ) ixceeded that of control and diabetic lortas in $5 \mathrm{mM}$ glucose (remaining ension $5 \pm 6 \%$; figures $2 \mathrm{~A}$ and $2 \mathrm{~B}$, Table 2). The relaxation in 9-day diabetic aorta was impaired in 5 and $30 \mathrm{mM}$ glucose remaining tension $85 \pm 13 \%$ ) and was similar compared to the response curve obtained in control aortas exposed to 30

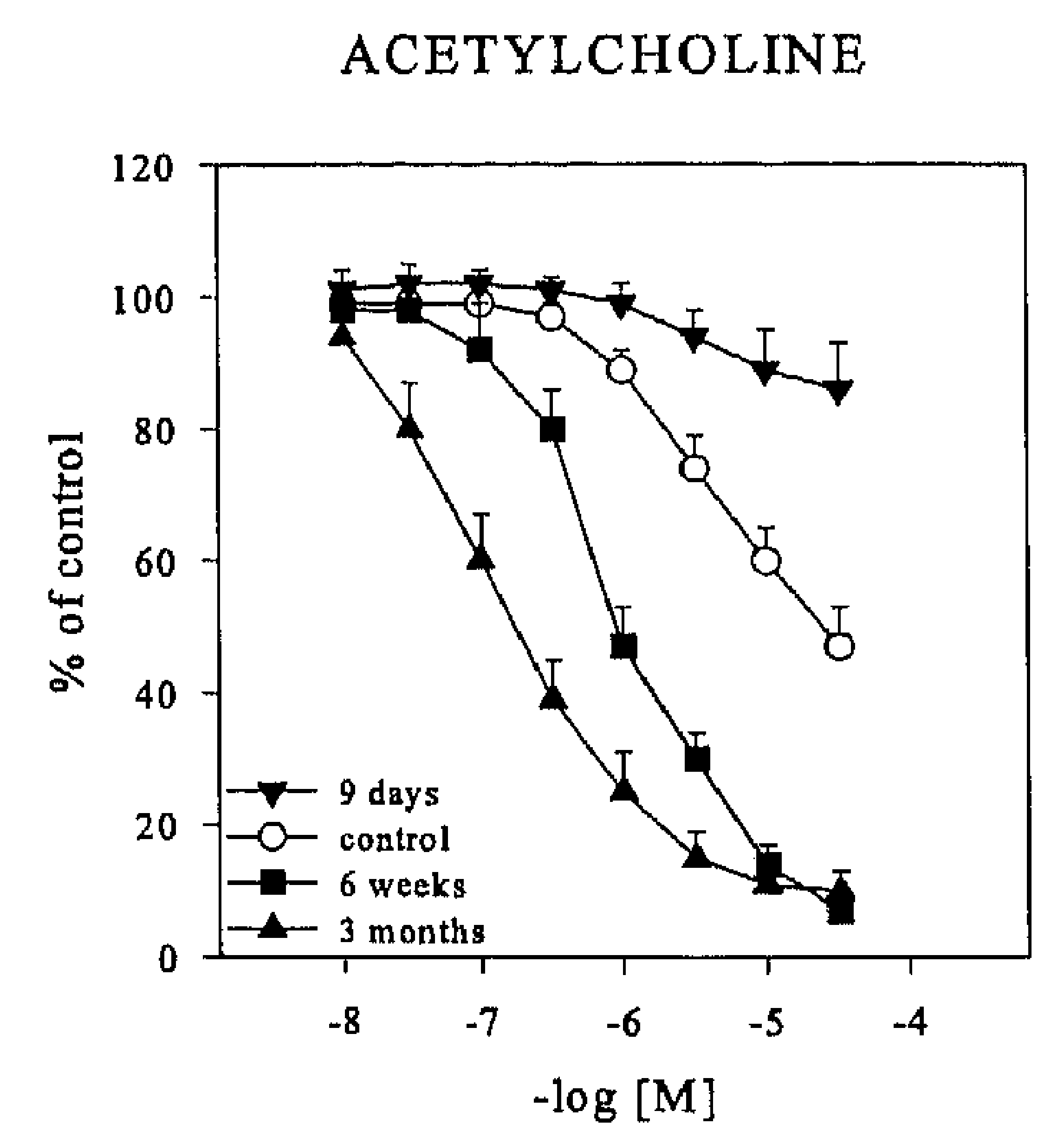

Figure 3. Cumulative dose-response curves of relaxation responses to acetylcholine of control aortas in $5 \mathrm{mM}$ glucose and 9 day diabetic, 6 week diabetic, and 3 month diabetic aorta all in $30 \mathrm{mM}$ glucose. 


\section{DIABETES DURATION AND GLUCOSE CONCENTRATION}

$\mathrm{mM}$ glucose (figure 3). The 3-month diabetic aortas showed a more enhanced relaxation than the control aortas and the 6-week diabetic aorta (figure 3, Table 2).

Sodium nitroprusside-induced relaxation

In aortas precontracted with $0.1 \mu \mathrm{M}$ $\mathrm{PHE}$, a concentration-dependent relaxation by SNP was observed. There was a significant difference in SNP-induced relaxation between control and 9-day diabetic aortas (figure 4); residual contractile tension in $3 \mu \mathrm{M}$ SNP was $0 \pm$ $1 \%$ and $33 \pm 30 \%$, respectively (Table 2). Relaxation of 6-week diabetic aortas was improved compared to 9-day diabetic, but similar to non-diabetic aortas, whereas relaxation of 3-month diabetic aortas exceeded that of control and 9-day and 6-week diabetic aortas (see figure 4 and table 2 for EC-50 values).
SODIUM NITROPRUSSIDE

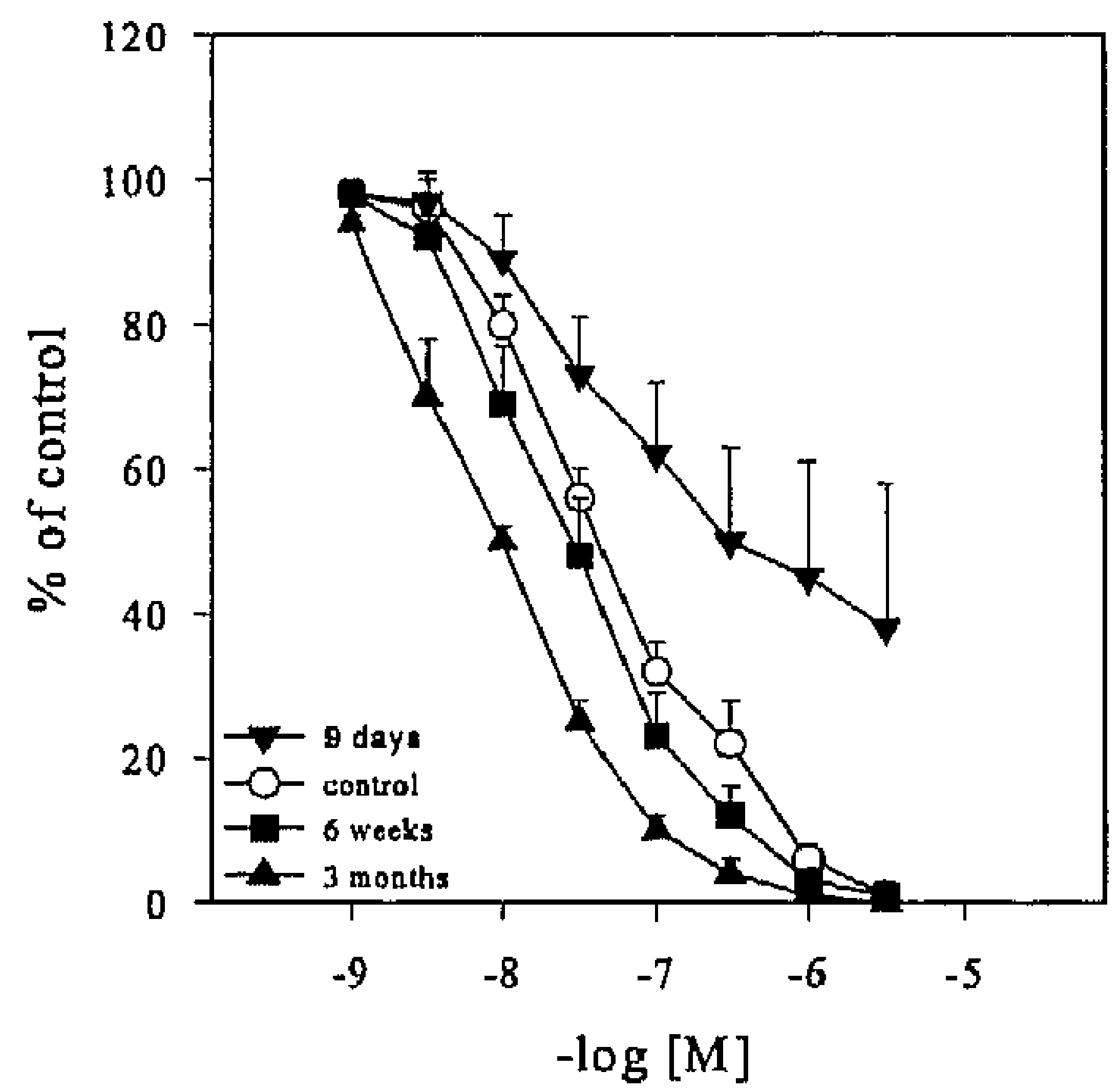

Figure 4. Cumulative dose-response curves of relaxation responses to sodium nitroprusside of control aortas in $5 \mathrm{mM}$ glucose and 9 day diabetic, 6 week diabetic, and 3 month diabetic aorta all in $30 \mathrm{mM}$ glucose.

Table 2. EC-50 values and maximum effects of phenylephrine PHE), acetylcholine (ACH) and sodium nitroprusside (SNP) in aortic rings from control and diabetic animals. EC-50 values are shown as negative log, maximum response shown as active wall tension $(\mathrm{mN} / \mathrm{mm})$ or as percentage of maximal relaxation.

\begin{tabular}{|c|c|c|c|c|c|c|c|}
\hline $\begin{array}{l}\text { Diabetes } \\
\text { duration }\end{array}$ & $\begin{array}{c}\text { [glucose] } \\
\text { in KREBS }\end{array}$ & $\begin{array}{c}\text { PHE } \\
\text { EC-50 } \\
-\log M\end{array}$ & $\begin{array}{c}\mathrm{ACH} \\
\mathrm{EC}-50 \\
-\log \mathrm{M}\end{array}$ & $\begin{array}{c}\text { SNP } \\
\text { EC-50 } \\
-\log M\end{array}$ & $\begin{array}{c}\max \\
\text { PHE } \\
\mathrm{mN} / \mathrm{mm}\end{array}$ & $\begin{array}{c}\max \\
\mathrm{ACH} \\
\%\end{array}$ & $\begin{array}{c}\max \\
\text { PHE } \\
\%\end{array}$ \\
\hline control (1) & $5 \mathrm{mM}$ & $7.3 \pm 0.3$ & $5.2 \pm 0.2$ & $7.4 \pm 0.3$ & $8.8 \pm 2.2$ & $63 \pm 15^{f}$ & $100 \pm 0$ \\
\hline control (2) & $30 \mathrm{mM}$ & $7.1 \pm 0.3$ & $4.8 \pm 0.1$ & NA & $6.5 \pm 2.5^{d}$ & $27 \pm 18^{8}$ & $\mathrm{NA}$ \\
\hline 9 days (3) & $30 \mathrm{mM}$ & $7.0 \pm 0.2$ & $5.1 \pm 0.6$ & $7.2 \pm 0.6$ & $7.3 \pm 1.6$ & $15 \pm 13^{8}$ & $67 \pm 30^{\mathrm{k}}$ \\
\hline 6 weeks (4) & $5 \mathrm{mM}$ & $7.2 \pm 0.3$ & $5.1 \pm 0.4$ & NA & $4.8 \pm 1.7^{d}$ & $69 \pm 17^{f}$ & NA \\
\hline 6 weeks (5) & $30 \mathrm{mM}$ & $7.3 \pm 0.3$ & $6.0 \pm 0.4^{n}$ & $7.7 \pm 0.2$ & $4.9 \pm 1.2^{d}$ & $95 \pm 5$ & $100 \pm 0$ \\
\hline 3 months (6) & $30 \mathrm{mM}$ & $6.9 \pm 0.3$ & $6.9 \pm 0.4$ & $7.9 \pm 0.1^{c}$ & $5.1 \pm 0.9$ & $90 \pm 7$ & $100 \pm 0$ \\
\hline
\end{tabular}

$\mathrm{p}<0.05$ vs. groups $1,2,3$ and 4

${ }^{\circ} \mathrm{p}<0.05$ vs. groups 1 and 3

e $p<0.05$ vs. group 3

$8 \mathrm{p}<0.05$ vs. group $1,4,5$ and 6

b $\mathrm{p}<0.05$ vs. group 5

$\mathrm{d} p<0.05$ vs. group 1

f $p<0.05$ vs group 5 and 6

${ }^{h} \mathrm{p}<0.05 \mathrm{vs}$. groups 1,5 and 6 


\section{DISCUSSION}

Our experiments provide new evidence that acute elevation of glucose levels in vitro impairs ACH-induced relaxation of the aorta from non-diabetic animals and improves relaxative function of the aorta from diabetic animals. In contrast, ACH-induced relaxation of 6-week and 3-month diabetic aortas in $30 \mathrm{mM}$ glucose was increased by $50 \%$ compared to control aortas in $5 \mathrm{mM}$ glucose. Our results suggest that the previously reported impairments in $\mathrm{ACH}$-induced relaxation in diabetic aortic rings ${ }^{[6.31 .12\}}$ may be due both to the duration of the experimental diabetes and to the glucose concentrations used in the Krebs solution in vitro.

The finding that $\mathrm{ACH}$-induced relaxation of diabetic aortas in $5 \mathrm{mM}$ glucose did not differ from that of controls in $5 \mathrm{mM}$ glucose is consistent with the observations of several other investigators ${ }^{[13-16]}$. The enhancement of relaxation induced in 6-week and 3 -month diabetic aortas in physiological bathing solution containing $30 \mathrm{mM}$ glucose versus control in 5 and $30 \mathrm{mM}$ glucose suggests intact endothelial cell function, and supports the likelihood that vascular relaxation function in vivo is impaired due to other disturbances than endothelial cell dysfunction, as suggested by many other groups $[4,6,11,12,17,18]$. The finding of enhanced relaxation to $\mathrm{ACH}$ may also be due to the fact that in none of the above studies a physiological glucose concentration was used in the Krebs-solution, as all of them had concentrations of $10-11 \mathrm{mM}$, which is low compared to the glucose levels in vivo. The relaxation in vivo is more complicated than in the isolated aortic ring. Firstly, there is a decrease in vascular compliance, due to an increased stiffness of the large arteries ${ }^{[3]}$, which is probably due to an increase in the formation of advanced glycosylation end products and collagen cross-linking. Secondly, increased glycation of elastin and increased calcium deposits in the diabetic aorta have been reported ${ }^{[19,20]}$. Thirdly, animals with streptozotocin-induced diabetes have a slightly lower blood pressure than non-diabetic controls when measured awake and by means of an intra-arterial catheter ${ }^{[3]}$. All these factors could lead to a smaller fall in blood pressure in diabetic animals after intravenous administration of acetylcholine ${ }^{[3]}$. In addition, Huijberts et al found that regional vascular relaxation in a striated muscle preparation was impaired both to acetylcholine and to the potassiumchannel opener BRL $38227^{[21]}$.

The impairment in $\mathrm{ACH}$-induced blood pressure response which was found in vivo by Bucala et al was postulated to be the result of quenching of EDRF (nitric oxide) due to the formation of advanced glycosylation end products ${ }^{[3]}$. Pieper et al demonstrated that the impairment they found in vitro was due to an increase in the quenching of nitric oxide by oxygen derived free radicals ${ }^{[4]}$. They concluded that the quenching of nitric oxide, in the rats with experimental diabetes, leads to an upregulation of its production, which acts to compensate in part for the quenching by the free radicals. Based on their data, we suggest that there is less nitric oxide capable to reach the smooth muscle cell to activate the soluble guanylate cyclase. This, in its turn, will lead to an upregulation of the soluble guanylate cyclase. The consequent higher sensitivity to sodium nitroprusside is indeed found by us. Aortic rings of animals with a 3-months diabetes duration are significantly more sensitive to sodium nitroprusside than the rings from the control animals. 


\section{DIABETES DURATION AND GLUCOSE CONCENTRATION}

The impairment of relaxation of aortic rings from rats with a 9-day diabetes duration supposedly is caused by the acute elevation of blood glucose soon after the administration of streptozotocin. The relaxation curve is similar to that of control aortas acutely subjected to $30 \mathrm{mM}$ glucose in vitro. Moreover, this effect can not be explained by the formation of advanced glycosylation end products, which take several weeks to develop ${ }^{[22]}$.

The only previous reports on the effects of acute elevation of tissue glucose levels on ACH-induced relaxation of aortas are those of Tesfamariam et al ${ }^{[23,24]}$. They reported that exposure of normal rabbit aortas to $44 \mathrm{mM}$ glucose for $6 \mathrm{~h}$ resulted in a $30 \%$ decrease in $\mathrm{ACH}$-induced relaxation which was prevented by indomethacin, by a thromboxane $\mathrm{A} 2$ receptor antagonist, and by addition of superoxide dismutase to the bath. In their study, glucose effects on $\mathrm{ACH}$-induced relaxation were much less pronounced after $2-3 \mathrm{~h}$ (than at 6 hours), a much longer time than the $45 \mathrm{~min}$ when a $50 \%$ inhibition of $\mathrm{ACH}-$-relaxation was evident in rat aortas exposed to $30 \mathrm{mM}$ glucose in our present experiments. This difference may be accounted for by the fact that their studies were carried out in rabbit aorta, while we used rat tissue. A possible explanation for the changes of relaxation after 'acute' glucose elevation either in vitro or after 9 days of diabetes may be increased sorbitol formation ${ }^{[25]}$, which can lead to depletion of the discrete myo-inositol pool ${ }^{[8,25,26]}$ and redox state imbalances, which both may eventually lead to impaired function of the enzyme $\mathrm{Na}^{+}-\mathrm{K}^{+}$-ATPase. More pharmacological and biochemical studies are needed to assess the exact mechanisms involved in the acute impairment of relaxation.

The finding that PHE-induced contractile force was impaired in diabetic aortas is in agreement with observations of Pfaffman et al ${ }^{[27]}$, but contrasts with reports by others ${ }^{[28,29]}$. The sensitivity to phenylephrine did not differ between the aortas from control and diabetic animals. The maximum contraction, however, decreased steadily with increasing duration of diabetes. This also appears when contraction is induced by potassium-chloride, in a Krebs solution in which all the $\mathrm{NaCl}$ is replaced by an equimolar amount of $\mathrm{KCl}{ }^{[14,29]}$. Stimulation of an isolated aorta with $125 \mathrm{mM}$ potassium leads to a depolarization, which sollicits a receptor-independent contraction due to an influx of $\mathrm{Ca}^{2+}$ ions. This suggest that the observed impairment of contraction is a receptor independent phenomenon.

In summary, acute glucose elevation impairs relaxation of isolated aortic rings, both in vitro and shortly after development of hyperglycemia due to STZ-administration. However, endothelium-dependent relaxation is improved in aortic rings from rats with diabetes duration of 6 weeks and 3 months, when studied in a $30 \mathrm{mM}$ glucose containing Krebs solution. In addition, increased relaxation after sodium nitroprusside suggests upregulation of the soluble guanylate cyclase enzyme. Phenylephrine-induced contraction is more severely impaired with increasing duration of experimental diabetes. 


\section{CHAPTER 3}

\section{ACKNOWLEDGMENTS}

This study was supported in part by the Kilo Diabetes \& Vascular Research Foundation (St. Louis, MO, USA).

\section{REFERENCES}

1. Tesfamariam B, Jakubowski JA, Cohen RA. Contraction of diabetic rabbit aorta caused by endothelium- derived PGH2-TxA2. Am J Physiol 1989;257:H1327-1333.

2. Hattori Y, Kawasaki H, Abe K, Kanno M. Superoxide dismutase recovers altered endotheliumdependent relaxation in diabetic rat aorta. Am J Physiol 1991;261:111086-1(194.

3. Bucala R, Tracey KJ, Cerami A. Advanced glycosylation products quench nitric oxide and mediate defective endothelium-dependent vasodilatation in experimental diabetes. J Clin lnvest $1991 ; 87: 432-438$.

4. Pieper GM, Gross GJ. Oxygen free radicals abolish endothelium-dependent relaxation in diabetic rat aorta. Am J Physiol 1988;255:H825-833.

5. Curcio F, Ceriello A. Decreased cultured endothelial cell proliferation in high gluense medium is reversed by antioxidants: new insights on the pathoplyssiological mechanisms of diabetio vascular complications. In Vitro Cell Dev Biol 1992;28:787-790.

6. Pieper GM, Mei DA, Langenstroer P, O'Rourke SI. Bioassay of endothelium-derived relaxing factor in diabetic rat aorta. Am J Physiol 1992;263:1676-680.

7. Langenstroer P, Pieper GM. Regulation of spontaneous IBIPRI relcase in diabetic rat anta by oxygen free radicals. Am J Physiol 1992;263:H257-265.

8. Simmons DA, Winegrad Al. Mechanism of glucose-induced ( $\mathrm{Na}, \mathrm{K}$ )-All'atse inhibition in aortic wall of rabbits. Diabetologia 1989;32:402-408.

9. Heesen BJ, De Mey JG. Effects of cyclic AMP-affecting agents on contractile rentivity of isolated mesenteric and renal resistance arteries of the rat. Br J Pharmac 199();101:859-864.

10. De Mey JG, Defreyn G, Lenars A, Calderon P, Roba J. Arterial reactivity, blood pressure, and plasma levels of artrial natriureticmpeptides in normotensive and hyperiensive rats: eflects of acute and chronic administration of atriopeptin III. I Cardiovase Pharmacol 1986;9:525-535.

11. Oyama Y, Kawasaki H, Hattori Y, Kanno M. Attenuation of endothelium-dependent relaxation in aorta from diabetic rats. Eur J Pharmacol 1986:132:75-78.

12. Kamata $\mathrm{K}$, Miyata N, Kasuya $\mathrm{Y}$. Impairment of endothelium-dependent relaxation and changes in levels of cyclic GMP in aorta from streptozotocin- induced diabetic rats. Br J Pharmacol 1989;97:614-618.

13. Head RJ, Longhurst PA, Panek R, Stitzel RE. A contrasting effect of the diabetic state upon the contractile responses of aortic preparations from the rat and rabbit. Br J Pharmacol 1987;91:275-286.

14. Fortes ZB, Leme JG, Scivoletto R. Vascular reactivity in diabetes mellitus: role of the endothelial cell. Br J Pharmac 1983;79:771-781.

15. Harris $\mathrm{KH}$, MacLeod KM. Influence of the endothelium on contractile responses of arteries from diabetic rats. Eur J Pharmacol 1988;153:55-64. 


\section{DIABETES DURATION AND GLUCOSE CONCENTRATION}

16. Wakabayashi I, Hatake K, Kimura N, Kakishita E, Nagai K. Modulation of vascular tonus by the endothelium in experimental diabetes. Life Sciences 1987;40:643-648.

17. Abiru $T$, Watanabe $Y$, Kamata K, Miyata N, Kasuya $Y$. Decrease in endothelium-dependent relaxation and levels of cyclic nucleotides in aorta from rabbits with alloxan-induced diabetes. Res Commun Chem Pathol Pharmacol 1990;68:13-25.

18. Meraji S, Jayakody L, Senaratne MP, Thomson AB, Kappagoda T. Endothelium-dependent relaxation in aorta of BB rat. Diabetes 1987;36:978-981.

19. Brownlee $M$, Cerami A, Vlassara $H$. Advanced products of nonezymatic glycosylation and the pathogenesis of diabetic vascular disease. Diabetes/Metab Rev 1988;4:437-451.

20. Tomizawa H, Yamazaki M, Kunika K, Itakura M, Yamashita K. Association of elastin glycation and calcium deposit in diabetic rat aorta. Diabetes Res Clin Pract 1993;19:1-8.

21. Huijberts MSP, Crijns FRL, Wolffenbuttel BHR, Nieuwenhuijzen Kruseman AC, Van Essen $\mathrm{H}$, Struijker Boudier HAJ. In vivo arteriolar reactivity to vasodilators in experimental diabetes. Pharmacology \& Toxicology 1990;72:16.

22. Bucala R, Cerami A. Advanced glycosylation: chemistry, biology, and implications for diabetes and aging. Adv Pharmacol 1992;23:1-34.

23. Tesfamariam B, Brown ML, Cohen RA. Elevated glucose impairs endothelium-dependent relaxation by activating protein kinase C. J Clin Invest 1991;87:1643-1648.

24. Tesfamariam B, Cohen RA. Free radicals mediate endothelial cell dysfunction caused by elevated glucose. Am J Physiol 1992;263:H321-326.

25. Pugliese G, Tilton RG, Williamson JR. Glucose-induced metabolic imbalances in the pathogenesis of diabetic vascular disease. Diabetes/Metab Rev 1991;7:35-59.

26. Ruderman NB, Williamson JR, Brownlee M. Glucose and diabetic vascular disease. Faseb J $1992 ; 6: 2905-2914$

27. Pfaffman MA, Ball CR, Darby A, Hilman R. Insulin reversal of diabetes-induced inhibition of vascular contractility in the rat. Am J Physiol 1982;242:H490-495.

28. Scarbourgh NL, Carrier GO. Nifedine and alpha adrenoreceptors in rat aorta. II. Role of extracellular calcium in enhanced alpha-2 adrenoceptor-mediated contraction in diabetes. $J$ Pharmacol Exp Ther 1984;231:603-609.

29. Fulton DJ, Hodgson WC, Sikorski BW, King RG. Attenuated responses to endothelin-1, KCl and $\mathrm{CaCl} 2$, but not noradrenaline, of aortae from rats with streptozotocin- induced diabetes mellitus. Br J Pharmacol 1991;104:928-932. 


\section{Contractile and relaxing responses in mesenteric and renal resistance arteries}

B.J. Heesen, J.G.R. De Mey, and B.H.R. Wolffenbuttel Cardiovascular Research Institute Maastricht (CARIM), Department of Internal Medicine, and Department of Pharmacology,

University of Limburg, Maastricht (NL) 


\section{SUMMARY}

In diabetic animals, disturbed reactivity to vasoactive agents has been described. We studied altered contractile properties in thoracic aorta $(A)$, mesenteric resistance $(M R A)$, and renal resistance arteries (RRA). Wistar $R P$ rats were made diabetic. After 3 months, blood glucose was $5.0 \pm 0.6$ (SD) $\mathrm{mM}$ in control (C) and $28.7 \pm 6.1$ $m M$ in diabetic (D). Isolated aorta, MRA, and RRA were mounted in an organ chamber. The chamber was filled with a Krebs bicarbonate solution (glucose concentrations $5 \mathrm{mM}$ for $C$ and $30 \mathrm{mM}$ for $D$ ). Contractile response to phenylephrine (PHE) in aorta was decreased by $37 \%$ in diabetes vs. control. This difference was not observed between diabetic and control in MRA and RRA. Relaxing responses to acetylcholine (ACH) and sodium nitroprusside (SNP) were studied during phenylephrine induced contraction. In $A$, acetylcholine $(A C H)$ endothelium dependent relaxation did differ between $C$ and $D$, the EC-50 (-log concentration in $M$ ) values: 6.0 and $6.4(p<0.05)$, respectively. Sodium nitroprusside (SNP) induced relaxation (endothelium independent) in aorta did differ between $C$ and $D$, with $E C-50$ values: 6.8 and $7.4(p<0.05)$. In MRA, ACH- and SNP-induced relaxation did also differ between $C$ and $D$, with EC-50 values, respectively: 7.6 for $D$ and 7.1 for $C$, and 7.9 for $D$ and 8.3 for $C$. In contrast to the aorta there was no difference in ACH-or SNPinduced relaxation in $R R A$, with EC-50 values respectively of 7.6 for $D$ and 7.6 for $C$, and 8.3 for $D$ and 8.1 for $C$. Our data suggest that endothelium-dependent relaxation is enhanced in diabetic aorta and MRA compared to control, but does not differ between diabetic and control in RRA. This study shows that experimental diabetes has different effects on vasoreactivity in different types of blood vessels. 


\section{REACTIVITY IN SMALL ARTERIES}

\section{INTRODUCTION}

The vasodilator effect of acetylcholine in preconstricted rings of isolated vessels is mediated by a chemically unstable substance called endothelium derived relaxing factor (EDRF) ${ }^{[1]}$, known as nitric oxide (NO) ${ }^{[2-5]}$ The synthesis and release of NO from vascular endothelial cells, by regulating the caliber of resistance blood vessels, may have a role in controlling vascular perfusion within individual organs ${ }^{[6]}$. Conversely impaired production of NO may contribute to vasospasm of coronary arteries associated with angina pectoris ${ }^{[7]}$ and with the increased peripheral resistance in hypertension ${ }^{88}$. Oyama provided evidence that aortic EDRF biosynthesis was reduced in rats made diabetic by streptozotocin injection ${ }^{[9]}$. Since then, different groups reported impaired ${ }^{[10]}$, unchanged ${ }^{[11]}$, or enhanced ${ }^{[12-14]}$ responses to acetylcholine in isolated aortas from diabetic rats. These findings raise the possibility that changes in EDRF (NO) release found in diabetes could differ in various vascular beds and account for the vascular complications found in diabetes.

The objective of the present study was to assess the effect of phenylephrine, acetylcholine, and sodium nitroprusside on vasoreactivity of the thoracic aorta, the mesenteric and renal resistance arteries. We studied the vasoreactivity in arteries which were obtained from diabetic and non-diabetic rats.

\section{RESEARCH DESIGN AND METHODS}

Diabetes was induced in six week old male Wistar RP rats by intravenous injection of $70 \mathrm{mg} / \mathrm{kg}$ streptozotocin. All diabetic and non-diabetic Wistar RP rats were housed individually in standard laboratory cages. They received food (type RMM-TM, Hope Farms, Woerden, the Netherlands) and water ad libitum.

On the day of the experiments, performed at the age of 18 weeks (diabetes duration 3 months), the animals were anaesthetized by ether and a blood sample of $5 \mathrm{ml}$ was drawn by puncture of the abdominal aorta. The mesentery was isolated from the rats, rinsed with a buffered physiological salt solution and pinned out on a petri dish coated with Silgard (Dow Corning Corp., USA) and filled with a buffered physiological salt solution. Third to fourth order branches of the superior mesenteric artery were dissected from the mesentery. The same procedure was performed when isolating renal resistance arteries, only the kidney was sliced into two pieces before being pinned out on a petri dish. Two stainless-steel wires (diameter $40 \mu \mathrm{m}$ ) were inserted into the lumen of the vessel, which was then mounted horizontally in an organ chamber (JP Trading, Aarhus, Denmark, volume $10 \mathrm{ml}$ ) between an isometric force transducer (Kistler Morse DSC6, Seattle WA, USA) and a displacement device (Mitatoyo, Tokyo, Japan). The organ chamber was filled with a modified Krebs-Ringer bicarbonate solution (KRB, composition in $\mathrm{mM}$ : $\mathrm{NaCl} 118.3, \mathrm{KCl} 4.7, \mathrm{MgSO}_{4} 1.2, \mathrm{CaCl}_{2} 2.5$, $\mathrm{KH}_{2} \mathrm{PO}_{4} 1.2, \mathrm{NaHCO}_{3} 25.0$, Ca-EDTA 0.026 and glucose 5.0 or 30.0) maintained at $37^{\circ} \mathrm{C}$ and $\mathrm{pH} 7.4$ and continuously aerated with $95 \% \mathrm{O}_{2}$ and $5 \% \mathrm{CO}_{2}$.

The preparations were exposed intermittently to Krebs-Ringer buffer in which all $\mathrm{NaCl}$ was replaced by an equimolar amount of $\mathrm{KCl}$. This procedure was continued 


\section{CHAPTER 4}

until a maximal contractile response to potassium was obtained. Subsequent experiments were performed at this optimal diameter. The diameter of the aorta was set to $2 \mathrm{~mm}$ and left at this diameter, as we know from previous studies that there was no difference in maximum active wall tension between an internal diameter of 2-3 $\mathrm{mm}$. During this procedure, control aortas were in buffer containing $5 \mathrm{mM}$ glucose; diabetic aortas were in buffer containing $30 \mathrm{mM}$ glucose. Acetylcholine- and sodium nitroprusside-induced relaxations were assessed in arteries pre-contracted to sub maximum of contractile tension.

Drugs

Streptozotocin, phenylephrine, sodium nitroprusside and acetylcholine were obtained from SIGMA (St. Louis, MO, USA). All drugs, except streptozotocin which was dissolved in citrate buffer ( $\mathrm{pH} 4.5)$, were prepared in distilled deionized water and 10 $\mu l$ aliquots were added to the organ bath to generate the concentration-response curves. All drug concentrations are expressed as the negative log of the final molar concentration in the organ bath. Blood glucose in the animals was measured with a hexokinase method.

\section{Calculations and statistics}

Contractile responses are expressed as increases in wall tension (increase in force $/ 2 \mathrm{x}$ length of arterial segment). Effects of pharmacological agents are expressed as \% remaining tension versus initial (55\% of maximum) contractile tension. EC-50 values were calculated using GraphPad Inplot (GraphPad Software Inc., San Diego, Ca, USA). Differences between groups were tested by ANOVA with Student-NewmanKeuls correction for multiple comparisons, using the SPSS for Windows version 6.0 software (SPSS Inc, Chicago, Il, USA). The number of animals which were used in the experiments are listed in table 1. Data are shown as means \pm SEM, unless stated otherwise. $P$ values $<0.05$ were considered statistically significant.

\section{RESULTS}

Data of blood glucose levels, body weight, and internal diameters are given in table 1.

Table 1. Body weights, blood glucose levels and internal diameters in control and diabetic animals.

\begin{tabular}{l|c|c} 
& control & diabetic \\
\hline Number $(\mathrm{n})$ & 9 & 8 \\
\hline Body weight $(\mathrm{g})$ & $333 \pm 38$ & $242 \pm 46^{\circ}$ \\
\hline Blood glucose (mM) & $5.0 \pm 0.6$ & $28.7 \pm 6.1^{\circ}$ \\
\hline Mesenteric resistance artery (MRA, mm) & $0.21 \pm 0.03$ & $0.27 \pm 0.03^{*}$ \\
\hline Renal resistance artery (RRA, mm) & $0.31 \pm 0.07$ & $0.30 \pm 0.04$
\end{tabular}

${ }^{*} \mathrm{p}<0.05$ vs control animals 


\section{REACTIVITY IN SMALL ARTERIES}

The optimal diameter did not differ between the diabetic and control in the renal resistance artery. However, the optimal internal diameter in the mesenteric resistance artery was significantly larger in the diabetic than in the control animal, probably due to an enlargement of the gut and mesentery caused by the diabetic state and its associated increase in food intake.

\section{Phenylephrine-induced contraction}

The maximal Phenylephrine-induced contractile force was $7.8 \pm 0.8 \mathrm{mN} / \mathrm{mm}$ in aortas obtained from non-diabetic animals. The phenylephrine-induced contractile force was $37 \%$ lower in aortas from diabetic animals compared to control aortas $(4.9 \pm 0.4$ $\mathrm{mN} / \mathrm{mm}, \mathrm{p}<0.05$ ). Sensitivity to phenylephrine in aortic rings did not differ between the groups. The EC-50 concentration, expressed as the negative log was 7.1 for control and 6.9 for rings from diabetic animals. (see table 2).

The renal and mesenteric resistance arteries showed a lower sensitivity to phenylephrine (EC-50 concentrations 5.8 and 5.4 respectively for control and 5.7 and 5.5 for diabetic animals) compared to aorta ( 7.1 for control and 6.9 for diabetic animals). Phenylephrine- induced contractile force in mesenteric or renal resistance arteries did not differ significantly between diabetic and control. The obtained maximum contractile

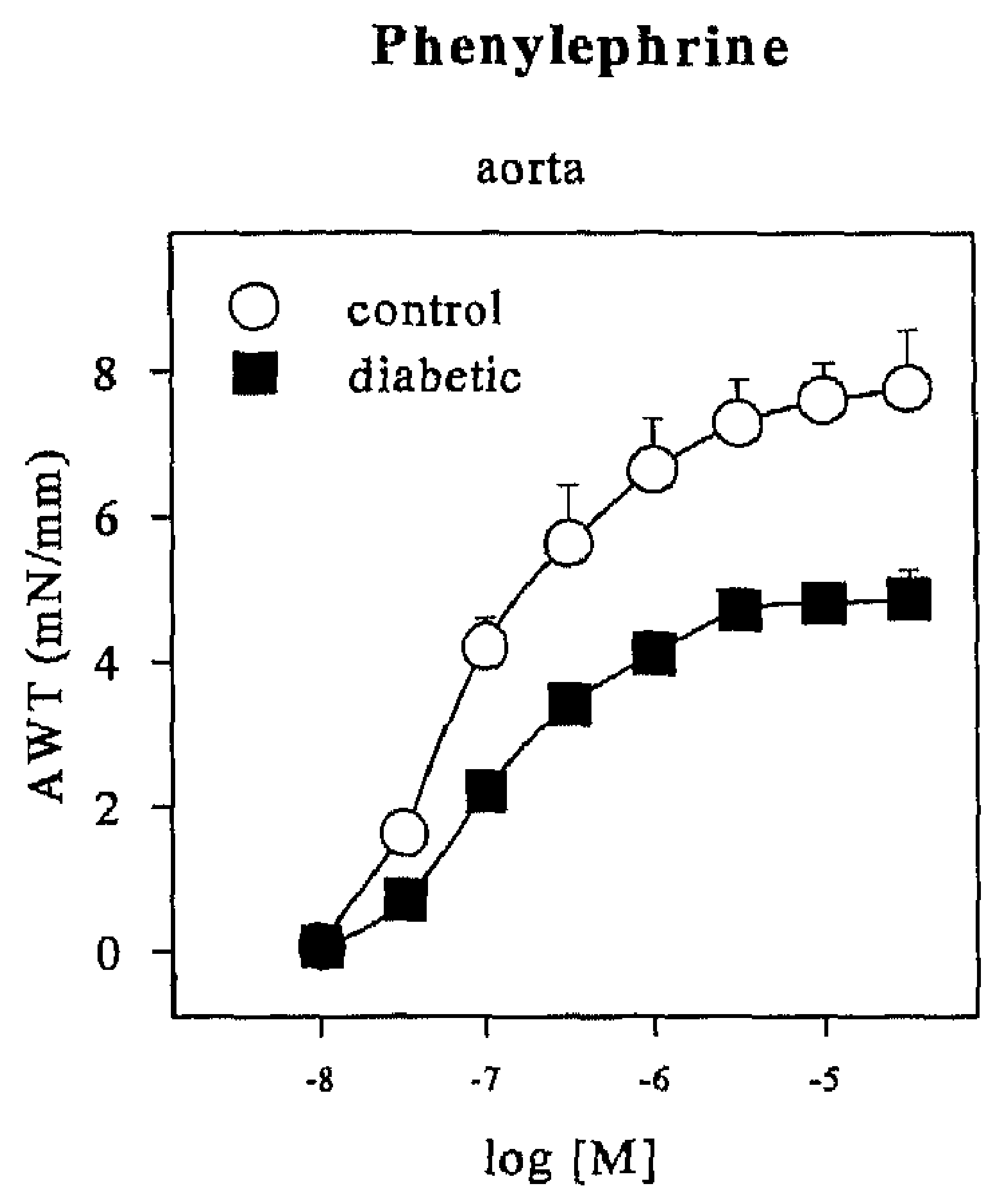

Figure 1. Phenylephrine induced contraction in aorta from diabetic and non-diabetic animals. $A W T=$ active wall tension force is much smaller in renal resistance (RRA) than in mesenteric resistance arteries (MRA).

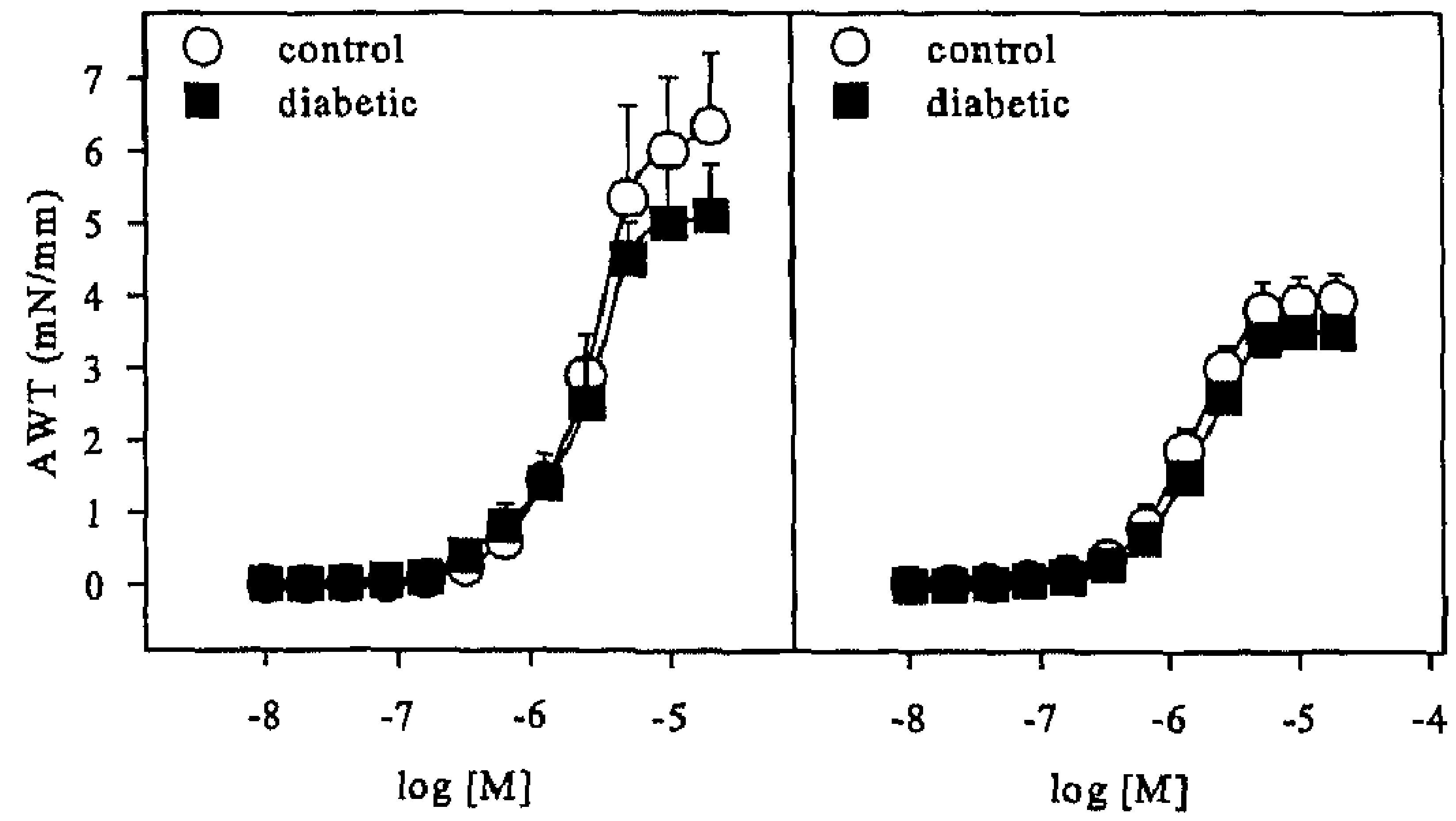

Figure 2. Phenylephrine induced contraction in mesenteric (MRA) and renal $(R R A)$ resistance arteries from diabetic and non-diabetic animals. $A W T=$ active wall tension. 


\section{CHAPTER 4}

Acetylcholine-induced relaxation

In aortas precontracted with $0.1 \mu \mathrm{M}$ phenylephrine, a concentration-dependent relaxing response to acetylcholine was observed. There was a significant difference in acetylcholine-induced relaxation at $32 \mu \mathrm{M}$ between control and diabetic aortas; residual contractile tensions were $27 \pm 9 \%$ and $5 \pm 5 \%$, respectively.

In mesenteric and renal resistance arteries precontracted with $10 \mu \mathrm{M}$ phenylephrine, a concentration-dependent relaxing response to acetylcholine was observed. There was a significant difference between control and diabetic mesenteric resistance arteries. However, there was no difference in relaxation between the control and diabetic renal resistance arteries. Control arteries isolated from the mesentery showed a more potent relaxation to $32 \mu \mathrm{M}$ acetylcholine than renal resistance arteries. Remaining tensions are respectively $4 \pm 3 \%$ and $22 \pm 8 \%$ of maximum.

Table 2. EC-50 values for response to phenylephrine (PHE), acetylcholine (ACH), and sodium nitroprusside (SNP) in aorta, mesenteric resistance artery (MRA), and renal resistance artery (RRA) from non-diabetic and diabetic animals.

\begin{tabular}{l|c|c|c|c|c|c} 
& $\begin{array}{c}\text { PHE } \\
\text { control }\end{array}$ & $\begin{array}{c}\text { PHE } \\
\text { diabetic }\end{array}$ & $\begin{array}{c}\text { ACH } \\
\text { control }\end{array}$ & $\begin{array}{c}\text { ACH } \\
\text { diabetic }\end{array}$ & $\begin{array}{c}\text { SNP } \\
\text { control }\end{array}$ & $\begin{array}{c}\text { SNP } \\
\text { diabetic }\end{array}$ \\
\hline aorta & $\begin{array}{c}7.1 \\
(6.9-7.3)\end{array}$ & $\begin{array}{c}6.9 \\
(6.8-7.1)\end{array}$ & $\begin{array}{c}6.0 \\
(5.8-6.2)\end{array}$ & $\begin{array}{c}6.4^{\mathrm{a}} \\
(6.3-6.6)\end{array}$ & $\begin{array}{c}7.1 \\
(7.0-7.3)\end{array}$ & $\begin{array}{c}7.5^{\mathrm{n}} \\
(7.4-7.6)\end{array}$ \\
\hline MRA & $\begin{array}{c}5.4^{\mathrm{b}} \\
(5.2-5.6)\end{array}$ & $\begin{array}{c}5.5^{\mathrm{b}} \\
(5.3-5.7)\end{array}$ & $\begin{array}{c}7.2^{\mathrm{b}} \\
(7.0-7.4)\end{array}$ & $\begin{array}{c}7.6^{\mathrm{ab}} \\
(7.5-7.8)\end{array}$ & $\begin{array}{c}7.9^{\mathrm{b}} \\
(7.7-8.0)\end{array}$ & $\begin{array}{c}8.3^{\mathrm{ab}} \\
(8.1-8.4)\end{array}$ \\
\hline RRA & $\begin{array}{c}5.8^{\mathrm{c}} \\
(5.5-6.0)\end{array}$ & $\begin{array}{c}5.7^{\mathrm{c}} \\
(5.5-5.9)\end{array}$ & $\begin{array}{c}7.6^{\mathrm{c}} \\
(7.5-7.7)\end{array}$ & $\begin{array}{c}7.6^{\mathrm{c}} \\
(7.5-7.7)\end{array}$ & $\begin{array}{c}8.1^{\mathrm{c}} \\
(7.8-8.4)\end{array}$ & $\begin{array}{c}8.3^{\mathrm{c}} \\
(8.0-8.5)\end{array}$
\end{tabular}

a $p<0.05$ diabetic vs control animals

${ }^{b} p<0.05$ MRA vs aorta

Aorta

c $p<0.05$ RRA vs aorta

acetylcholine

sodium nitroprusside

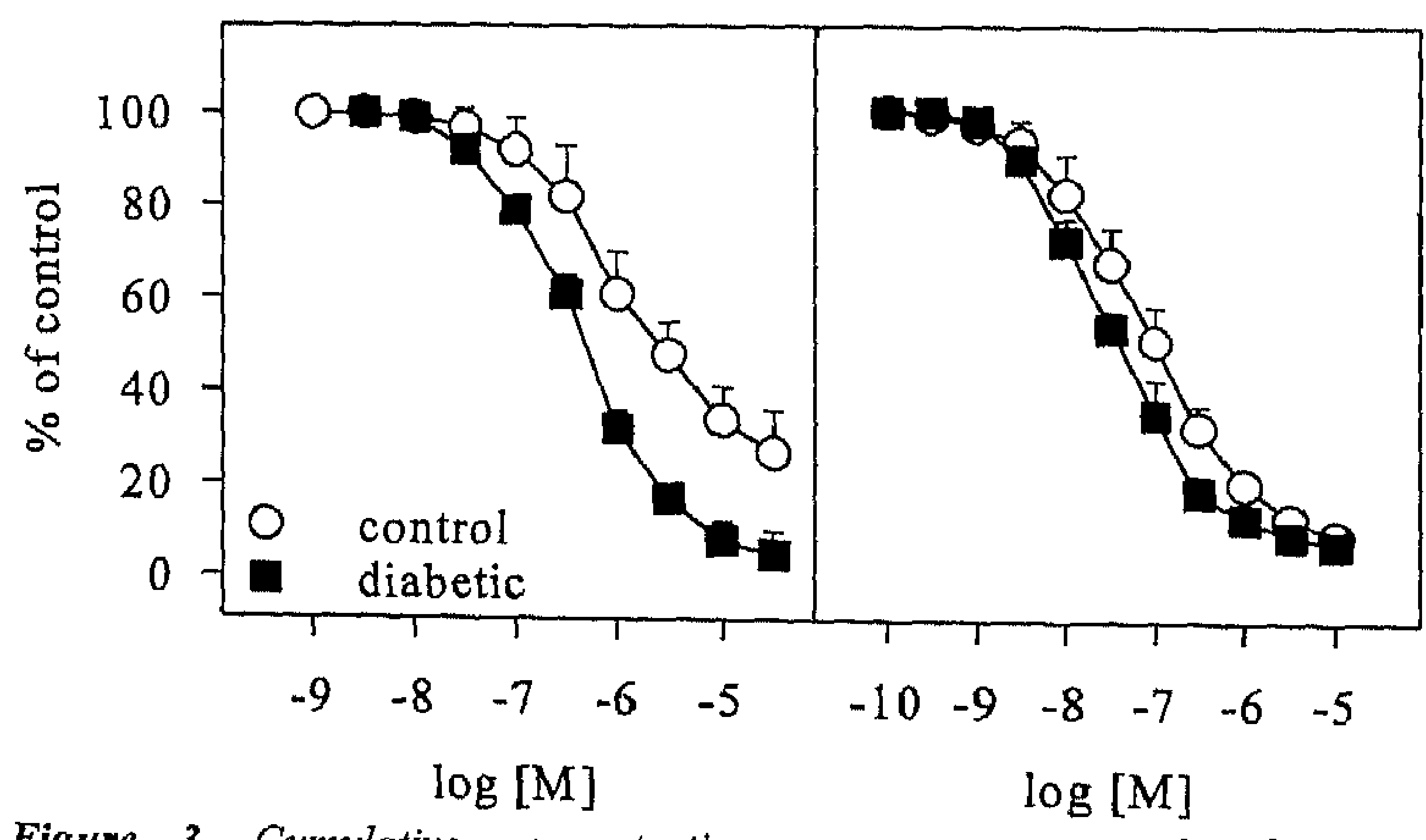

Figure 3. Cumulative concentration-response curves of relaxation responses to acetylcholine (left panel) and sodium nitroprusside (right panel). 
REACTIVITY IN SMALL ARTERIES

\section{MRA}

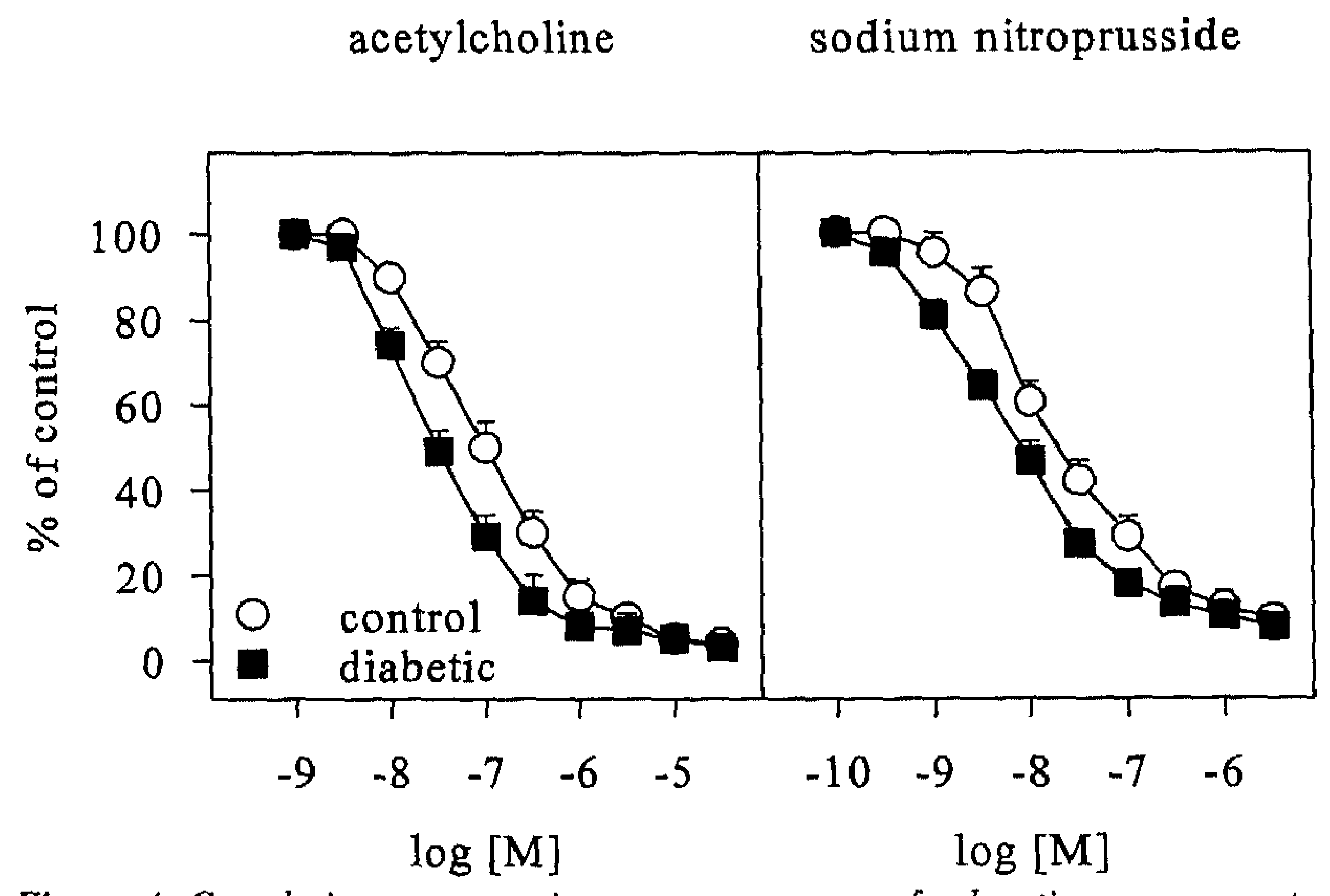

Figure 4. Cumulative concentration-response curves of relaxation responses to acetylcholine (left panel) and sodium nitroprusside (right panel).

\section{RRA}

acetylcholine

sodium nitroprusside

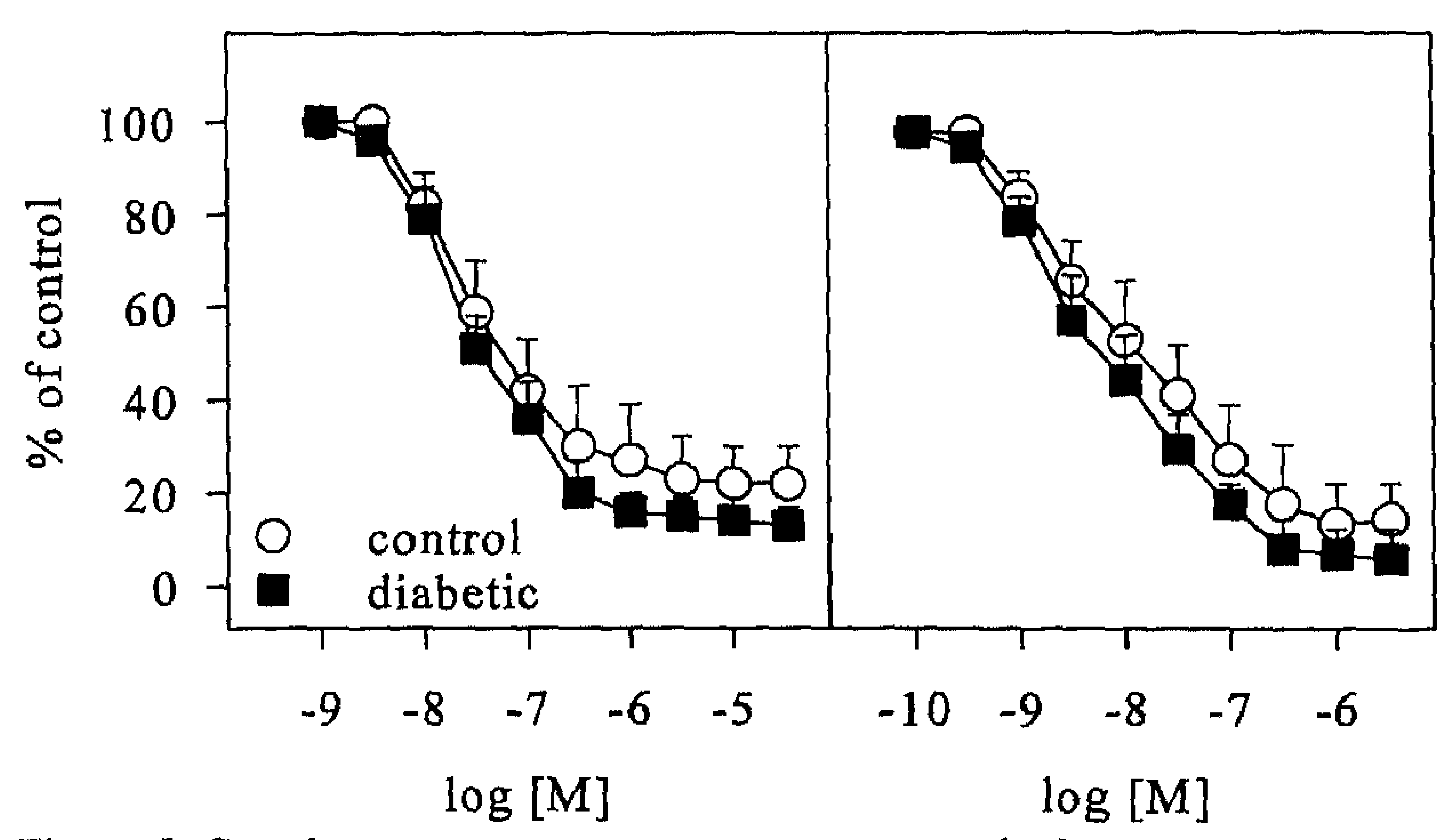

Figure 5. Cumulative concentration-response curves of relaxation responses to acetylcholine (left panel) and sodium nitroprusside (right panel). 


\section{CHAPTER 4}

Sodium nitroprusside-induced relaxation

In aortas precontracted with $0.1 \mu \mathrm{M}$ phenylephrine, a concentration-dependent relaxation by sodium nitroprusside was observed. Sensitivity to sodium nitroprusside was greater in diabetic aortas compared to non-diabetic aortas (figure 3 and table 2). This difference was also present in mesenteric resistance arteries. (figure 4 and table 2), but not in renal resistance arteries (figure 5, table 2). The renal resistance arteries also failed to relax completely to sodium nitroprusside, remaining tension in control renal resistance arteries $22 \pm 7 \%$ vs control mesenteric resistance arteries $2 \pm 1 \%(\mathrm{p}<0.05)$.

\section{DISCUSSION}

Our data suggest that contraction force is impaired in aorta from animals with experimental diabetes compared to non-diabetic animals. This finding is consistent with observations from several other groups ${ }^{[11,15-17]}$. The smaller contractile force in diabetic aorta is unlikely to be attributed to differences in weight. Head et al. showed in $1987^{\text {[11] }}$ that contractile force was lower in diabetic aorta than in the age-matched and food restricted control animals. Therefore, we believe that decreased contractile responses in tissues from diabetic rats are not attributable to an inappropriate source of control tissues, i.e. only the use of age-matched rats.

The deficit in contractile tension in diabetic aorta was not found in the diabetic mesenteric and renal resistance arteries compared with control. This was earlier reported for mesenteric resistance arteries by Longhurst ${ }^{[16 !}$, but not for isolated renal resistance arteries from diabetic animals. Bhardwaj ${ }^{[12]}$ reported that the vasodilatation was enhanced in an intact perfused kidney compared to non-diabetic animals. Bhardwaj and Moore assessed the renal vasoconstrictor effect of noradrenaline which was increased in diabetic rats, both in terms of the concentration required to produce $50 \%$ of the maximal effect (EC50) and in the maximal response achieved. The vasodilator effect of acetylcholine and nitroprusside and the vasoconstrictor effect of noradrenaline in the perfused kidney of streptozotocin diabetic rats were increased compared to control animals.

The results of the study described in this chapter suggest that there is an increase in the diabetic aorta and MRA endothelium derived relaxing factor (EDRF), showed by the increased sensitivity to acetylcholine. These results are in contrast to previous published reports demonstrating reduced biosynthesis of EDRF in the aorta of diabetic rats. However, in the renal resistance arteries this enhanced sensitivity to acetylcholine was not observed. One explanation could be that this is a more muscular artery than the aorta, which has a larger elastic component. It is likely that the effects of the formation of advanced glycosylated endproducts due to hyperglycemia, as discussed in chapter 1 and 5, are accountable for this difference between aorta, MRA and RRA. Another explanation could be that the aorta and MRA are more capable to upregulate the guanylate cyclase to compensate for the effects of the quenching of nitric oxide.

The existence of differences between the arteries isolated from several vascular beds was recently shown by Wu et al. ${ }^{[18]}$. They described the effects of insulin and insulinlike growth factor I (IGF-I) on vasoactivity in aorta and the mesenteric artery. In this 


\section{REACTIVITY IN SMALL ARTERIES}

study they showed that insulin and IGF-I potentiate the response to arginine vasopressin (AVP, a vasoconstrictor) in mesenteric arteries, but decreased the response to AVP in aortic rings by $30 \%$. This finding could be one of the keys of understanding the complex relationship between insulin resistance and hypertension as often observed in people with diabetes.

Overall these data show that the endothelium dependent and independent relaxation is intact or even enhanced in the aorta and mesenteric resistance arteries isolated from animals with experimental diabetes. However, the difference in relaxation between renal resistance arteries isolated from diabetic and non-diabetic animals was not statistically significant.

\section{REFERENCES}

1. Furchgott RF. Role of endothelium in response of vascular smooth muscle. Circ Res $1983 ; 53: 557-573$.

2. Ignarro LJ, Byrns RE, Buga GM, Wood KS. Endothelium-derived relaxing from pulmonary artery and vein posses pharmacologic and chemical properties identical to those of nitric oxide radical. Circ Res 1987;61:866-879.

3. Furchgott RF, Vanhoutte PM. Endothelium-derived relaxing and contracting factors. Faseb J 1989;3:2007-2014.

4. Furchgott RF. The discovery of endothelium-dependent relaxation. Circulation 1993;87:3-8.

5. Vanhoutte PM. The end of the quest? Nature $1987 ; 327: 459-460$.

6. Vanhoutte PM. Endothelium and the control of vascular tissue. News In Physiol Sci 1987;2:1822.

7. Ganz P, Alexander RW. New insights into the cellular mechanism of vasospasm. Am J Cardiol $1985 ; 56: 11-15 \mathrm{E}$

8. Lockette $\mathrm{W}$, Otsuka $\mathrm{Y}$, Caretto $\mathrm{O}$. The loss of endothelium-dependent vascular relaxation in hypertension. Hypertension 1986;8:ii61-ii66.

9. Oyama $Y$, Kawasaki H, Hattori $Y$, Kanno M. Attenuation of endothelium-dependent relaxation in aorta from diabetic rats. Eur J Pharmacol 1986;132:75-78.

10. Meraji S, Jayakody L, Senaratne MP, Thomson AB, Kappagoda T, Endothelium-dependent relaxation in aorta of BB rat. Diabetes 1987;36:978-981.

11. Head RJ, Longhurst PA, Panek R, Stitzel RE. A contrasting effect of the diabetic state upon the contractile responses of aortic preparations from the rat and rabbit. $\mathrm{Br} \mathrm{J}$ Pharmacol 1987;91:275-286.

12. Bhardwaj R, Moore PK. Increased vasodilator response to acetylcholine of renal blood vessels from diabetic rats. J Pharm Pharmacol 1988;40:739-742.

13. Heesen BJ, Ido Y, Williamson JR, Wolffenbuttel BHR. Acetylcholine-induced relaxation of isolated aortas is modulated by ambient glucose, L-arginine, and myo-inositol concentrations. Diabetes 1992;41(Suppl. 1):680. 


\section{CHAPTER 4}

14. Heesen BJ, De Mey JGR, Wolffenbuttel BHR. Aminoguanidine and insulin treatment prevent vascular reactivity disturbances in experimental diabetes. Diabetes 1994;43(Suppl. 1):76A.

15. Pfaffman MA, Ball CR, Darby A, Hilman R. Insulin reversal of diabetes-induced inhibition of vascular contractility in the rat. Am J Physiol 1982;242:H490-495.

16. Longhurst PA, Head RJ. Responses of the isolated perfused mesenteric vasculature from diabetic rats: the significance of appropriate control tissues. J Pharmacol Exp Ther $1985 ; 235: 45-49$.

17. Ramanadham S, Lyness WH, Tenner TEJ. Alterations in aortic and tail artery reactivity to agonists after streptozotocin treatment. Can J Physiol Pharmacol 1984;62:418-423.

18. Wu H, Jeng YY, Yue C, Chuyu KY, Hsueh WA, Chan TM. Endothelial-dependent vascular effects of insulin and insulin-like growth factor $I$ in the perfused rat mesenteric artery and aortic ring. Diabetes 1994;43:1027-1032. 


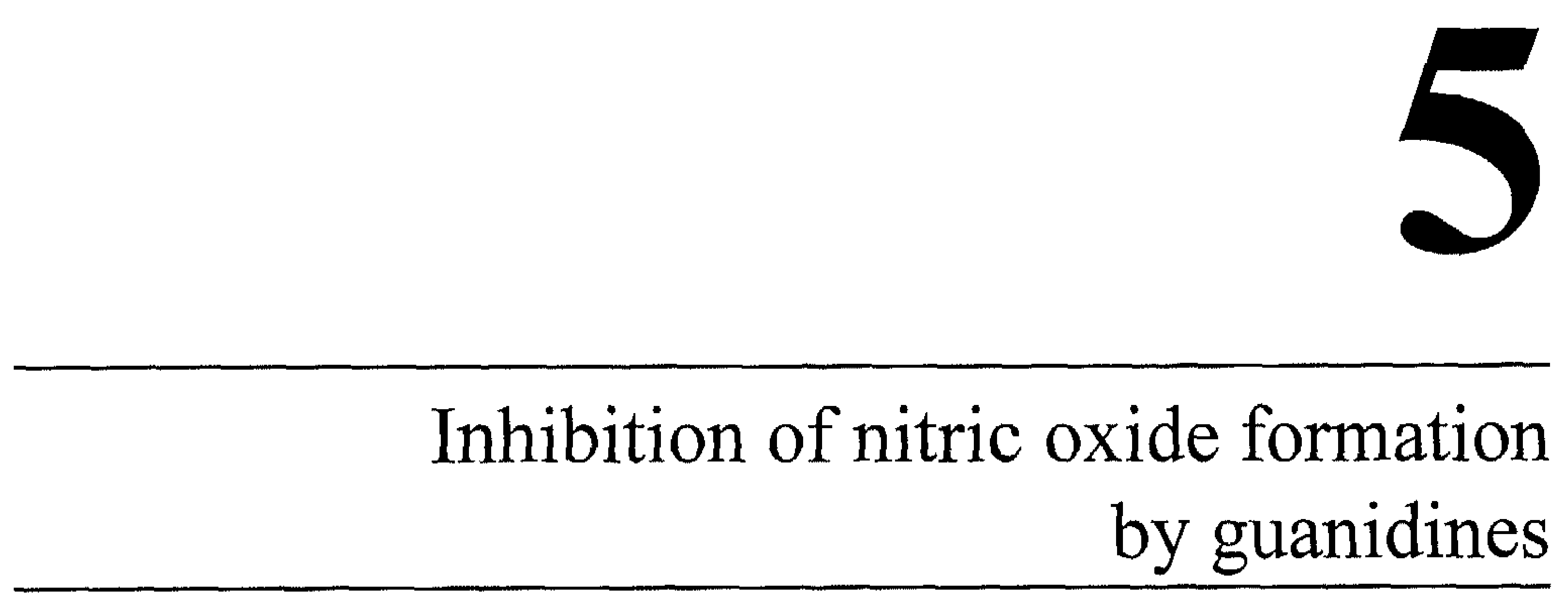

K. Hasan, B.J. Heesen, J.A. Corbett, M.L. McDaniel, K. Chang, W. Allison, B.H.R. Wolffenbuttel, J.R. Williamson and R.G. Tilton Washington University, St. Louis (USA), and University of Limburg, Maastricht (NL)

European Journal of Pharmacology

1993; 249: 101-106 


\section{SUMMARY}

Aminoguanidine, $N, N$-diaminoguanidine, methylguanidine, and 1,1-dimethylguanidine were compared to $N^{G}$-monomethyl-L-arginine (L-NMMA) for their ability to inhibit nitric oxide (NO) formation by cytokine-inducible and vascular constitutive isoforms of NO synthase. These comparisons were performed by assessing (I) cytokine-induced production of nitrite by RINmSF cells, (2) vasoconstrictor responses of isolated rat mesenteric arteries, and (3) in vivo blood pressure responses following intravenous bolus injection into anesthetized rats. Aminoguanidine and L-NMMA were the most potent inhibitors of cytokine-induced NO formation in RINm5F cells, while the other guanidine compounds were 10 (1,1-dimethylguanidine) to 100 (methylguanidine) times less potent. L-NMMA and l,l-dimethylguanidine were the most potent inhibitors of the vascular constitutive isoform of NO synthase in both assay systems, while aminoguanidine and $N, N^{\prime}$-diaminoguanidine were the least potent. These results (1) confirm the selective inhibition of the inducible isoform of NO synthase by aminoguanidine, (2) indicate that $N, N^{\prime}$-diaminoguanidine, while $\sim 30$ times less potent than aminoguanidine in inhibiting inducible NO synthase, has very little effect on constitutive NO synthase activity, and (3) I,I-dimethylguanidine, like L-NMMA, is a relatively potent inhibitor of both isoforms of NO synthase. 


\section{INHIBITION OF NITRIC OXIDE FORMATION BY GUANIDINES}

\section{INTRODUCTION}

Several isoforms of nitric oxide (NO) synthase have been characterized, and are classified as constitutive or inducible subtypes based on gene expression and co-factor requirements. The constitutive subtype (found in vascular endothelium and brain) is $\mathrm{Ca}^{2+}$ and calmodulin dependent, and releases small amounts of NO in response to physical stimuli or receptor activation ${ }^{[1-3]}$. The inducible subtype can be expressed in a variety of cells, including macrophages, vascular smooth muscle, fibroblasts, endothelial cells, and pancreatic $\beta$-cells by exposure to endotoxins and cytokines, and much larger quantities of NO are produced which function as effector molecules mediating cytostatic and cytotoxic effects on target cells ${ }^{[4-6]}$. Excess production of NO by this isoform has been implicated in the pathogenesis of septic shock [7], inflammatory and immunologically mediated diseases ${ }^{[8,9]}$, and with the onset of diabetes associated with the destruction of $\beta$-cells ${ }^{[10-12]}$. As shown in table 1 , an analogue of $\mathrm{L}$-arginine in which one of the guanidino nitrogens is methylated $\left(\mathrm{N}^{\mathrm{G}}\right.$ monomethyl-L-arginine; L-NMMA) is a competitive inhibitor of both isoforms of NO synthase.

Table 1. Chemical structure of L-NMMA and guanidines

\begin{tabular}{llcc}
\hline & & & \\
& & $\mathrm{R}_{2}$ & $\mathrm{R}_{3}$ \\
\hline Compound & $\mathrm{R}$ & $\mathrm{H}$ & $\mathrm{CH}_{3}$ \\
\hline L-NMMA & $\mathrm{NH}_{2}$ & $\mathrm{H}$ & $\mathrm{H}$ \\
Aminoguanidine & $\mathrm{NH}_{2}$ & $\mathrm{H}$ & $\mathrm{H}$ \\
Methylguanidine & $\mathrm{CH}_{3}$ & $\mathrm{H}$ & $\mathrm{H}$ \\
1,1-Dimethylguanidine & $\mathrm{CH}_{3}$ & $\mathrm{CH}_{3}$ & \\
\hline
\end{tabular}

a $\left(\mathrm{CH}_{2}\right)_{3}-\mathrm{CH}\left(\mathrm{NH}_{2}\right)-\mathrm{COOH}$

Aminoguanidine, which contains two chemically equivalent guanidino nitrogen groups in addition to a hydrazine moiety, recently has been shown to be a potent and selective inhibitor of the inducible isoform of NO synthase ${ }^{[13]}$. The purpose of this study was to evaluate the potency and selectivity of other guanidine compounds, which contain substitutions on the hydrazine and guanidino portions of the molecule, for inhibition of the inducible versus constitutive subtypes of NO synthase. 


\title{
CHAPTER 5
}

\section{MATERIALS AND METHODS}

\begin{abstract}
Materials
Male, Sprague-Dawley rats (250-300 g) were purchased from Sasco (O'Fallon, MO) and were housed and cared for in accordance with the guidelines of the University Committee for the Humane Care of Laboratory Animals and in accordance with NIH guidelines on laboratory animal welfare. Rats were housed individually, allowed standard rat chow (Ralston Purina Richmond, IN) and water ad libitum, and were on a $12 \mathrm{~h}$ light/ dark cycle. $\mathrm{N}^{\mathrm{G}}$-Monomethyl-L-arginine (acetate salt), aminoguanidine (hemisulfate salt) $N, N^{\prime}$-diaminoguanidine (monohydrochloride salt), methylguanidine (hydrochloride salt), and 1,1-dimethylguanidine (hemisulfate salt) were purchased from Sigma (Saint Louis, MO). Human recombinant interleukin-1 $\beta$ was from Cistron (Pine Brook, NJ).
\end{abstract}

Inhibition of interleukin-l $\beta$-induced nitrite formation by RINm $5 \mathrm{~F}$ cells

RINm5F cells (a rodent $\beta$-cell insulinoma cell line obtained from the Washington University Tissue Culture Support Center) were removed from the growth flasks (5580 million cells/ flask) by trypsin $/ 0.05 \%$ EDTA treatment, and aliquoted into $1 \mathrm{ml}$ Petri dishes ( 1-2 million RINm5F cells per condition). The cells were incubated for 2$4 \mathrm{~h}$ in $1 \mathrm{ml}$ of complete CMRL-1066 tissue culture medium (Gibco, Grand Island, NY; supplemented with $10 \%$ heat-inactivated, fetal bovine serum, $2 \mathrm{mM}$ L-glutamine, 50 units $/ \mathrm{ml}$ penicillin, and $\mu \mathrm{g} / \mathrm{ml}$ streptomycin), then incubated for an additional $18 \mathrm{~h}$ at $37^{\circ} \mathrm{C}$ under an atmosphere of $95 \%$ air and $5 \% \mathrm{CO}_{2}$ with increasing concentrations of L-NMMA $\quad(n=3), \quad$ aminoguanidine $\quad\left(n=8, \quad N, N^{\prime}\right.$-di-aminoguanidine $\quad(n=4)$, methylguanidine $(n=5)$, or 1,1 -dimethylguanidine $(n=8)$ in the presence or absence of 5 units/ml interleukin-1 $\beta$. Guanidines were dissolved in CMRL-1066 tissue culture medium prior to use. Following incubation, the supernatant was isolated by centrifugation and nitrite was quantified on aliquots of the supernatant as previously described ${ }^{[10]}$. Very briefly, $100 \mu \mathrm{l}$ aliquots of supernatant were mixed with $100 \mu \mathrm{l}$ of Griess reagent ${ }^{[14]}$ plus $200 \mu$ l of distilled $\mathrm{H}_{2} \mathrm{O}$ and nitrite production determined at an absorbance of $546 \mathrm{~nm}$ using a Beckman DU-6 spectrophotometer. In some experiments, a Titertek Multiskan $\mathrm{MCC} / 340$ plate reader was used in which absorbance was read at $540 \mathrm{~nm}$ and the $200 \mu \mathrm{l}$ of $\mathrm{H}_{2} \mathrm{O}$ were excluded. Results are expressed as the percentage of interleukin- $1 \beta$-induced nitrite produced in the absence of the guanidine compounds, and are the mean \pm S.E.M. of individual experiments containing 3-4 replicates per experiment.

Inhibition of constitutive NO synthase: effects on isolated mesenteric resistance arteries

Animals were anesthetized by intraperitoneal injection of pentobarbital $(45 \mathrm{mg} / \mathrm{kg})$. Fourth- to fifth-order side branches of the superior mesenteric artery were isolated, trimmed free of connective tissue, and cut into small rings (length $=2.0 \pm 0.5 \mathrm{~mm}$ ) avoiding damage to the endothelial layer. Two stainless steel wires (diameter $40 \mu \mathrm{m}$ ) were inserted into the lumen of the mesenteric resistance artery which were then mounted horizontally in an organ chamber ( $10 \mathrm{ml}$ volume) between an isometric force 


\section{INHIBITION OF NITRIC OXIDE FORMATION BY GUANIDINES}

transducer (Kistler Morse DSC6, Seattle, WA) and a displacement device (Mitatoyo, Tokyo, Japan). The organ chamber contained a modified Krebs-Ringer bicarbonate solution (KRB; composition in $\mathrm{mM}: \mathrm{NaCl} 118.3, \mathrm{KCl} 4.7, \mathrm{MgSO}_{2}$ 0.6, $\mathrm{CaCl}_{2} 2.5$, $\mathrm{KH}_{2} \mathrm{PO}_{4}$ 1.2, $\mathrm{NaHCO}_{3}$ 25.0, Ca-EDTA 0.026, glucose 5.0, L-arginine 0.1, and myoinositol 0.1 ), which was maintained at $37^{\circ} \mathrm{C}$ and $\mathrm{pH} 7.4$ and continuously aerated with $95 \% \mathrm{O}_{2}$ and $5 \% \mathrm{CO}_{2} .100 \mu \mathrm{M} \mathrm{L}$-arginine was added to the incubation bath to ensure that substrate availability for this enzyme was not rate limiting. Previous studies have reported that bovine aortic endothelial cells can be depleted by $75 \%$ after $3 \mathrm{~h}$ incubation in buffer containing no L-arginine ${ }^{[15]}$ and that constitutive NO synthase acts as a NADPH: oxidoreductase, catalyzing the formation of hydrogen peroxide when Larginine is at submaximal concentrations ${ }^{[16]}$. The mesenteric artery was stretched to a optimal lumen diameter as described previously ${ }^{[17,18]}$ and subsequent experimentation was performed at this optimal diameter (internal diameter, $0.29 \pm 0.08 \mathrm{~mm}$ ). To study responses to aminoguanidine, $N, N^{\prime}$-diaminoguanidine, methylguanidine, 1,1dimethylguanidine and L-NMMA, resistance arterial segments were first made to contract to $45 \%$ of maximum contraction by replacing the fluid in the chamber with a prewarmed and oxygenated solution containing four parts $\mathrm{KRB}$ containing $6 \mathrm{mM} \mathrm{K} \mathrm{K}^{+}$ and one part $\mathrm{KRB}$ containing $125 \mathrm{mM} \mathrm{K}^{+}$(final $\mathrm{K}^{+}$concentration $=30 \mathrm{mM}$ ). Effects of the guanidine compounds were expressed as a percentage change from the preexisting contractile tension of $30 \mathrm{mM} \mathrm{K}^{+}$(set equal to $100 \%$ ). Contractile responses were measured after a 10-min exposure to each concentration of guanidine. Data are given as mean \pm SEM of 6 separate experiments for each compound.

\section{Inhibition of constitutive NO synthase: effects on arterial blood pessure}

Normal male, Sprague-Dawley rats were anesthetized with $100 \mathrm{mg} / \mathrm{kg}$ body weight Inactin, followed by $0.1 \mathrm{ml} / \mathrm{kg}$ body weight $d$-tubocurarine chloride i.v., the left femoral vein (for tracer injection) and right iliac artery (for monitoring blood pressure) were cannulated with polyvinyl tubing $(0.8 \times 0.5 \mathrm{~mm})$ filled with heparinized saline, and the trachea was cannulated and connected to a small rodent respirator for continuous ventilatory support. After stabilizing arterial pressure, increasing amounts of L-NMMA $(\mathrm{n}=6)$, aminoguanidine $(\mathrm{n}=16), N, N^{\prime}$-diaminoguanidine $(\mathrm{n}=4)$, methylguanidine $(n=5)$, and 1,1-dimethylguanidine $(n=4)$ were injected intravenously in a volume of $0.5 \mathrm{ml} / \mathrm{kg}$ body weight in separate animals and the peak pressure increase was recorded. Results are reported as the absolute increase in pressure above baseline and represent means \pm SEM

\section{Statistical analysis}

An analysis of variance was performed using the SAS general linear models procedure [19]. Student-Newman-Keuls correction for multiple comparison was used when more than two groups were compared. $P$ values $<0.05$ were considered significant. 


\section{CHAPTER 5}

\section{RESULTS}

The dose responses of aminoguanidine, $\mathrm{N}, \mathrm{N}^{\prime}$-di-aminoguanidine, methylguanidine, 1,1-dimethylguanidine, and L-NMMA on interleukin-1 $\beta$-induced nitrite formation (an oxidation product of NO) by RINm5F cells are shown in figure 1. L-NMMA and all guanidines inhibited nitrite production in a dose-dependent fashion in the order: aminoguanidine $\left(\mathrm{IC}_{50}=7 \mu \mathrm{M}\right)<\mathrm{L}$ - NMMA $(10 \mu \mathrm{M})<1,1$-dimethylguanidine $(70$ $\mu \mathrm{M})<N, N^{\prime}$-diaminoguanidine $(250 \mu \mathrm{M})<$ methylguanidine $(750 \mu \mathrm{M})$. Aminoguanidine differed significantly from all other guanidine compounds at $10 \mu \mathrm{M}$.

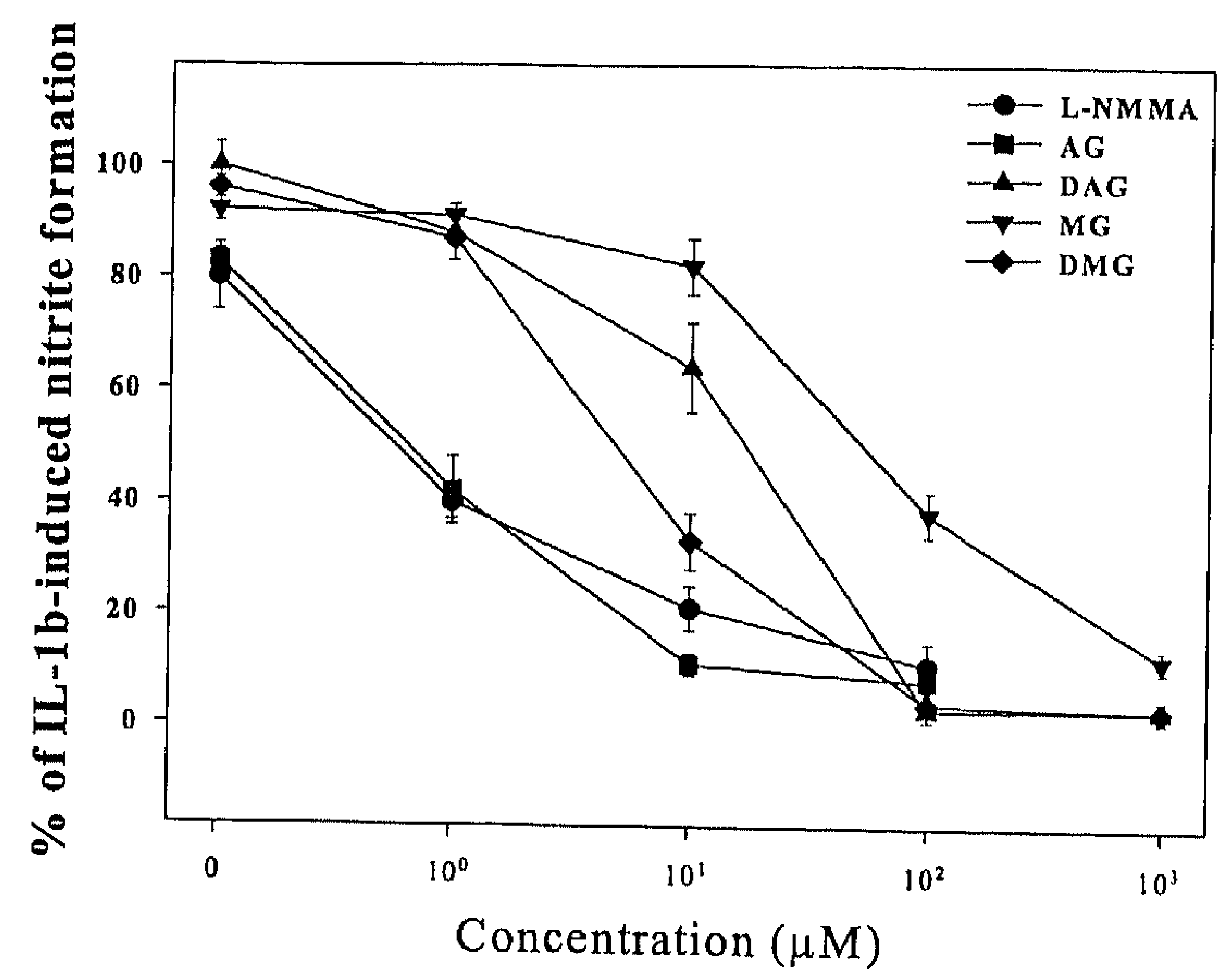

Figure 1. Effects of L-NMMA, aminoguanidine, diaminoguanidine, metly/guamidine, and dimethylguanidine on interleukin-1 $\beta$-induced nitrite formation by RINm5F cells. RINmSF cells were incubated for $18 \mathrm{~h}$ in CMRL-1066 tissue culture medium supplemented with $5 \mathrm{U} / \mathrm{ml}$ interleukin-1 $\beta \pm$ the inhibitors (see material and methods). Results are the mean \pm SEM of individual experiments containing 3-4 replicates por experiment. Basal nitrite production is $0.54 \pm 0.27 \mathrm{pmol} / 2000$ cells versus $3.3 \pm 1.4$ (SD) $100 \%$ of total nitrite production.

Effects of L-NMMA, aminoguanidine, N,N'-di-aminoguanidine, methylguanidine, and 1,1-dimethyl- guanidine on the vascular constitutive isoform were assessed over several $\log$ doses by measuring contractile force in isolated mesenteric resistance arteries (figure 2). L-NMMA and 1,1-dimethylguanidine inhibited the constitutive isoform of NO with similar efficacy at doses greater than $1 \mathrm{mM}$, but differed in their
vasoconstrictor responses at the lower doses. L-NMMA produced an increase in contraction over the entire dose-response curve (significantly different from all other 


\section{INHIBITION OF NITRIC OXIDE FORMATION BY GUANIDINES}

guanidine compounds at all concentrations) while the contractile response to 1,1dimethylguanidine increased rapidly only at doses equal to and greater than $1 \mathrm{mM}$ (significantly different from all other guanidine compounds above $100 \mu \mathrm{M}$ ). Aminoguanidine and $N, N^{\prime}$-diaminoguanidine had little effect on contractile force over the entire dose-response curve, and $N, N^{\prime}$-diaminoguanidine actually decreased contraction below baseline at the highest dose used. Methylguanidine (like 1,1dimethylguanidine) had very little effect on contractile function of mesenteric arteries below $100 \mu \mathrm{M}$. Contraction power (percent increase in active wall tension at the highest concentration used, expressed as a percent of preconstriction wall tension set equal to $100 \%$ ) varied in the order 1,1-dimethylguanidine $(160 \%)>$ L-NMMA $(150 \%)$ $>$ methylguanidine $(110 \%)>$ aminoguanidine $(100 \%)>N, N^{\prime}$-diaminoguanidine $(90 \%)$.

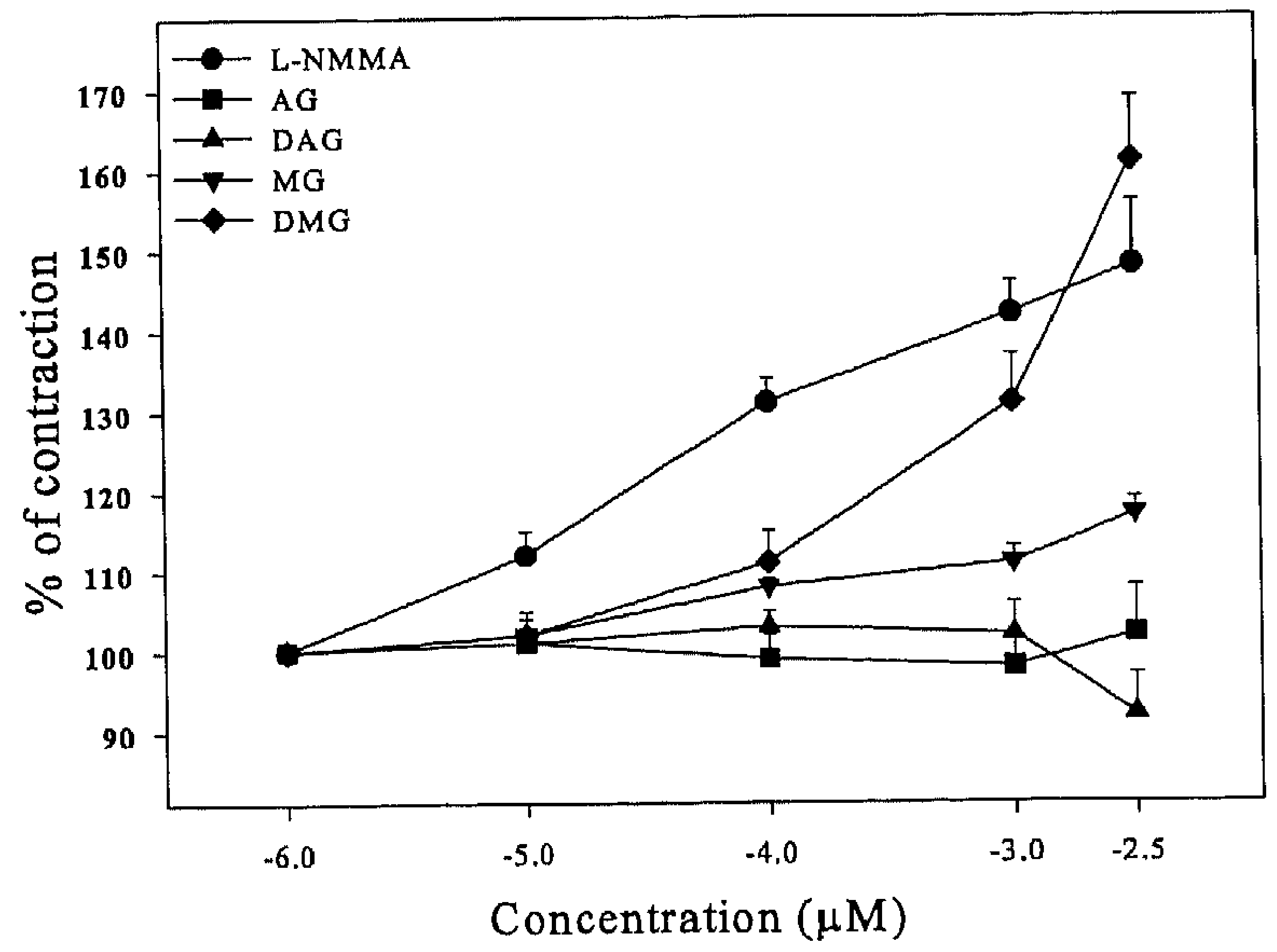

Figure 2. Effects of guanidine compounds on vascular constitutive NO synthase were assessed by measuring contractile force in isolated mesenteric resistance arteries (after a $45 \%$ preconstriction with $K R B$ solution containing $30 \mathrm{mM} \mathrm{K} \mathrm{K}^{+}$) during dose-response curves for L-NMMA, aminoguanidine, diaminoguanidine, methylguanidine, and dimethylguanidine. Results are mean \pm SEM of 6 separate experiments for each compound.

Constitutive activity of vascular NO synthase also was assessed by monitoring mean arterial blood pressure changes following iv bolus injection of increasing concentrations of L-NMMA, aminoguanidine, $N, N^{\prime}$-diaminoguanidine, methylguanidine, and 1,1-dimethyl-guanidine in anesthetized, normal rats (figure 3). The dose ( $\mu \mathrm{mol} / \mathrm{kg}$ body weight) required to produce a $10 \mathrm{~mm} \mathrm{Hg}$ increase in mean blood pressure was in the order: L-NMMA $(5 \mu \mathrm{mol} / \mathrm{kg})<1,1$-dimethylguanidine (13 


\section{CHAPTER 5}

$\mu \mathrm{mol} / \mathrm{kg})<N, N^{\prime}$-diaminoguanidine $(38 \mu \mathrm{mol} / \mathrm{kg})<$ methylguanidine $(50 \mu \mathrm{mol} / \mathrm{kg})<$ aminoguanidine $(80 \mu \mathrm{mol} / \mathrm{kg})$. The maximum increase in arterial blood pressure produced by four of the five compounds (L-NMMA, aminoguanidine, methylguanidine, and $N, N^{\prime}$-diaminoguanidine) was $\sim 15 \mathrm{~mm} \mathrm{Hg}$; this required $25 \mu \mathrm{mol}$ of L-NMMA, $\sim 100 \mu \mathrm{mol}$ of $N, N^{\prime}$-diaminoguanidine and aminoguanidine, and $>800$ $\mu \mathrm{mol}$ of methylguanidine. Bolus injections of the higher doses of 1,l-dimethylguanidine produced rapid increases in blood pressure $(>30 \mathrm{~mm} \mathrm{Hg}$ increase in pressure above baseline at the highest dose used).

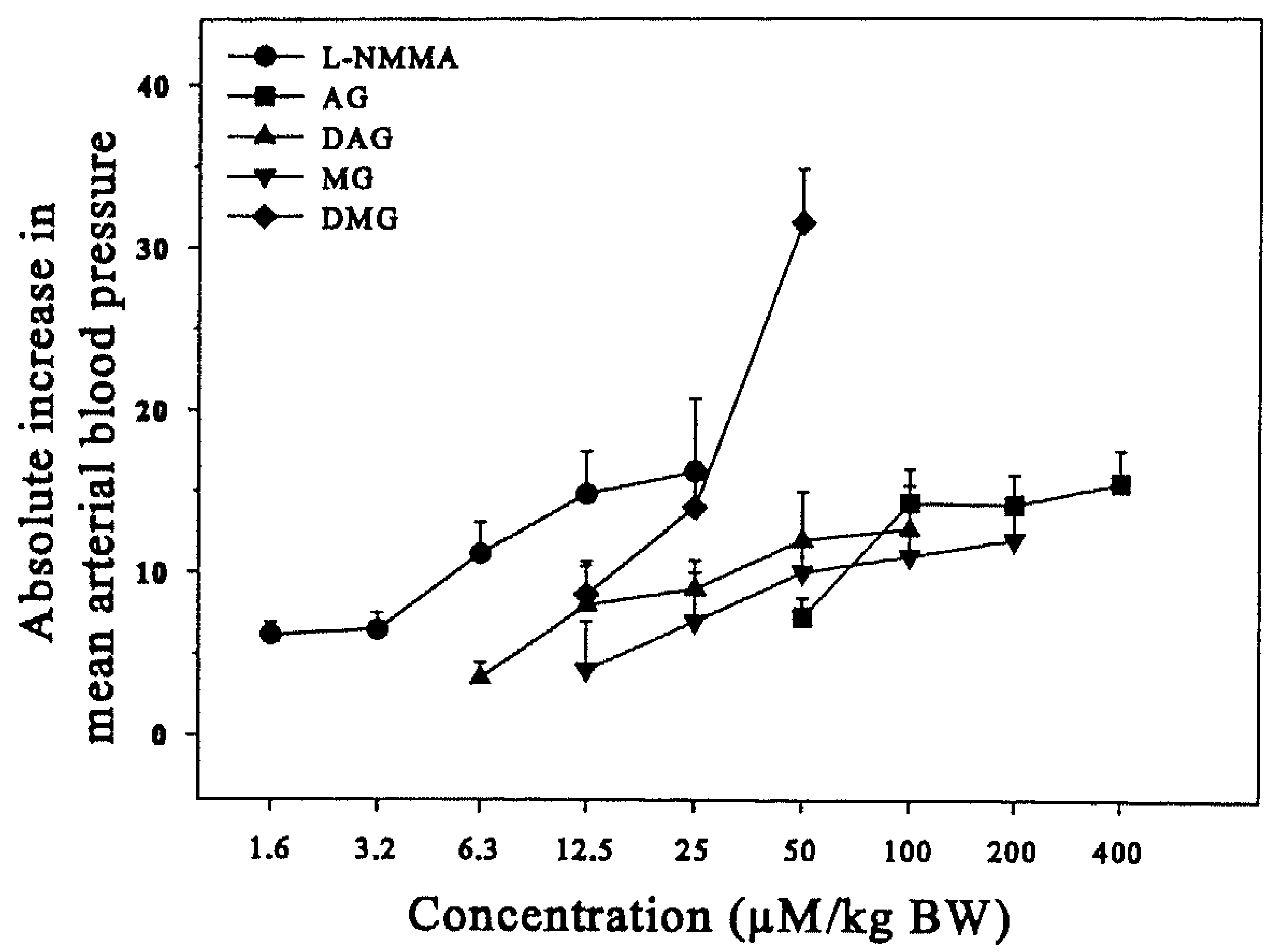

Figure 3. Mean arterial blood pressure changes following intravenous bolus injection of increasing amounts of L-NMMA, aminoguanidine, diaminoguanidine, methylguanidine in anesthetized, male Sprague-Dawley rats. Results are mean \pm SEM.

\section{DISCUSSION}

These observations demonstrate that aminoguanidine is equally as effective as LNMMA in blocking NO formation by the inducible isoform of NO synthase, yet is much less effective than L-NMMA as an inhibitor of the constitutive isoform. The dose of aminoguanidine required to produce an increase in mean arterial blood pressure comparable to L-NMMA is 16 times (in this study) to 40 times ${ }^{[13]}$ greater, and furthermore, no contraction was observed in the isolated mesenteric artery over the entire dose-response curve for aminoguanidine. On the other hand, L-NMMA increased contraction in isolated mesenteric arteries at all doses evaluated. Differences in cellular uptake by L-NMMA and aminoguanidine would not appear to explain these differences in potency for inhibiting constitutive NO synthase since (1) time-to-peak pressure following intravenous bolus injection $(2-5 \mathrm{~min})$ was similar for both 


\section{INHIBITION OF NITRIC OXIDE FORMATION BY GUANIDINES}

aminoguanidine and L-NMMA, and (2) 10 min equilibration periods, used for assessing contractile responses in the isolated mesenteric arteries, were sufficient to produce maximal responses.

The hydrazine moiety of aminoguanidine may confer selectivity for the inducible isoform of nitric oxide synthase since replacement with methyl groups (methylguanidine and 1,1-dimethylguanidine) results in loss of selectivity and reduced potency. Methylguanidine was the least effective inhibitor of the inducible isoform ( 100 times less potent than L-NMMA and aminoguanidine) and also was a relatively poor inhibitor of NO produced by constitutive NO synthase. 1,1-Dimethylguanidine was 10 times less potent than L-NMMA and aminoguanidine as an inhibitor of the inducible isoform of NO synthase, but its effect on the constitutive enzyme was similar to L-NMMA in the isolated mesenteric artery preparation and it caused a rapid rise in blood pressure in vivo at doses greater than $25 \mu \mathrm{mol} / \mathrm{kg}$ body weight. The elevation in blood pressure induced by 1,1-dimethylguanidine is not abolished with $\alpha$-adrenergic blockade ${ }^{[20]}$; unpublished observations). It is noteworthy that methylguanidine is an endogenous metabolite and its levels are known to increase in uremic patients ${ }^{[21,22]}$. While $N, N^{\prime}$-diaminoguanidine was 25-35 times less effective as an inhibitor of the inducible isoform than L-NMMA ${ }^{[13]}$ and aminoguanidine, it was even less effective as an inhibitor of the constitutive isoform. The dose-response curves for aminoguanidine and $N, N^{\prime}$-diaminoguanidine did not differ in isolated mesenteric arteries, and at the highest dose used, $N, N^{\prime}$-diaminoguanidine produced an $\sim 10 \%$ decrease in contraction below baseline. While the significance of this small change in relaxation is unknown, the contractile state of mesenteric vessels precontracted with $30 \mathrm{mM} \mathrm{K}^{+}$remains very stable over time and these differences are probably real. The slight differences in potencies of aminoguanidine and $N, N^{\prime}$-diaminoguanidine may be due to specific differences in uptake and metabolism by endothelial cells or to their interaction with the L-arginine transporter ${ }^{[23,24]}$. However, these results indicate that these two compounds are the most selective inhibitors of the inducible isoform of NO synthase examined in this study. Our results are consistent with older reports that guanidine compounds, including methylguanidine and dimethylguanidine, increase blood pressure following intravenous injection ${ }^{[20,25,26]}$. Since guanidine compounds demonstrate tachyphylaxis, i.e., an impaired pressor response to subsequent injections of the same dose of guanidine compound ${ }^{[25]}$, the pressure increases reported in figure 3 for the higher guanidine doses may be lower than the pressor response following a single injection of the same dose. The maximum increase in blood pressure for LNMMA is lower in this study than previously reported by Rees et al. ${ }^{[27]}$. These findings may represent methodological differences since, in the latter study, a different strain of rat was used, the animals were preinjected with a large dose of indomethacin, then exposed to a phenylephrine infusion during generation of the dose-response curve. While we do not know at this time whether these guanidine compounds are competitive, noncompetitive, or irreversible inhibitors of NO synthase, it is noteworthy that an excess of L-arginine given prior to the bolus intravenous injection of aminoguanidine will blunt the arterial pressure rise, and if given after the guanidine compound has produced a maximum pressure rise, will rapidly return mean arterial blood pressure to baseline (unpublished observations). The data in figure 1 obtained 


\section{CHAPTER 5}

from whole cells indicate that guanidine compounds are transported into cells and inhibit, dose dependently, cytokine-induced nitrite formation. Similar results employing RINm5F cells have been obtained by measuring aminoguanidine and LNMMA inhibition of cGMP levels ${ }^{[13]}$. These results indicate that small molecules resembling the guanidino moiety of $\mathrm{L}$-arginine are an important group of modulators of NO synthesis and deserve further study.

\section{ACKNOWLEDGMENTS}

This study was made possible by support from the US National institutes of Health (grants DK06181, F32DK08748, EY06600, HL39934, and DK20579), from the Department of Endocrinology and Metabolism (University Hospital Maastricht, Netherlands) and from the Kilo Diabetes and Vascular Research Foundation (St. Louis, MO, USA)

\section{REFERENCES}

1. Bredt DS, Snyder SH. Isolation of nitric oxide synthase, a calmodulin-requiring enzyme. Proc Natl Acad Sci U S A 1990;87:682-685. 2. Moncada S, Palmer RMJ, Higgs EA. Nitric oxide: physiology, pathophysiology, and
pharmacology. Pharm Rev 1991;43:109-141.

3. Pollock JS, Fostermann U, Mitchell JA, Warner TD, Schmidt HHHW, Nakanc M, Murad F, Purification and characterization of particulate endothelium-derived relaxing factor synthase from cultured and native bovine endothelial cells. Proc Natl Acad Sci U S A 1991;88:10480-
10484 .

4. Hibbs JB, Taintor RR, Vavrin Z, Granger DL, Drapier JC, Amber IJ, Lancaster J. Synthesis of nitric oxide from a terminal guanidino nitrogen atom of L-arginine: a molecular mechansim regulating cellular proliferation that targets intra-cellular iron in. New York: Elsevier, 1990.

5. Rosa MD, Radomski M, Carnuccio R, Moncada S. Glucocorticoids inhibit the induction of nitric oxide synthase in macrophages. Biochemical \& Biophysical Rescarch Communications
$1990 ; 172: 1246-1253$.

6. Stuer DJ, Cho HJ, Kwon NS, Weise MF, Nathan CF. Purification and characterization of flavoprotein flavoprotein. Proc Natl Acad Sci U S A 1991;88:7773-7778.

7. Kilbourn R, Jubran A, Gross SS, Griffith OW, Levi R, Adams J, Lodato RF. Reversal of endotoxin-mediated shock by Ng-Methyl-L-arginine, an inhibitor of nitric oxide synthase.
Biochemical \& Biophysical Research Communications 1990;172:1132-1137.

8. Mulligan $M$, Hevel J, Marletta M, Ward P. The effects of methylguanidine upon the blood pressure of adrenalectomized dogs-arginine dependent. Proc Natl Acad Sci U S A
1991;888:6338-6341.

9. Lin RF, Lin TS, Tilton RG, Cross AH. Nitric oxide localized to spinal cords of mice with 1993; 178:643-648. 


\section{INHIBITION OF NITRIC OXIDE FORMATION BY GUANIDINES}

10. Corbett JA, Lancaster JR, Sweetland MA, McDaniel ML. Interleukin-1B-induced formation of EPR-detectable iron-nitrosyl complexes in islets of Langerhans. J Biol Chem 1991;266:21351 21358.

11. Kroncke KD, Kolk-BAchofen V, Bershick B, Burkart V, Kolb H. Activated macrophages kill pancreatic syngeneic islet cells via arginine-dependent nitric oxide generation. Biochemical \& Biophysical Research Communications 1991;175:752-757.

12. Lukic ML, Stosic-Grujicic S, Ostojic N, Chan WL, Liew FY. Inhibition of nitric oxide generation affects the induction of diabetes by streptozotocin in mice. Biochemical \& Biophysical Research Communications 1991;178:913-916.

13. Corbett JA, Tilton RG, Chang K, Hasan KS, Ido Y, Wang JL, Sweetland MA, Lancaster JR, Williamson JR, McDaniel ML. Aminoguanidine, a novel inhibitor of nitric oxide formation, prevents diabetic vascular dysfunction. Diabetes 1992;41:552-556.

14. Green LC, Wanger DA, Glogowski J, Skipper PL, Wishnok JS, Tannenbaum SR. Analysis of nitrate, nitrite and [15N]nitrate in biological fluids. Anal Biochem 1982;126:131-135.

15. Baydon AR, Emery PW, Pearson JD, Mann GE. Substrate-dependent regulation of intraceilular amino acid concentrations in cultured bovine aortic endothelial cells. Biochemical \& Biophysical Research Communications 1990;173:940-944.

16. Heinzel B, John M, Klatt P, Pohme E, Mayer B. Ca2+ / calmodulin-dependent formation of hydrogen peroxide by brain nitric oxide synthase. Biochem J 1992;281:627-632.

17. De Mey JG, Defreyn G, Lenars A, Calderon P, Roba J. Arterial reactivity, blood pressure, and plasma levels of artrial natriureticmpeptides in normotensive and hypertensive rats: effects of acute and chronic administration of atriopeptin III. J Cardiovasc Pharmacol 1986;9:525-535.

18. Heesen BJ, De Mey JG. Effects of cyclic AMP-affecting agents on contractile reactivity of isolated mesenteric and renal resistance arteries of the rat. Br J Pharmac 1990;101:859-864.

19. Anderson TW. An introduction to multivariate statistical analysis. New York: Wiley, 1958.

20. Ozawa H, Sugawara K. structure-activity relationship of alkylguanidines on smooth muscle organs. Chem Pharm Bull 1986;16:2376-2380.

21. Giovannetti S, Balestri PL, Barsotti G. Methylguanidine in uremia. Arch Intern Med 1973;131:709-714

22. Orita Y, Ando A, Tsubakihara Y, Mikami H, Kikuchi T, Nakata K, Abe H. Tissue and blood cell concentration of methylguanidine in rats and patients with chronic renal failure. Nephron $1981 ; 27: 35-38$

23. Tilton GR, Williamson JR. Glucose-induced metabolic imbalances in the pathogenesis of diabetic vascular disease. Diabetes/Metab Rev 1991;7:35-59.

24. Vlassara H, Brownlee $M$, Cerami A. Specific macrophage receptor activity for advanced glycosylation end products inversely correlates with insulin levels in vivo. Diabetes $1988 ; 37: 456-461$.

25. Fastier FN, Smirk FH. Circulatory properties of isothoiureas, guanidines, iso-ureas and amidines. J Pharmacol 1947;89:256-260.

26. Major RH, Weber CJ. The effects of methylguanidine upon the blood pressure of adrenalectomized dogs. J Pharmacol Exp Ther 1929;35:351-355. 


\section{CHAPTER 5}

27. Rees DD, Palmer RMJ, Schultz R, Hodson HF, Moncada S. Characterization of three inhibitors of endothelial NO synthase in vitro and in vivo. Br J Pharmac 1990;101:746-752. 


\section{Effects of guanidine compounds or insulin treatment on responses to vasoactive agents in aortic rings of streptozotocin-induced diabetic rats}

B.J. Heesen, J.G.R. De Mey, J.R. Williamson and B.H.R. Wolffenbuttel Cardiovascular Research Institute Maastricht (CARIM),

Depts. of Internal Medicine and Pharmacology, University of Limburg, Maastricht (NL), and Dept. of Pathology, Washington University, St. Louis (USA) 


\section{SUMMARY}

The objective of the present study was to assess the effect of long term treatment with aminoguanidine, methylguanidine, and insulin on the reactivity of isolated aortas obtained from non-diabetic and diabetic animals. Aortic rings from these animals were isolated and mounted between an isometric force transducer and a displacement device in a $10 \mathrm{ml}$ organ bath containing Krebs buffer. Maximum PHE-induced contraction was reduced by $24 \%$ in untreated diabetic animals. This impairment was prevented by treatment of the animal with aminoguanidine, methylguanidine, and insulin. Maximum relaxation to acetylcholine was enhanced in diabetic animals vs non-diabetic controls. Aminoguanidine and insulin, but not methylguanidine, prevented the enhanced relaxation. Relaxation induced by SNP was enhanced in diabetes and was unaffected by aminoguanidine or methylguanidine. Insulin however prevented this enhanced relaxation. We conclude that guanidine compounds in part and insulin treatment in total prevent the development of vascular disturbances as observed in isolated aortic rings obtained from rats with experimental diabetes. 


\section{DIABETES TREATMENT WITH GUANIDINES OR INSULIN}

\section{INTRODUCTION}

Advanced products of nonenzymatic glycosylation are thought to play a critical role in the evolution of diabetic complications because of their characteristic chemical properties. These slowly-formed glucose-derived compounds are chemically irreversible, and thus accumulate over time. The degree of this accumulation in patients' dermal collagen has been shown to correlate with the severity of diabetic retinopathy present ${ }^{[1]}$. These products participate in glucose-derived crosslink formation ${ }^{[2]}$, and may thereby alter the structure and function of the vascular wall.

The role for nonenzymatic glycation in the pathogenesis of diabetic complications has drawn support from evidence that aminoguanidine, a nucleophilic hydrazine compound, interferes with advanced glycosylation end products (AGE) formation ${ }^{33}$ and prevents or significantly ameliorates; 1 ) diabetes-induced collagen cross-linking ${ }^{[4]}$; 2) glucose-induced vascular dysfunction in skin chamber granulation tissue ${ }^{[5]}$; and 3) diabetes-induced vascular dysfunction in retina, peripheral nerve, aorta, carotid artery ${ }^{[6]}$, and kidney ${ }^{[7,8]}$. Vlassara and her group demonstrated that injection of glycated rat or rabbit serum albumin induces similar complications in control rats and rabbits as seen in diabetic animals ${ }^{[9]}$. The recent demonstration that aminoguanidine inhibits NO-synthase activity ${ }^{[5,10]}$ raises the possibility that some of the diabetes-induced functional and structural changes referred to above may reflect a relative or absolute increase in nitric oxide formation in addition to increased AGE formation. Because inhibition of AGE formation by aminoguanidine is attributed to an interaction between the reactive hydrazine moiety of aminoguanidine and carbonyl groups of Amadori or glycosylation products ${ }^{[11]}$, methylguanidine (which lacks the hydrazine of aminoguanidine; figure 1) should be much less effective as an inhibitor of AGE formation than aminoguanidine.

A<smiles>N=C(N)NN</smiles>

aminoguanidine
B<smiles>CNC(N)N</smiles>

methylguanidine
$\mathrm{C}$<smiles>CNC(=N)NCCCCC(N)=O</smiles>

$\mathrm{N}^{G}$ - monomethyl-L-arginine

Figure 1. Structures of 3 inhibitors of NO synthase: aminoguanidine $(A)$, methylguanidine $(B)$, and I-NNMA (C).

In diabetes altered vascular responses to vasoactive agents, such as phenylephrine and acetylcholine have been linked to disturbed endothelial function, increased endogenous production of free radicals, and increased formation of AGE's. The superoxides which are generated by the formation of AGE's are believed to quench nitric oxide, the endothelium derived relaxing factor. Nitric oxide is released at a basal level or after stimulation of the endothelium with agents like acetylcholine. It activates the soluble guanylate cyclase in the smooth muscle cells, which produces cyclic GMP, 


\section{CHAPTER 6}

a vasodilator. Several studies have shown a changed response to acetylcholine in diabetes (see chapter 3 and 4 ).

The objective of the present study was to assess the effect of treatment with guanidine compounds on the reactivity of isolated aortas from diabetic animals. Aminoguanidine was evaluated because of its effects as an inhibitor of the AGE formation, as well as of the nitric oxide synthase. Methylguanidine was included because of its selective inhibition of nitric oxide synthase ${ }^{[10,12]}$. We furthermore used insulin to obtain a normoglycemic diabetic control group.

\section{RESEARCH DESIGN AND METHODS}

Diabetes was induced in six week old male Sprague-Dawley rats (Sasco, O' Fallon, MO, USA) by an intravenous injection of $65 \mathrm{mg} / \mathrm{kg}$ streptozotocin. All diabetic and non-diabetic animals were housed and cared for in accordance with the guidelines of the University Committee for the Human Care of Laboratory Animals, and NIHguidelines on laboratory animal welfare. Rats were housed individually, fed standard rat chow (Ralston Purina, Richmond, In, USA), water ad libitum, and were on a 12 hour light/dark cycle.

Part of the non-diabetic and diabetic rats were continuously treated with different experimental drugs. Aminoguanidine hemisulfate and methylguanidine hydrochloride were administered subcutaneously once daily at a dose of $50 \mathrm{mg} / \mathrm{kg}$ body weight; nondiabetic rats also were given water containing $2 \mathrm{~g} / \mathrm{l}$ of one of these drugs, whereas diabetic rats were given water containing $1 \mathrm{~g} / \mathrm{l}$, because the water intake in diabetic animals is approximately two times higher. Insulin (Lilly Ultralente 1, 100 units/ml) was diluted 1 to $10 \mathrm{in} 10 \mathrm{ml}$ saline and given by a one daily subcutaneous injection (1 unit / $100 \mathrm{~g}$ body weight).

On the day of the experiments, performed at the age of 12 weeks (diabetes duration 6 weeks), the animals were anaesthetized by intraperitoneal injection of pentobarbital $(45 \mathrm{mg} / \mathrm{kg})$, and a blood sample of $5 \mathrm{ml}$ was drawn by puncture of the abdominal aorta. The thoracic aorta was removed, trimmed free of adventitial connective tissue and cut into small rings ( $1.6 \mathrm{~mm}$ in length). Special care was taken to avoid damage to the endothelial layer. Two stainless-steel wires (diameter $40 \mu \mathrm{m}$ ) were inserted into the lumen of the aorta, which was then mounted horizontally in an organ chamber (JP Trading, Aarhus, Denmark, volume $10 \mathrm{ml}$ ) between an isometric force transducer (Kistler Morse DSC6, Seattle WA, USA) and a displacement device (Mitatoyo, Tokyo, Japan). The organ chamber was filled with a modified Krebs-Ringer bicarbonate solution (KRB, composition in $\mathrm{mM}: \mathrm{NaCl} 118.3, \mathrm{KCl} 4.7, \mathrm{MgSO}_{4} 1.2, \mathrm{CaCl}_{2} 2.5$, $\mathrm{KH}_{2} \mathrm{PO}_{4} 1.2, \mathrm{NaHCO}_{3} 25.0$, Ca-EDTA 0.026 and glucose 5.0 or 30.0) maintained at $37^{\circ} \mathrm{C}$ and pH 7.4 and continuously aerated with $95 \% \mathrm{O}_{2}$ and $5 \% \mathrm{CO}_{2}$.

Before assessment of pharmacological responses, the aorta was stretched to an optimal lumen diameter for mechanical performance. The diameter was therefore initially set at $1.34 \mathrm{~mm}$ and increased by $0.22 \mathrm{~mm}$ increments. The preparations were exposed intermittently to Krebs-Ringer buffer in which all $\mathrm{NaCl}$ was replaced by an equimolar amount of $\mathrm{KCl}{ }^{[13,14]}$. This procedure was continued until a maximal 


\section{DIABETES TREATMENT WITH GUANIDINES OR INSULIN}

contractile response to potassium was obtained. Subsequent experiments were performed at this optimal diameter. During this procedure, aortas from control and diabetic animals which were treated with insulin were kept in buffer containing $5 \mathrm{mM}$ glucose; aortas from diabetic animals were kept in buffer containing $30 \mathrm{mM}$ glucose. The reasons for this are described in chapter 3. Acetylcholine- and sodium nitroprusside-induced relaxations were assessed in arteries pre-contracted by $0.1 \mu \mathrm{M}$ Phenylephrine to $55 \%$ of maximal contractile tension.

Drugs

Aminoguanidine (hemisulfate) and methylguanidine (hydrochloride) phenylephrine (hydrochloride), sodium nitroprusside and acetylcholine were purchased from Sigma Chemicals (St. Louis, MO, USA). Streptozotocin was purchased from Upjohn Co. (Kalamazoo, MI, USA), and pentobarbital from Fort Dodge Laboratories (Iowa, USA).

Stock concentrations of phenylephrine, sodium nitroprusside and acetylcholine were prepared freshly every day in distilled deionized water and $10 \mu \mathrm{l}$ aliquots were added to the organ bath to generate the dose-response curves. All drug concentrations are expressed as the negative log of the final molar concentration in the organ bath.

Blood glucose in the animals was measured with a hexokinase method (Sigma Chemicals, St. Louis, MO, USA).

\section{Calculations and statistics}

Contractile responses are expressed as increases in wall tension (increase in force $/ 2 \mathrm{x}$ length of arterial segment). Effects of relaxing agents are expressed as \% remaining tension versus initial (55\% of maximum) contractile tension. EC-50 values were calculated using GraphPad Inplot (GraphPad Software Inc., San Diego, Ca, USA). Differences between groups were tested by ANOVA with Student-Newman-Keuls correction for multiple comparisons, using the SPSS for Windows version 6.0 software (SPSS Inc, Chicago, Il, USA). The number of animals which were used in the experiments are listed in table 1. Data in tables and text are shown as means $\pm \mathrm{SD}$, and in figures means \pm SEM, unless stated otherwise. $P$ values $<0.05$ were considered statistically significant.

\section{RESULTS}

Data of blood glucose levels and body weight in the different groups of animals are given in table 1 . None of the diabetic animals treated with one of the guanidine compounds received insulin. The optimal internal diameter of aorta, which was set to be the internal diameter at which the most powerful contraction to depolarization with $125 \mathrm{mM}$ potassium was observed (see methods) did not differ significantly between the various groups $(2.56 \pm 0.24 \mathrm{~mm})$.

\section{Phenylephrine-induced contraction}

The maximal Phenylephrine-induced contractile force was $7.6 \pm 1.1 \mathrm{mN} / \mathrm{mm}$ in aortas obtained from non-diabetic animals. The phenylephrine-induced contractile force was 


\section{CHAPTER 6}

decreased by $24 \%$ in 6 week diabetic aortas compared to control aortas (table 2). Phenylephrine-induced contractile force in diabetic animals treated with aminoguanidine, methylguanidine or insulin was maintained at the level of nondiabetic control animals (see table 2). Aortas from non-diabetic animals treated with the two guanidine compounds achieved similar contractile force. Sensitivity to phenylephrine did not differ between the groups: the $\mathrm{pD}_{2}$ was $7.1 \pm 0.3$ for all groups. (see table 2).

Table 1. Internal diameter of aorta (ID), maximum response to $K C l$ (E-max), blood glucose (BG), body weight $(B W)$, in non-diabetic and diabetic animals treated with aminoguanidine $(A G)$, methylguanidine $(M G)$, or insulin.

\begin{tabular}{l|c|c|c|c|c|c} 
& $\mathrm{n}$ & Treatment & $\begin{array}{c}\mathrm{ID} \\
(\mathrm{mm})\end{array}$ & $\begin{array}{c}\mathrm{E}-\mathrm{max} \\
(\mathrm{mNN} / \mathrm{mm})\end{array}$ & $\begin{array}{c}\mathrm{BG} \\
(\mathrm{mmol} / \mathrm{l})\end{array}$ & $\begin{array}{c}\mathrm{BW} \\
(\mathrm{gram})\end{array}$ \\
\hline control & 10 & $-\cdots$ & $2.6 \pm 0.2$ & $7.4 \pm 1.8$ & $6.9 \pm 1.2$ & $379 \pm 46$ \\
\hline control & 5 & $\mathrm{AG}$ & $2.5 \pm 0.1$ & $6.9 \pm 1.6$ & $7.0 \pm 1.3$ & $377 \pm 52$ \\
\hline control & 5 & $\mathrm{MG}$ & $2.5 \pm 0.2$ & $6.8 \pm 1.7$ & $7.1 \pm 1.1$ & $387 \pm 41$ \\
\hline diabetic & 14 & -- & $2.5 \pm 0.1$ & $5.9 \pm 1.6^{\mathrm{b}}$ & $31.0 \pm 5.0^{\mathrm{a}}$ & $276 \pm 55^{\mathrm{n}}$ \\
\hline diabetic & 6 & Insulin & $2.6 \pm 0.2$ & $7.1 \pm 1.6$ & $4.9 \pm 1.5^{\circ}$ & $391 \pm 30$ \\
\hline diabetic & 9 & $\mathrm{AG}$ & $2.4 \pm 0.2$ & $6.9 \pm 1.4$ & $29.9 \pm 6.5^{\mathrm{n}}$ & $282 \pm 35^{\mathrm{n}}$ \\
\hline diabetic & 6 & $\mathrm{MG}$ & $2.5 \pm 0.1$ & $6.8 \pm 1.6$ & $28.7 \pm 5.4^{\mathrm{n}}$ & $293 \pm 6^{\mathrm{n}}$
\end{tabular}

${ }^{a} \mathrm{p}<0.05$ vs control and diabetic treated with insulin

${ }^{b} \mathrm{p}<0.05$ vs untreated control

\section{PHENYLEPHRINE}

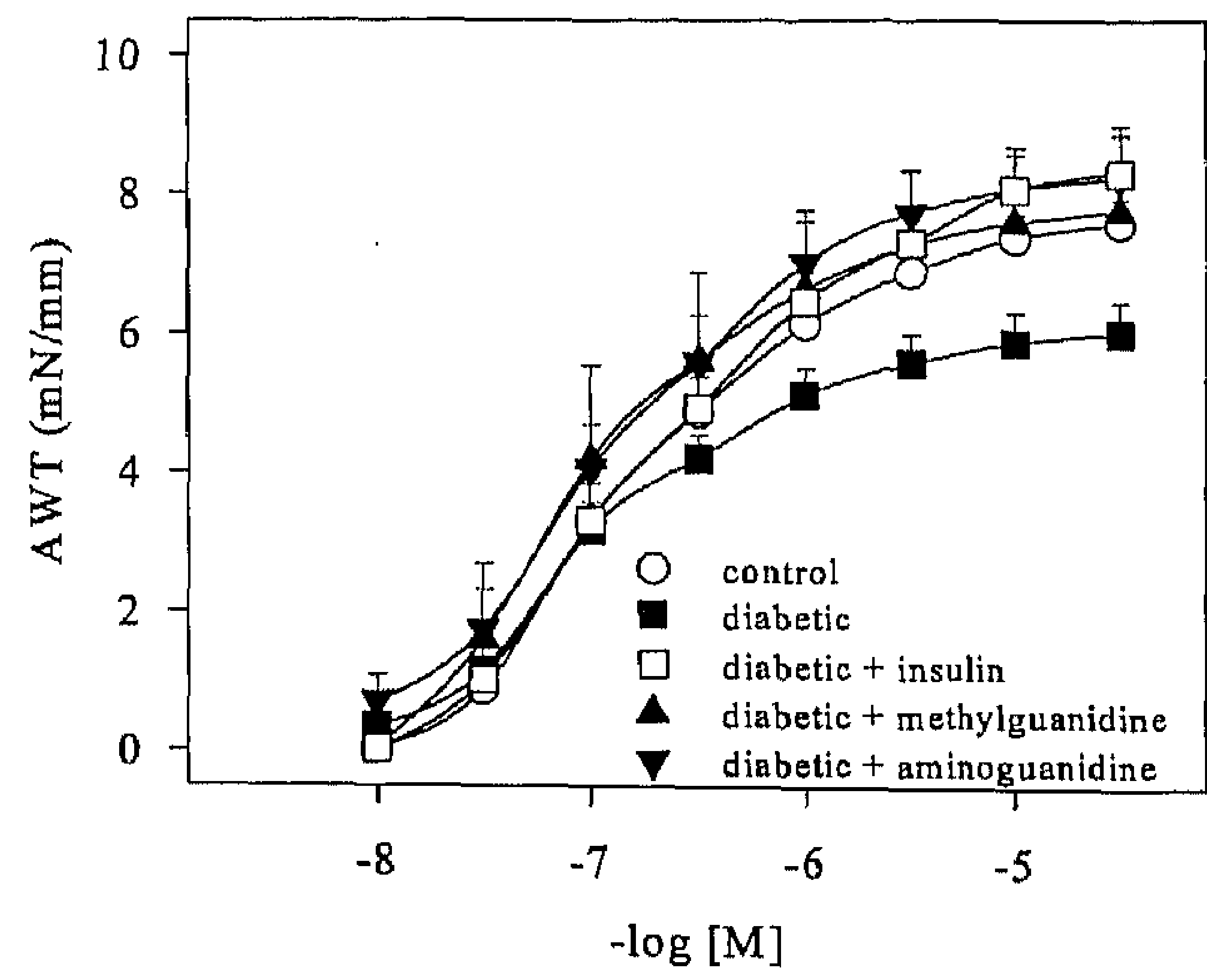

Figure 2. Phenylephrine induced contraction in aorta from diabetic and non-diabetic animals untreated or treated with insulin, methylguanide or aminoguanidine. 


\section{DIABETES TREATMENT WITH GUANIDINES OR INSULIN}

\section{Acetylcholine-induced relaxation}

In aortas precontracted with $0.1 \mu \mathrm{M}$ Phenylephrine, a concentration-dependent relaxing response to acetylcholine was observed. There was a significant difference in relaxation between control and diabetic aortas; residual contractile tensions at $100 \mu \mathrm{M}$ acetylcholine were $30 \pm 6 \%$ and $13 \pm 6 \%$, respectively. Relaxation of diabetic aortas was restored to control levels after treatment of the rats with aminoguanidine or insulin (see figure 3 and table 2 for remaining contraction). However, treatment with methylguanidine did not restore relaxation to control levels.

\section{Sodium nitroprusside-induced relaxation}

In aortas precontracted with $0.1 \mu \mathrm{M}$ phenylephrine, a concentration-dependent relaxing response to sodium nitroprusside was observed. Sensitivity to sodium nitroprusside was greater in diabetic aortas compared to non-diabetic aortas. Normalizing the blood glucose by treating the animals with insulin did prevent this enhanced relaxative response. Whereas relaxation of aortas from animals which were treated with aminoguanidine or methylguanidine did not differ from untreated diabetic aorta's (see figure and table 2 for EC-50 values).

Table 2. Maximum force development to phenylephrine, remaining contractile force to acetylcholine, and $\mathrm{pD}_{2}$. for response to sodium nitroprusside in aortas.

\begin{tabular}{l|c|c|c|c} 
& Treatment & $\begin{array}{c}\text { Phenylephrine } \\
\mathrm{mN} / \mathrm{mm}\end{array}$ & Acetylcholine \% & $\begin{array}{c}\text { Nitroprusside } \\
\text { log }\end{array}$ \\
\hline Control &.-- & $7.6 \pm 1.1$ & $30 \pm 6$ & $\begin{array}{c}7.3 \\
\left(7.4^{-7.2)}\right.\end{array}$ \\
\hline Control & AG & $8.0 \pm 1.3$ & $33 \pm 7$ & $\begin{array}{c}7.2 \\
(7.4-7.1)\end{array}$ \\
\hline Control & MG & $7.8 \pm 1.5$ & $31 \pm 8$ & $\begin{array}{c}7.3 \\
(7.4-7.1)\end{array}$ \\
\hline Diabetic & $\cdots--$ & $5.8 \pm 1.7^{\circ}$ & $13 \pm 6^{\circ}$ & $\begin{array}{c}7.6^{\mathrm{d}} \\
(7.7-7.4)\end{array}$ \\
\hline Diabetic & Insulin & $8.7 \pm 1.5$ & $32 \pm 11$ & $\begin{array}{c}7.3 \\
(7.4-7.2)\end{array}$ \\
\hline Diabetic & AG & $7.8 \pm 2.6$ & $7 \pm 4^{\circ}$ & $\begin{array}{c}7.9^{\mathrm{d}} \\
\left(8.0^{\circ} 7.6\right)\end{array}$ \\
\hline Diabetic & MG & $8.2 \pm 1.9$ & $35 \pm 8$ & $\begin{array}{c}7.7^{\mathrm{d}} \\
\left(7.9^{\circ} 7.5\right)\end{array}$
\end{tabular}

${ }^{\mathrm{a}} \mathrm{p}<0.05$ untreated diabetic vs all other groups.

${ }^{b} p<0.05$ untreated diabetic vs all other groups except diabetic treated with MG.

${ }^{c} \mathrm{p}<0.05$ diabetic treated with $M G$ vs all other groups except untreated diabetic.

${ }^{d} p<0.05$ diabetic, untreated or treated with $A G$ or MG vs all other groups. 


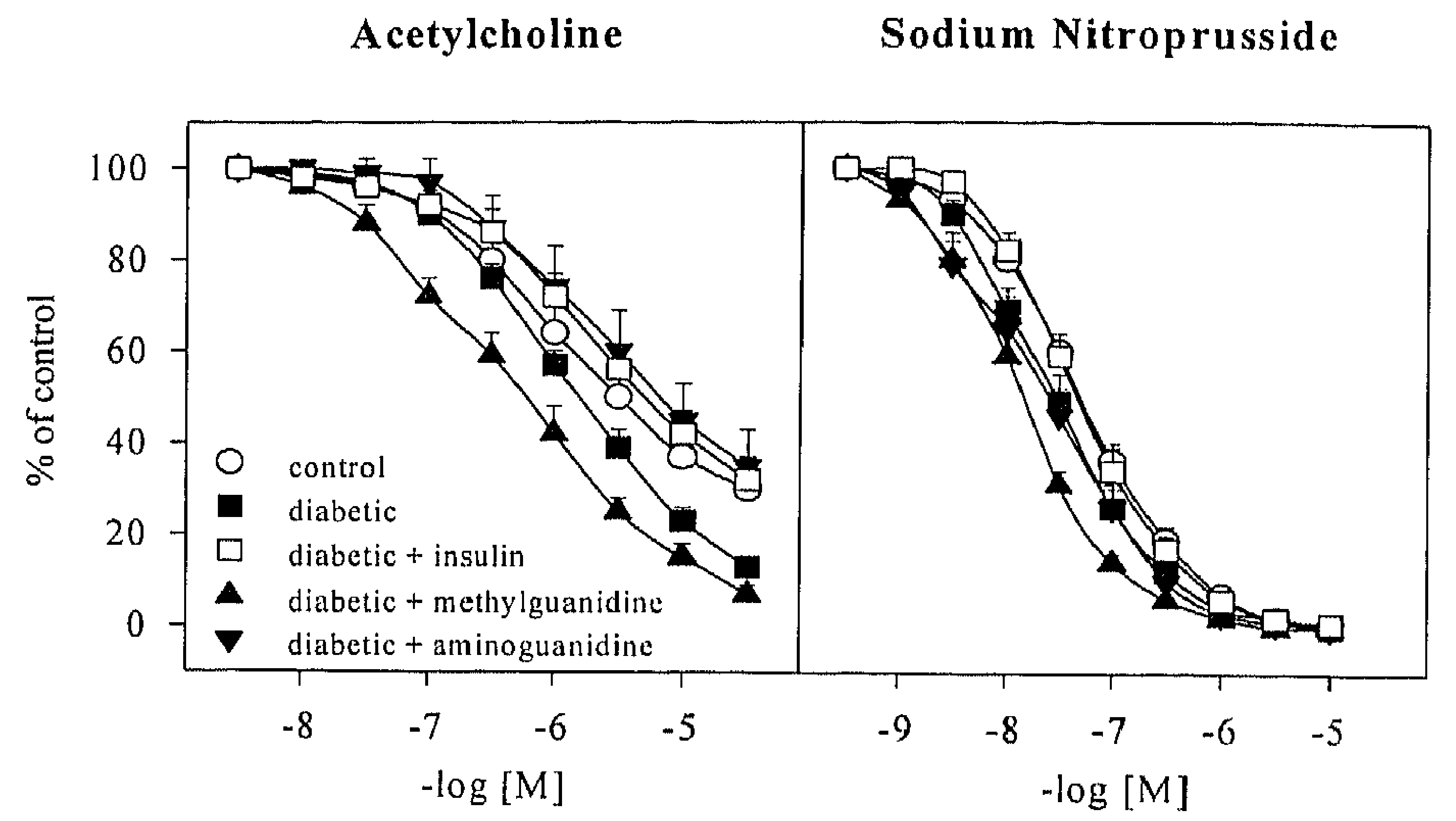

Figure 3. Acetylcholine and sodium nitroprusside induced relaxation in arrtas from diabetic and non-diabetic animals untreated and treated with insulin, methylguanidine or aminoguanidine

\section{DISCUSSION}

Impaired force development in response to phenylephrine, as presently observed in the isolated aortic rings from rats with experimental diabetes, is in agreement with observations of Pfaffman et al ${ }^{[15]}$, but contrasts with reports by others ${ }^{[16,17]}$. These observed differences can not be explained by differences in diabeles duration or methods employed. The impaired maximum contraction in diabetic rats was restored by treatment with methylguanidine, aminoguanidine or insulin. This suggests that the correction is not solely due to the inhibition of advanced glycosylation end producls formation, because the methylguanidine treatment also prevents this impaired contractile response. It is possible that this correction is due to chronic inhibition of the basal production of nitric oxide. Although one would expect a higher contractile force in control animals treated with aminoguanidine or methylguanidine, this however was not observed.

The enhanced relaxing response to acetylcholine which we found in diabetic aortas is in contradiction with the impairment of acetylcholine-induced blood pressure response which was found in vivo by Bucala et al ${ }^{[18]}$. He postulated that this could be the result of quenching of EDRF (nitric oxide) by advanced glycosylation end products. Different groups demonstrated that the impairment in endothelial function found in vitro was due to an increase in the quenching of nitric oxide by oxygen derived free radicals ${ }^{[19-21]}$. They suggested that the quenching of nitric oxide by free radicals, which can be formed by advanced glycosylation end products, leads to an upregulation of nitric oxide production, which acts to compensate for the quenching by the free radicals. That less nitric oxide is capable to reach the smooth muscle, may also lead to an upregulation of the normal target of nitric oxide, guanylate cyclase. The 


\section{DIABETES TREATMENT WITH GUANIDINES OR INSULIN}

consequent higher sensitivity to sodium nitroprusside, which acts as a direct nitric oxide donor, was indeed found by us.

One of the effects of aminoguanidine as an inhibitor of the formation of advanced glycosylation end products is to prevent the changed reactivity of the aorta to acetylcholine. Aminoguanidine showed indeed this beneficial effect, but failed to normalize the sensitivity to sodium nitroprusside. This could result from chronic treatment with aminoguanidine in vivo leading to inhibition of nitric oxide synthase ${ }^{[10,22]}$ which then leads to an upregulation of the soluble guanylate cyclase. In this case methylguanidine should have only an effect on the sensitivity to sodium nitroprusside, because it does not inhibit the formation of advanced glycosylation end products ${ }^{[12]}$. To be really sure we should perform an experiment with a drug which only effect is inhibition of the formation of advanced glycosylation end products. Such drugs have thus far not been available.

Normalizing the blood glucose by treating the animal with one daily injection of insulin does prevent all the changes seen in this model of experimental diabetes. This confirms previous clinical observations that correcting the blood glucose in diabetes should have the highest priority.

We conclude that guanidine compounds have a partial beneficial effect on the development of vascular disturbances as observed in isolated aortic rings obtained from rats with experimental diabetes. The different effects of aminoguanidine and methylguanidine on acetylcholine-induced relaxation are most likely due to the prevention of AGE-formation, but could also be due to more effective inhibition of nitric oxide synthase by aminoguanidine. However, from this and other studies we may conclude that the guanidine compounds and their analogues could very well have a place, beside insulin treatment, as a therapeutic agents to help prevent the macrovascular complications as seen in diabetic patients.

\section{REFERENCES}

1. Monnier VM, Vishwanath V, Frank KE, Elmets GA, Dauchot P, Kohn RR. Relation between complications of type 1 diabetes mellitus and collagen-linked fluorescence. $\mathrm{N}$ Engl J Med 1986;314:403-408.

2. Monnier VM, Kohn RR, Cerami A. Accelerated age-related browning of human collagen in diabetes mellitus. Medical Sciences 1984;81:583-587.

3. Brownlee $\mathrm{M}$, Vlassara $\mathrm{H}$, Kooney A, Ulrich $\mathrm{P}$, Cerami A. Aminoguanidine prevents diabetesinduced arterial wall protein cross-linking. Science 1986;232:1629-1632.

4. Brownlee $M$, Cerami $A$, Vlassara $H$. Advanced glycosylation end products in tissue and the biochemical basis of diabetic complications. N Engl J Med 1988;318:1315-1321.

5. Corbett JA, Tilton RG, Chang K, Hasan KS, Ido Y, Wang JL, Sweetland MA, Lancaster JR, Williamson JR, McDaniel ML. Aminoguanidine, a novel inhibitor of nitric oxide formation, prevents diabetic vascular dysfunction. Diabetes 1992;41:552-556.

6. Huijberts MSP, Wolffenbuttel BHR, Struyker Boudier HAJ, Crijns FRL, Nieuwenhuijzen Kruseman AC, Poitevin P, Levy BI. Aminoguanidine treatment increases elasticity and decreases fluid filtration of large arteries from diabetic rats. J Clin Invest 1993;92:1407-1411. 


\section{CHAPTER 6}

7. Wolffenbuttel BHR, Huijberts MSP. Aminoguanidine, a potential-drug for the treatment of diabetic complications. Neth J Med 1993;42:205-208.

8. Ido $\mathrm{Y}$, Chang $\mathrm{K}$, Ostrow $\mathrm{E}$, Allison W, Kilo C, Tilton R. Aminoguanidine prevents regional blood flow increases in streptozotocin-diabetic rats (abstract). Diabetes 1990;39(Suppl. 1):93A.

9. Vlassara H, Fuh H, Makita Z, Sudratana K, Cerami A, Bucala R. Exogenous advanced glycosylation end products induce complex vascular dysfunction in normal animals: a model for diabetic and aging complications. Proc Natl Acad Sci U S A 1992;89:12043-12047.

10. Hasan K, Heesen BJ, Corbett JA, McDaniel ML, Chang K, Allison W, Wolffenbuttel BHR, Williamson JR, Tilton RG. Inhibition of nitric-oxide formation by guanidines. Eur J Pharmacol 1993;249:101-106.

11. Yagihashi S, Kamijo M, Taniguchi N, Satoh K. Increased glycation of axonal cytoskeleton and preventive effect of aminoguanidine on development of experimental diabetic neuropathy. Diabetes 1991;40(Suppl. 1):302A.

12. Tilton RG, Chang K, Hasan KS, Smith SR, Petrash JM, Misko TP, Moore WM, Currie MG, Corbett JA, McDaniel ML, Williamson JR. Prevention of diabetic vascular dysfunction by guanidines. Inhibition of nitric oxide synthase versus advanced glycation end-product formation. Diabetes 1993;42:221-232.

13. Heesen BJ, De Mey JG. Effects of cyclic AMP-affecting agents on contractile reactivity of isolated mesenteric and renal resistance arteries of the rat. Br J Pharmac 1990;101:859-864.

14. De Mey JG, Defreyn G, Lenars A, Calderon P, Roba J. Arterial reactivity, blood pressure, and plasma levels of artrial natriureticmpeptides in normotensive and hypertensive rats: effects of acute and chronic administration of atriopeptin III. J Cardiovasc Pharmacol 1986;9:525-535.

15. Pfaffman MA, Ball CR, Darby A, Hilman R. Insulin reversal of diabetes-induced inhibition of vascular contractility in the rat. Am J Physiol 1982;242:H490-H495.

16. Scarbourgh NL, Carrier GO. Nifedipine and alpha adrenoreceptors in rat aorta. II. Rolc of extracellular calcium in enhanced alpha-2 adrenoceptor-mediated contraction in diabetes. $\mathrm{J}$ Pharmacol Exp Ther 1984;231:603-609.

17. Fulton DJ, Hodgson WC, Sikorski BW, King RG. Attenuated responses to endothelin-1, KCl and $\mathrm{CaCl}_{2}$, but not noradrenaline, of aortae from rats with streptozotocin- induced diabetes mellitus. Br J Pharmacol 1991;104:928-932.

18. Bucala R, Tracey KJ, Cerami A. Advanced glycosylation products quench nitric oxide and mediate defective endothelium-dependent vasodilatation in experimental diabetes. J Clin Invest $1991 ; 87: 432-438$.

19. Pieper GM, Gross GJ. Oxygen free radicals abolish endothelium-dependent relaxation in diabetic rat aorta. Am J Physiol 1988;255:H825-833.

20. Curcio F, Ceriello A. Decreased cultured endothelial cell proliferation in high glucose medium is reversed by antioxidants: new insights on the pathophysiological mechanisms of diabetic vascular complications. In Vitro Cell Dev Biol 1992;28:787-790.

21. Pieper GM, Mei DA, Langenstroer P, O'Rourke ST. Bioassay of endothelium-derived relaxing factor in diabetic rat aorta. Am J Physiol 1992;263:H676-680.

22. Manduteanu I, Calb M, Lupu C, Simionescu N, Simionescu M. Increased adhesion of human diabetic platelets to cultured valvular endothelial cells. J Submicrosc Cytol Pathol 1992;24:539-547. 


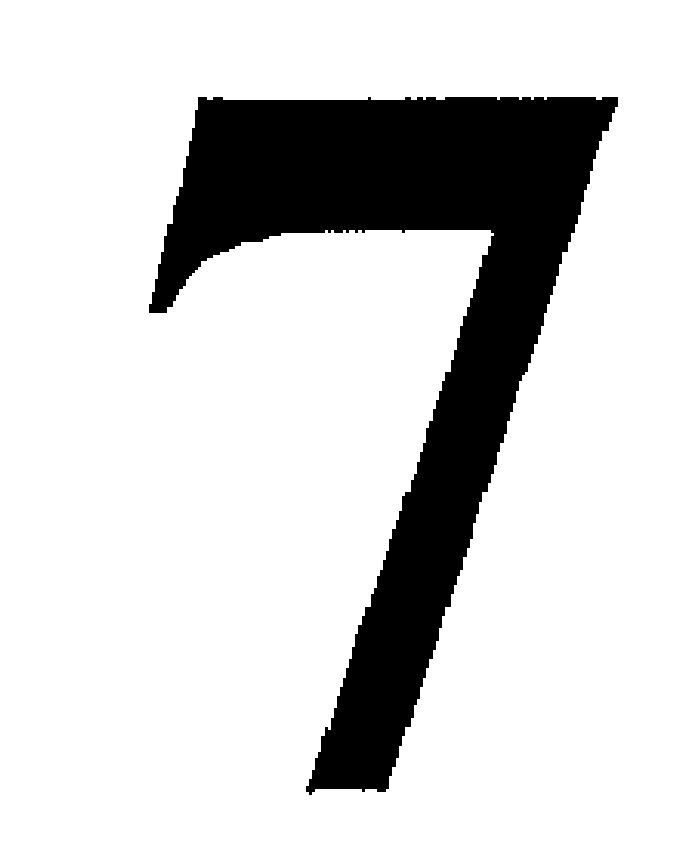

\section{Effects of perindoprilat treatment on vascular responses of aorta and resistance arteries of diabetic and non-diabetic rats}

B.J. Heesen, J.G.R. De Mey, and B.H.R. Wolffenbuttel Cardiovascular Research Institute Maastricht (CARIM), Depts. of Internal Medicine and Pharmacology, University of Limburg, Maastricht (NL) 


\section{SUMMARY}

We evaluated the effects of treatment with the ACE-inhibitor perindoprilat on the reactivity of isolated aortas, mesenteric and renal resistance arteries obtained from non-diabetic and diabetic animals. Male rats were treated for three months with 1 $\mathrm{mg} / \mathrm{kg} /$ day perindoprilat. Perindoprilat was administered by subcutaneous osmotic mini-pumps. Aortic rings, and mesenteric and renal resistance arteries obtained from male diabetic and non-diabetic Wistar-rp rats which were treated with perindoprilat were mounted between an isometric force transducer and a displacement device in a $10 \mathrm{ml}$ organ bath containing Krebs buffer ( $\mathrm{pH} 7.4,37^{\circ} \mathrm{C}$, aerated with $95 \% \mathrm{O}_{2}$ and $5 \% \mathrm{CO}_{2}$ ). Maximal contractile responses in the aorta to PHE was decreased, from $7.2 \pm 0.9 \mathrm{mN} / \mathrm{mm}$ in control aortas, to $4.2 \pm 0.3 \mathrm{mN} / \mathrm{mm}$ in diabetic aortas $(p<0.05)$. Aortic contractile force in control animals was reduced by treatment with perindoprilat $(5.7 \pm 0.8 \mathrm{mN} / \mathrm{mm}, p<0.05)$; however, in diabetic animals treatment did not influence maximum contractile force $(4.3 \pm 0.3 \mathrm{mN} / \mathrm{mm})$. The contractile force to phenylephrine in MRA and RRA was not significantly different in diabetic vs control. The MRA $(5.8 \pm 1.6 \mathrm{mN} / \mathrm{mm})$ showed a much more powerful contraction than the $R R A(3.4 \pm 0.4 \mathrm{mN} / \mathrm{mm})$. ACH-induced relaxation was enhanced in diabetic aortas, $M R A$ and RRA compared to control. An increase in relaxation was observed in aorta, but not in MRA and RRA, when control rats were treated with perindoprilat. In contrast, ACH-induced relaxation in diabetic aortas, MRA, and RRA treated with perindoprilat did not show an increase in relaxation compared to aorta of untreated diabetic rats. Relaxation to SNP was enhanced in diabetic aortas, MRA, and RRA compared to control. Perindoprilat treatment did not modify the response to SNP in diabetic and control aorta, MRA, and RRA. Perindoprilat treatment had no effect on the various dose-response curves assessed in mesenteric and renal resistance renal arteries. However, we conclude that perindoprilat augments the acetylcholine induced relaxation and diminishes the phenylephrine induced contraction as observed in isolated aortic rings obtained from non-diabetic rats. 


\section{DIABETES TREATMENT WITH PERINDOPRILAT}

\section{INTRODUCTION}

Diabetes induces metabolic, functional, and structural changes of the vasculature, which greatly increases the susceptibility of vessels to injury by other risk factors. The beneficial effects of angiotensin-converting enzyme (ACE) inhibitors on blood pressure in patients with hypertension ${ }^{[1]}$ and diabetic patients with nephropathy ${ }^{[2]}$ are well known. Although inhibition of angiotensin II formation is thought to be pivotal, experimental evidence for additional mechanisms is growing ${ }^{[3]}$. For instance, endothelial cells express ACE on their plasma membrane ${ }^{[4]}$. ACE catalyzes the generation of angiotensin II and the degradation of bradykinin ${ }^{[5]}$, both of which possess potent vasoactive effects that are dependent on, or modulated by, endotheliumderived mediators. From several studies it is known that chronic treatment with ACE inhibitors reduces endothelial dysfunction in experimental models of hypertension ${ }^{[6]}$ and hypercholesterolemia ${ }^{[7]}$.

The objective of the present study was to assess the effects of long term treatment with the ACE inhibitor, perindoprilat, on the response of isolated mesenteric resistance arteries, renal resistance arteries, and aortic rings from diabetic and non-diabetic animals.

\section{RESEARCH DESIGN AND METHODS}

Diabetes was induced in six week old male Wistar RP rats for a diabetes duration of three months by intraperitoneal injection of $70 \mathrm{mg} / \mathrm{kg}$ streptozotocin. Rats were housed individually, fed standard rat chow, water ad libitum, and were on a 12 hour light/dark cycle. Development of diabetes was verified by blood glucose measurement. Immediately after diabetes induction, diabetic and control rats were randomized into two groups: one group receiving perindoprilat $(1 \mathrm{mg} / \mathrm{kg} /$ day) and another receiving saline. In previous studies, this dose of perindoprilat was shown to reduce blood pressure by $15 \%{ }^{[8]}$. Perindoprilat and saline were administered subcutaneously by implanted osmotic minipumps (Alzet model 2002, Alza Corporation, Palo Alto, $\mathrm{Ca}$, USA). Rats were treated for 10-12 weeks. On the day of the experiments the animals were anaesthetized by ether. The thoracic aorta was removed, trimmed free of adventitial connective tissue and cut into small rings (1.6 mm in length). Special care was taken to avoid damage to the endothelial layer. The mesentery was isolated from the rats, rinsed with a buffered physiological salt solution and pinned out on a petri dish coated with Silgard (Dow Corning Corp.) filled with a buffered physiological salt solution. Third to fourth order branches of the superior mesenteric artery were dissected from the mesentery. A stainless steel wire with a diameter of $40 \mu \mathrm{m}$ was inserted into the lumen of the vessel proximal from the segment we would use for experimentation, before it was taken out of the mesentery. A second wire was then inserted into the lumen of the vessel and the vessel segments were mounted for recording of isometric force development (Chapter 2). The same procedure was followed when isolating renal intralobar arteries, only the kidney was sliced into two pieces before being pinned out on a petri dish. Two stainless-steel wires (diameter 40 


\section{CHAPTER 7}

$\mu \mathrm{m})$ were inserted into the lumen of the artery, which was then mounted horizontally in an organ chamber (myograph, JP Trading, Aarhus, Denmark, volume $10 \mathrm{ml}$ ) between an isometric force transducer (Kistler Morse DSC6, Seattle WA, USA) and a displacement device (Mitatoyo, Tokyo, Japan). The organ chamber was filled with a modified Krebs-Ringer bicarbonate solution (KRB, composition in mM: $\mathrm{NaCl} 118.3$, $\mathrm{KCl}$ 4.7, $\mathrm{MgSO}_{4} 1.2, \mathrm{CaCl}_{2} 2.5, \mathrm{KH}_{2} \mathrm{PO}_{4} 1.2, \mathrm{NaHCO}_{3}$ 25.0, Ca-EDTA 0.026 and glucose 5.0 or 30.0 ) maintained at $37^{\circ} \mathrm{C}$ and $\mathrm{pH} 7.4$ and continuously aerated with $95 \% \mathrm{O}_{2}$ and $5 \% \mathrm{CO}_{2}$. Before assessment of vasoreactivity, the renal resistance (RRA) and mesenteric resistance artery (MRA) were stretched to determine the optimal lumen diameter for mechanical performance; the diameter was therefore initially set at $50 \mu \mathrm{m}$ and increased by $40 \mu \mathrm{m}$ increments. The diameter of the aorta was set to $2 \mathrm{~mm}$ and left at this diameter, as we know from previous studies that there was no difference in maximum active wall tension between an internal diameter of 2-3 mm. The MRA and RRA preparations were exposed intermittently to Krebs-Ringer buffer in which all $\mathrm{NaCl}$ was replaced by an equimolar amount of $\mathrm{KCl}$. This procedure was continued until a maximal contractile response to potassium was obtained. Subsequent experiments were performed at this optimal diameter. During this procedure all control arteries were in buffer containing $5 \mathrm{mM}$ glucose, and diabetic arteries were in buffer containing $30 \mathrm{mM}$ glucose. Relaxation was assessed in arteries pre-contracted by phenylephrine, dosed in such a way that a sub-maximum contraction was produced.

\section{Drugs}

Streptozotocin, phenylephrine hydrochloride, sodium nitroprusside and acetylcholine hydrochloride were purchased from Sigma Chemicals Co. (St. Louis, MO, USA). Perindoprilat was a kind gift of Servier (Courbevoie, France). Streptozotocin was dissolved in citrate buffer ( $\mathrm{pH} 4.5$ ) and perindoprilat in saline. Stock concentrations of phenylephrine, sodium nitroprusside and acetylcholine were prepared in distilled deionized water and $10 \mu \mathrm{l}$ aliquots were added to the organ bath to generate the dose-response curves. All drug concentrations are expressed as the negative log of the final molar concentration in the organ bath.

\section{Calculations and statistics}

Contractile responses are expressed as increases in wall tension (increase in force $/ 2 \mathrm{x}$ length of arterial segment). Effects of pharmacological agents are expressed as $\%$ remaining tension versus initial (50-60\% of maximum) contractile tension. EC-50 values were calculated using GraphPad Inplot (GraphPad Software Inc., San Diego, $\mathrm{Ca}$, USA). Differences between groups were tested by ANOVA with StudentNewman-Keuls correction for multiple comparisons, using SPSS for Windows (version 6.0, SPSS Inc, Chicago, Il, USA). The number of animals was 6-10 in all experiments. Data in tables, figures and text are shown as means \pm SEM, unless stated otherwise. $P$ values $<0.05$ were considered statistically significant. 


\section{DIABETES TREATMENT WITH PERINDOPRILAT}

\section{RESULTS}

Data of blood glucose levels and body weight in the different groups of animals are given in table 1 . The optimal internal diameter for all arteries did not differ significantly between the groups (see table 1).

Table 1. Number of animals, internal diameters of aorta, mesenteric resistance arteries (MRA), and renal resistance arteries ( $R R A)$, body weight $(B W)$, and blood glucose levels $(B G)$ in control and diabetic animals.

\begin{tabular}{l|c|c|c|c} 
& control & control & diabetic & diabetic \\
\hline perindoprilat & - & + & - & + \\
\hline number & 9 & 6 & 8 & 10 \\
\hline Aorta (mm) & 2.0 & 2.0 & 2.0 & 2.0 \\
\hline MRA (mm) & $0.23 \pm 0.01$ & $0.24 \pm 0.01$ & $0.22 \pm 0.01$ & $0.25 \pm 0.01$ \\
\hline RRA (mm) & $0.29 \pm 0.02$ & $0.31 \pm 0.02$ & $0.28 \pm 0.03$ & $0.30 \pm 0.02$ \\
\hline BW (g) & $345 \pm 16$ & $339 \pm 18$ & $253 \pm 20^{\mathrm{a}}$ & $261 \pm 23^{\mathrm{a}}$ \\
\hline BG (mM) & $4.8 \pm 0.3$ & $5.1 \pm 0.4$ & $26.8 \pm 2.1^{\mathrm{a}}$ & $25.4 \pm 1.8^{\circ}$
\end{tabular}

${ }^{\mathrm{a}} \mathrm{p}<0.05$ for diabetic and diabetic + perindoprilat vs control and control + perindoprilat.

\section{Phenylephrine-induced contraction}

The maximal phenylephrine-induced contractile force was $7.4 \pm 0.6 \mathrm{mN} / \mathrm{mm}$ in aortas obtained from non-diabetic animals. The phenylephrine-induced contractile force was $43 \%$ lower in aortas from diabetic animals compared to control aortas $(4.2 \pm 0.3 \mathrm{mN} / \mathrm{mm}$, $\mathrm{p}<0.05)$. Treatment with perindoprilat lowered maximum contraction in control animals by $23 \%(5.7 \pm 0.8)$ vs aorta from untreated control animals, but did not have any effect in the diabetic aorta (figure 1). Sensitivity to phenylephrine in aortic rings did not differ between the different groups. The EC-50 concentrations, expressed as the negative $\log$, are shown in table 2.

The renal and mesenteric resistance arteries showed a lower sensitivity to phenylephrine compared to aorta (see table 2). Phenylephrine-induced
AORTA

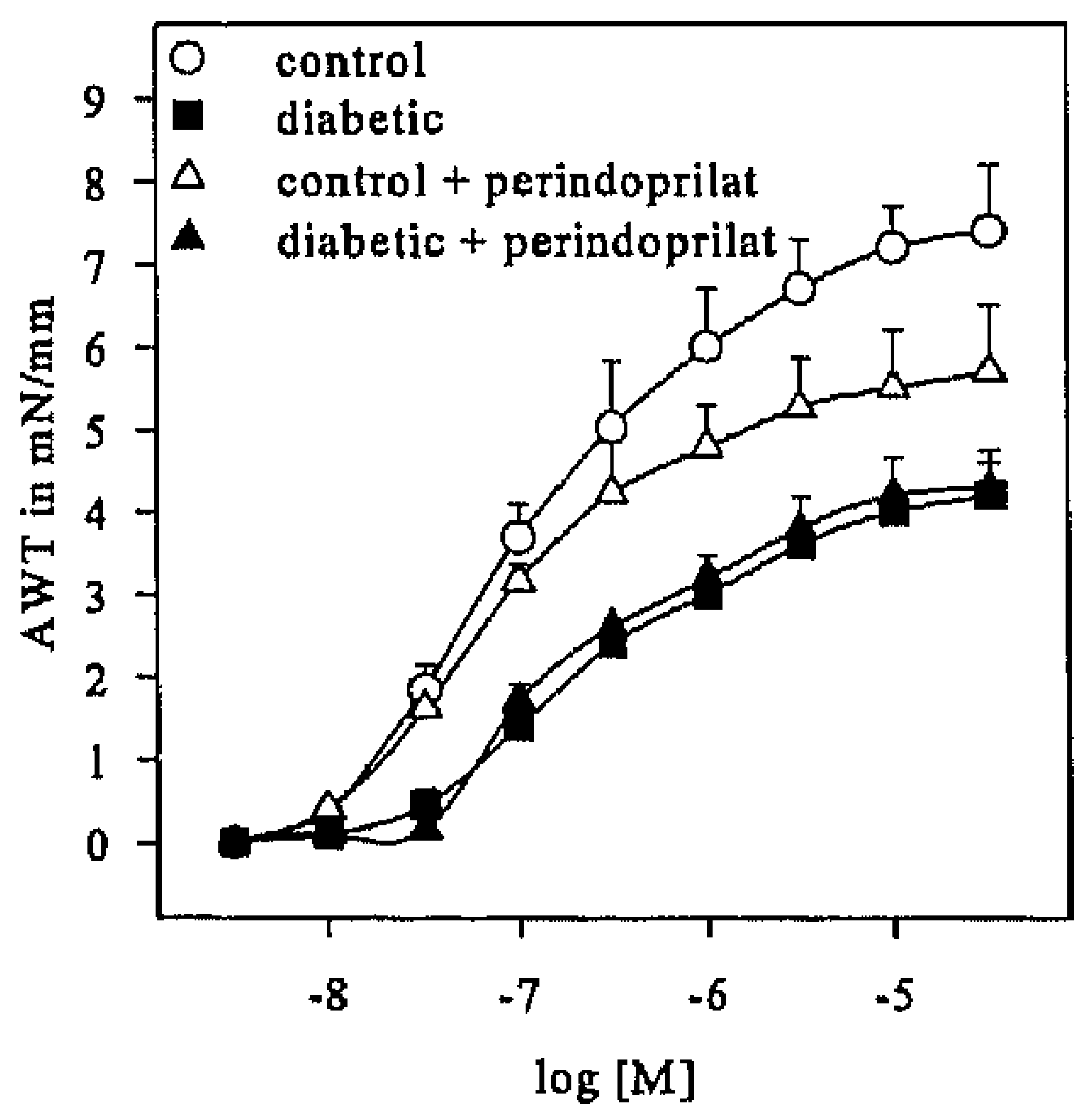

Figure 1. Phenylephrine induced contraction in aorta from diabetic and non-diabetic animals untreated and treated with perindoprilat. 


\section{CHAPTER 7}

contractile force in mesenteric or renal resistance arteries did not differ significantly between diabetic and control (figure 2). Treatment with perindoprilat had no effect on the phenylephrine induced contraction. The obtained maximum contractile force was much smaller in renal resistance arteries than in mesenteric resistance arteries $(5.8 \pm$ 0.9 vs $3.7 \pm 0.4 \mathrm{mN} / \mathrm{mm}$ ).

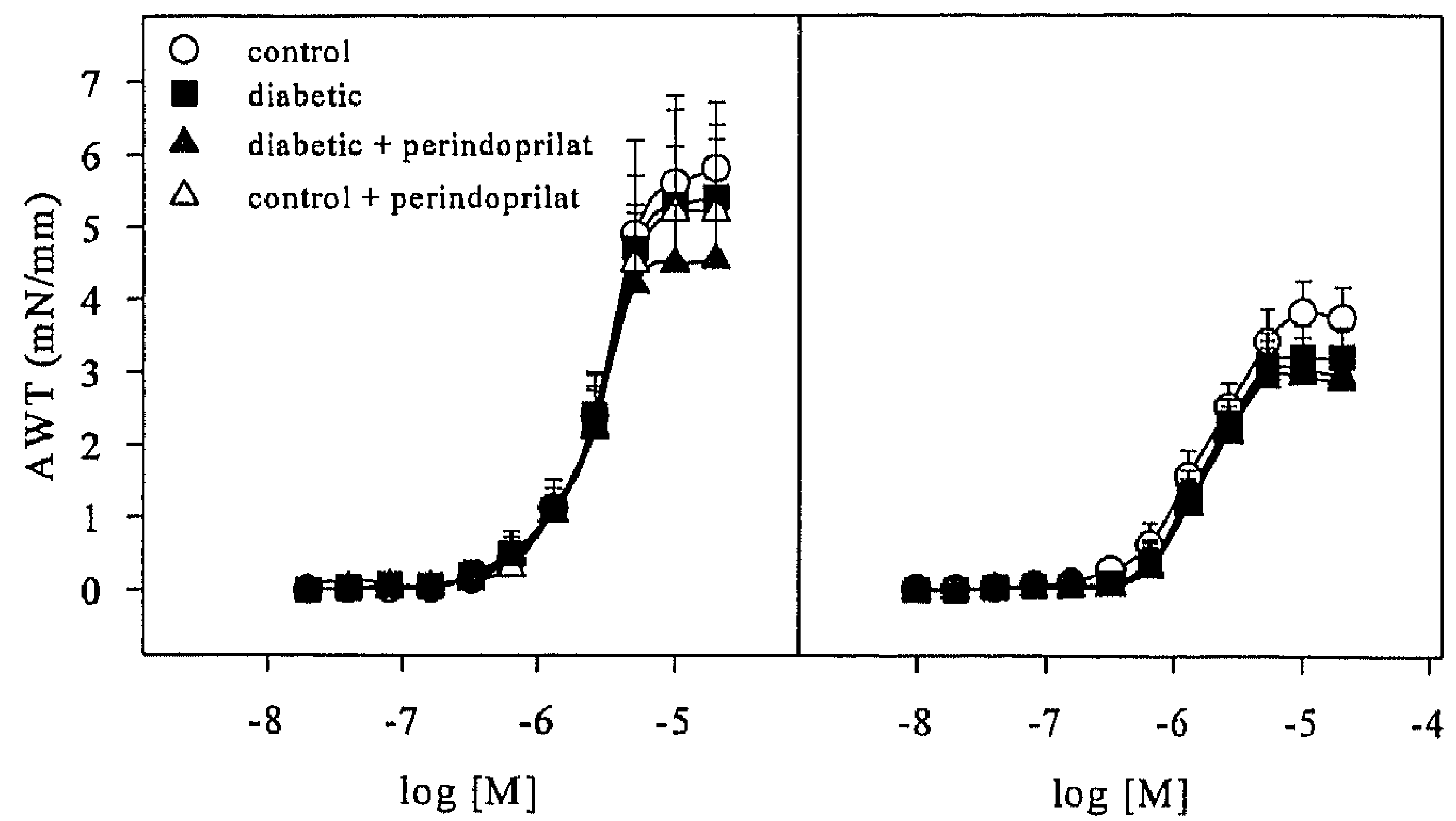

Figure 2. Phenylephrine induced contraction in mesenteric resistance and renal resistance arteries from diabetic and non-diabetic animals untreated and treated with perindoprilat.

Table 2. EC-50 values for response to phenylephrine in aorta, MRA, and RRA from non-diabetic and diabetic animals.

\begin{tabular}{l|c|c|c|c} 
& $\begin{array}{c}\text { PHE } \\
\text { control }\end{array}$ & $\begin{array}{c}\text { PHE } \\
\text { control }\end{array}$ & $\begin{array}{c}\text { PHE } \\
\text { diabetic }\end{array}$ & $\begin{array}{c}\text { PHE } \\
\text { diabetic }\end{array}$ \\
\hline perindoprilat & - & + & - & + \\
\hline aorta & $\begin{array}{c}7.1 \\
(6.8-7.3)\end{array}$ & $\begin{array}{c}7.2 \\
(7.0-7.4)\end{array}$ & $\begin{array}{c}6.6 \\
(6.5-6.8)\end{array}$ & $\begin{array}{c}6.7 \\
(6.4-7.0)\end{array}$ \\
\hline MRA & $\begin{array}{c}5.5^{\mathrm{a}} \\
(5.5-5.6)\end{array}$ & $\begin{array}{c}5.5^{\mathrm{a}} \\
(5.5-5.6)\end{array}$ & $\begin{array}{c}5.6^{\mathrm{a}} \\
(5.5-5.6)\end{array}$ & $\begin{array}{c}5.6^{\mathrm{a}} \\
(5.5-5.7)\end{array}$ \\
\hline RRA & $\begin{array}{c}5.8^{\mathrm{b}} \\
(5.7-5.8)\end{array}$ & $\begin{array}{c}5.8^{\mathrm{b}} \\
(5.7-5.8)\end{array}$ & $\begin{array}{c}5.8^{\mathrm{b}} \\
(5.7-5.8)\end{array}$ & $\begin{array}{c}5.8^{\mathrm{b}} \\
(5.7-5.8)\end{array}$
\end{tabular}

$\mathrm{p}<0.05$ MRA vs aorta

b $p<0.05$ RRA vs aorta

\section{Acetylcholine-induced relaxation}

In aortas precontracted with $0.1 \mu \mathrm{M}$ phenylephrine, a concentration-dependent relaxation by acetylcholine was observed (figure 3 ). There was a significant difference in acetylcholine-induced relaxation at $32 \mu \mathrm{M}$ between control and diabetic aortas; 


\section{DIABETES TREATMENT WITH PERINDOPRILAT}

residual contractile tensions were $33 \pm 10 \%$ and $5 \pm 4 \%$, respectively. In the aorta from control animals, which were treated with perindoprilat the relaxation to acetylcholine was augmented vs untreated control $(19 \pm 4 \%, p<0.05$ vs untreated control). Perindoprilat treatment of diabetic rats did not have any significant effect in correcting the enhanced sensitivity as observed in the isolated aorta from diabetic rats.

In mesenteric resistance (figure 4) and renal resistance (figure 5) arteries precontracted with $10 \mu \mathrm{M}$ phenylephrine, a concentration-dependent relaxation by acetylcholine was observed. There was a significant difference between control and diabetic mesenteric resistance arteries. However, there was no difference in relaxation between the diabetic and non-diabetic renal resistance arteries. Control arteries isolated from the mesentery showed a more potent relaxation to $32 \mu \mathrm{M}$ acetylcholine than renal resistance arteries, remaining tensions are respectively $3 \pm 5 \%$ and $21 \pm 12 \%$ of maximum. Perindoprilat treatment did not have any effect on these dose response curves.

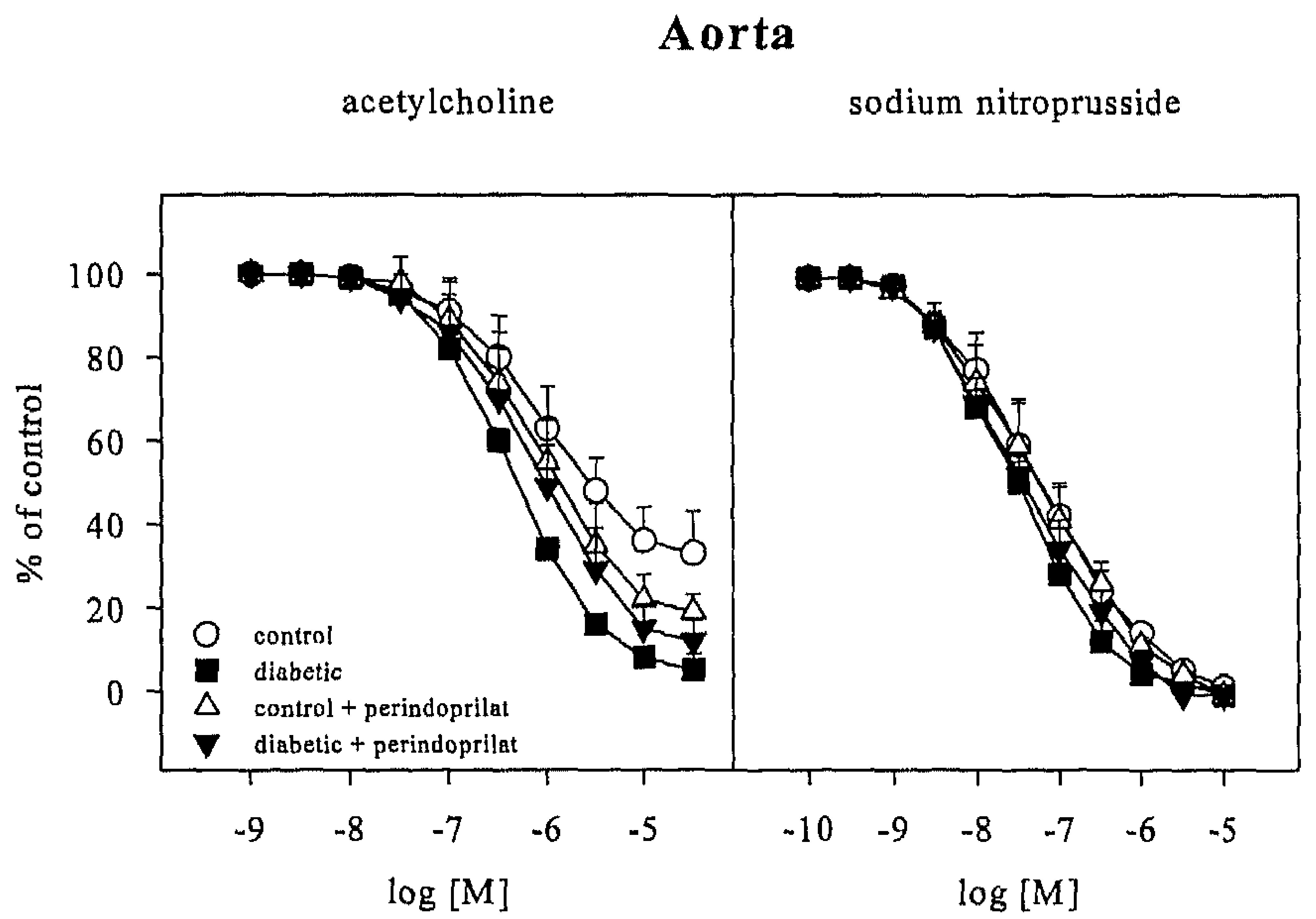

Figure 3. Acetylcholine and sodium nitroprusside induced relaxation in aorta from diabetic and non-diabetic animals untreated and treated with perindoprilat.

\section{Sodium nitroprusside-induced relaxation}

In aortas precontracted with $0.1 \mu \mathrm{M}$ phenylephrine, a concentration-dependent relaxation by sodium nitroprusside was observed (figure 3 ). Sensitivity to sodium nitroprusside did not differ between aorta, MRA and RRA isolated from diabetic rats compared to those from non-diabetic animals. The renal resistance arteries failed to relax completely to sodium nitroprusside (figure 5), remaining tension in control renal resistance arteries $19 \pm 8 \%$ vs control mesenteric resistance arteries $5 \pm 3 \%(p<0.05)$. Perindoprilat treatment did not have any effect on the dose response curves of the different arteries. 


\section{CHAPTER 7}

\section{MRA}

acetylcholine sodium nitroprusside

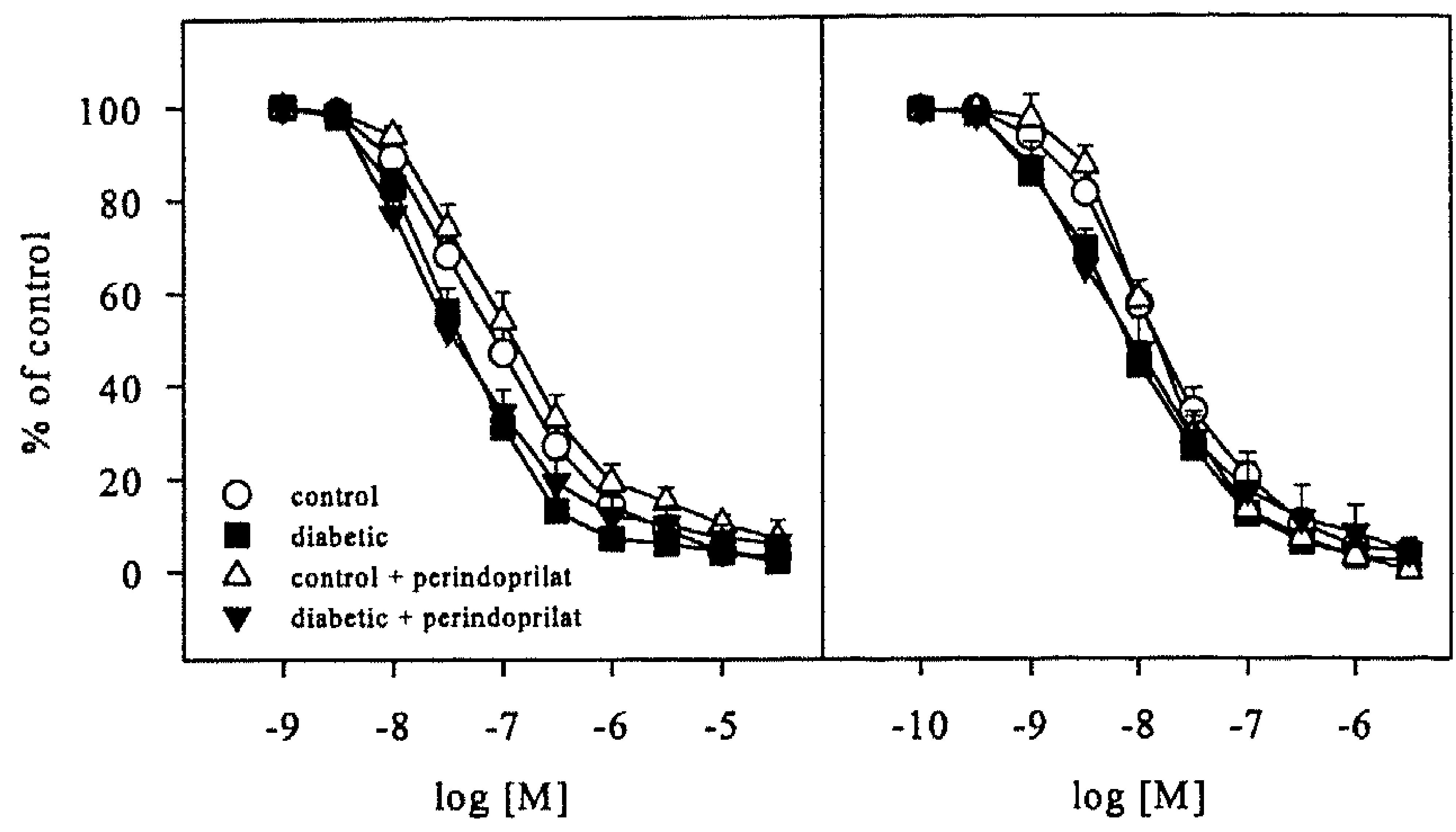

Figure 4. Acetylcholine and sodium nitroprusside induced relaxation in mesenteric resistance arteries from diabetic and non-diabetic animals untreated and treated with perindoprilat.

\section{RRA}

acetylcholine sodium nitroprusside

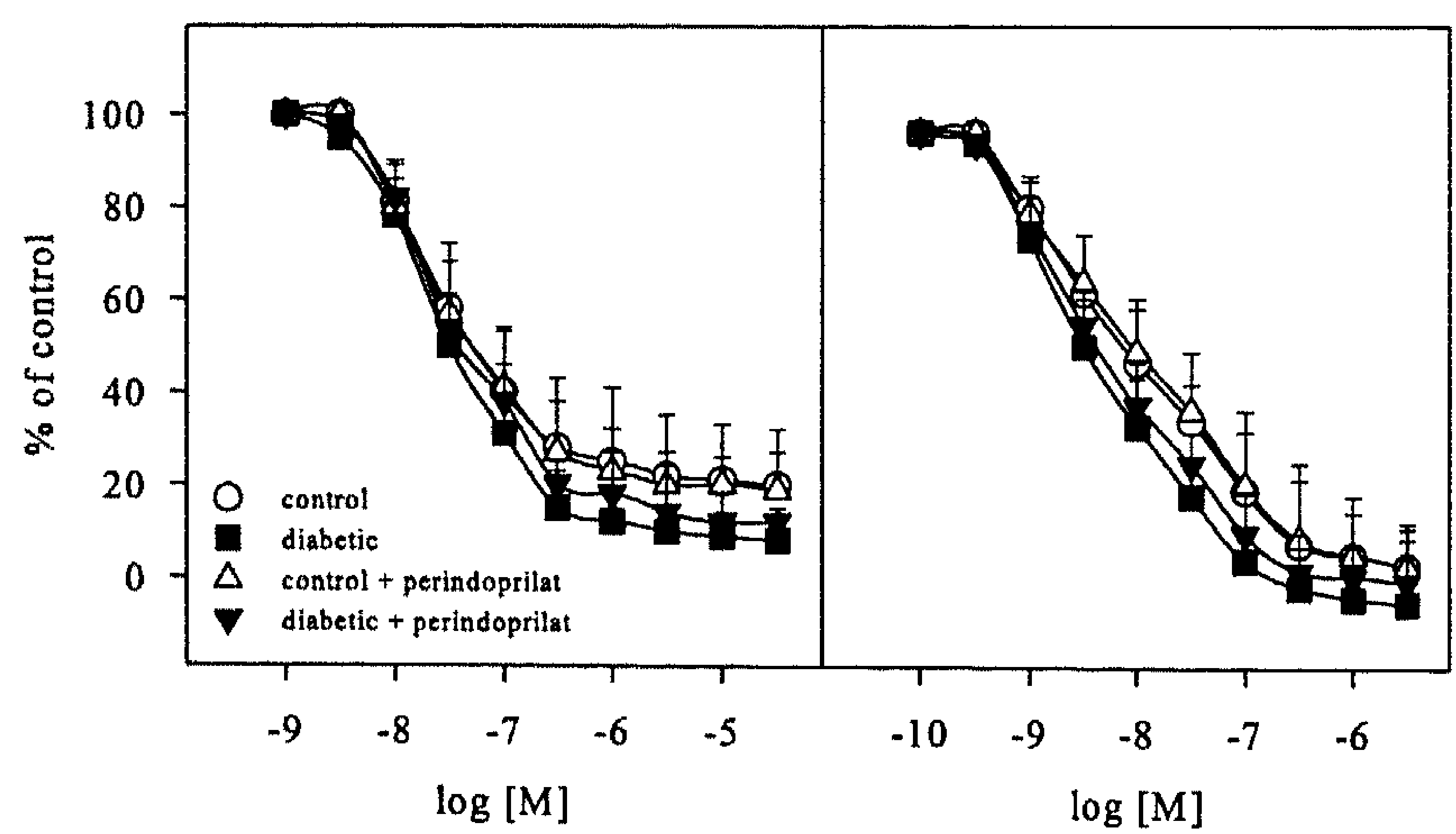

Figure 5. Acetylcholine and sodium nitroprusside induced relaxation in renal resistance arteries from diabetic and non-diabetic animals untreated and treated with perindoprilat. 


\section{DIABETES TREATMENT WITH PERINDOPRILAT}

\section{DISCUSSION}

The development of diabetes by streptozotocin administration in adult Wistar rats leads to changes in vascular responsiveness in vitro. Most of the changes are observed in the larger arteries, like the aorta. Marked reduction of phenylephrine-induced vascular contraction developed in the aorta, but not in the mesenteric and renal resistance arteries. Sensitivity to the constrictor was not different between control and diabetic aortae, but differed between the aorta and mesenteric resistance and renal resistance arteries. Treatment with perindoprilat did not prevent the development of reduced contraction in the aorta from diabetic animals. Instead, the aorta from the control animals treated with perindoprilat showed a reduced maximum contraction to phenylephrine. However, this was not observed in the mesenteric resistance and renal resistance arteries from non-diabetic animals, or in the arteries from the diabetic rats treated with perindoprilat.

The present study also demonstrates enhanced endothelium-dependent relaxation to acetylcholine in the aorta after perindoprilat treatment, but not in the mesenteric resistance artery and renal resistance artery. This suggest a different effect of ACE inhibition in these various arteries. For the perindoprilat treated aorta one could presume that the augmented relaxation by acetylcholine, but normal relaxation to sodium nitroprusside, is due to an increase in production of endothelial relaxing factors and not to a decrease in blood pressure as calcium antagonists are reported not to alter endothelium-dependent relaxation in isolated vessels ${ }^{\text {[?] }}$. The phenomenon of augmented endothelium-dependent relaxation after ACE inhibition was previously described by two other groups ${ }^{[10,11]}$.

The reason for the almost opposite effect of perindoprilat treatment on the response of the aorta to acetylcholine in diabetic vs non-diabetic aorta is not known, and has to be explored further. A possibility could be that inhibition of ACE chronically lowers the vasopressor response, leading to a state of vasorelaxation. In diabetes there is already a state of vasorelaxation, as is shown by the enhanced relaxation to acetylcholine and lower blood pressure in diabetic animals, without the presence of hypovolemia ${ }^{[8]}$. This suggests that the inhibition of ACE does not have any additional effect on the acetylcholine induced relaxation. Further chronic inhibition of the normal angiotensin-II stimulus could lead to some form of vascular hypotrophy with a reduction of vascular mass.

In conclusion, perindoprilat treatment had no major beneficial effects on the disturbed vasoreactivity in mesenteric resistance arteries, renal resistance arteries, and aorta from rats with streptozotocin-induced experimental diabetes. Only a small beneficial effect on disturbed acetylcholine-induced vasorelaxation of diabetic aorta was observed. Beside this we observed an augmented response in the perindoprilat treated control aorta. These conflicting results suggest that inhibition of the vascular renin-angiotensin system has different effects in various vascular beds and diabetic and non-diabetic animals, but does not influence vascular reactivity to a great extent. The major beneficial therapeutic benefit of ACE-inhibitors in the treatment of diabetic complications may lie in their effects of renal hemodynamics and the slowing of progression of diabetic nephropathy ${ }^{[12,13]}$. 


\section{CHAPTER 7}

\section{REFERENCES}

1. The CONSENSUS Trial study group. Effects of enalapril on mortality in severe congestive heart failure: results of the Cooperative North Scandinavian Enalapril Survival Study. N Eng! J Med 1987;316:1429-1435.

2. Christensen $\mathrm{CK}$, Pedersen MM, Mogensen CE. Combining antihypertensive agents in early diabetic nephropathy. J Diabet Complications 1990;4:88-90.

3. Erdos GE. Angiotensin converting enzyme and the changes in our concepts through the years. Hypertension 1990;16:363-370.

4. Alhenc-Gelas F, Soubrier F, Hubert C, Allegrini J, Lattion AL. The angiotensin I-converting enzyme (kininase II): progress in molecular and genetic stucture. J Cardiovasc Pharmacol 1990;16(Suppl. 6):S25-29.

5. Yang H, Erdos EG, Levin Y. A dipeptidyl carboxypeptidase that converts angiotensin and inactivates bradykinin. Biochim Biophys Acta 1970;214:374-376.

6. Clozel $M$, Kuhn H, Hefti $F$. Effects of angiotensin-converting enzyme inhibitors and of hydralazine endothelial function in hypertensive rats. Hypertension 1990;16:532-540.

7. Becker RHA, Wiemer G, Linz W. Preservation of endothelial function by ramipril in rabbits on a long-term atherogenic diet. J Cardiovasc Pharmacol 1991;18(Suppl. 2):S110-S115.

8. Huijberts MSP, Wolffenbuttel BHR, Crijns FRL, Nieuwenhuijzen Kruseman AC, Bemelmans MHA, Van Essen H, Smits JFM, Struijker Boudier HAJ. Angiotensin converting enzymeinhibition reduces urinary albumin excretion but not regional albumin clearance in experimental diabetes. Eur J Pharmacol 1993; 240: 207-212.

9. Auch-Schwelk W, Vanhoutte PM. Endothelium-derived relaxing factor(s) and calcium antagonists. Z Kardiol 1989;78(Suppl. 6):120-123.

10. Bossaller C, Auch-Schwelk W, Weber. Endothelium-dependent relaxations are augmented in rats chronically treated with the angiotensin-converting enzyme inhibitor enalapril. $\mathrm{J}$ Cardiovasc Pharmacol 1992;22(Suppl. 5):517-522.

11. Schultz PJ, Raij L. Effects of antihypertensive agents on endothelium-dependent and endothelium-independent relaxations. Br J Pharmacol 1989;28:151-157S.

12. Marre M, Chatellier G, Leblanc H. Prevention of diabetic nephropathy with enalapril in normotensive diabetics with microalbuminuria. BMJ 1988;297:1092-1095.

13. Mathiesen E, Hommel E, Giese J, Parving H. Efficacy of captopril in postponing nephropathy in normotensive insulin dependent diabetic patients with microalbuminuria. BMJ 1991; 303:81-87. 


\section{Aldose reductase inhibitors have little effect on altered reactivity in aortic rings of diabetic rats}

B.J. Heesen, J.R. Williamson, and B.H.R. Wolffenbuttel Cardiovascular Research Institute Maastricht (CARIM), Department of Internal Medicine, University of Limburg, Maastricht (NL), and Department of Pathology, Washington University, St. Louis (MO,USA) 


\section{SUMMARY}

The objective of the present study was to assess the effect of treatment with aldose reductase inhibitors (zopolrestat or sorbinil) on the reactivity of isolated aortas from diabetic animals. We treated 7 non-diabetic and 7 diabetic animals with 0.2 mmol/kg. body weight/day sorbinil, and 7 non-diabetic and 8 control animals with $0.2 \mathrm{mmol} / \mathrm{kg}$ body weight/day zopolrestat. Isolated aorta was mounted in an organ chamber. The chamber was filled with a Krebs bicarbonate solution (glucose concentrations $5 \mathrm{mM}$ for control and $30 \mathrm{mM}$ for diabetic). Maximum phenylephrine-induced contraction was reduced in diabetic animals by $21 \%$ (control $7.8 \pm 0.6 \mathrm{mN}$ vs diabetic $6.1 \pm 0.2 \mathrm{mN}$ ). This impairment was not prevented in total by both aldose reductase inhibiting agents. Maximum acetylcholine-induced relaxation was enhanced in diabetic animals (87\%) vs non-diabetic controls (66\%). Zopolrestat treatment did not have any effect on relaxation, but sorbinil treatment partly prevented this disturbance (zopolrestat treated diabetic $85 \%$ vs sorbinil treated diabetic 76\%). Relaxation induced by sodium nitroprusside was enhanced in diabetes and was unaffected by zopolrestat or sorbinil treatment. We conclude that aldose reductase inhibitors have minor effects on the vascular disturbances as observed in aortic rings from rats with experimental diabetes. 


\section{ALDOSE REDUCTASE INHIBITORS}

\section{INTRODUCTION}

Normal intracellular glucose metabolism uses aldose reductase to convert glucose to sorbitol which is further processed to fructose. The enzyme aldose reductase is present in most tissues and its possible physiological role is to produce an electrical neutral, non-diffusible osmolyte in cells exposed to hypertonicity, as typified by the renal medullary cells of the loop of Henle. The enzyme has a low affinity for glucose, and under normal conditions it processes little substrate. However, in diabetes mellitus, the marked rise in intracellular glucose that occurs in cells causes marked production of sorbitol and marked increases in fructose (figure 1). The increased flux and accumulation of sorbitol is damaging to cells and may result in some of the long-term complications of diabetes. The increased flux and formation of fructose leads to an increase in the NADH/NAD ${ }^{+}$ratio which can cause a whole cascade of biochemical changes (see chapter 1). These biochemical changes may lead to an increase in vascular permeability ${ }^{[1]}$.

Since the presence of aldose reductase was described in the endothelial cell of the aorta several experimental studies have shown that ARI treatment prevented the development of increase in vascular permeability ${ }^{[2]}$, or the disturbed vascular reactivity ${ }^{[3-5]}$. However, in another experimental study, in which the influence of aldose reductase inhibitors on responses to endothelin- 1 was studied ${ }^{[6]}$, no effect was found. In some clinical trials, mainly focused on neuropathy and retinopathy, no beneficial effect has been shown on preventing or delaying the onset of these complications ${ }^{[7]}$. An explanation for the negative findings in these clinical studies can probably be found in: 1 . the fact that the begin and end points from a study are not easy to define; 2 . the effect of these compounds in the prevention of diabetic complications may not show up in the relative limited time span of a study ${ }^{[8]} ; 3$. the fact that treatment is started late in the course of the disease.

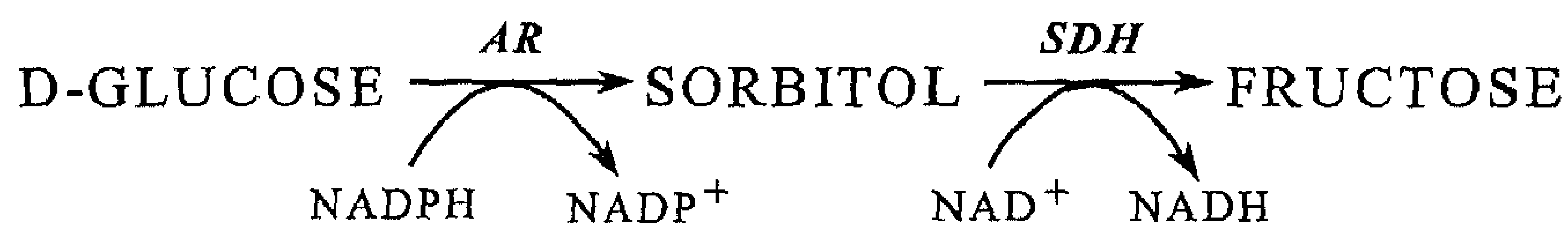

Figure 1. Reduction of glucose to sorbitol and oxidation of sorbitol to fructose. Reduction of glucose to sorbitol by aldose reductase $(A R)$ is coupled to oxidation of NADPH to NADP. NADP ${ }^{+}$is reduced to NADPH by the hexose monophosphate pathway. Oxidation of sorbitol to fructose by sorbitol-dehydrogenase (SDH) is coupled to reduction of $N A D^{+}$to $N A D H$.

Aldose reductase inhibitors prevent the formation of sorbitol and fructose by inhibiting the enzyme aldose reductase. In this chapter we describe the results of a study that we designed to investigate the effect of a 6 week treatment with two different aldose reductase inhibitors on the reactivity of the isolated aorta from rats with or without experimental diabetes. The two aldose reductase inhibitors used in this study are; the spiro hydantoin Sorbinil and the benzothiazole-containing phathalazinone Zopolretstat on the reactivity of the isolated aorta. 


\section{CHAPTER 8}

\section{RESEARCH DESIGN AND METHODS}

Diabetes was induced in six week old male Sprague-Dawley rats by intravenous injection of $65 \mathrm{mg} / \mathrm{kg}$ streptozotocin. All diabetic and non-diabetic animals were housed and cared for in accordance with the guidelines of the University Committee for the Human Care of Laboratory Animals, and NIH-guidelines on laboratory animal welfare. Rats were housed individually, fed a ground rat chow (Ralston Purina, Richmond, In, USA), water ad libitum, and were on a 12 hour light/dark cycle. Sorbinil was added to the diet of the control and diabetic animals which were treated with sorbinil to provide a dose of approximately $0.2 \mathrm{mmol} / \mathrm{kg}$ body weight $/$ day. Zopolretstat was added to the diet of the control and diabetic animals which were treated with zopolrestat to provide a dose of approximately $0.2 \mathrm{mmol} / \mathrm{kg}$ body weight/day. Previous studies have indicated that these drugs were dosed high enough to prevent excessive polyol levels in different tissues ${ }^{[9,101}$.

Experiments were performed at the age of 12 weeks after a diabetes duration of 6 weeks. The animals were anaesthetized $(45 \mathrm{mg} / \mathrm{kg}$ pentobarbital i.p). The thoracic aorta was removed, trimmed free of adventitial connective tissue and cut into small rings (1.6 $\mathrm{mm}$ in length). Two stainless-steel wires (diameter $40 \mu \mathrm{m}$ ) were inserted into the lumen of the aorta, which was then mounted horizontally in an organ chamber (JP Trading, Aarhus, Denmark, volume $10 \mathrm{ml}$ ) between an isometric force transducer (Kistler Morse DSC6, Seattle WA, USA) and a displacement device (Mitatoyo, Tokyo, Japan). The organ chamber was filled with a Krebs-Ringer bicarbonate solution (KRB, composition in mM: $\mathrm{NaCl} 118.3, \mathrm{KCl} 4.7, \mathrm{MgSO}_{4} 1.2, \mathrm{CaCl}_{2} 2.5, \mathrm{KH}_{2} \mathrm{PO}_{4} 1.2$, $\mathrm{NaHCO}_{3} 25.0$, Ca-EDTA 0.026 and glucose 5.0 or 30.0) maintained at $37^{\circ} \mathrm{C}$ and $\mathrm{pH}$ 7.4 and continuously aerated with $95 \% \mathrm{O}_{2}$ and $5 \% \mathrm{CO}_{2}$.

Before assessment of reactivity, the aorta was set to an internal diameter of $1.98 \mathrm{~mm}$ for optimal mechanical performance. The preparation was then exposed to a KrebsRinger buffer in which all $\mathrm{NaCl}$ was replaced by an equimolar amount of $\mathrm{KCl}$. Subsequent experiments were performed at this diameter. During this procedure, control aortas were in buffer containing $5 \mathrm{mM}$ glucose; diabetic aortas were in buffer containing $30 \mathrm{mM}$ glucose. Relaxation was studied in arteries pre-contracted by 0.1 $\mu \mathrm{M}$ phenylephrine to $55 \%$ of maximal contractile tension; $15 \mathrm{~min}$ was allowed for stabilization of contractile tension before assessing acetylcholine-induced relaxation.

\section{Drugs}

Streptozotocin was purchased from Upjohn Co. (Kalamazoo, MI, USA), pentobarbital from Fort Dodge Laboratories (Iowa, USA), Sorbinil and Zopolretstat were kind gifts from Pfizer Inc.(Connecticut, USA), and phenylephrine hydrochloride, sodium nitroprusside and acetylcholine from Sigma Chemicals Co. (St. Louis, MO, USA). All drugs, except Sorbinil and Zopolrestat which were added to the diet, were prepared in distilled deionized water and $10 \mu \mathrm{l}$ aliquots were added to the organ bath to generate the dose-response curves. All drug concentrations are expressed as the negative log of the final molar concentration in the organ bath. Blood glucose in the animals was measured with a hexokinase method. 


\section{ALDOSE REDUCTASE INHIBITORS}

\section{Calculations and statistics}

Contractile responses are expressed as increases in wall tension (increase in force $/ 2 \mathrm{x}$ length of arterial segment). Effects of relaxing agents are expressed as \% remaining tension versus initial (55\% of maximum) contractile tension. EC-50 values were calculated using GraphPad Prism (version 1.00, 1994, Graphpad Inc., San Diego, Ca, USA). Differences between groups were tested by ANOVA with Student-NewmanKeuls correction for multiple comparisons, using the SPSS for Windows version 6.01 software (SPSS Inc, Chicago, Il, USA). The characteristics of the animals used in the experiments are listed in table 1. Data in tables and figures are shown as means \pm SEM or $95 \%$ confidence interval. $P$ values $<0.05$ were considered statistically significant.

\section{RESULTS}

Data of number, body weight, and blood glucose levels of the various groups are given in table 1. All three diabetic groups were severely hyperglycemic compared to the nondiabetic control animals

Table 1. Body weight $(B W)$ and blood glucose levels $(B G)$ in treated and untreated non-diabetic and diabetic animals.

\begin{tabular}{l|c|c|c|c|c|c} 
& control & control & control & diabetic & diabetic & diabetic \\
\hline treatment & --- & zopolrestat & sorbinil & $-\ldots$ & zopolrestat & sorbinil \\
\hline number & 8 & 7 & 7 & 7 & 8 & 7 \\
\hline BW (g) & $393 \pm 24$ & $377 \pm 13$ & $396 \pm 11$ & $329 \pm 14^{*}$ & $296 \pm 21^{*}$ & $307 \pm 20^{*}$ \\
\hline BG $(\mathbf{m M})$ & $5.8 \pm 0.4$ & $6.3 \pm 0.6$ & $5.9 \pm 0.5$ & $29.3 \pm 2.0^{*}$ & $27.4 \pm 2.1^{*}$ & $27.1 \pm 2.3^{\circ}$
\end{tabular}

" $\mathrm{p}<0.05$ diabetic vs control.

\section{Phenylephrine-induced contraction}

The maximal phenylephrine-induced contractile force was $21 \%$ lower in the diabetic aorta compared to the non-diabetic control aorta (figure 2, $6.1 \pm 0.2$ vs. $7.8 \pm 0.6$ $\mathrm{mN} / \mathrm{mm}, \mathrm{p}<0.05$ ). Treatment of control animals with sorbinil or zopolrestat did not change contractile force. However, treating the diabetic animals with sorbinil or zopolrestat showed a small improvement in the contractile force $(p=0.035)$. However, there was no normalization of the contractile force by treatment with aldose reductase inhibitors. The sensitivity to phenylephrine in the different groups did not differ (see table 2).

\section{Acetylcholine-induced relaxation}

After precontracting the aorta with $0.1 \mu \mathrm{M}$ phenylephrine we assessed an acetylcholine dose-response curve. There was a significant difference in the acetylcholine-induced relaxation between non-diabetic and diabetic aortas (figure 3); residual contractile 


\section{CHAPTER 8}

tension at $100 \mu \mathrm{M}$ (maximum dose) acetylcholine was $34 \pm 6 \%$ in non-diabetic versus $13 \pm 2 \%$ in diabetic aortas $(\mathrm{p}<0.05)$. Treatment with sorbinil or zopolrestat did not have any effect on acetylcholine-induced relaxation in the aorta from non-diabetic animals. In the aortas isolated from the diabetic animals which were treated with sorbinil the acetylcholine induced curve partial shifted back to control levels. This was not observed in diabetic animals treated with zopolrestat.

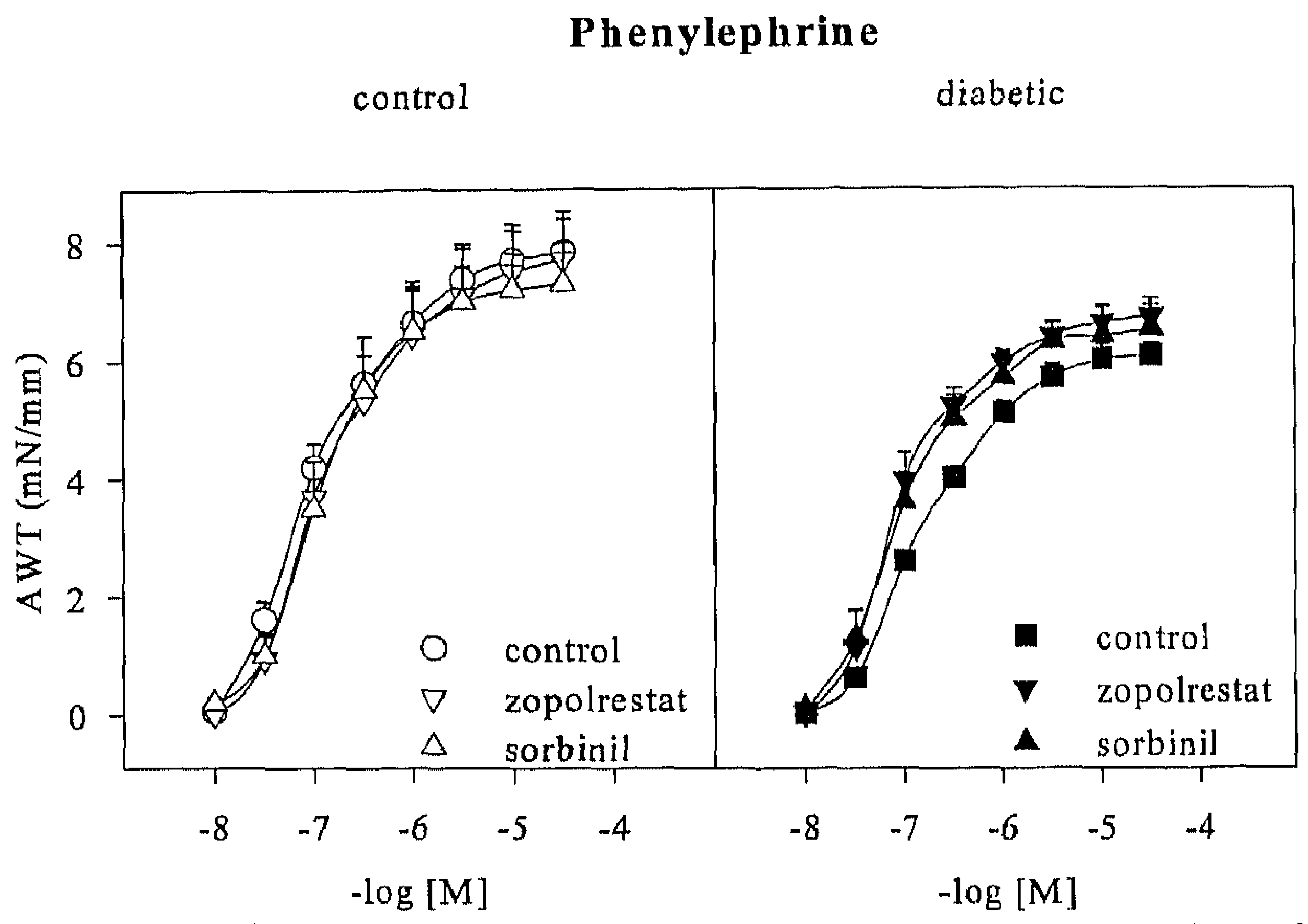

Figure 2. Cumulative dose-response curves af contractile responses to phenylephinte of aortas from diabetic and non-diabetic animals with or without (6 weeks) ARI treatment.

Table 2. EC-50 values (-log M) for response to phenylephrine (PHE), acetylcholine (ACH), and sodium nitroprusside (SNP) in aorta from treated and untreated non-diabetic and diabetic animals.

\begin{tabular}{l|c|c|c|c|c|c} 
treatment & $\begin{array}{c}\text { PHE } \\
\text { control }\end{array}$ & $\begin{array}{c}\text { PHE } \\
\text { diabetic }\end{array}$ & $\begin{array}{c}\text { ACH } \\
\text { control }\end{array}$ & $\begin{array}{c}\text { ACH } \\
\text { diabetic }\end{array}$ & $\begin{array}{c}\text { SNP } \\
\text { control }\end{array}$ & $\begin{array}{c}\text { SNP } \\
\text { diabetic }\end{array}$ \\
\hline$\cdots$ & $\begin{array}{c}7.1 \\
(7.3-6.9)\end{array}$ & $\begin{array}{c}6.9 \\
(7.0-6.7)\end{array}$ & $\begin{array}{c}5.8 \\
(5.9-5.7)\end{array}$ & $\begin{array}{c}6.1^{\circ} \\
(6.2-6.0)\end{array}$ & $\begin{array}{c}7.3 \\
(7.4-7.1)\end{array}$ & $\begin{array}{c}7.6^{*} \\
(7.7-7.5)\end{array}$ \\
\hline zopolrestat & $\begin{array}{c}7.0 \\
(7.2-6.8)\end{array}$ & $\begin{array}{c}7.2 \\
(7.4-7.0)\end{array}$ & $\begin{array}{c}6.0 \\
(6.1-5.9)\end{array}$ & $\begin{array}{c}6.3^{*} \\
(6.4-6.2)\end{array}$ & $\begin{array}{c}7.4 \\
(7.5-7.4)\end{array}$ & $\begin{array}{c}7.5 \\
(7.7-7.4)\end{array}$ \\
\hline sorbinil & $\begin{array}{c}7.0 \\
(7.1-6.9)\end{array}$ & $\begin{array}{c}7.2 \\
(7.3-7.0)\end{array}$ & $\begin{array}{c}6.1 \\
(6.2-6.1)\end{array}$ & $\begin{array}{c}6.3 \\
(6.4-6.2)\end{array}$ & $\begin{array}{c}7.4 \\
(7.5-7.4)\end{array}$ & $\begin{array}{c}7.5 \\
(7.6-7.4)\end{array}$
\end{tabular}

$* \mathrm{p}<0.05$ diabetic vs control 


\section{ALDOSE REDUCTASE INHIBITORS}

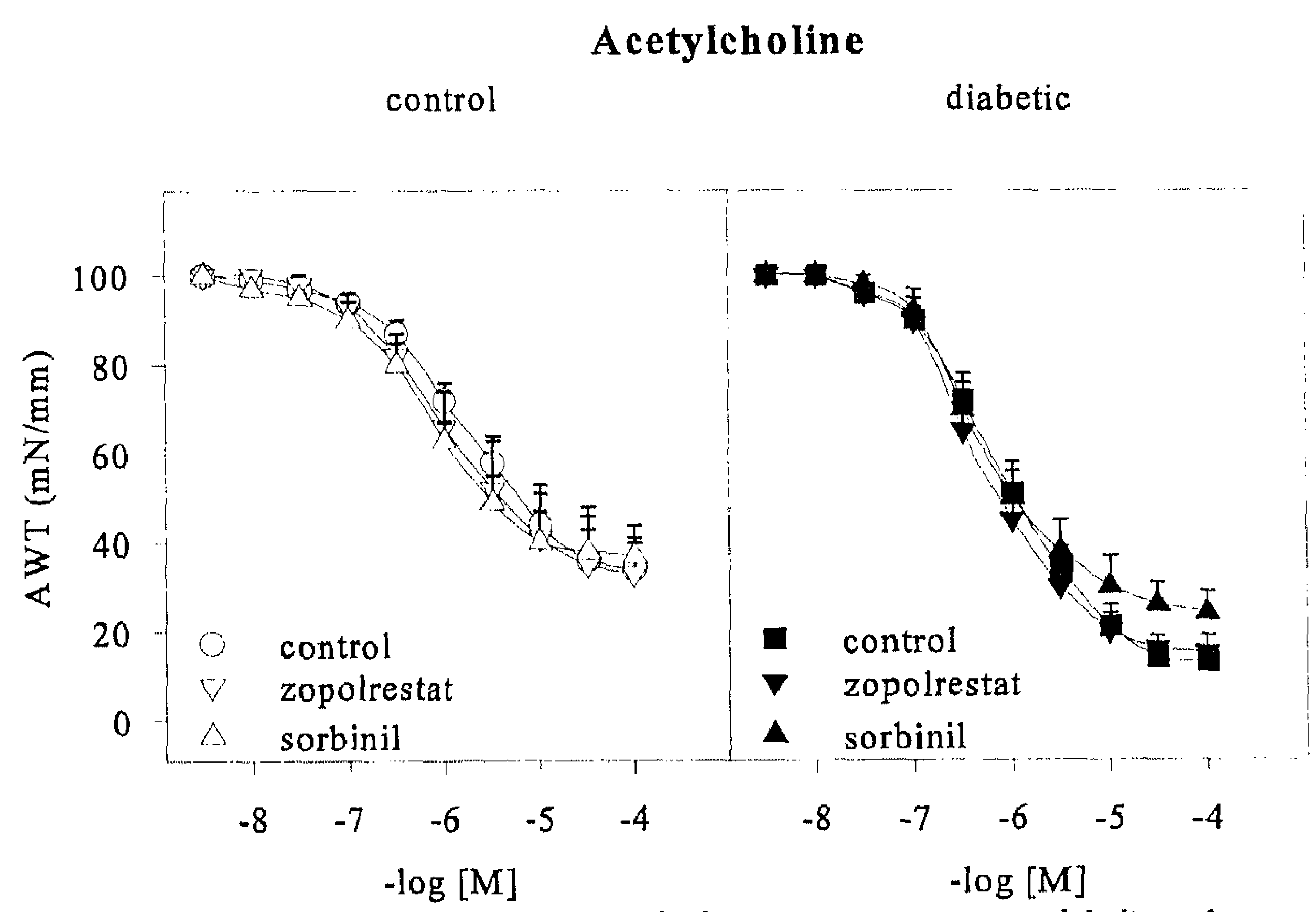

Figure 3. Cumulative dose-response curves of relaxing responses to acetylcholine of aortas from diabetic and non-diabetic animals with or without (6 weeks) ARI treatment.

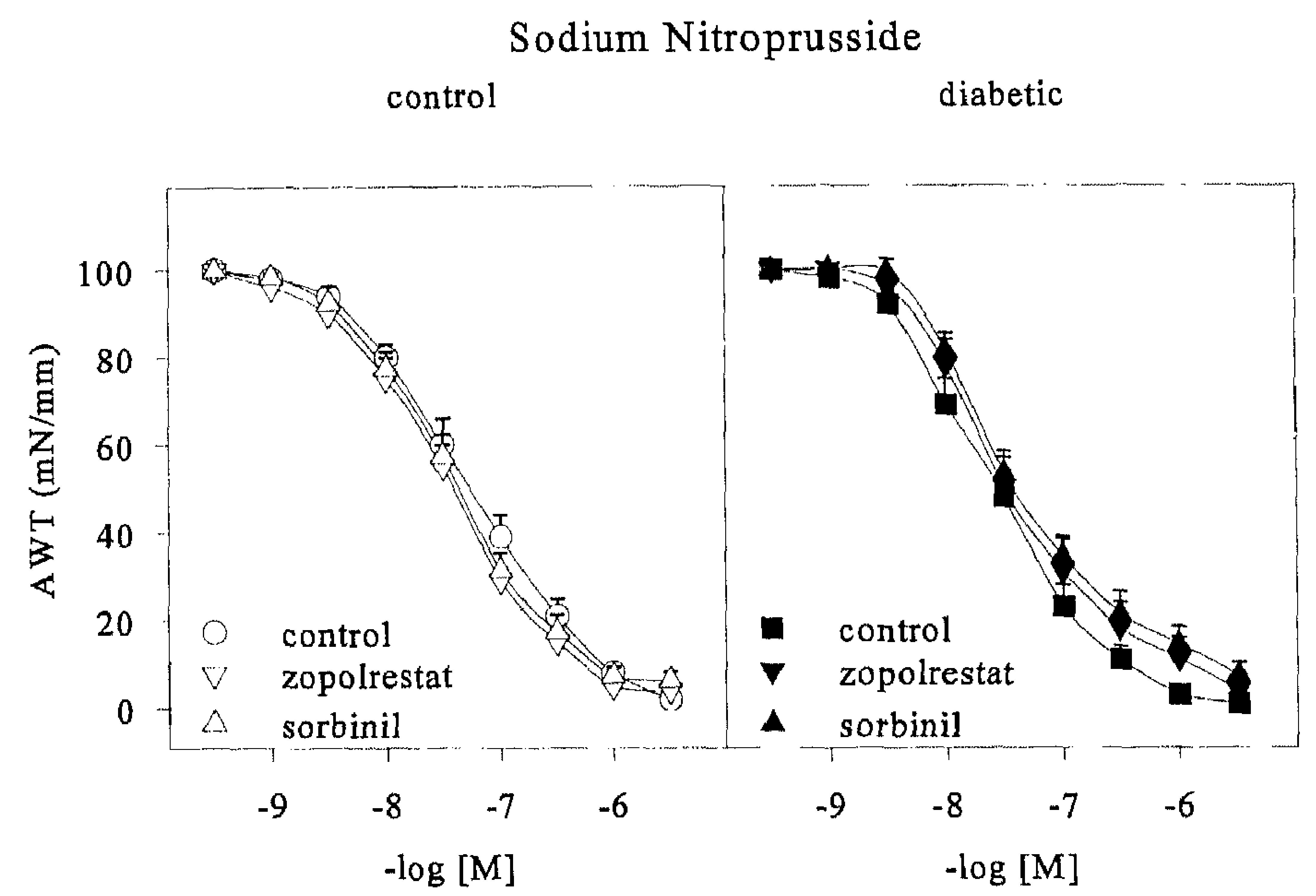

Figure 4. Cumulative dose-response curves of relaxative responses to sodium nitroprusside of aortas from diabetic and non-diabetic animals with or without ( 6 weeks) aldose reductase inhibitor treatment. $A W T=$ active wall tension 


\section{CHAPTER 8}

sodium nitroprusside-induced relaxation

There was a small, but significant difference, in sodium nitroprusside-induced relaxation between aortas from control animals and aortas from animals with experimental diabetes (figure 4, table 2). Treatment with sorbinil or zopolrestat did have an effect on sodium nitroprusside induced relaxation. However, this effect did not reach statistical significance.

\section{DISCUSSION}

Contractions tend to be weaker in the isolated aorta of diabetic rats, without significant changes in sensitivity as reflected by $\mathrm{EC}_{50}$ values. Our observations that the effect of aldose reductase inhibitors on contractile deficits in the aorta of diabetic rats without effecting hyperglycemia or body weight has also been reported by the group of Cameron ${ }^{[3]}$. They described a beneficial effect of long term treatment with aldose reductase inhibitors on the impaired contraction to phenylephrine and norepinephrine as observed in diabetic animals. A possible explanation for the impaired contractile function could be the suggestion that the contractile responses of aorta from diabetic animals show an increased susceptibility to low extracellular $\mathrm{Ca}^{2+}$. This suggests a greater reliance on this source ${ }^{[1]}$. This may be combined with an impaired release from intra cellular stores ${ }^{[12]}$ leading to an impaired contractile function. This study shows that aldose reductase inhibitors have a beneficial effect on the impaired contractile function in the aorta from diabetic animals. It is possible that the ARI's have this effect by improving the calcium handling of the smooth muscle cell.

Sorbinil, but not zopolrestat, prevented in part the development of the pathological enhanced relaxation to acetylcholine. The restoration of endothelial function was also shown by Tesfamariam ${ }^{[4]}$, but was not found by others ${ }^{[7]}$. The cause of the difference between the two drugs in preventing the enhanced vasodilatation to acetylcholine is not known.

One particular appeal of ARI's could be that they may be able to prevent or arrest progression of neuropathy, nephropathy or retinopathy without the danger of hypoglycemia ${ }^{[13]}$. The effectiveness of aldose reductase inhibitors in vivo and in vitro have been shown in preventing neuropathy, nephropathy and retinopathy $[2,9,10,14-18]$. This improvement was also shown, although less clear, in some clinical trials ${ }^{[19,20]}$, but not in others ${ }^{[7,21]}$. There is no simple explanation to this discrepancy between these studies. One of the reasons could be that end-points are 'soft' ${ }^{[22]}$ due to the fact that the time span, or starting and end point, studied are too short. Or that the tissue prone to diabetic complications is already irreversibly affected by the diabetic milieu so that one can not expect to see any influence of aldose reductase inhibitors. In addition, Tilton et al. ${ }^{[10]}$ reported that in diabetic rats treated with two different doses of an ARI, vascular dysfunction was normalized only by the higher dose despite normalization of tissue sorbitol levels by both doses. It is unclear whether vascular and neural dysfunction in chronically diabetic animals can be prevented by complete inhibition of AR or by other interventions. Another explanation for the discrepancy between animal and human 


\section{ALDOSE REDUCTASE INHIBITORS}

studies may be found in the fact that aldose reductase activity is much higher in rodents than in humans.

From this we conclude that aldose reductase inhibitors show a discordant effect in preventing vascular disturbances in experimental diabetes. It remains unclear how likely these agents are going to be useful in treatment and prevention of diabetic complications.

\section{REFERENCES}

1. Williamson JR, Chang K, Frangos M, Hasan KS, Ido Y, Kawamura T, Nyengard JR, Van Den Enden M, Kilo C, Tilton RG. Hyperglycemic pseudohypoxia and diabetic complications. Diabetes 1993;42:801-813.

2. Williamson JR, Chang K, Tilton RG, Prater C, Jeffrey JR, Weigel C, Sherman WR, Eades DM, Kilo C. Increased vascular permeability in spontaneously diabetic $\mathrm{BB} / \mathrm{W}$ rats and in rats with mild versus severe streptozocin- induced diabetes. Prevention by aldose reductase inhibitors and castration. Diabetes 1987;36:813-821.

3. Cameron NE, Cotter MA. Impaired contraction and relaxation in aorta from streptozotocindiabetic rats: role of polyol pathway. Diabetologia 1992;35:1011-1019.

4. Tesfamariam B, Palacino JJ, Weisbrod RM, Cohen RA. Aldose reductase inhibition restores endothelial cell function in diabetic rabbit aorta. J Cardiovasc Pharmacol 1993;21:205-211.

5. Tesfamariam B, Gupta S, Oates PJ, Ruderman NB, Cohen RA. Reduced $\mathrm{Na}^{+}-\mathrm{K}^{+}$pump activity in diabetic rabbit carotid-artery -reversal by aldose reductase inhibition. Am J Physiol 1993;265:H1189-1194.

6. Hodgson WC, King RG. Effects of glucose, insulin or aldose reductase inhibition on responses to endothelin- 1 of aortic rings from streptozotocin-induced diabetic rats. $\mathrm{Br} \mathrm{J}$ Pharmacol 1992;106:644-649.

7. Sima AA, Nathaniel V, Prashar A, Bril V, Greene DA. Endoneurial microvessels in human diabetic neuropathy. Endothelial cell dysjunction and lack of treatment effect by aldose reductase inhibitor. Diabetes 1991;40:1090-1099.

8. Frank RN. The aldose reductase controversy. Diabetes 1994;43:169-172.

9. Tilton GR, Chang K, Pugliese G, Eades DM, Province MA, Sherman WR, Kilo C, Williamson JR. Prevention of hemodynamic and vascular albumin filtration changes in diabetic rats by aldose reductase inhibitors. Diabetes 1989;38:1258-1270.

10. Tilton RG, Pugliese G, LaRose LS, Faller AM, Chang K, Province MA, Williamson JR. Discordant effects of the aldose reductase inhibitor, sorbinil, on vascular structure and function in chronically diabetic and galactosemic rats. J Diab Complic 1991;5:230-237.

11. Owen MP, Carrier GO. Calcium dependence of norepinephrine-induced vascular contraction in experimental diabetes. J Pharmacol Exp Ther 1980;212:253-258.

12. Pieper GM, Gross GJ. Augmented vascular relaxation to KT-362 in diabetic rat aorta: comparison to diltiazem. J Cardiovasc Pharmacol 1990;16:394-400.

13. Wolffenbuttel BHR. The DCCT - metabolic control matters. Neth J Med 1993;43:241-245. 


\section{CHAPTER 8}

14. Tilton RG, Chang K, Pugliese G, Eades DM, Province MA, Sherman WR, Kilo C, Williamson JR. Prevention of hemodynamic and vascular albumin filtration changes in diabetic rats by aldose reductase inhibitors. Diabetes 1989;38:1258-1270.

15. Schmidt RE, Plurad SB, Sherman WR, Williamson JR, Tilton RG. Effects of aldose reductase inhibitor sorbinil on neuroaxonal dystrophy and levels of myo-inositol and sorbitol in sympathetic autonomic ganglia of streptozocin-induced diabetic rats. Diabetes 1989;38:569579.

16. Williamson JR, Ostrow E, Eades D, Chang K, Allison W, Kilo C, Sherman WR. Glucoseinduced microvascular functional changes in nondiabetic rats are stereospecific and are prevented by an aldose reductase inhibitor. J Clin Invest 1990;85:1 167-1172.

17. Yorek MA, Dunlap JA. The effect of elevated glucose levels on myo-inositol metabolism in cultured bovine aortic endothelial cells. Metabolism 1989;38:16-22.

18. Meyer LA, Ubels JL, Edelhauser HF. Comeal endothelial morphology in the rat. Effects of aging, diabetes, and topical aldose reductase inhibitor trcatment. Invest Ophthalmol Vis Sci $1988 ; 29: 940-948$.

19. Sima AAF, Prashar A, Nathaniel V, Bril V, Werb MR, Greene DA. Overt diabetic neuropathy: repair of axo-glial dysjunction and axonal athrophy by aldose reductase inhibition and its correlation to improvement in nerve velocity. Diabetic Med 1993;10:115-121.

20. Judzewitsch RG, Jaspan JB, Polonsky KS, Weinberg CR, Halter JB, Halar E, Pfeifer MA, Vukadinovic C, Bernstein L, Schneider M, Liang K-Y, Gabbay KH, Rubenstein AH, Porte DJ. Aldose reductase inhibition improves nerve conduction velocity in diabetic patients. $\mathrm{N}$ Engl $\mathrm{J}$ Med 1983;308:119-125.

21. Sorbinil Rethinopathy Trial Research Group. A randomized trial of sorbinil, an aldose reductase inhibitor, in diabetic retinopathy. Ophthalmology 1990;108:1234-1244.

22. Tomlinson DR, Stevens EJ", Diemel LT. Aldose reductase inhibitors and their potential for the treatment of diabetic complications. TiPS 1994;15:293-297. 


\section{Aorta compliance in intact diabetic rats}

B.J. Heesen, D.S. Van Ingen Schenau, B.H.R. Wolffenbuttel, and J.G.R. De Mey

Cardiovascular Research Institute Maastricht (CARIM),

Depts. of Internal Medicine and Pharmacology,

University of Limburg, Maastricht (NL) 


\section{SUMMARY}

We compared in intact control rats and in rats with 6 week old streptozotocininduced (STZ) diabetes, the diameter, distensibility and compliance of the thoracic aorta. During urethane-anesthesia intra-aortic pressure $(P)$ was recorded and the diameter of the aorta and its distension during the cardiac cycle were determined by ultrasound arterial wall tracking. From these and ex vivo morphometric measurements, the lumen area at end-diastole $\left(A_{\text {dia }}\right)$, the compliance $(C C)$, the distensibility $(D C)$ and the elastic modulus $\left(E_{\text {ind }}\right.$ of the vessel were calculated. In diabetic rats: (1) $P_{\text {dia }}$ and $C C$ were not significantly altered, (2) body weight, pulse pressure, heart rate, $A_{\text {dia }}$ the cross sectional area of the aortic media and the $E_{\text {inc }}$ of the aorta were significantly reduced and (3) the DC of the aorta was significantly increased. Intravenous infusion of low subpressor doses of phenylephrine $(0.5$ $\mu \mathrm{g} / \mathrm{min})$ reduced $A_{\text {dia }}$ and $C C$ to the same extent in control and diabetic rats and did not modify DC. During administration of a high pressor dose of phenylephrine (2.5 $\mu \mathrm{g} / \mathrm{min})$, the local vasoconstrictor action of the agonist was overruled by the increased distending pressure and besides the $C C$ also the DC of the aorta was reduced. Under this condition, differences between the aorta of diabetic and control rats were abolished. Infusion of sodium nitroprusside $(3,10,30 \mu \mathrm{g} / \mathrm{min})$, reduced both $P_{\text {dia }}$ and $A_{\text {diw }}$ and increased $D C$, but not CC. Differences between diabetics and controls persisted in the presence of sodium nitroprusside. These observations indicate that the dynamic compliance of the aorta is not modified in experimental diabetes despite alterations of aortic structure and aortic smooth muscle reactivity. The restriction of aortic lumen diameter and wall mass seems to be compensated by a reduction of the stiffness of the aortic wall materials. Aortic smooth muscle tone influences compliance only moderately. 


\section{COMPLIANCE OF THE AORTA}

\section{INTRODUCTION}

Diabetic patients are particularly prone to develop hypertension, atherosclerosis, coronary artery disease and ischemic heart diseases ${ }^{[1,2]}$. In general, these cardiovascular diseases involve stiffening of the large arteries ${ }^{[3-6]}$ and hence a reduction of their compliance. This vascular mechanical property depends on the structure of the arterial wall, the reactivity of the arterial smooth muscle and on the distending pressure ${ }^{[7-10]}$. These may all be modified during chronic hyperglycemia. For instance in rats, in which diabetes was induced by streptozotocin (STZ) ${ }^{[1,12]}$, the thoracic aorta wall contains elevated levels of calcium and of advanced glycosylation endproducts ${ }^{[1,13]}$, the responsiveness of the aortic wall to various vasoactive agents is altered ${ }^{[11,14-19]}$, and mean arterial blood pressure and pulse pressure are reduced ${ }^{[11,20,21]}$.

In the present study we used ultrasound arteriography and a wall tracking system ${ }^{[22]}$ to compare in intact anesthetized control and STZ-treated diabetic rats the caliber, compliance and distensibility of the thoracic aorta ${ }^{[23,24]}$. Furthermore, intravenous infusions of phenylephrine and sodium nitroprusside, and morphometric analysis of cross sections of the isolated fixed vessel were performed to evaluate contributions of smooth muscle tone, blood pressure and aortic wall structure.

\section{RESEARCH DESIGN AND METHODS}

Experiments were performed in male Wistar RP rats (TNO-REPGO, Rijswijk, The Netherlands). At 12 weeks of age, diabetes was induced in part of the animals by a single ip injection of streptozotocin $(65 \mathrm{mg} / \mathrm{kg})^{[11,12]}$. Development of diabetes was assessed by measurements of blood glucose levels with the hexokinase method. At 18 weeks of age the animals were anesthetized with sodium-pentobarbital $(60 \mathrm{mg} / \mathrm{kg}$ ip) and equipped with catheters for intra-aortic pressure recording and intravenous drug infusion. The catheters were advanced from a femoral artery and vein into the abdominal aorta (just below the orifice of the left renal artery) and vena cava, respectively. They were guided under the skin and exteriorized at the back of the head. Two days later, the animals were anesthetized with urethane $(800 \mathrm{mg} / \mathrm{kg}$ iv) after which their body temperature was controlled through a rectal thermistor and infrared heating lamp. The intra-aortic catheter was connected to a low volume displacement pressure transducer (CP-01, Century Technology $\mathrm{Co}$, Inglewood $\mathrm{Ca}$, USA) and pressure was allowed to stabilize during $30 \mathrm{~min}$. Subsequently in the intact anesthetized animals the diameter and distension of the thoracic aorta were recorded under basal conditions and during infusion of either phenylephrine (Sigma Chemicals, Saint Louis Mo, USA; $0.1,0.5,2.5 \mu \mathrm{g} / \mathrm{min}$ ) or sodium nitroprusside (Janssen Chemica, Beerse, Belgium; 3, 10,30 $\mu \mathrm{g} / \mathrm{min}$ ). Separate animals were used for evaluation of effects of the vasopressor agent and of the vasodilator. 


\section{CHAPTER 9}

\section{Ultrasound Assessment of Aorta Diameter and Wall Movement}

The diameter and the change in diameter during the cardiac cycle were assessed at the level of the thoracic aorta as a continuous function of time using a vessel wall tracking system (WTS) attached to a conventional B-mode ultrasound system (Pie480, 7.5 MHz linear array, Pie Medical, Maastricht, The Netherlands) ${ }^{[22-25]}$. The ultrasound probe was placed on the thorax slightly to the left of the sternum. The thoracic aorta was visualized in B-mode and an M-line was positioned perpendicular to the vessel walls approximately $10 \mathrm{~mm}$ cranially from the diaphragm. Thereafter the ultrasound system was switched to $\mathrm{M}$-mode, where ultrasound was emitted and received along the selected line of sight at a programmable emission trigger frequency. The concept of the WTS has been described in detail before ${ }^{[22]}$. It is based on a data acquisition system, capable of capturing the received and amplified radio frequency (RF) signals synchronously with the emission trigger at a programmable sample frequency of up to $30 \mathrm{MHz}$ and with a dynamic range of $48 \mathrm{~dB}$ (8 bits). The position and width of the range of interest are programmable (on average 20 and $10 \mathrm{~mm}$, respectively, in the present study). The size of the internal data memory is 1 MByte, allowing for the temporary storage of e.g. $512 \mathrm{RF}$ lines of 2000 data points each. At an emission trigger frequency of $250 \mathrm{~Hz}$ the memory will then hold $2.5 \mathrm{sec}$ of data corresponding to approximately 15 cardiac cycles (and 3 respiration cycles) under the present experimental conditions. The WTS is also equipped with an acquisition system for reference signals such as blood pressure, which are sampled synchronously with the emission trigger, activating the capture of an RF line. After completion of the data acquisition the data are transferred to a personal computer. The first line acquired is graphically presented an a display, allowing manual identification of the anterior and posterior wall boundaries by placing two markers, representing the sample windows for data processing. Once the walls are identilied the remaining data are transferred and processed on the fly (less than $10 \mathrm{sec}$ ). To extract the change in position of either the anterior or posterior wall, averaged over a few RF lines, the approach based on the cross correlation model (CCM) for corresponding segments of subsequent RF lines, was applied ${ }^{[25]}$. This method has a low noise sensitivity and is insensitive to the RF carrier frequency. The estimates for the cross correlation cocflicients are based on a running average over a programmable number of RF lines (data window in time) to enhance stability of the estimate for the mean displacement. To ensure that always the signals returned by the same structure are considered, the position of the sample windows are adjusted according to the observed displacements (tracking window). The difference between the displacement signal of the posterior and anterior wall yields the change in diameter as a function of time. From the observed distension wave form, in combination with the initial distance between the sample windows, the end diastolic diameter, the peak-to-peak change in diameter, and the length of the cardiac cycle can be extracted for each cardiac cycle. Measurements were started after blood pressure and heart rate had stabilized under anaesthesia $(30 \mathrm{~min})$. In each animal one observer performed two $2.5 \mathrm{sec}$ recordings under basal conditions and during administration of each dose of vasoactive agent. For each condition, the observations during the two 2.5 sec periods (approximately 30 cardiac cycles) were averaged. Diameters and diameter changes were converted to lumen area's and changes thereof ( $A$ and $\Delta A)$, assuming a 


\section{COMPLIANCE OF THE AORTA}

perfect circular cross section of the vessel. With the additional assumption that the vessel segment length remains constant, the absolute and the relative change in aortic lumen area noted during the cardiac cycle and expressed per unit of pressure provide information about the compliance and distensibility of the vessel, respectively ${ }^{[25]}$. $\Delta \mathrm{A} / \Delta \mathrm{P}$ and $(\Delta \mathrm{A} / \mathrm{A}) / \Delta \mathrm{P}$ will be referred to as the compliance coefficient $(\mathrm{CC})$ and the distensibility coefficient (DC), respectively ${ }^{[25]}$.

Structural Measurements.

Following ultrasound recording of aortic wall mechanics, the rats were killed by exsanguination and their thoracic aorta was isolated. The extent of longitudinal retraction of the vessel during isolation was determined by measurements of the distance between intercostal arteries before $\left(L_{i}\right)$ and after $\left(L_{e}\right)$ isolation. Retraction was in the order of $25 \%$ and did not differ significantly between control and diabetic rats. A $10 \mathrm{~mm}$ long supradiaphragmatic segment of the vessel was then fixed by immersion in $4 \%$ phosphate buffered paraformaldehyde at room temperature. Following dehydration and imbedding in paraffin, $4 \mu \mathrm{m}$ thick cross sections were stained with Lawson's solution, a classical elastin stain. Using semi-automated morphometry as described before ${ }^{[26,27]}$, the cross sectional area of the tunica media $\left(\mathrm{CSA}_{c}\right.$; defined as the area enclosed by the internal and external elastic laminae) was determined. This measure was converted to the media cross sectional area expected in vivo $\left(\operatorname{CSA}_{i}\right)$ taking into account the retraction of the vessel during isolation; i.e. $\operatorname{CSA}_{\mathrm{i}}=\mathrm{L}_{\mathrm{e}} / \mathrm{L}_{\mathrm{i}}$ * $\mathrm{CSA}_{\mathrm{c}}$. Media cross sectional area in vivo was used together with the lumen diameter at diastolic pressure $\left(\mathrm{D}_{\text {dia }}\right)$ determined by ultrasound in the intact rats, to calculate media thickness $\left(\mathrm{M}_{\mathrm{l}}\right)$ and media to lumen ratio $(\mathrm{W} / \mathrm{L})$ at end-diastole according to:

$$
\begin{aligned}
& \mathrm{Mt}=-\left(\mathrm{D}_{\mathrm{dia}} / 2\right)+\left\{\left(\mathrm{D}_{\mathrm{dia}} / 2\right)^{2}+\mathrm{CSA}_{\mathrm{i}} / \pi\right\}^{1 / 2} \\
& \mathrm{~W} / \mathrm{L}=\mathrm{Mt} /\left(\mathrm{D}_{\mathrm{dia}} / 2\right)
\end{aligned}
$$

In these calculations it is assumed that wall volume remains constant under all conditions and that the cross-section of the aorta is perfectly circular in situ. From these morphometric measurements and the distensibility coefficient (DC) that was determined in vivo, the incremental elastic modulus or Young's modulus $\left(\mathrm{E}_{\text {inc }}\right.$ ) was calculated according to:

$$
\mathrm{E}_{\mathrm{inc}}=\mathrm{D}_{\mathrm{dia}} /\left(\mathrm{M}_{\mathrm{t}} \cdot \mathrm{DC}\right) \text {. }
$$

Drugs

Streptozotocin and phenylephrine hydrochloride were purchased from Sigma Chemicals Co. (St. Louis, MO, U'SA), sodium nitroprusside was purchased from Janssen Chemica (Beerse, Belgium). Streptozotocin was dissolved in citrate buffer $(\mathrm{pH}$ 4.5). Phenylephrine and sodium nitroprusside were dissolved in saline and given to the animal with a variable flow rate to change the dose submitted to the animal. 


\section{CHAPTER 9}

\section{Statistics}

Statistical significance of differences between groups was evaluated by unpaired t-test, using the SPSS for Windows version 6.0 software (SPSS Inc, Chicago, Il, USA). Data are shown as means \pm SEM, unless stated otherwise. $P$ values $<0.05$ were considered statistically significant.

\section{RESULTS}

\section{Basal Conditions}

In STZ-treated rats, body weight was significantly lower and blood glucose significantly higher than in age-matched controls (table 1). During urethane anesthesia, pulse pressure and heart rate were significantly lower in diabetic rats than in controls (table 1). Also diastolic blood pressure tended to be reduced in the diabetics, but this did not reach statistical significance.

Table 1. General properties of intact anesthetized control and STZ-treated diabetic rats.

\begin{tabular}{l|c|c} 
& CONTROL & DIABETIC \\
\hline number & 10 & 9 \\
\hline Body Weight $(\mathrm{g})$ & $372 \pm 26$ & $220 \pm 24^{\circ}$ \\
\hline Blood Glucose (mM) & $7 \pm 1$ & $27 \pm 7^{*}$ \\
\hline Diastolic Pressure (mmHg) & $87 \pm 13$ & $78 \pm 13$ \\
\hline Pulse Pressure (mmHg) & $34 \pm 4$ & $24 \pm 2^{\circ}$ \\
\hline Heart Rate (b/min) & $347 \pm 40$ & $309 \pm 37^{*}$ \\
${ }^{*} \mathrm{p}<0.05$ diabetic vs control & &
\end{tabular}

In Figure 1, the aortic lumen caliber is shown during consecutive heart beats in a control rat. Lumen caliber increased and decreased as pressure increased and decreased. Aortic wall behavior differed only minimally during the rising and falling phase of the cardiac cycle. On average (two series of $10-12$ consecutive heart beats in 10 control rats), the area enclosed by lumen caliber - pressure loops was not statistically significant $(0.25 \pm 0.25 \mathrm{mN})$. This suggests that viscous wall properties did not interfere with wall movement during individual cardiac cycles. This was also the case for the thoracic aorta of diabetic rats for which the area enclosed by lumen caliber - pressure loops averaged $-0.15 \pm 0.15 \mathrm{mN}$. The behavior of the aorta during the cardiac cycle in intact rats can thus be accurately described by (1) the lumen area $\left(A_{\text {dia }}\right)$ at diastolic pressure $\left(\mathrm{P}_{\mathrm{diz}}\right)$ and by $(2)$ the maximal changes in lumen area $(\Delta A)$ and pressure $(\Delta \mathrm{P})$ during the cardiac cycle. Furthermore because of the apparent lack of viscous wall behavior, differences in aortic wall mechanics between controls and 


\section{COMPLIANCE OF THE AORTA}

diabetics and effects of vasoactive agents, are unlikely to be influenced by differences or changes in pulse pressure or heart rate.

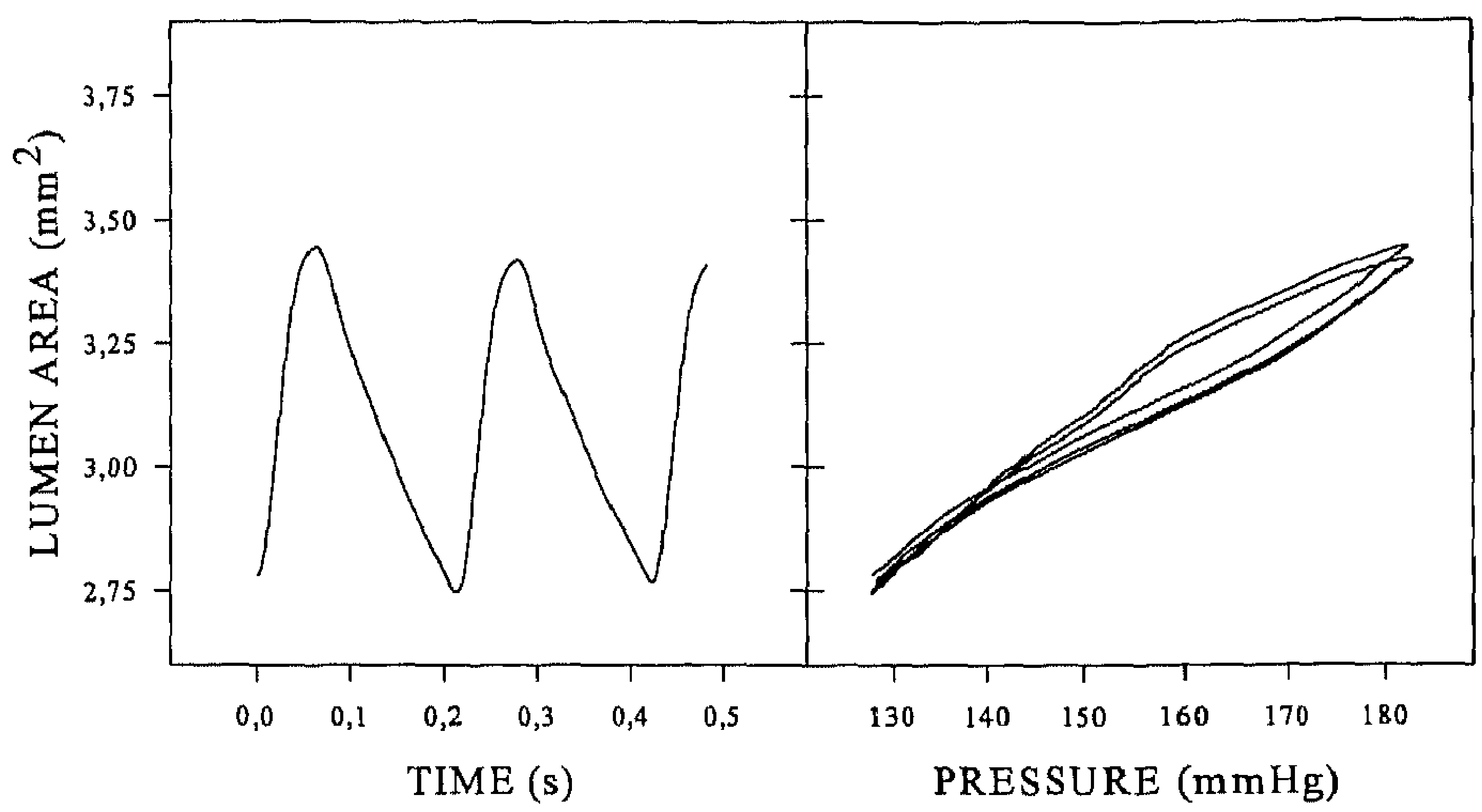

Figure 1. Aortic lumen area during 2.5 heart beats in a control rat. Left: lumen area as a function of time; Right: lumen area of the aorta as a function of intra-aortic pressure.

In table 2, aortic wall properties are summarized for anesthetized rats under basal conditions. In STZ-diabetic rats, compared to controls: (1) $P_{\text {dia }}$ tended to be lower, (2) $\mathrm{A}_{\text {dia }}, \Delta \mathrm{A}$ and $\Delta \mathrm{P}$ and the cross sectional area of the media (CSA) were significantly smaller, but (3) the compliance $(\mathrm{CC}=\Delta \mathrm{A} / \Delta \mathrm{P})$ was not modified. Consequently the distensibility $((\Delta \mathrm{A} / \mathrm{A}) / \Delta \mathrm{P})$ was significantly larger and the incremental elastic modulus $\left(E_{\text {inc }}\right)$ significantly smaller in diabetic than control rats (table 2$)$.

In neither control nor diabetic rats, there was a significant correlation between $A_{\text {dia }}$ or CSA on the one hand and body weight on the other hand (figure 2). Yet, it can not be excluded that the smaller body weight of diabetic rats was responsible for the smaller lumen caliber and smaller media mass of their aorta. This may also be the case for the smaller distension during the cardiac cycle because, at least in diabetic rats, there was a significant linear correlation between $\Delta \mathrm{A}$ and body weight (figure 2).

Effects of Vasoactive Agents.

Effects of the vasoconstrictor and pressor agent phenylephrine and of the vasodilator and depressor agent sodium nitroprusside on aortic wall mechanics were compared in intact anesthetized control and STZ-induced diabetic rats. In view of the difference in body mass, doses of the iv infused agents were normalized to body weight. 


\section{CHAPTER 9}
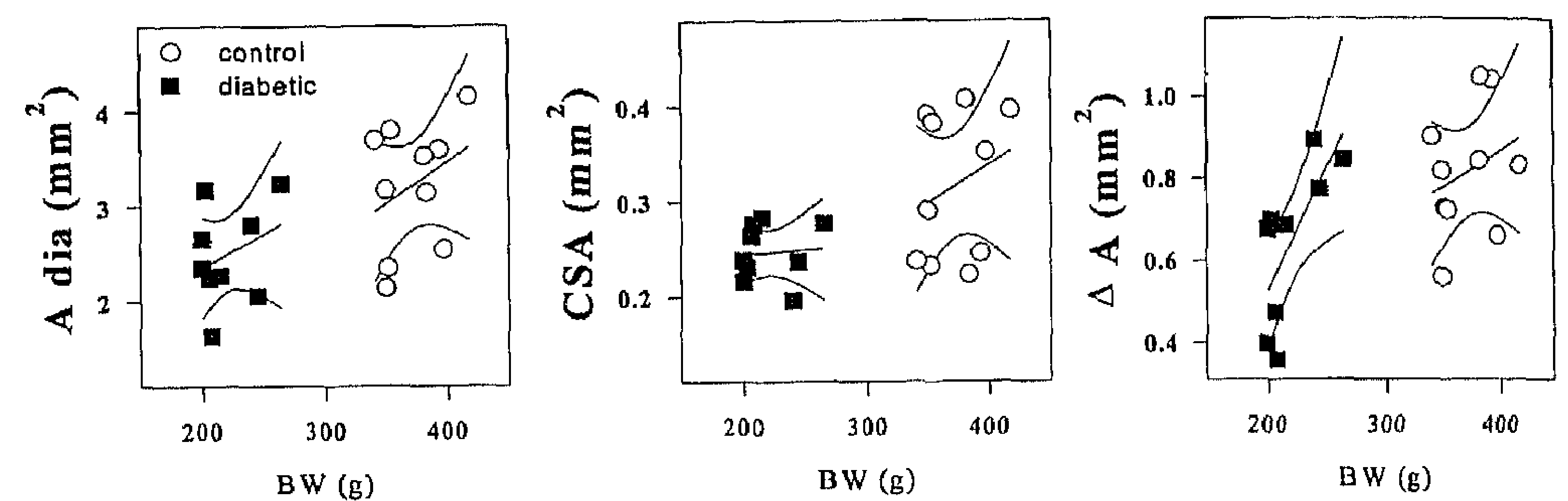

Figure 2. Relationship between body weight $(B W)$ and diastolic lumen area $\left(A_{\text {citr }}\right.$ left) media cross sectional area (CSA, middle) and maximal area change during the cardiac cycle $(\triangle A$, right) in the thoracic aorta of control (open circles) and diabetic (closed squares) rats.

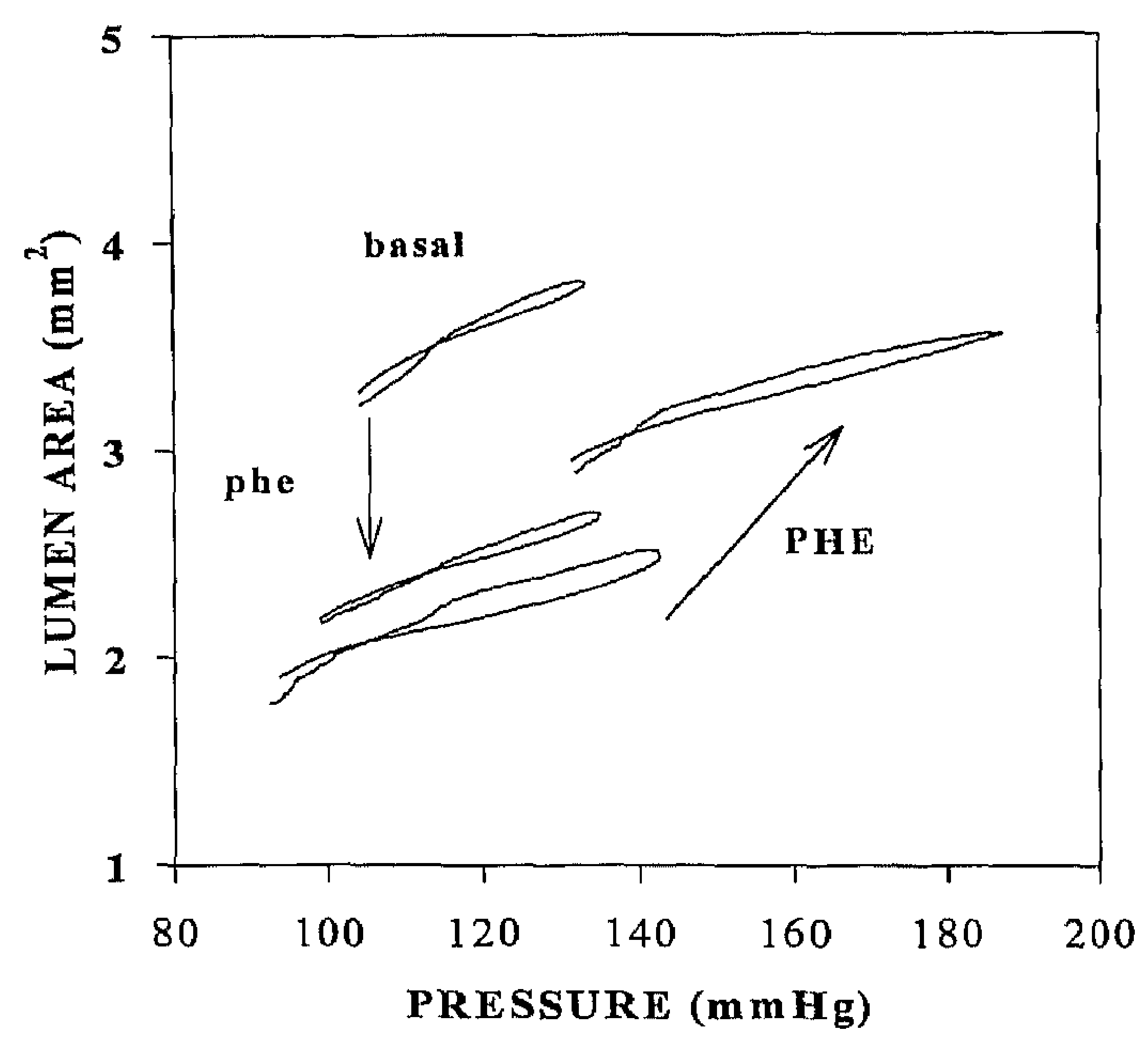

Figure 3. Effects of iv infusion of phenylephrine (low dose 'phe'; $0.1,0.5$, and high dose 'PHE' 2.5 $\mu \mathrm{g} / \mathrm{min})$ on intra-aortic pressure, thoracic aorta lumen caliber and their interrelationship in a urethane-anesthetized control rat. Randomly selected cardiac cycles after approximalely $10 \mathrm{~min}$ infusion of each dose of drug are shown. 


\section{COMPLIANCE OF THE AORTA}

\section{Phenylephrine}

In figure 3 the effect of iv infusion of phenylephrine on the thoracic aorta of a control rat is illustrated. The low doses of the $\alpha_{1}$-adrenoceptor agonist did not modify diastolic blood pressure but reduced the diastolic lumen caliber of the aorta. Furthermore, the compliance of the vessel, represented by the slope of the A-P relationship, was reduced. At $2.5 \mu \mathrm{g} / \mathrm{kg} . \mathrm{min}$, phenylephrine significantly increased the diastolic blood pressure. This was accompanied by an increase of the diastolic aortic lumen caliber back to near basal values. Also, compliance was further reduced.

\begin{tabular}{l|c|c|c}
\multicolumn{2}{l|}{} & CONTROL & DIABETIC \\
\hline $\mathrm{n}$ & & 10 & 9 \\
\hline $\mathrm{P}_{\text {dia }}$ & $\mathrm{kPa}$ & $11.96 \pm 0.51$ & $10.96 \pm 0.57$ \\
\hline $\mathrm{A}_{\text {dia }}$ & $\mathrm{mm}^{2}$ & $3.21 \pm 0.21$ & $2.49 \pm 0.18^{*}$ \\
\hline$\Delta \mathrm{P}$ & $\mathrm{kPa}$ & $4.46 \pm 0.18$ & $3.17 \pm 0.01^{*}$ \\
\hline$\Delta \mathrm{A}$ & $\mathrm{mm}^{2}$ & $0.82 \pm 0.05$ & $0.64 \pm 0.06^{*}$ \\
\hline $\mathrm{CC}$ & $\mathrm{mm}^{2} / \mathrm{kPa}$ & $0.186 \pm 0.038$ & $0.197 \pm 0.061$ \\
\hline $\mathrm{DC}$ & $1 / \mathrm{kPa}$ & $0.059 \pm 0.013$ & $0.079 \pm 0.021^{*}$ \\
\hline $\mathrm{CSA}_{\mathrm{m}}$ & $\mathrm{mm}$ & $0.710 \pm 0.073$ & $0.612 \pm 0.026^{*}$ \\
\hline $\mathrm{M}_{\mathrm{t}}$ & $\mu \mathrm{m}$ & $81.6 \pm 12.0$ & $75.4 \pm 14.0$ \\
\hline $\mathrm{E}_{\text {inc }}$ & $\mathrm{kPa}$ & $409 \pm 57$ & $287 \pm 40^{*}$
\end{tabular}

Table 2. Aortic wall properties in intact anesthetized control and STZ-treated diabetic rats under basal conditions. $P$, Intra-aortic blood pressure; $A$, aortic lumen area; $\triangle P$, pulse pressure; $\triangle A$, aortic distension during the cardiac cycle; $C C$, compliance coefficient; $D C$, distensibility coefficient; $C S A$, cross sectional area of the media; $M_{n}$ thickness of the media at $P_{\text {dia }} ; E_{\text {inc }}$ incremental elastic modulus. Means $\pm S E M .^{*}$, the difference from control is statistically significant $(P<0.05)$.

Mean observations in control and diabetic rats are summarized in figure 4 . In both groups of animals, the low doses of phenylephrine $(0.1$ to $1.0 \mu \mathrm{g} / \mathrm{kg} \cdot \mathrm{min})$; (1) did not modify diastolic blood pressure, while increasing pulse pressure and reducing heart rate, (2) caused an isobaric vasoconstriction of the aorta and (3) reduced aortic compliance but not distensibility. Under this condition, differences in $A_{\text {dia }}$ between diabetics and controls persisted although the tendency for $P_{\text {dia }}$ to differ under basal conditions was not seen during administration of low doses of phenylephrine. In diabetic rats as in controls, the high pressor dose of phenylephrine overruled the local vasoconstriction induced by the agonist and reduced both compliance and distensibility. Under this condition, differences between diabetics and controls in terms of diastolic lumen area and distensibility of the aorta were abolished (figure 4). 


\section{CHAPTER 9}
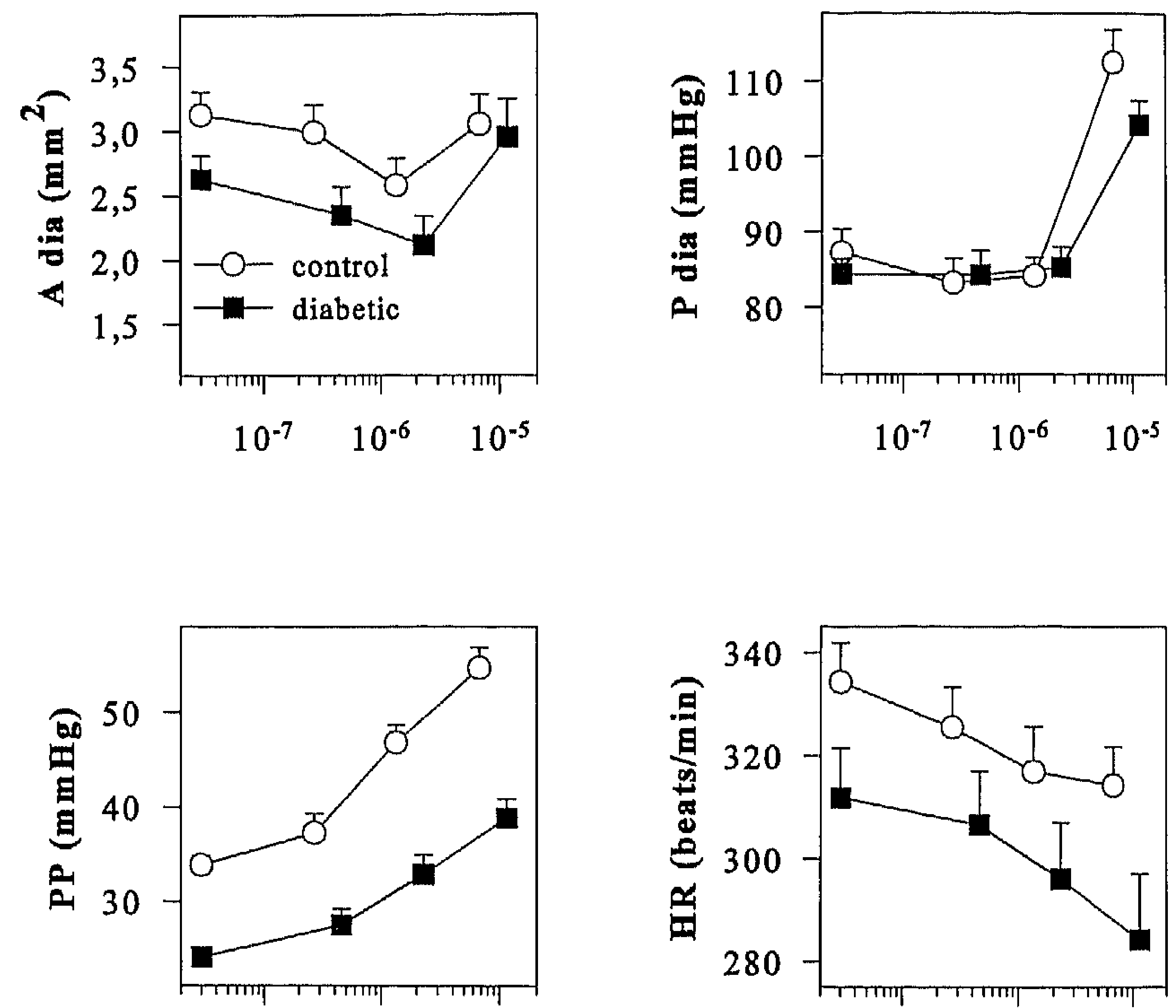

$10^{-7} \quad 10^{-6} \quad 10^{-5}$
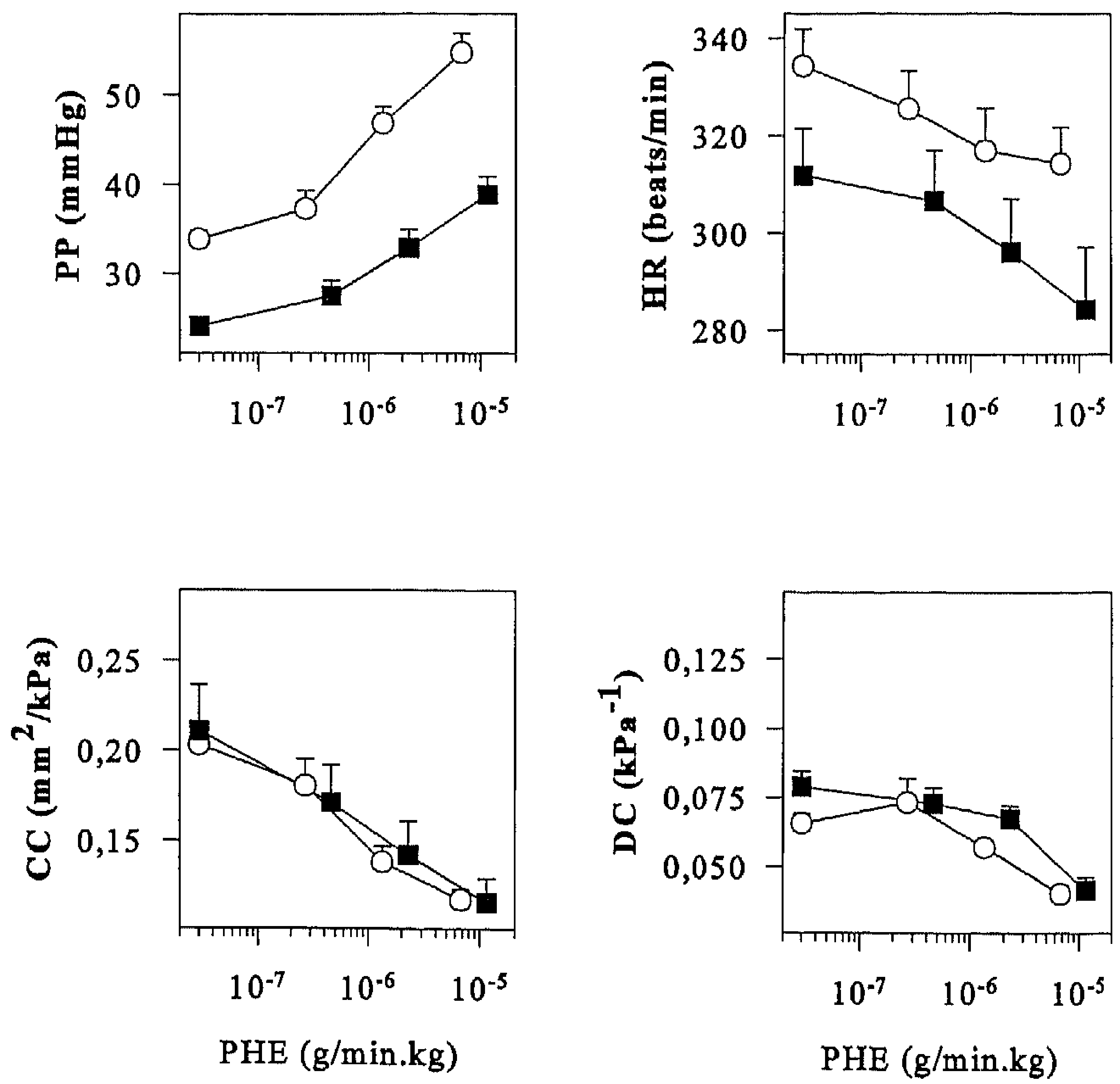

Figure 4. Effects of phenylephrine on aortic wall mechanics in diabetic (closed square) and control rats (open circle). Thoracic aorta lumen area at diastolic pressure $\left(A_{\text {dio }}\right)$, the compliance coefficient $(C C)$ and distensibility coefficient $(D C)$ of the vessel are shown along with the intra-aortic diastolic blood pressure (Pdia), pulse pressure (PP), and heart rate (HR) under basal conditions and during iv infusion of increasing doses of phenylephrine. 

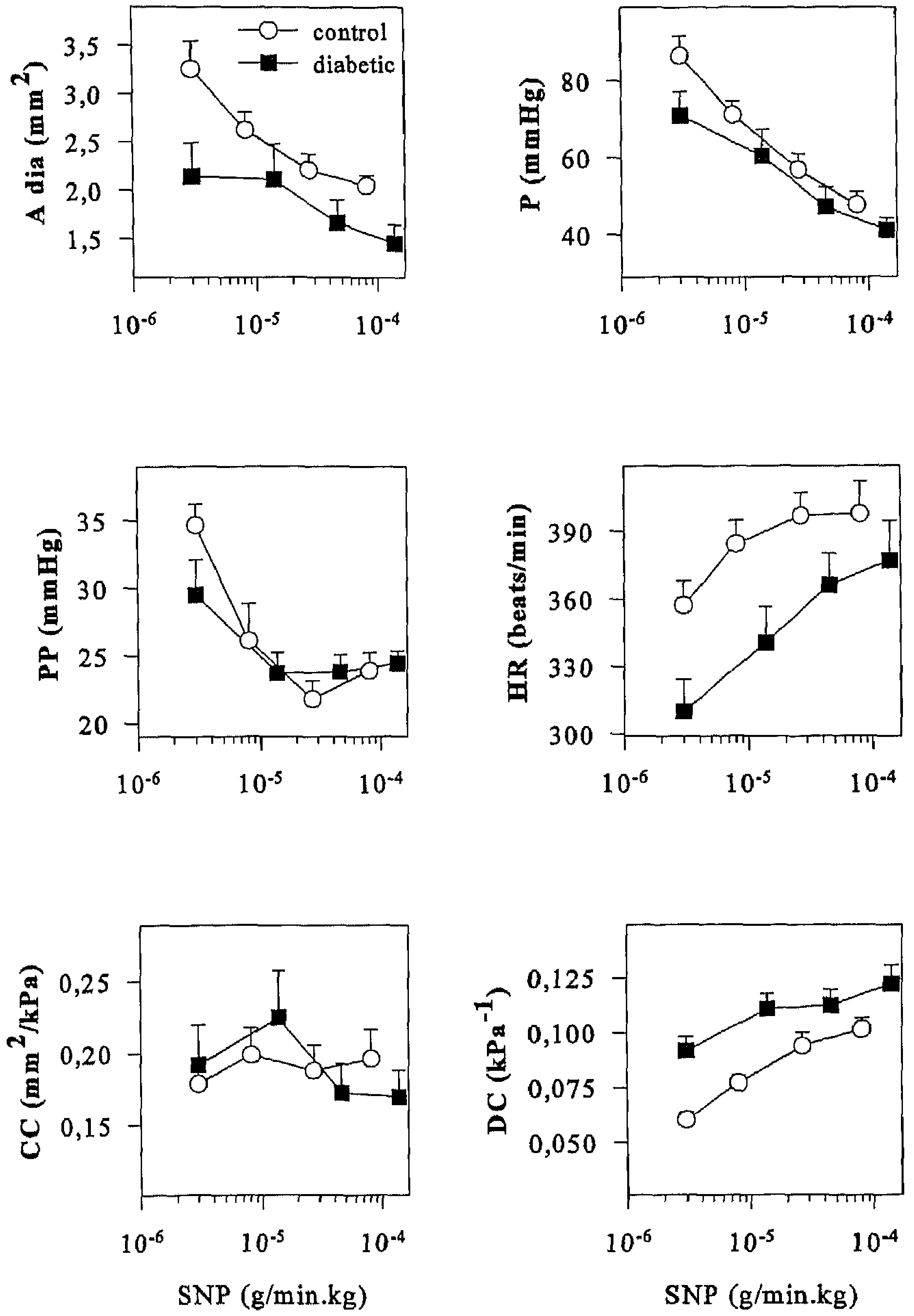

Figure 5. Effects of sodium nitroprusside on aortic wall mechanics in diabetic (closed square) and control rats (open circle). Thoracic aorta lumen area at diastolic pressure $\left(A_{\text {dia }}\right)$, the compliance coefficient (CC) and distensibility coefficient $(D C)$ of the vessel are shown along with the intra-aortic diastolic blood pressure $\left(P_{\text {dia }}\right)$, pulse pressure (PP), and heart rate (HR) under basal conditions and during iv infusion of increasing doses of sodium nitroprusside. 


\section{CHAPTER 9}

\section{Sodium nitroprusside.}

The three doses of the nitrovasodilator which we used, lowered diastolic blood pressure and pulse pressure and increased heart rate in control rats (figure 5). This was accompanied by a reduction of the diastolic lumen caliber of the aorta without a significant alteration of the compliance of the vessel. Consequently aortic distensibility increased during administration of the vasodilator (figure5).

In diabetic rats the effects of iv administered sodium nitroprusside were qualitatively similar (figure 5). Diastolic pressure, pulse pressure and aortic diastolic lumen area were significantly reduced while aortic distensibility was significantly increased. Yet, higher doses of the vasodilator seemed to be required to affect lumen caliber in diabetic animal than in controls. Furthermore, differences between both groups in terms of aortic lumen area and distensibility persisted in the presence of a high dose of sodium nitroprusside.

\section{DISCUSSION}

In anesthetized intact diabetic rats the lumen diameter of the thoracic aorta was reduced and the distensibility of the vessel was increased while the pulsatile compliance was not altered. We evaluated whether this was due to (1) modified distending pressure, (2) increased aortic smooth muscle tone, (3) altered aortic wall mass and composition or to (4) reduced body mass.

Stiffening of large elastic arteries may contribute to the development of systolic hypertension, cardiac hypertrophy and atherosclerosis in diabetic patients $[1,2,4,-6]$. Arterial stiffness determines the arterial lumen caliber at a given distending pressure and the caliber change during the cardiac cycle ${ }^{[4-10]}$. It is often described in terms of the compliance and distensibility of the vessel wall and of the elastic modulus of the vessel wall material ${ }^{[4,8,9,23]}$. These parameters modulate the contractility and energetic efficacy of the heart ${ }^{[28,29]}$ and are influenced by the actual pressure level and by vessel wall properties such as the mass, composition and contractile activity of the wall ${ }^{[8,9]}$. To evaluate the contribution of each of these variables to large artery changes in diabetes, we used an experimental animal model of type I diabetes [11,12] and determined intra-aortic pressure, aortic diameter and aortic distension during the cardiac cycle.

We previously approached arterial compliance in diabetic rats, by measurements of the diameter of an in situ isolated carotid artery during pressurization by volume infusion ${ }^{[20]}$. Systemic arterial compliance is, however, for a large part (approximately $80 \%)$ located in the aorta and the relationship between the static compliance which we recorded previously and pulsatile compliance is only poorly understood ${ }^{[7,8]}$. Aortic pulsatile compliance in diabetic rats has previously been approximated from measurements of stroke volume and intra-aortic pressures following thoracotomy ${ }^{[30]}$. Thoracotomy, however, interferes markedly with central hemodynamics and does so more drastically in diabetic than in control rats ${ }^{[30]}$. In the present study we used in intact rats a non-invasive technique, adapted from the ultrasound arteriography and wall tracking approach that is widely used in humans ${ }^{[4,6,22-24,31]}$. In vitro findings 


\section{COMPLIANCE OF THE AORTA}

indicate that this approach can resolve vessel wall displacements of a few micrometers

[22]. In vivo, we have observed with this technique statistically significant drug induced aortic vasoconstrictions of the order of $50 \mu \mathrm{m}{ }^{[24]}$. As in humans ${ }^{[3]]}$, this technique is highly reproducible in rats ${ }^{[24]}$. In the present study we observed that in both control and diabetic rats under basal conditions and during administration of vasopressor and vasodilator drugs, the A-P relations were roughly similar during the rising and falling phase of the cardiac cycle. This apparent lack of hysteresis, suggests that viscous wall properties do not interfere with aortic wall behavior during an individual heart beat in the rat and thus simplifies the analysis of drug effects and of differences between experimental groups. The mechanical properties of the vessel can be accurately described by the situation at end-diastole and the maximal changes during the cardiac cyle. Furthermore, compliance and distensibility measurements may under these conditions be considered to be independent of rate and pulse amplitude. This may not be the case in species displaying slower heart rates such as dogs, sheep and man $[10,29,32]$.

We observed that under basal conditions, the lumen caliber of the thoracic aorta at end-diastole was significantly smaller in diabetic than in control rats. Despite this, the dynamic compliance of the vessel was not modified. As a consequence the distensibility of the aortic wall, i.e. the relative change in lumen caliber during the cardiac cycle expressed per unit of pressure, was significantly increased in diabetic rats. The smaller lumen caliber was paralleled by an equivalent reduction of the media cross sectional area such that the wall-to-lumen ratio of the aorta was comparable to that noted in controls. The narrower lumen and elevated distensibility thereby resulted in a significantly lower incremental elastic modulus, suggesting reduced stiffness of the wall material. It is not likely that these differences are due to the lower diastolic blood pressure and pulse pressure during the measurement of aortic properties in diabetic rats. The difference in diastolic lumen caliber between diabetics and controls persisted during administration of subpressor doses of phenylephrine which abolished the tendency of the diabetics to display a lower diastolic pressure. Furthermore, in view of the apparent lack of hysteresis and viscosity, aortic compliance may be considered to be independent of the actual pulse pressure.

In STZ-induced diabetes the circulating levels of many endogenous vasodilator and vasoconstrictor agents are modified. Furthermore in vitro studies have suggested many alterations in the contractile reactivity of the aortic wall ${ }^{[1,1,14,15,20]}$. The neurohumoral mechanisms that control aorta diameter in intact rats are unclear. In the present study we infused phenylephrine and sodium nitroprusside to asses the contribution of smooth muscle to some of the alterations which we noted under basal conditions. Low subpressor doses of phenylephrine reduced the lumen caliber of the thoracic aorta. This may represent the first demonstration of aortic vasoconstriction in intact rats. The drug-induced isobaric constriction of the aorta was accompanied by a significant reduction of the dynamic compliance of the vessel. This may represent stretching (and stiffening) of the elastic elements ${ }^{[8,33]}$, which may be even more pronounced during infusion of high doses of phenylephrine, which besides stimulating aortic constriction 


\section{CHAPTER 9}

also elevates the distending pressure by increasing cardiac output and especially peripheral vascular resistance.

In the case of sodium nitroprusside, local actions could not be dissociated from systemic effects. In control rats, aortic lumen caliber decreased as diastolic pressure dropped. In diabetic rats, on the other hand, the lowest dose of the vasodilator did not result in an alteration of the aortic lumen caliber despite reducing pressure. This may be interpreted to represent a dilatation of the vessel. Thus under basal conditions, the aorta of diabetic rats may constricted to a larger extent than the aorta of control rats. Alternatively, the maintenance of aortic lumen caliber in the diabetic rats during administration of the lowest depressor dose of sodium nitroprusside, may represent the hypersensitivity of the aorta of diabetics to the nitrovasodilator previously observed in vitro ${ }^{[34]}$.

Combined our findings with the vasoconstrictor and the vasodilator agent indicate that effects of aortic smooth muscle tone on aortic lumen diameter and distensibility are minimal and suggest that in the rat these parameters are primarily modulated by transmural pressure. Aorta compliance on the other hand was found to be particularly sensitive to vasoconstriction, but this did not differ between diabetic and control rats. Large artery pulsatile compliance was previously noted to be comparable in open chest control and diabetic rats ${ }^{[30]}$ and in healthy volunteers and in uncomplicated insulindependent diabetic individuals ${ }^{[34]}$.

Rather than directly related to the diabetic state, the modification of aortic mechanisms which we noted in diabetic rats, may very well be related to the reduction of body mass that characterizes this model. We recently compared the same experimental parameters in 3 and 6 month old control rats ${ }^{[23]}$. With age, body mass, aortic lumen diameter increased and distensibility decreased while compliance and the elastic modules was not modified. Diabetes may thus have prevented the changes in aortic mechanism that normally accompany an increase in body weight. It has recently been suggested that diabetic rats exhibit a relative rather than an absolute hypertrophy of their aorta, i.e. an increased aortic wall mass per unit of body weight ${ }^{[35]}$. Analysis of the mechanical consequences of this will require comparison of diabetic rats with weight-matched controls.

In summary, pulsatile compliance of the thoracic aorta did not differ between intact diabetic and age-matched control rats, because a reduction of lumen diameter was accompanied by a reduction of wall mass and by an increase of the distensibility of the wall mass and of the elasticity of the wall material. These alterations are more likely due to differences in body weight than to changes in aortic smooth muscle reactivity.

\section{REFERENCES}

1. Garcia MJ, Mc Namara PM, Gordon T, Kannell WB. Morbidity and mortality in diabetics in the Framingham population: sixteen year follow up study. Diabetes 1974;23:105-111.

2. Jarrett RJ. Cardiovascular disease and hypertension in diabetes mellitus. Diabetes Metab 1989;5:547-558. 


\section{COMPLIANCE OF THE AORTA}

3. Heickendorff L, Ledet T, Rasmussen LM. Glycosaminogycans in the human aorta in diabetes mellitus: a study of the tunica media from areas with and without artherosclerotic plaque. Diabetologia 1994;37:286-292.

4. Van Merode T, Lodder J, Smeets FAM, Hoeks APG, Reneman RS. Accurate non-invasive method to diagnose minor atherosclerotic lesions in carotid artery bulb. Stroke 1989;20:13361340 .

5. Fuster V, Badimon L, Badimon JJ, Chesebro $\mathrm{JH}$. The pathogenesis of coronary artery disease and the acute coronary syndromes. N Engl J Med 1992;326:242-248.

6. Laurent S, Caviezel B, Beck L, Girerd X, Billaud E, Boutouyrie P, Hoeks A, Safer M. Carotid artery distensibility and distending pressure in hypertensive humans. Hypertension 1994;23:878-883.

7. Wolinsky $\mathrm{H}$, Glagov SG. Structural basis of the static mechanical properties of the aortic media. Circ Res 1964;14:400-413.

8. Dobrin PB. Mechanical properties of arteries. Physiol Rev 1978;58:397-460.

9. Hoeks AP, Samijo SK, Brands PJ, Reneman RS. Noninvasive determination of shear-rate distribution across the arterial lumen. Hypertension 1995;26:26-33.

10. Barra JG, Armentano L, Levenson J, Fischer EIC, Pichel RH, Simon A. Assessment of smooth muscle contribution to descending thoracic aortic elastic mechanics in concious dogs. Circ Res 1993;73:1040-1050.

11. Tomlinson KC, Gardiner SM, Hebden A, Bennett T. Functional consequences of streptozotocin-induced diabetes mellitus, with particular reference to the cardiovascular system. Pharm Rev 1992;44:103-150.

12. Junod A, Lambert AE, Orci L, Pictet R, Gonet AE, Renold AE. Studies of the diabetogenic action of streptozotocin. Proc Soc Exp Biol Med 1967;126:201-205.

13. Tomizawa $\mathrm{H}$, Yamazaki $\mathrm{H}$, Kunika $\mathrm{K}$, Itakura $\mathrm{M}$, Yamashita $\mathrm{K}$. Association of elastin glycation and calcium deposition in diabetic rat aorta. Diabetes Res Clin Pract 1993;19:1-8.

14. Ramanadham S, Lyness WH, Tenner TEJ. Alterations in aortic and tail artery reactivity to agonists after streptozotocin treatment. Can J Physiol Pharmacol 1984;62:418-423.

15. Harris $\mathrm{KH}$, MacLeod $\mathrm{KM}$. Influence of the endothelium on contractile responses of arteries from diabetic rats. Eur J Pharmacol 1988;153:55-64.

16. Heesen BJ, De Mey JGR, Wolffenbuttel BHR. Aminoguanidine and insulin treatment prevent vascular reactivity disturbances in experimental diabetes. Diabetes 1994;43(Suppl. 1):76A.

17. Heesen BJ, Ido Y, Williamson JR, Wolffenbuttel BHR. Acetylcholine-induced relaxation of isolated aortas is modulated by ambient glucose, L-arginine, and myo-inositol concentrations. Diabetes 1992;41(Suppl. 1):680.

18. Gupta S, Sussman I, McArthur CS, Tornheim K, Cohen RA, Ruderman NB. Endotheliumdependent inhibition of $\mathrm{Na}^{+}-\mathrm{K}^{+}$ATPase activity in rabbit aorta by hyperglycemia. Possible role of endothelium-derived nitric oxide. J Clin Invest 1992;90:727-732.

19. Tesfamariam B, Brown ML, Cohen RA. Elevated glucose impairs endothelium-dependent relaxation by activating protein kinase C. J Clin Invest 1991;87:1643-1648. 


\section{CHAPTER 9}

20. Huijberts MSP, Wolffenbuttel BHR, Struijker Boudier HAJ, Crijns FRL, Nieuwenhuijzen Kruseman AC, Poitevin P, Levy BI. Aminoguanidine treatment increases elasticity and decreases fluid filtration of large arteries from diabetic rats. J Clin Invest 1993;92:1407-1411.

21. Tomlinson KC, Gardiner SM, Bennett T. Blood pressure in streptozotocin-treated Brattleboro and Long Evans rats. Am J Physiol 1990;258:R852-859.

22. Hoeks APG, Brands PJ, Smeets FAM, Reneman RS. Assessment of the distensibility of superficial arteries. Ultrasound in Med \& Biol 1990;16:121-128.

23. Van Gorp AW, Van Ingen Schenau DS, Hoeks APG, Struijker Boudier HAJ, Reneman RS, De Mey JRG. Aortic wall properties in 3 and 6 month old normotensive and spontaneously hypertensive rats at comparable operating pressure in vivo. Hypertension 1995;26:363-368.

24. Van Gorp AW, Van Ingen Schenau DS, Willigers J, Hoeks APG, De Mey JGR, Struijker Boudier HAJ, Reneman RS. Assessment of aortic distensibility and compliance in anesthetized and awake rats. 1995 ; in press

25. Hoeks APG. Non-invasive study of the local mechanical arterial characteristics in humans. In: Safar ME, O'Rourke MF, eds. The arterial system in hypertension. Amsterdam: Kluwer Academic Publishers, 1993:119-134.

26. Boonen HCM, Schiffers PMH, Fazzi GE, Janssen GMJ, Daemen MJAP, De Mey JGR. DNA synthesis in isolated arteries. Kinetics and structural consequences. Am J Physiol 1991;260:H210-217.

27. Boonen HCM, Daemen MJAP, Eerdmans PE, Fazzi GE, Van Kleef E, Schiffers PMH, De Mey JGR. Mesenteric small artery changes following vasoconstrictor infusion in young rats. J Cardiovasc Pharmacol 1993;22:388-395.

28. Yin FCP. The aging vasculature and its effects on the heart. In: Weisfeldt ML, ed. The Aging Heart. New York: Raven Press, 1980:137-213.

29. Kelly RP, Tunin R, Kass DA. Effect of reduced aortic compliance on cardiac efficiency and contractile function of in situ canine left ventricle. Circ Res 1992;71:490-502.

30. Litwin SE, Raya TE, Daugherty S, Golman S. Pheripheral circulatory control of cardiac output in diabetic rats. Am J Physiol 1991;261:H836-842.

31. Kool MJF, Van Merode T, Reneman RS, Hoeks APG, Struijker Boudier HAJ, Van Bortel LMAB. Evaluation of reproducibility of a vessel wall movement detector system for assessment of large artery compliance. Cardiovasc Res 1994;28:610-614.

32. Pagani M, Mirsky I, Baig H, Manolers WT, Kerkhof P, Vatner SF. Effects of age on aortic pressure-diameter and elastic stifness-stress relationships in unanesthetized sheep. Circ Res $1979 ; 44: 420-429$.

33. Benetos A, Pannier BM, Brahim M, Safar ME, Levy BI. Dose-related changes in the mechanical properties of the carotd artery in WKY rats and SHR following relaxation of arterial smooth muscle. J Vasc Res 1993;30:24-29.

34. Heesen BJ, De Mey JG, Williamson JR, Wolffenbuttel BH. Effects of hyperglycemia and experimental diabetes on rat aorta reactivity. Submitted for publication.

35. Kool MJ, Lambert J, Stehouwer CD, Hoeks AP, Struijker Boudier HA, Van Bortel LM. Vessel wall properties of large arteries in uncomplicated IDDM. Diabetes Care 1995;18:618-624

36. Vranes D, Cooper ME, Dilley RJ. Anigiotensin-converting enzyme inhibition reduces diabetesinduced vascular hypertrophy: morphometric studies. J Vas Res;32:183-189 


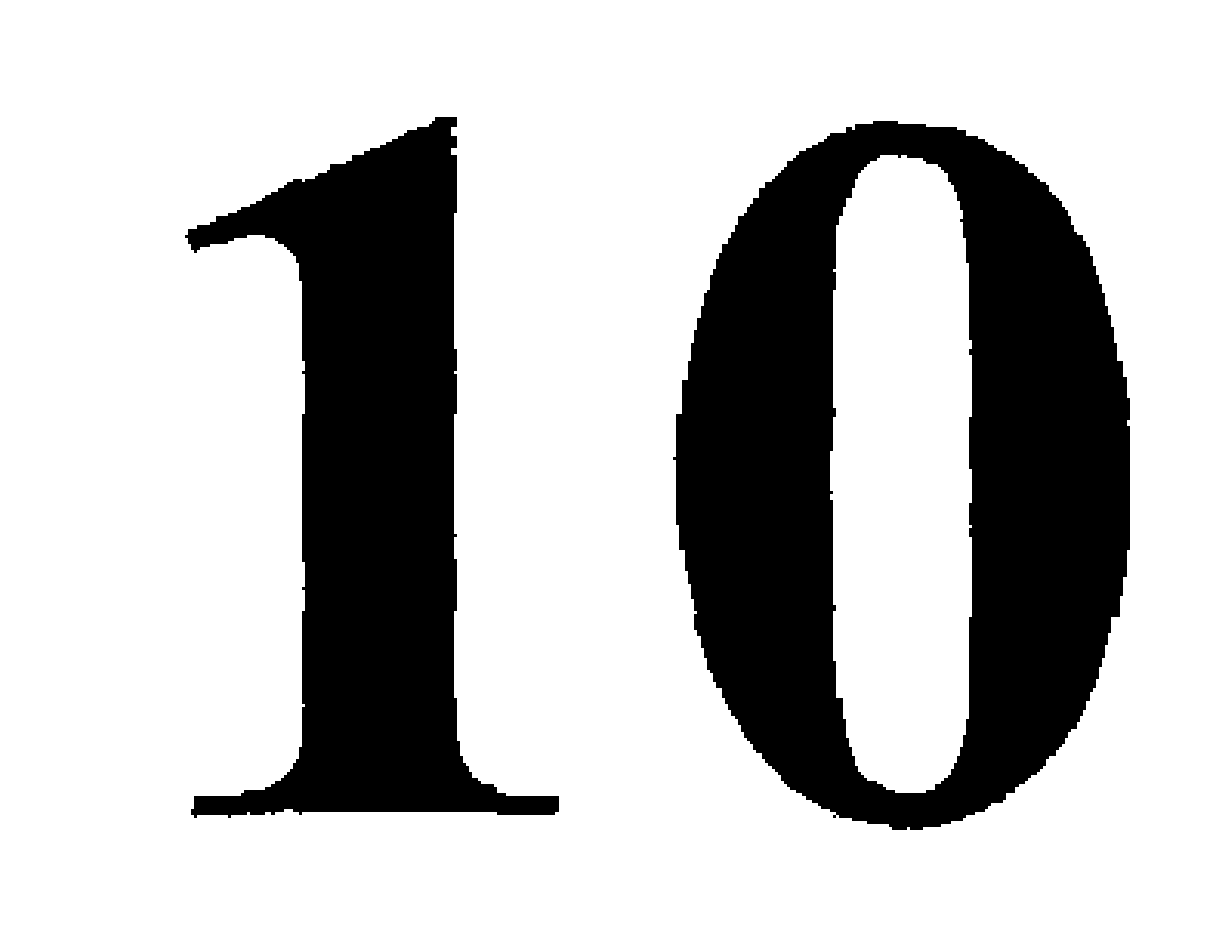

General Discussion 


\section{GENERAL DISCUSSION}

\section{GENERAL DISCUSSION}

Our knowledge on the mechanisms involved in the pathogenesis of diabetic vascular complications is gradually increasing. However, many topics are still disputed because of conflicting experimental results. In the studies presented in this thesis we have studied the consequences of experimental diabetes on the intrinsic properties of blood vessels, by examining alterations of reactivity of isolated vessels in vitro and in vivo. In these systems, we have specifically assessed the effect of pharmacological interventions which have been proposed for the prevention or treatment of diabetic complications.

\section{Interpretation of vascular reactivity}

Many studies on vascular reactivity changes in diabetes have been carried out in isolated vessels. Our observations (chapter 3 ) clearly indicate that the response of an isolated vessel, for instance the aorta, to vasoconstricting or vasodilating agents is strongly dependent on the glucose concentration in the medium in which the vessel is studied. This observation is not without consequences for the interpretation of the observations by other groups. Many previous studies have reported disturbances in vascular reactivity with experimental diabetes, while these experiments were performed in standard glucose concentrations. Frequently, investigators have used glucose concentrations of $11 \mathrm{mM}$, but a rationale for using this specific glucose concentration is lacking. It is relatively high for a non-diabetic animal, which exhibits average daily blood glucose levels around 5-6 mM. In contrast, it is remarkably low for a rat with diabetes, which exhibits blood glucose levels of approximately $25-30 \mathrm{mM}$.

When the endothelium dependent relaxation of aortas obtained from control and diabetic animals was studied in a medium glucose concentration of $5 \mathrm{mM}$, no differences were observed. This was reported previously by other groups ${ }^{[1-6]}$. In addition, our studies clearly indicate that endothelium-dependent relaxation worsens with increasing glucose concentration of the medium. In contrast, this acetylcholineinduced relaxation improved when the aorta of diabetic animals was exposed to glucose concentrations of $30 \mathrm{mM}$ instead of $5 \mathrm{mM}$. These alterations in diabetic animals have not been described before and suggest an adaptation of the aorta to the chronically elevated glucose in diabetic animals. This finding is supported by the observation that in animals with a short duration of diabetes of 9 days the relaxation to acetylcholine is severely impaired, almost similar to the response of a control aorta subjected to high glucose concentrations (chapter 3). Therefore, it is important to take into account the duration of diabetes when one wishes to interpret and compare different studies.

A third important factor is the existence of regional differences between vessels. We know from earlier studies performed in our laboratory ${ }^{[7]}$ that these differences exist. In chapter 4 we have compared the effects of diabetes on aorta, and mesenteric and renal resistance arteries. In the renal resistance arteries we did not observe any difference between diabetic and control arteries in their response to vasoactive agents. This suggests that diabetes especially influences large vessels, which could be explained by a difference in composition between large elastic arteries and small muscular 


\section{CHAPTER 10}

resistance arteries. The finding that mesenteric resistance arteries are also slightly affected can perhaps be explained by the mesenteric vessel hypertrophy which is found in streptozotocin-induced diabetes. This is among other factors due to the fact that these animals ingest more food and fluids than non-diabetic animals.

\section{Pharmacological intervention}

The Diabetes Control and Complications Trial showed that near-normalization of blood glucose control by intensive insulin therapy could reduce the risk of development of complications, such as retinopathy, nephropathy or neuropathy, by 50 to $60 \%$. However, intensive insulin therapy does not prevent or cure complications, and may carry a high risk of side-effects, especially hypoglycemia. Development of severe hypoglycemia may necessitate to accept less optimal control, especially when patients exhibit hypoglycemia unawareness. Thus, still a large number of people are prone to develop vascular complications, and additional pharmacological approaches are warranted. Therefore, we have studied the effects of various candidate drugs on vascular dysfunction. Because of the strong evidence that the formation of advanced glycation endproducts on structural proteins is a major factor in the development of vascular dysfunction, we have assessed the effects of two guanidino compounds, aminoguanidine and methylguanidine, drugs of which it is known that they interfere with this specific pathogenetic process. The ACE-inhibitor perindoprilat was used to test the hypothesis that inhibition of local effects of angiotensin II may prevent the development of endothelial dysfunction. The effects of two inhibitors of the enzyme aldose reductase, sorbinil and zopolrestat, were studied to prevent sorbitol accumulation and the consequent increase in the intracellular NADH/NAD ${ }^{+}$ratio, another pathogenetic factor which is held responsible for the development of vascular dysfunction in diabetes.

\section{Aminoguanidine}

Aminoguanidine prevents the formation of advanced glycation endproducts. The biochemical background of this process has been explained in chapter 1. Previous studies have reported that aminoguanidine prevented the development of several abnormalities in diabetic animals, such as retinal changes, advanced glycation endproduct accumulation in the glomerulus, glomerular basement membrane thickening, microalbuminuria, and structural and functional nerve abnormalities. As we have described in chapter 6, long-term treatment of diabetic rats with aminoguanidine prevented the development of disturbed vascular reactivity to phenylephrine and acetylcholine.

Recently, it was demonstrated that aminoguanidine also can inhibit the enzyme NOsynthase; this enzyme catalyzes the formation of nitric oxide, a strong endogenous vasodilating agent, from $\mathrm{L}$-arginine ${ }^{[8,9]}$. This finding raised the possibility that some diabetes-induced vascular changes are the consequence of a relative or absolute increase in nitric oxide formation, in addition to increased advanced glycation endproducts formation, or -as was postulated recently- increased formation of free radicals (Figure 1.). Methylguanidine is a guanidino compound, similar to aminoguanidine, which is not effective as an inhibitor of AGE-formation, but strongly 


\section{GENERAL DISCUSSION}

inhibits the activity of NO-synthase ${ }^{[8,9]}$. Therefore, we compared the effects of both compounds. Methylguanidine was capable to prevent the development of disturbed contractile function of the diabetic aorta, but did not prevent the increase of endothelium-dependent and independent relaxation. This suggests that the beneficial effects observed with aminoguanidine are mainly due to interference with AGEformation, and not due to the inhibition of NO-synthase activity. Our group has previously demonstrated that long-term aminoguanidine treatment prevented the increase of general vascular albumin leakage with only minor effects on albuminuria, and prevented the decrease of carotid artery elasticity that developed consequently of the diabetic state ${ }^{[10,11]}$

\section{Angiotensin Converting Enzyme Inhibitors}

The beneficial effects of ACE-inhibitors on blood pressure in patients with hypertension ${ }^{[12]}$ and diabetic patients with incipient nephropathy ${ }^{[13]}$ are well known. Inhibition of angiotensin II formation is thought to be critical. ACE catalyzes the generation of angiotensin II and the degradation of bradykinin ${ }^{[14]}$, both of which possess potent vasoactive effects that depend on, or are modulated by, endotheliumderived mediators. Chronic treatment with ACE inhibitors reduces endothelial dysfunction in experimental models of hypertension ${ }^{[15]}$ and hypercholesterolemia ${ }^{[16]}$. Treatment of diabetic rats with the ACE-inhibitor perindoprilat reduced urinary albumin excretion, but did not reduce vascular albumin leakage ${ }^{[17]}$. This suggests that the effects of these drugs are mainly caused by intra renal hemodynamic changes, not by an effect on the vessel wall per se.

In chapter 7 we describe that long-term treatment with the ACE inhibitor perindoprilat did not have any beneficial effect on the response of isolated mesenteric resistance arteries, renal resistance arteries, and aortic rings from diabetic animals. However, the aorta of the control animals showed a diminished contractile force and an enhanced response to acetylcholine after treatment with perindoprilat. The reason for these almost opposite effects between diabetic and non-diabetic aortae is not known. Factors that could play a role are: local angiotensin II activity or an inhibition of chronic vasopressor effects, or a chronic inhibition of $\mathrm{ACE}$ that lowers the vasopressor response, leading to a state of vasorelaxation. In diabetes there is already a state of vasorelaxation, as is shown by the enhanced relaxation to acetylcholine and lower blood pressure in diabetic animals. This suggests that the inhibition of ACE does not affect the acetylcholine induced relaxation.

\section{Aldose Reductase Inhibitors}

Increased polyol pathway activity and intracellular accumulation of sorbitol due to hyperglycemia may damage cells and promote development of diabetic complications (Figure 1.). Inhibition of the enzyme aldose reductase, which is responsible for the conversion of glucose to sorbitol, prevented diabetes-induced increases in vascular permeability as well as regional blood flow in granulation chamber tissue and other tissues from streptozotocin-induced diabetic and spontaneously diabetic BB/W rats. It was postulated that aldose reductase inhibitors have advantageous effects by normalizing the increased $\mathrm{NADH} / \mathrm{NAD}^{+}$ratio which results from increased sorbitol 


\section{CHAPTER 10}

pathway metabolism. With respect to experimental diabetic nephropathy, Cohen et al. ${ }^{[18]}$ showed that sorbinil normalized the decreased glomerular Na $\mathrm{K}^{+}$-ATPase activity. There are also reports that the development of hyperfiltration and albuminuria were prevented. In addition, aldose reductase inhibitors had positive effects on nerve $\mathrm{Na}^{+}-$ $\mathrm{K}^{+}$-ATPase activity and neurophysiological parameters. A summary of studies has been given by Masson and Boulton ${ }^{[19]}$.

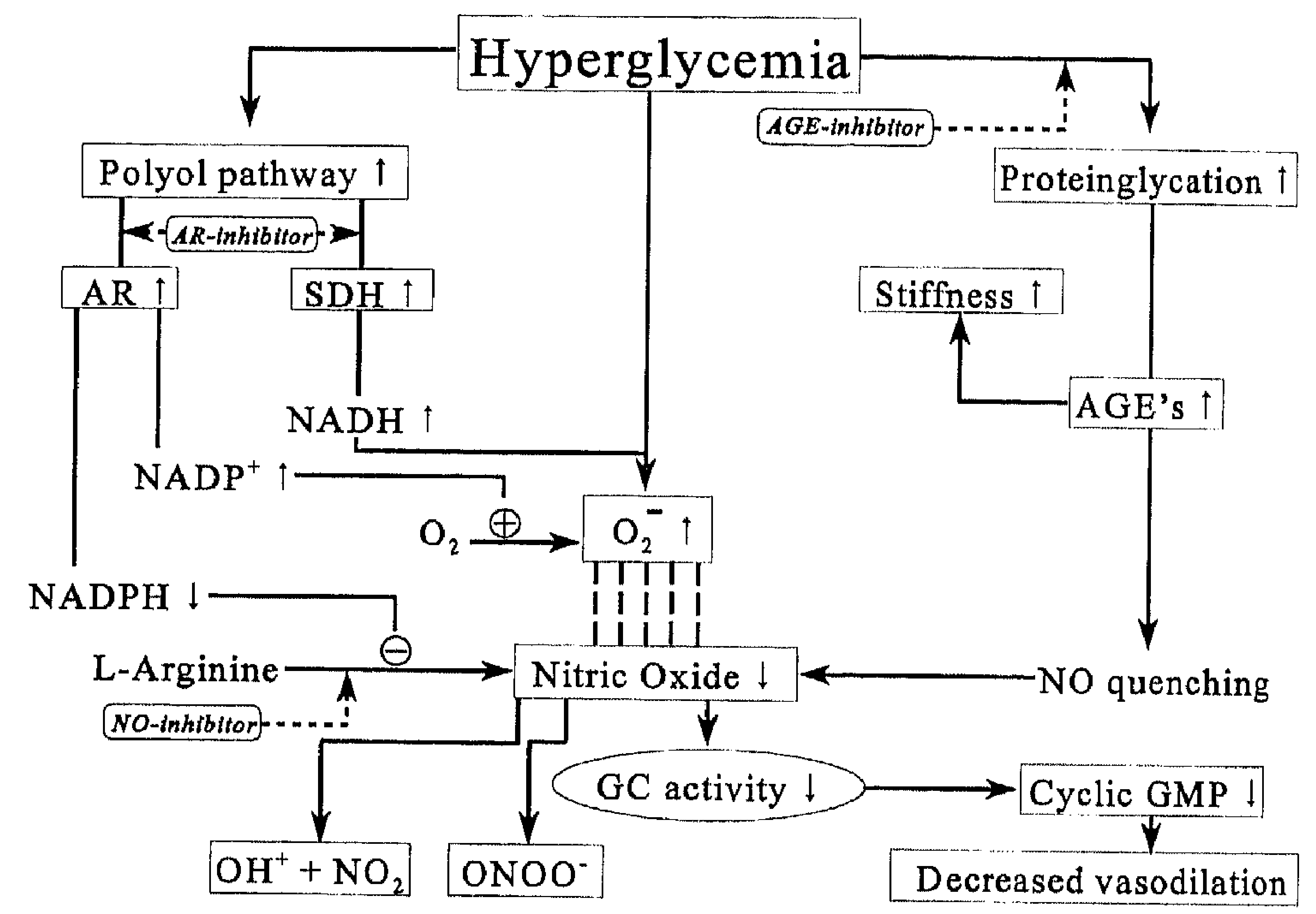

Figure 1. Interrelationship between hyperglycemia and the balance between nitric oxide and superoxide anions. $A R=$ aldose reductase, $S D H=$ sorbitol dehydrogenase, $A G E$ 's $=$ advanced glycation endproducts, $G C=$ guanylate cyclase, $G M P=$ guanidine monophosphate. The grey boxes show the intervention with different types of drugs.

In chapter 8, we describe the effects of two aldose reductase inhibitors on vascular reactivity. Sorbinil, but not zopolrestat, partially prevented the development of the enhanced relaxation to acetylcholine. This restoration of endothelial function was also shown by Tesfamariam ${ }^{[20]}$. The reason for the difference between sorbinil and zopolrestat in this respect is not known.

With regards to the treatment of diabetic complications in humans, the results to date have not been very promising. Sorbinil did not slow the progression of retinopathy or prevent its development, while glomerular hyperfiltration was only slightly reduced. Possible explanations for this relative lack of effect in diabetic patients might be the interventional character of the performed studies: the drug is administered late in the development of complications, Also, too low doses of the drug, leading to inadequate inhibition of aldose reductase activity, may play a role. Furthermore, aldose reductase 


\section{GENERAL DISCUSSION}

activity is much higher in rodents than in humans, and its relevance in the development of human diabetic complications has been disputed ${ }^{[21]}$.

\section{Vascular elasticity}

The existence of alterations in vascular elasticity is a relative unexplored topic in diabetes research. Huijberts et al ${ }^{[10]}$ reported in 1993 on different parameters reflecting arterial wall elasticity in the carotid artery in diabetic rats, and showed that treatment with aminoguanidine prevented the decrease in carotid static compliance. Diabetic patients are particularly prone to develop hypertension, atherosclerosis, and ischemic heart disease ${ }^{[22,23]}$. Overall, these cardiovascular diseases involve stiffening of the larger arteries ${ }^{[24-27]}$ and therefore a reduction of their compliance. This may be accelerated during chronic hyperglycemia. For instance in diabetic rats, the thoracic aorta wall contains elevated levels of calcium and of advanced glycation endproducts [28-30].

Diabetes-associated reactivity changes were more pronounced in the thoracic aorta than in small resistance-sized arteries of either the mesenteric or renal vascular bed. This regional heterogeneity has to be taken into account when considering the functional consequences of the reactivity alterations noted in vitro. Although most analyses of vascular reactivity in experimental diabetes concentrated on aortic preparations it should be kept in mind that these are not representative for the systemic vasculature as a whole.

We therefore attempted in chapter 9 to evaluate whether diabetes-associated changes in the reactivity of the aorta resulted in detectable modifications of local aortic function in the intact cardiovascular system. To test this hypothesis we used a sensitive ultrasound technique to monitor aortic diameter and distension in anesthetized rats during iv infusion of phenylephrine and sodium nitroprusside. Acetylcholine could not be used in these experiments because of the marked cardiac actions of this agonist.

No distinct modification of the responsiveness of the aorta to phenylephrine or sodium nitroprusside could be demonstrated in intact diabetic rats. Several aspects seem to be responsible for this discrepancy between the isolated vessel and the aorta in the intact system. (1) Direct effects of aortic smooth muscle on aortic wall mechanics were rather limited. (2) Influences of local vasoconstriction and vasodilatation were readily overruled by changes in distending pressure resulting from vasomotor changes in distal resistance vessels. (3) There were marked differences in aorta morphology between control and diabetic rats. The lumen diameter and wall mass of the aorta were smaller in the diabetic rats than in age-matched controls. These differences were accompanied by an elevation of the elasticity of the aortic wall material, resulting in a maintenance of the dynamic compliance of the vessel. These modifications may be due to the considerably smaller body weight of the diabetic rats due to their diabetic state.

\section{Final remarks}

In summary we conclude that several factors can complicate the comparison of in vitro with in vivo data. One factor is the fact that in vitro a simple modified Krebs Ringer solution is used. This solution only holds the most necessary electrolytes to guarantee a correct osmolarity and lacks for example proteins and vasoactive substances like 


\section{CHAPTER 10}

angiotensin and nitric oxide. Mimicking all the in vivo contents is however almost impossible as we do not know which differences do exist between diabetic and nondiabetic animals.

Beside this factor we showed in this thesis that one has to take significant factors, like glucose concentrations into account. As the used glucose concentration in vitro is probably the most confounding factor in studies described so far. In chapter 3 we showed that the outcome of an experiment depends on the glucose concentration in the medium. The use of a "wrong" glucose concentration could therefore mask or even induce alterations in vascular responsiveness. We thus strongly recommend that comparisons of isolated vessels between diabetic and controls should be performed at their respective glucose levels.

A third factor complicating the comparison of in vivo with in vitro data is the difference in the way pharmacological agents, like phenylephrine, are administrated. In in vivo experiments the drugs are systemically administered leading to a systemic effect, like a rise or fall in blood pressure or heart rate. An advantage of such a system is that studying the effect of a drug in a more physiological way is possible. However, it is difficult to distinguish between the local and systemic effects. In vitro the pharmacological agents are added to an organ bath holding $10 \mathrm{ml}$ of a modified Krebs Ringer solution. This leads to a local effect on the aorta without the physiological response of a whole complex system. Allowing one to focus on the local effects without the influences of counter regulation systems.

Overall one can say that there are discrepancies between in vitro and in vivo data. In this thesis we have tried to elucidate some of the observed differences between in vivo and in vitro studies and between various research groups. However the effect of some drugs like aminoguanidine show to be beneficial in different setups and consequently could hold a promise in preventing vascular complications in people with diabetes.

\section{REFERENCES}

1. Head RJ, Longhurst PA, Panek R, Stitzel RE. A contrasting effect of the diabetic state upon the contractile responses of aortic preparations from the rat and rabbit. $\mathrm{Br} \mathrm{J}$ Pharmacol $1987 ; 91: 275-286$

2. Fortes ZB, Leme JG, Scivoletto R. Vascular reactivity in diabetes mellitus: role of the endothelial cell. Br J Pharmac 1983;79:771-781.

3. Harris $\mathrm{KH}$, MacLeod KM. Influence of the endothelium on contractile responses of arteries from diabetic rats. Eur J Pharmacol 1988;153:55-64.

4. Wakabayashi I, Hatake K, Kimura N, Kakishita E, Nagai K. Modulation of vascular tonus by the endothelium in experimental diabetes. Life Sciences 1987;40:643-648.

5. Fortes ZB, Garcia Leme J, Scivoletto R. Vascular reactivity in diabetes mellitus: role of the endothelial cell. Br J Pharmac 1983;79:771-781.

6. Meraji S, Jayakody L, Senaratne MP, Thomson AB, Kappagoda T. Endothelium-dependent relaxation in aorta of $\mathrm{BB}$ rat. Diabetes 1987;36:978-981. 


\section{GENERAL DISCUSSION}

7. Heesen BJ, De Mey JG. Effects of cyclic AMP-affecting agents on contractile reactivity of isolated mesenteric and renal resistance arteries of the rat. Br J Pharmac 1990;101:859-864.

8. Corbett JA, Tilton RG, Chang K, Hasan KS, Ido Y, Wang JL, Sweetland MA, Lancaster JR, Williamson JR, McDaniel ML. Aminoguanidine, a novel inhibitor of nitric oxide formation, prevents diabetic vascular dysfunction. Diabetes 1992;41:552-556.

9. Hasan K, Heesen BJ, Corbett JA, McDaniel ML, Chang K, Allison W, Wolffenbuttel BHR, Williamson JR, Tilton RG. Inhibition of nitric-oxide formation by guanidines. Eur I Pharmacol $1993 ; 249: 101-106$

10. Huijberts MSP, Wolffenbuttel BHR, Struijker Boudier HAJ, Crijns FRL, Nieuwenhuijzen Kruseman AC, Poitevin P, Levy BI. Aminoguanidine treatment increases elasticity and decreases fluid filtration of large arteries from diabetic rats. J Clin Invest 1993;92:1407-I411.

11. Huijberts MSP, Wolffenbuttel BHR, Crijns FRL, Nieuwenhuijzen Kruseman AC, Bemelmans MH, Struijker Boudier HAJ. Aminoguanidine reduces regional albumin clearance but not urinary albumin excretion in streptozotocin-diabetic rats. Diabetologia 1994;37:10-14.

12. The CONSENSUS Trial study group. Effects of enalapril on mortality in severe congestive heart failure: results of the Cooperative North Scandinavian Enalapril Survival Study. N Engl J Med 1987;316:1429-1435.

13. Christensen CK, Pedersen MM, Mogensen CE. Combining antihypertensive agents in early diabetic nephropathy. J Diab Complic 1990;4:88-90.

14. Yang $\mathrm{H}$, Erdos EG, Levin Y. A dipeptidyl carboxypeptidase that converts angiotensin and inactivates bradykinin. Biochim Biophys Acta 1970;214:374-376.

15. Clozel $M$, Kuhn $H$, Hefti $F$. Effects of angiotensin-converting enzyme inhibitors and of hydralazine endothelial function in hypertensive rats. Hypertension 1990;16:532-540.

16. Becker RHA, Wiemer G, Linz W. Preservation of endothelial function by ramipril in rabbits on a long-term atherogenic diet. J Cardiovasc Pharmacol 1991;18(Suppl. 2):S110-115.

17. Huijberts MSP, Wolffenbuttel BHR, Crijns FRL, Nieuwenhuijzen Kruseman AC, Bemelmans $M$, Van Essen $H_{2}$ Smits JFM, Struijker Boudier HAJ. Inhibition of angiotensin-converting enzyme reduces urinary albumin excretion but not regional albumin clearance in experimental diabetes. Eur J Pharmacol 1993;240:207-212.

18. Cohen RA. Dysfunction of vascular endothelium in diabetes-mellitus. Circulation $1993 ; 87: 67-$ 76.

19. Masson EA, Boulton AJ. Aldose reductase inhibitors in the treatment of diabetic neuropathy. A review of the rationale and clinical evidence. Drugs 1990;2:190-202.

20. Tesfamariam B, Palacino JJ, Weisbrod RM, Cohen RA. Aldose reductase inhibition restores endothelial cell function in diabetic rabbit aorta. J Cardiovasc Pharmacol 1993;21:205-211.

21. Wolffenbuttel BHR, Van Haeften TW. Prevention of complications in non-insulin-dependent diabetes mellitus (NIDDM). Drugs 1995;50:263-288.

22. Garcia MJ, McNamara PM, Gordon T, Kannell WB. Morbidity and mortality in diabetics in the Framingham population: sixteen year follow up study. Diabetes 1974;23:105-111.

23. Jarrett RJ. Cardiovascular disease and hypertension in diabetes mellitus. Diabetes Metab $1989 ; 5: 547-558$ 


\section{CHAPTER 10}

24. Heickendorff L, Ledet T, Rasmussen LM. Glycosaminogycans in the human aorta in diabetes mellitus: a study of the tunica media from areas with and without artherosclerotic plaque. Diabetologia 1994;37:286-292.

25. Van Merode T, Lodder J, Smeets FAM, Hoeks APG, Reneman RS. Accurate non-invasive method to diagnose minor atherosclerotic lesions in carotid artery bulb. Stroke 1989;20:13361340.

26. Fuster V, Badimon L, Badimon JJ, Chesebro JH. The pathogenesis of coronary artery disease and the acute coronary syndromes. N Engl J Med 1992;326:242-248.

27. Laurent S, Caviezel B, Beck L, Girerd X, Billaud E, Boutouyrie P, Hoeks A, Safer M. Carotid artery distensibility and distending pressure in hypertensive humans. Hypertension 1994;23:878-883.

28. Tomlinson KC, Gardiner SM, Hebden A, Bennett T. Functional consequences of streptozotocin-induced diabetes mellitus, with particular reference to the cardiovascular system. Pharm Rev 1992;44:103-150.

29. Junod A, Lambert AE, Orci L, Pictet R, Gonet AE, Renold AE. Studies of the diabetogenic action of streptozotocin. Proc Soc Exp Biol Med 1967;126:201-205.

30. Tomizawa H, Yamazaki H, Kunika K, Itakura M, Yamashita K. Association of elastin glycation and calcium deposition in diabetic rat aorta. Diabetes Res Clin Pract 1993;19:1-8.

31. Hoeks APG, Brands PJ, Smeets FAM, Reneman RS. Assessment of the distensibility of superficial arteries. Ultrasound in Med \& Biol 1990;16:121-128.

32. Van Gorp AW, Van Ingen Schenau DS, Hoeks APG, Struijker Boudier IIAJ, Reneman RS, De Mey JRG. Aortic wall properties in 3 and 6 month old normotensive and spontaneously hypertensive rats at comparable operating pressure in vivo. Hypertension 1995;26:363-368.

33. Litwin SE, Raya TE, Daugherty S, Goldman S. Peripheral circulatory control of cardiac outpul in diabetic rats. Am J Physiol 1991;261:H836- 842. 


\section{SUMMARY}

Diabetes mellitus is characterized by a chronic elevation of the blood glucose concentration. It is caused by an absolute or a relative deficiency of insulin. Diabetes affects more than 300 thousand people in the Netherlands and about 200 million world-wide. Morbidity and mortality as well as quality of life of people with diabetes mellitus are usually determined by the development of vascular complications. Vascular dysfunction in diabetes has many features which range from mild abnormalities such as micro albuminuria and background retinopathy to severe conditions like end-stage renal failure, blindness and atherosclerosis.

In this thesis characteristics of vascular dysfunction were studied using an experimental diabetes model. The use of animal models allowed us to study different aspects of vascular dysfunction at a more basal level. We studied changes in large and smaller arteries in rats who were made diabetic by streptozotocin.

In chapter 3 we describe the effects of duration of experimental diabetes, and glucose concentration on the vascular reactivity of the isolated aorta. We compared in vitro contractile responses to phenylephrine and relaxation responses to acetylcholine and sodium nitroprusside in isolated aortic rings from diabetic and control rats in normal $(5 \mathrm{mM})$ and high $(30 \mathrm{mM})$ glucose concentrations. Aortic rings from male Sprague Dawley rats who were diabetic for 9-days, 6-weeks and 3-months and from age-matched control rats were mounted in a myograph. With increasing duration of diabetes, maximal contractile responses to phenylephrine decreased. Acetylcholineinduced relaxation was decreased in aorta's from 9-day diabetic animals, compared to control aortas in $5 \mathrm{mM}$ glucose. This decrease was also observed in control aortas exposed in vitro to $30 \mathrm{mM}$ glucose for only $45 \mathrm{~min}$. In contrast, acetylcholine-induced relaxation of 6-week and 3-month diabetic aortas in $30 \mathrm{mM}$ glucose was increased by $50 \%$ compared to control aortas in $5 \mathrm{mM}$ glucose. Relaxation to sodium nitroprusside was reduced in short-term diabetes compared to control aorta, but enhanced with longer duration of diabetes. These observations indicate that: 1) aortic cyclic GMP relaxation function is impaired by acute elevation of glucose levels after nine days of diabetes or in vitro in control aorta exposed to hyperglycemia. 2) in $30 \mathrm{mM}$ glucose the aorta's of animals with six weeks and three months diabetes show an enhanced relaxation to acetylcholine and sodium nitroprusside in vitro compared to control aortas in $5 \mathrm{mM}$ glucose. Thus, in time the vessel seems to adapt to this new situation.

In chapter 4 we describe the influence of a diabetes on smaller arteries than the aorta. For this we isolated mesenteric and renal resistance arteries. There is a difference in the degree by which aorta, mesenteric and renal resistance arteries are affected by the diabetic state. The aorta was most severely affected by diabetes in both contractile and relaxing properties. The mesenteric resistance artery is less affected, since in this vessel no effect was seen on contractile function, but relaxation response to an endothelium-dependent relaxing agent was increased. Renal resistance arteries were unaffected, and no influence of the diabetic state was measurable. 


\section{SUMMARY}

In chapter 5 we describe the influence of various guanidine compounds on the inhibition of nitric oxide (NO) formation by cytokine-inducible and vascular constitutive isoforms of NO synthase. We compared aminoguanidine, diaminoguanidine, methylguanidine, and dimethylguanidine to $\mathrm{N}^{\mathrm{G}}$-monomethyl-L-arginine. These comparisons were performed by assessing (1) cytokine-induced production of nitrite by rodent $\beta$-cell insulinoma cells, (2) vasoconstrictor responses of isolated rat mesenteric arteries, and (3) in vivo blood pressure responses following intravenous bolus injection in anesthetized rats. We conclude that aminoguanidine is a selective inhibitor of the inducible isoform of NO synthase and that dimethylguanidine, like $\mathrm{N}^{\mathrm{G}}$-monomethyl- L-arginine, is a relatively potent inhibitor of both isoforms of NO synthase.

In chapter 6, 7, and 8 we describe the effect of different pharmacological agents on the disturbed vascular reactivity in experimental diabetes. We studied the effects of normal blood glucose levels by insulin therapy, the effects of the nitric oxide inhibitors aminoguanidine and methylguanidine, the angiotensin converting enzyme inhibitor perindoprilat, and the aldose reductase inhibitors sorbinil and zopolrestat. We conclude that (1) insulin treatment prevents the disturbed vascular reactivity as observed in experimental diabetes. (2) Aminoguanidine treatment also prevented the development of disturbed the vascular reactivity, but methylguanidine has a less pronounced effect. (3) Perindoprilat does not affect the altered vascular reactivity in the diabetic animal, but reduces the contractile force to phenylephrine and enhances the response to acetylcholine in the aorta of control animals. (4) Sorbinil and zopolrestat had no effect on preventing the disturbed vascular reactivity in the aorta of diabetic animals.

In chapter 9 we describe the differences in compliance and distensibility of the aortas of diabetic and non-diabetic rats. Our in vitro experiments showed that the contractile reactivity of the aorta was disturbed in experimental diabetes. We therefore compared in anesthetized control and diabetic rats, the compliance and distensibility of the thoracic aorta. In diabetic rats: (1) compliance was not significantly altered, (2) body weight, pulse pressure, heart rate, and the cross sectional area of the aortic media were significantly reduced and, (3) the distensibility of the aorta was significantly increased. Intravenous infusion of low doses of phenylephrine reduced the compliance coefficient to the same extent in control and diabetic rats and did not modify the distensibility. A high dose of phenylephrine reduced the compliance and distensibility to the same extent in aorta of control and diabetic rats, abolishing the differences between diabetic and control. Infusion of sodium nitroprusside reduced diastolic pressure and increased the distensibility coefficient, but not the compliance coefficient. Differences between diabetic and control animals persisted in the presence of sodium nitroprusside. We conclude that in intact diabetic rats the main alteration of the aorta consists of a reduction of the lumen caliber and of the wall mass, which involves an elevation of the distensibility and is not accompanied by alteration of the dynamic compliance of the vessel.

From the studies, described in this thesis we conclude that vascular reactivity is changed in experimental diabetes. Insulin treatment prevents this disturbed vascular reactivity, suggesting that the change in vascular reactivity is due to hyperglycemia 
perse. In people with diabetes intensive insulin therapy is necessary to achieve (near) normoglycemia. As (near) normoglycemia can not always be reached because of the development of hypoglycemia the use of additional drugs is warranted. From the studies presented in this thesis we conclude that amionoguanidine maybe such a drug. At the moment aminoguanidine is tested in a clinical trial in the USA, the results are to be expected in the next years. 


\section{SAMENVATTING}

Diabetes mellitus is een chronische ziekte die gekenmerkt wordt door een verhoging van de bloedglucose concentratie. Diabetes mellitus wordt veroorzaakt door een absoluut of relatief gebrek aan insuline. Meer dan driehonderdduizend mensen in Nederland en ongeveer tweehonderd miljoen mensen wereldwijd hebben diabetes. Morbiditeit, mortaliteit en de kwaliteit van het leven van de mensen met diabetes mellitus wordt normaal gesproken bepaald door de ontwikkeling van diabetes mellitus. Vasculaire dysfunctie in diabetes heeft verscheidene vormen welke variëren van milde symptomen zoals micro-albuminurie en retinopathy tot ernstigere aandoeningen zoals nierfalen, blindheid en atherosclerose.

In dit proefschrift zijn karakteristieken van vasculaire dysfunctie bestudeerd, gebruikmakend van een experimenteel diabetes model. Het gebruik van diermodellen stelt ons in staat om het aspect van vasculaire dysfunctie beter te bestuderen. Wij bestudeerden de veranderingen in vasculaire reactiviteit in de aorta, mesenteriale en renale weerstandsvaten in ratten met streptozotocine geïnduceerde diabetes.

In hoofdstuk 3 beschrijven wij de effecten van experimentele diabetes, diabetes duur en glucose concentratie op de vasculaire reactiviteit in de geïsoleerde aorta. Wij vergeleken in vitro contractie van phenylephrine en relaxatie met acetylcholine of natrium nitroprusside in geïsoleerde ringen van de aorta van diabetische en controle ratten in normale $(5 \mathrm{mM})$ en hoge $(30 \mathrm{mM})$ glucose. Geïsoleerde aorta's van ratten met een diabetes duur van 9 dagen, 6 weken en 3 maanden werden vergeleken met leeftijdsgecontroleerde controle ratten. Met toename van de diabetesduur nam de maximale contractiele response op phenylephrine af. De door acetylcholine geïnduceerde relaxatie was afgenomen in de aorta van ratten met kortdurende diabetes vergeleken met controle aorta's in $5 \mathrm{mM}$ glucose. Deze verminderde relaxatie werd ook waargenomen in controle aorta's welke in vitro gedurende 45 minuten werden blootgesteld aan $30 \mathrm{mM}$ glucose. Dit in tegenstelling tot de door acetylcholine geïnduceerde relaxatie in aorta's van ratten met een diabetes duur van 6 weken en 3 maanden in $30 \mathrm{mM}$ welke was toegenomen met $50 \%$ vergeleken met controle aorta's in $5 \mathrm{mM}$ glucose. De door natrium nitroprusside geïnduceerde relaxatie was verminderd in de aorta's van dieren met 9 dagen diabetes vergeleken met controle aorta, maar verbeterde naarmate de diabetes duur langer werd. Deze observaties tonen aan dat: 1) relaxatie verminderd is wanneer de glucose concentratie acuut verhoogd wordt. 2) in $30 \mathrm{mM}$ glucose de aorta's van dieren met zes weken en drie maanden diabetes een toegenomen relaxatie laten zien ten opzichte van controle aorta's in $5 \mathrm{mM}$ glucose. De aorta's lijken zich dus aan te passen aan de nieuwe situatie.

In hoofdstuk 4 beschrijven wij de invloed van diabetes op kleinere bloedvaten, zoals mesenteriale en renale weerstandsvaten. Diabetes blijkt een andere invloed te hebben op aorta, mesenteriale en renale weerstandsvaten. De aorta lijkt het meeste aangedaan in zowel contractiele als relaxerende eigenschappen. De reactiviteit van mesenteriale weerstandsvaten is minder veranderd, er werd geen afwijking in de 


\section{SAMENVATTING}

contractiele component gevonden. Diabetes mellitus lijkt geen meetbare invloed op de vaatreactiviteit van renale weerstands vaten te hebben.

In hoofdstuk 5 beschrijven wij de invloed van verschillende guanidine substanties op de inhibitie van stikstof oxyde (NO) vorming via de cytokine-geïnduceerde en constitutieve isovormen van NO synthase. Wij vergeleken aminoguanidine, diamino-guanidine, methylguanidine en dimethylguanidine met NG-monomethyl-L-arginine. Deze vergelijkingen werden gedaan door (1) het meten van cytokine geïnduceerde produktie van nitriet door $\beta$-cell insulinoma cellen, (2) het meten van vasoconstrictoire respons van geïsoleerde mesenteriale weerstandsarteriën van de rat en (3) het meten van de bloeddruk reactie na toediening van een intraveneuze bolus injectie in verdoofde ratten. Wij concluderen dat aminoguanidine een selectieve remmer van de induceerbare isovorm van NO synthase is en dat dimethylguanidine, net als NG-mono-methyl-L-arginine, een relatief sterke remmer is van beide isovormen van NO synthase.

In hoofdstuk 6, 7 en 8 beschrijven wij de effecten van verschillende farmacologische interventies op de vasculaire reactiviteit bij experimentele diabetes. Wij bestudeerden de effecten van insuline, de effecten van medicamenten, als de NO synthase remmers aminoguanidine en methylguanidine, de ACE remmer perindoprilat en de aldose reductase remmers sorbinil en zopolrestat. In deze hoofdstukken concluderen wij dat: (1) insuline behandeling een verstoring van de vasculaire reactiviteit, zoals die optreedt bij experimentele diabetes, voorkomt. (2) Aminoguanidine heeft een vergelijkbaar effect op de vasculaire reactiviteit, methylguanidine heeft een minder duidelijk effect. (3) Perindoprilat heeft geen invloed op de veranderde vaatreactiviteit in ratten met experimentele diabetes, maar wel de contractie kracht, welke vermindert in controle dieren. (4) Sorbinil en zopolrestat hebben geen effect op de vasculaire reactiviteit in de aorta van ratten met diabetes.

In hoofdstuk 9 beschrijven wij de verschillen tussen de compliantie en distensibiliteit in ratten met en zonder diabetes. De in vitro experimenten lieten zien dat de contractiele reactiviteit van de aorta veranderd is in de diabetische rat. Daarom vergeleken wij in verdoofde diabetische en niet diabetische dieren de compliantie en distensibiliteit van de thoracale aorta m.b.v. een echo. In diabetische ratten vonden wij dat: (1) de compliantie niet significant veranderd was, (2) lichaamsgewicht, polsdruk, hartslagfrequentie en de cross sectionele oppervlakte van de aorta significant verlaagd waren. Daarnaast was de distensibiliteit van de aorta significant toegenomen. Intraveneuze toediening van een lage, niet bloeddruk verhogende, dosis phenylephrine verminderde de compliantie coëfficiënt in dezelfde mate bij controle en diabetische ratten en had geen invloed op de distensibiliteit. Een hoge dosis phenylephrine verminderde de compliantie en distensibiliteit evenveel in controle en diabetische ratten waardoor de verschillen tussen diabeten en controles verdwenen. Toediening van natrium nitroprusside verminderde de diastolische druk en verhoogde de distensibiliteits coëfficiënt maar niet de compliantie coëfficiënt. De verschillen tussen dieren met diabetes en controles bleven bestaan in de aanwezigheid van natrium nitroprusside. Wij concluderen hieruit dat in intacte diabetische ratten de belangrijkste verandering van de aorta bestaat uit een reductie van de lumen diameter en de wand 


\section{SAMENVATTING}

massa. Deze gaan gepaard met een toename van de distensibiliteit, zonder dat de dynamische compliantie van het bloedvat gemodificeerd wordt.

Uit de studies, die beschreven staan in dit proefschrift, concluderen wij dat de vasculaire reactiviteit verstoord is in ratten met door streptozotocine veroorzaakte diabetes. Behandeling met insuline voorkomt deze verandering hetgeen suggereert dat de veranderingen te wijten zijn aan de chronische hyperglycaemie. Voor mensen met diabetes is een intensief insuline regime noodzakelijk om zorg te dragen voor een zo normaal mogelijke bloedglucose spiegel. Aangezien normalisatie van de bloedglucose niet altijd goed mogelijk is en gepaard kan gaan met ongewenste neveneffecten als hypoglycaemie, is behandeling met additionele medicamenten geïndiceerd. Uit de studies beschreven in dit proefschrift zou men kunnen afleiden dat aminoguanidine zo'n medicament kan zijn. Het zichtbaar en meetbaar maken van de effecten van een medicament als aminoguanidine is erg ingewikkeld, aangezien de ontwikkeling van complicaties ten gevolge van diabetes meestal vele jaren in beslag neemt. Momenteel is de eerste grote klinische studie met aminoguanidine in de Verenigde Staten begonnen. De resultaten van deze studie zijn over een aantal jaren te verwachten. 


\section{CURRICULUM VITAE}

De schrijver van dit proefschrift werd op 1 oktober 1966 geboren in Schiedam. Na het behalen van het atheneum B diploma aan de rijksscholengemeenschap Schravenlant ving hij in 1986 met zijn studie Geneeskunde aan. Hij vertrok hiervoor naar het Bourgondische zuiden en schreef zich in aan de Rijksuniversiteit Limburg te Maastricht. Tijdens zijn studie geneeskunde deed hij gedurende een half jaar onderzoek in het laboratorium van dr. J.G.R. De Mey en werkte hij gedurende een jaar als student-assistent mee aan onderzoek naar vetstofwisselingsstoornissen o.l.v. dr. B.H.R. Wolffenbuttel. In 1991 legde hij zijn doctoraalexamen af, waarna hij van september 1991 tot augustus 1994 als assistent in opleiding (AIO) verbonden was aan de werkgroep endocrinologie (hoofd Prof. dr. A.C. Nieuwenhuijzen Kruseman). Tijdens deze periode werkte hij gedurende anderhalf jaar in het laboratorium voor experimentele diabetes van de KILO foundation aan de Washington University (St. Louis, USA: hoofd Prof. J.R. Williamson). Sinds 1 september 1994 is hij als coassistent ingeschreven aan de Rijksuniversiteit Limburg. In april 1997 zal hij aanvangen met zijn opleiding tot internist in het Elisabeth Ziekenhuis te Tilburg (opleider dr. C. Van der Heul). 


\section{PUBLICATIONS}

articles:

(1) Heesen BJ, De Mey JGR: Effects of cyclic AMP-affecting agents on contractile reactivity of isolated mesenteric and renal resistance arteries of the rat. Br J Pharmac 101:859-64, 1990

(2) Wolffenbuttel BHR, Sels JPJE, Heesen BJ, Menheere PPCA, Nieuwenhuijzen Kruseman $\mathrm{AC}$ : De effecten van voedingsvezel en insuline behandeling op het serum gehalte van lipiden en lipoproteine(a) bij patienten met diabetes mellitus type Il. Ned Tijdschr Geneeskd 136:739-42, 1992

(3) Heesen BJ, Wolffenbuttel BHR, Leurs PB, Sels JP, Menheere PP, JäckleBeckers SE, Nieuwenhuijzen Kruseman AC: Lipoprotein(a) levels in relation to diabetic complications in patients with non-insulin-dependent diabetes. Eur $J$ Clin Invest 23:580-84, 1993

(4) Hasan K, Heesen BJ, Corbett J, McDaniel ML, Chang K, Allison W, Wolffenbuttel BHR, Williamson JR, Tilton RG: Inhibition of nitric oxide formation by guanidines. Eur J Pharmacol 249:101-6,1993

(5) Wolffenbuttel BH, Huijberts MS, Heesen BJ, Leurs PB, Nieuwenhuijzen Kruseman $\mathrm{AC}$ : Goede instelling van diabetes mellitus verkleint de kans op diabetische complicaties. Ned Tijdschr Geneeskd 137:2179-83, 1993

(6) Heesen BJ, Hotchkiss RS, Karl IE: Sepsis decreases phenylephrine and $\mathrm{KCl}$ induced aortic ring contraction and decreases the frequency of oscillations in active wall tension. Shock 2:106-112, 1994

(7) Heesen BJ, De Mey JGR, Williamson JR, Wolffenbuttel BHR: Effects of hyperglycemia and experimental diabetes on rat aorta reactivity. (submitted for publication)

abstracts:

(1) Heesen BJ, Struijker Boudier HAJ, De Mey JGR: Absence of Beta-adrenergic relaxing responses in isolated renal resistance arteries. The Pharmacologist $31: 170,1989$ 
(2) Wolffenbuttel BHR, Heesen BJ, Menheere PPCA, Rondas-Colbers GJWM. Donselaar LAM, Sels JPJE, Nieuwenhuijzen Kruseman AC: Lipoprotein(a) levels in relation to diabetic complications in patients with non-insulindependent diabetes. Eur J Clin Invest 22:a56, 1992

(3) Heesen BJ, Ido Y, Williamson JR, Wolffenbuttel BHR: Acetylcholine-induced relaxation of isolated aortas is modulated by ambient glucose, L-arginine and myo-inositol concentrations. Diabetes 41:680, 1992

(4) Heesen BJ, Ido Y, Williamson JR, Wolffenbuttel BHR: Vasoreactivity of aortic rings from diabetic rats is dependent on diabetes duration and glucose concentration. Diabetologia 35:23, 1992

(5) Heesen BJ, De Mey JGR, Williamson JR, Wolffenbuttel BHR: Reactivity of aortic rings from rats is dependent on diabetes duration and glucose concentration. Pharm weekblad 14(6):H6, 1992

(6) Heesen BJ, De Mey JGR, Williamson JR, Wolffenbuttel BHR: Different effects of amino- and methylguanidine on the disturbances of vasoreactivity in isolated diabetic aortic rings. Proceedings: Symposium on Vascular Complications of Diabetes Mellitus, 6-9 October 1993

(7) Heesen BJ, De Mey JGR, Wolffenbuttel BHR: Aminoguanidine and insulin treatment prevent vascular reactivity disturbances in experimental diabetes Diabetes 43(1):76A, 1994

various:

(1) Eerdmans PH, Heesen BJ, Struijker Boudier HAJ, De Mey JGR: Sympathetic heterogenity in mesenteric and renal resistance arteries [chapter]. Resistoncil Arteries, structure and function:156-59, 1991

(2) Wolffenbuttel BHR, Sels JP, Heesen BJ, Menheere PP, Nieuwenhuijzers Kruseman AC: Lipoprotein(A) levels and diabetes control [letter]. Diab Carpli $15: 941,1992$ 


\section{NAWOORD}

Eindelijk is het zover dat ik dit laatste stukje voor mijn boekje kan schrijven; in menig proefschrift het meest gelezen gedeelte.

Bruce Wolffenbuttel, mijn mentor en co-promotor wil ik als eerste bedanken. Beste Bruce, zonder jou had ik dit boekje nooit geschreven. U zult denken, dat zal toch wel meevallen, maar dat is niet zo. Bruce is namelijk een persoon die nergens een probleem in ziet. Als gisteren herinner ik mij de dag dat ik aan hem vroeg of ik voor een jaar naar Amerika kon. Bruce zei: "dat moet kunnen". Een kleine vijf maanden later woonde ik in Amerika. Ik denk nog met veel plezier terug an onze eerste ervaringen met het toen nog onbekende en onbeminde internet om gegevens uit te wisselen. Jouw bezoeken aan St. Louis waren altijd een welkome afleiding. Een wedstrijd van de St. Louis Cardinals hebben wij helaas nooit samen meegemaakt. Nu, vier jaar later is mijn proefschrift af. Eigenlijk is heel dit boekje een wat uit de hand gelopen "reisje". Mijn dank is groot Bruce.

Arie Nieuwenhuijzen Kruseman, mijn promotor heeft waarschijnlijk zonder dat hij dit zelf wist mij al op een vroeg tijdstip in mijn studie geinspireerd tot het volgen van de opleiding voor internist. In café "De Oude Klok" wist hij na faculteitsraadsvergaderingen altijd smeuïge verhalen te vertellen over zijn periode als assistent. Arie, gedurende mijn onderzoeksperiode bewoog jij je op de achtergrond, maar tijdens de afrondingsfase van dit proefschrift waren jouw punten van kritiek een zeer waardevolle aanvulling.

Harry Struijker Boudier wil ik bedanken voor het veelvuldig stellen van kritische vragen. Zijn kritische blik heeft veel bijgedragen tot de inhoud en leesbaarheid van dit proefschrift.

Jo de Mey wil ik bedanken voor de onderzoekstechnieken die hij mij anleerde. Hij is de persoon die mij in mijn derde jaar van mijn studie als eerste kennis liet maken met fundamenteel onderzoek. Door de gezelligheid van Jo\&Co voelde ik mij geen vreemde eend in de bijt, toen ik terug kwam in zijn lab om mijn onderzoek in Nederland te hervatten. Meestal kon ik mijn koffiemok weer terugvinden, al moest ik die wel vaak ontdoen van een door mij achtergelaten bodem koffie.

Op het lab van Jo\&Co is veel veranderd. Ik wil hier voornamelijk de "oude" groep bedanken. Harrie Boonen, het is jammer dat je nu in Denemarken zit. Wie weet zullen wij in de toekomst nog eens samen een onderzoekje doen. Paul Schiffers, jouw kamer was, toen mijn proefschrift in de laatste fase verkeerde, een goede plek om mijn hart even te luchten. Dit stimuleerde mij om vol goede moed de draad weer op te pakken. Frank Stassen, gedurende het grootste gedeelte van deze studies was jij mijn kamergenoot, onze gesprekken over "andere dingen" dan onderzoek waren een welkome afwisseling. Gregorio Fazzi, Ger Janssen, Dorette van Ingen Schenau en Harrie van der Heijden waren altijd bereid mee te helpen aan mijn experimenten of een avondje uit voor Jo\&Co te regelen. 
De werkgroep experimentele diabetes, in de vorm van Francy Crijns, May, Huijberts, Paul Leurs en Mark-Jan Janssen wil ik bedanken voor de inspiratie, alls hulp, de lekkere etentjes en gezellige avonden in Nederland of daar buiten.

I would like to thank Prof Dr. Joe Williamson for providing me the facilities anct stimulating environment to perform a large part of the studies described in this thesi: My stay in St. Louis was a great and inspiring experience. During the one and hall years I stayed in the USA you and the people in your lab showed me how to work ants live like an American. For this I am very grateful to you all. I would like to than Yasuo Ido for teaching me some basics on biochemistry and the way sushi has to be eaten. Ron Tilton, his wife Kate and their kids for all the good times I had at them place. Judi for being so nice to send me some E-mail each month so I can keep up with the latest rumors in the lab.

Mijn huisgenoten en het Heerendispuut Prometheus wil ik bedanken voor allmas belangstelling die zij hadden voor mijn "scriptie". Menig Promeeth vond het toch we" vreemd dat het schrijven van mijn "scriptie" vier jaar duurde.

Mijn ouders, zus en Oma wil ik bedanken voor de continue belangstelling voor allse vorderingen en het vormen van een basis waarop ik altijd terug kan vallen. Hierdoom was het mogelijk om ook dit stukje van mijn leven tot een goed einde te brengen. Fijer dat wij zulke goede vrienden zijn.

Rosan. Wij leerden elkaar een half jaar voor dit uit de hand gelopen "reisje" kenner $\mathrm{Nu}$, aan het eind van deze reis sta jij er nog. Afstand blijkt een relatief begrip. Samerent hebben wij veel bruggen geslagen. Jouw liefde is het beste wat mij is overkomere Rosan, ik ben klaar voor ons volgende "reisje"! 